Vladimir Guilherme Haach

\title{
ANÁLISE TEÓRICO-EXPERIMENTAL DA INFLUÊNCIA DA FORÇA NORMAL EM NÓS DE PÓRTICO EXTERNOS DE CONCRETO ARMADO
}

\author{
Dissertação apresentada à Escola de \\ Engenharia de São Carlos da Universidade \\ de São Paulo, como parte dos requisitos para \\ a obtenção do Título de Mestre em \\ Engenharia de Estruturas.
}

Orientadora: Prof. Dra. Ana Lúcia Homce De Cresce El Debs

São Carlos

2005 
Dedico este trabalho aos meus pais que muitas vezes abandonaram seus sonhos para realizarem os meus, e a minha esposa que caminha sempre ao meu lado. 


\section{AGRADECIMENTOS}

Primeiramente a Deus que me deu o dom da vida e me fortalece a cada dia.

Aos meus pais, que acreditaram em mim, me apoiaram nesta caminhada e sempre me servirão de exemplos.

À minha esposa, pelo amor, dedicação e paciência principalmente nos momentos mais tribulados.

À Professora Ana Lúcia pela orientação e pela amizade criada durante esta pesquisa.

À minha avó e minhas irmãs, pelo amor, carinho e incentivo.

Aos funcionários do Laboratório de Estruturas que tanto me ajudaram durante os experimentos.

Aos professores e funcionários do Departamento de Engenharia de Estruturas que de alguma forma contribuíram no desenvolvimento desta pesquisa.

Aos amigos feitos no Departamento de Engenharia de Estruturas que proporcionaram uma convivência diária sempre muito descontraída.

Ao Conselho Nacional de Desenvolvimento Científico e Tecnológico - CNPq que financiou esta pesquisa. 
"Existem homens de bom senso que, por serem incapazes de decifrar as coisas que são "grego para eles", convencem-se de que a lógica e a filosofia estão acima deles. Pois bem, gostaria que vissem que, assim como a natureza os dotou de olhos com os quais enxergar as obras dela, também lhes concedeu cérebros para penetrar e compreendê-las."

Galileu Galilei 


\section{RESUMO}

HAACH, V. G. (2005). Análise teórico-experimental da influência da força normal em nós de pórtico externos de concreto armado. Dissertação (Mestrado), 159p - Escola de Engenharia de São Carlos, Universidade de São Paulo, São Carlos, 2005.

Os nós de pórtico são locais de mudança de direção do eixo da estrutura, logo são regiões descontínuas, ou seja, as hipóteses de Bernoulli de deformações lineares ao longo da seção transversal não são válidas. Sendo assim os métodos convencionais de dimensionamento não se aplicam a esta região. Além disso, são regiões problemáticas também do ponto de vista construtivo, por apresentarem geralmente uma alta taxa de armadura em dimensões reduzidas. Diversas são as variáveis que influenciam o comportamento dos nós de pórtico externos, dentre elas está a força normal aplicada no pilar. Esta variável foi observada por diversos pesquisadores (Parker \& Bullman, 1997; Scott et al., 1999; Hwang \& Lee, 1999; Bakir \& Boduroglu, 2002; Hegger et al., 2003), porém com grandes divergências de opiniões sobre sua influência na ligação. Desta forma, este trabalho visa analisar a influência da força normal no comportamento de nós de pórtico externos de concreto armado. Neste sentido é apresentada uma extensa pesquisa bibliográfica abordando trabalhos experimentais e modelos teóricos propostos para o dimensionamento dos nós (bielas e tirantes). Inserindo-se no contexto é analisada a influência da força normal nos nós de pórtico externos por meio da análise experimental de quatro ligações sujeitas a diferentes níveis de força normal, da comparação com os modelos teóricos apresentados e da simulação numérica do nó de pórtico com o aplicativo $A B A Q U S^{\circledast}$, utilizando como ferramenta básica o método dos elementos finitos (MEF).

Palavras-Chave: nós de pórtico, ligação, cisalhamento, aderência, método dos elementos finitos (MEF), concreto armado. 


\section{ABSTRACT}

HAACH, V. G. (2005). Theoretical-Experimental analysis of the Influence of Normal Force on the exterior reinforced concrete joints behavior. Dissertação (Mestrado), 159p - Escola de Engenharia de São Carlos, Universidade de São Paulo, São Carlos, 2005.

The joints are points where the structures' axes swerving, therefore they are discontinuous regions, it means, Bernoulli's hypotheses of linear deformations over the section are not valid. Consequently the conventional methods of design are not applied to this region. Moreover, the joints are also problematic regions to build, for generally presenting one high reinforcement ratio in reduced geometricals dimensions. The normal force applied in the column is one among several variables that influence exterior joints behavior. This variable was observed by many researchers (Parker \& Bullman, 1997; Scott et al., 1999; Hwang \& Lee, 1999; Bakir \& Boduroglu, 2002; Hegger et al., 2003), however with divergences of opinions on its influence in the connection. So, this work aims to analyze the influence of the normal force in reinforcement concrete exterior joint behavior. In this way an extensive literature review is presented approaching experimental works and proposed theoretical models for the joint design (strut an ties). Inserting the research on the context, the influence of the normal force in exterior joints was done through experimental analysis of four connections with different levels of normal force, comparisons with the theoretical models presented and numerical simulation of the joint using finite elements method (FEM) packages at the software ABAQUS ${ }^{\circledR}$.

Keywords: joints, connection, shear, bond, finite elements method (FEM), reinforced concrete. 


\section{LISTA DE FIGURAS}

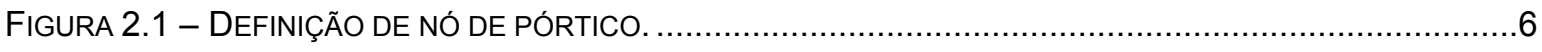

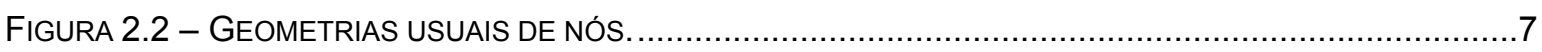

FIGURA 2.3 - TIPOS DE LIGAÇÕES DE CONCRETO ARMADO EM EDIFÍCIOS. .............................................

FIGURA 2.4 - POSSÍVEIS ESFORÇOS ATUANTES NA LIGAÇÃO VIGA-PILAR. ..........................................

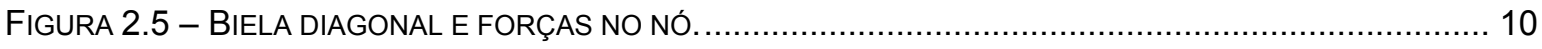

FIGURA 2.6 - MECANISMO DE TRANSFERÊNCIA DE TENSÕES. ................................................... 11

FIGURA 2.7 - MECANISMO DE TRANSFERÊNCIA DE TENSÕES (DETALHES 2 E 3). ................................... 12

FIGURA 2.8 - RUPTURA DA ADERÊNCIA POR: (A) FISSURAÇÃO POR FENDILHAMENTO EM CONCRETO NÃO

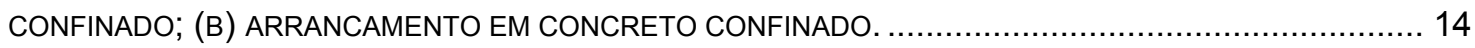

FIGURA 2.9 - CURVA EXPERIMENTAL TENSÃO DE ADERÊNCIA-DESLIZAMENTO PARA AÇÃO CÍCLICA

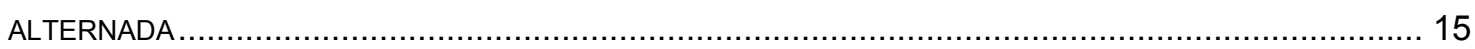

FIGURA 2.10 - DETALHES ENSAIADOS POR SCOTT, R. H. (1996).................................................. 16

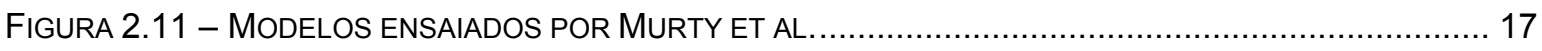

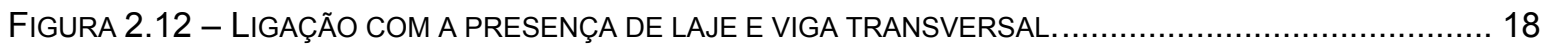

FIGURA 2.13 - MODELOS, COM VIGA ESTENDIDA ALÉM DOS LIMITES DO PILAR, ENSAIADOS POR PATTON

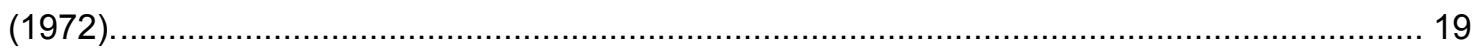

FIGURA 2.14 - MECANISMOS RESISTENTES DA BARRA LONGITUDINAL DA VIGA. ................................. 20

FIGURA 2.15 - DIAGRAMAS UTILIZADOS PARA A APRESENTAÇÃO DE DADOS EXPERIMENTAIS: FORÇA VS. DESLOCAMENTO (A) E HISTÓRICO DO CARREGAMENTO (B) ...................................................... 24

FIGURA 2.16 - DETALHES DAS ARMADURAS DOS MODELOS DE MURTY ET AL. (2003).......................... 25

FIGURA 2.17 - DETALHES DAS ARMADURAS DOS MODELOS DE HA ET AL. (1992). .............................. 26

FIGURA 3.1 - ESFORÇOS CONSIDERADOS POR PAULAY \& PRIESTELEY (1992). .................................. 33

FIGURA 3.2 - LARGURA MÁXIMA DISPONÍVEL PARA A BIELA SEGUNDO ORTIZ (1993)............................ 36

FIGURA 3.3 - MODELO DE BIELAS E TIRANTES PROPOSTO POR ORTIZ (1993)....................................... 37

FIGURA 3.4 - VARIÁVEIS ENVOLVIDAS NO MODELO DE PARKER \& BULLMAN (1997)............................. 38

FIGURA 3.5 - MECANISMOS RESISTENTES NO NÓ EXTERNO (1999). ................................................ 40

FIGURA 3.6 - ModELo DE BIELAS E TIRANTES DE HWANG E LEE (1999). ........................................... 41 
FIGURA 3.7 - INCLINAÇÃO DA BIELA DIAGONAL PARA O MODELO DE HWANG \& LEE (1999)..................... 41

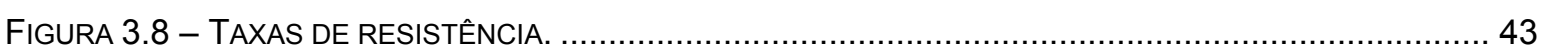

FIGURA 3.9 - RELAÇÃO TENSÃO VS. DEFORMAÇÃO CONSIDERADA POR HWANG \& LEE (1999)................ 44

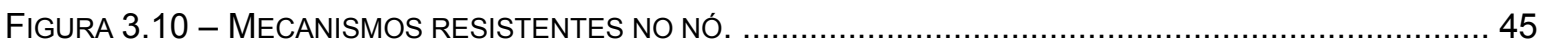

FIGURA 3.11 - COMPORTAMENTO DO CONCRETO SOB TENSÕES BIAXIAIS. ................................... 47

FIGURA 3.12 - MODELO DE BIELAS E TIRANTES PROPOSTO POR PANTELIDES ET AL. (1999). ................. 49

FIGURA 3.13 - POSICIONAMENTO DAS PLACAS DE ANCORAGEM E DAS DOBRAS A $90^{\circ} \ldots \ldots \ldots \ldots \ldots \ldots \ldots . . . . . . . . . . . . . .56$

FIGURA 4.1 - EQUILÍBRIO ESTÁTICO DA LIGAÇÃO VIGA-PILAR DE EXTREMIDADE. ................................... 61

FIGURA 4.2 - POSICIONAMENTO DA LIGAÇÃO E DOS DISPOSITIVOS DE ENSAIO (VISTA SUPERIOR)............ 62

FIGURA 4.3 - POSICIONAMENTO DA LIGAÇÃO E DOS DISPOSITIVOS DE ENSAIO: EIXO DO ATUADOR........... 62

FIGURA 4.4 - POSICIONAMENTO DA LIGAÇÃO E DOS DISPOSITIVOS DE ENSAIO: EIXO DO CILINDRO

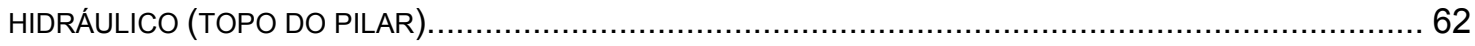

FIGURA 4.5 - POSICIONAMENTO DA LIGAÇÃO E DOS DISPOSITIVOS DE ENSAIO: EIXO DO CILINDRO

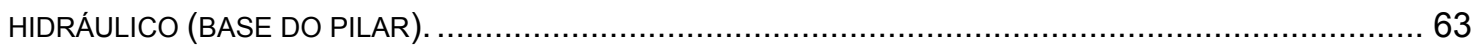

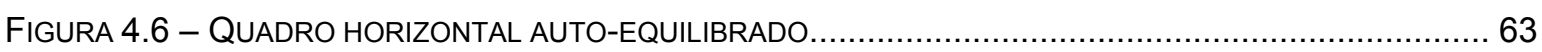

FIGURA 4.7 - PILAR METÁlICO PARA FIXAÇÃO DO EQUIPAMENTO E AS BARRAS INCLINADAS DE

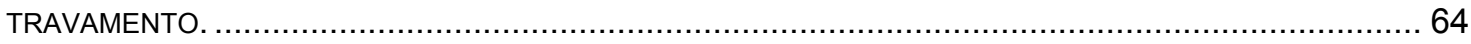

FIGURA 4.8 - CONFIGURAÇÃO DO PÓRTICO DE REAÇÃO (FIGURA 4.7) PARA VERIFICAÇÃO DA CAPACIDADE

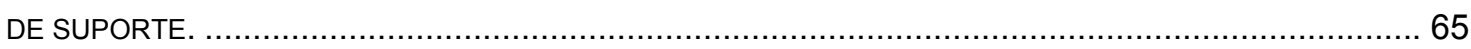

FIGURA 4.9 - PROPRIEDADES GEOMÉTRICAS DOS MODELOS A SEREM ENSAIADOS. .............................. 66

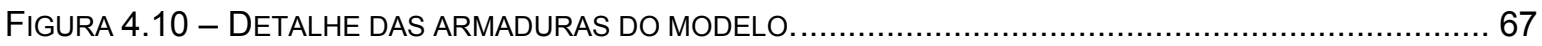

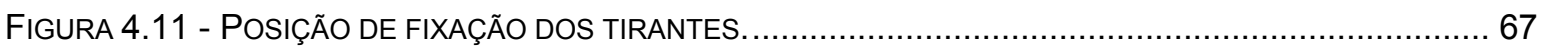

FIGURA 4.12 - TIRANTES UTILIZADOS PARA A REDUÇÃO DO ÍNDICE DE ESBELTEZ DA PEÇA (ENSAIO PILOTO).

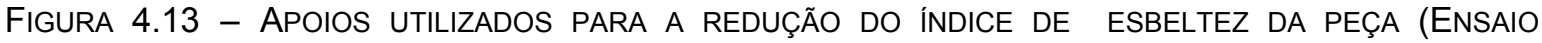

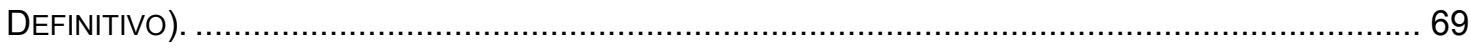

FIGURA 4.14 - RÓTULAS UTILIZADAS NOS PONTOS DE APLICAÇÃO DE FORÇA. ...................................... 69

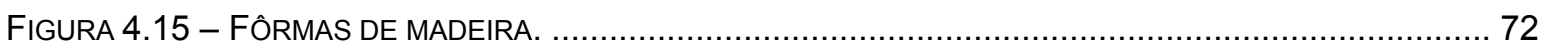

FIGURA 4.16 - TRAVAS PARA EVITAR MOVIMENTO RELATIVO ENTRE AS PARTES DA FÔRMA..................... 73

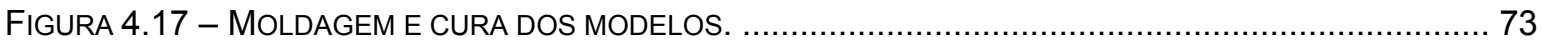

FIGURA 4.18 - POSICIONAMENTO DOS TRANSDUTORES DE DESLOCAMENTOS HORIZONTAIS NA LIGAÇÃO VIGA-PILAR.

FIGURA 4.19 - POSICIONAMENTO DOS TRANSDUTORES DE DESLOCAMENTOS NO PILAR DO EIXO DO MACACO HIDRÁULICO E DOS TRANSDUTORES DE DESLOCAMENTOS VERTICAIS NA LIGAÇÃO VIGA-PILAR........... 75

FIGURA 4.20 - TRANSDUTORES POSICIONADOS NO PILAR DO EIXO DO ATUADOR. .................................. 75

FIGURA 4.21 - TRANSDUTORES POSICIONADOS NO QUADRO HORIZONTAL. .......................................... 75

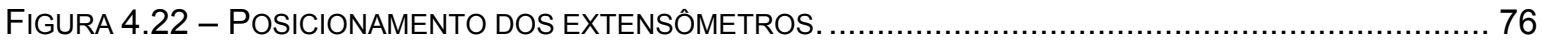

FIGURA 4.23 - NOMEAÇÃO DOS EXTENSÔMETROS .................................................................... 77 
FIGURA 5.1 - RUPTURA DA EXTREMIDADE DO PILAR POR CONCENTRAÇÃO DE TENSÕES 79

FIGURA 5.2 - CORREÇÃO DA SUPERFÍCIE DA EXTREMIDADE DO PILAR E REFORÇO COM CAMISA METÁLICA.

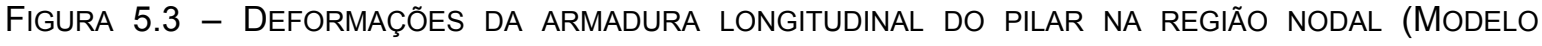

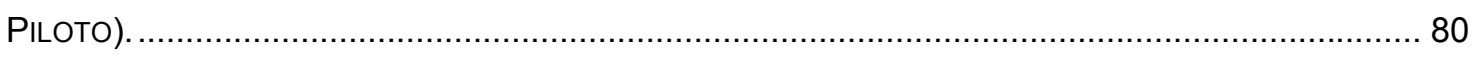

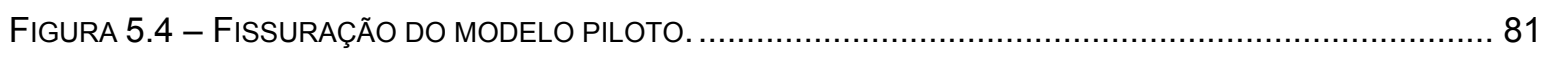

FIGURA 5.5 - DEFORMAÇÕES DO ESTRIBO NA REGIÃO NODAL..................................................... 81

FIGURA 5.6 - DEFORMAÇÕES DAS BARRAS LONGITUDINAIS DO PILAR NA SEÇÃO ONDE OCORREU A RUPTURA

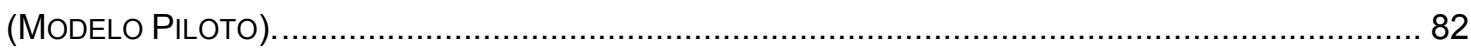

FIgURA 5.7 - DEFORMAÇÕES DA ARMADURA LONGITUDINAL DO PILAR NA REGIÃO NODAL (MODELO N400).

FIGURA 5.8 - DEFORMAÇÕES DA ARMADURA LONGITUDINAL DO PILAR AO LONGO DO EIXO CAUSADAS PELA FORÇA NORMAL: (A) FACE EXTERNA E (B) FACE INTERNA (MODELO N400) . ................................ 83

FIgURA 5.9 - DEFORMAÇÕES DA ARMADURA LONGITUDINAL DO PILAR AO LONGO DO EIXO APÓS CARREgamento da Viga: (A) FACE EXterna E (B) FACE InTERnA (Modelo N400). ..................... 83

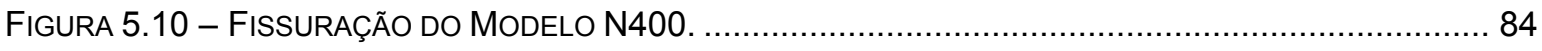

FIGURA 5.11 - DEFORMAÇÕES DO ESTRIBO NA REGIÃO NODAL (MODELO N400) ................................. 84

FIGURA 5.12 - DEFORMAÇÕES DOS ESTRIBOS DO PILAR (MODELO N400). ….................................... 85

FIGURA 5.13 - DEFORMAÇÕES DOS ESTRIBOS DA VIGA (MODELO N400)......................................... 85

FIGURA 5.14 - DEFORMAÇõES DA ARMADURA LONGITUDINAL DA VIGA (MODELO N400) ........................ 85

FIGURA 5.15 - DEFORMAÇÕES DA ARMADURA LONGITUDINAL DA VIGA AO LONGO DO EIXO (MODELO N400). 86

FIGURA 5.16 - RUPTURA DO COBRIMENTO NO LADO EXTERNO DO NÓ (MODELO N400)........................ 86

FIGURA 5.17 - DEFORMAÇõES DA ARMADURA LONGITUDINAL DO PILAR NA REGIÃO NODAL (MODELO N300). 87

FIGURA 5.18 - DEFORMAÇÕES DA ARMADURA LONGITUDINAL DO PILAR AO LONGO DO EIXO CAUSADAS PELA FORÇA NORMAL: (A) FACE EXTERNA E (B) FACE INTERNA (MODELO N300) . .................................. 87

FIGURA 5.19 - DEFORMAÇÕES DA ARMADURA LONGITUDINAL DO PILAR AO LONGO DO EIXO APÓS

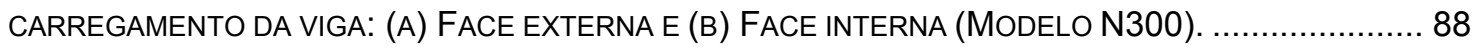

FIGURA 5.20 - DEFORMAÇÕES DO ESTRIBO NA REGIÃO DO NÓ (MODELO N300) ................................ 88

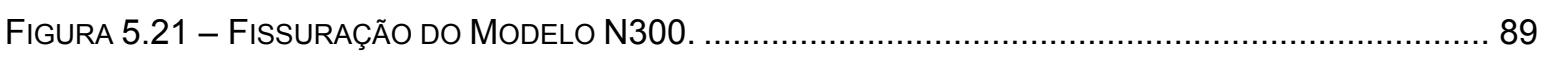

FIGURA 5.22 - DEFORMAÇÕES DOS ESTRIBOS DO PILAR (MODELO N300). ........................................ 89

FIGURA 5.23 - DEFORMAÇÕES DOS ESTRIBOS DA VIGA (MODELO N300) .......................................... 90

FIGURA 5.24 - DEFORMAÇÕES DA ARMADURA LONGITUDINAL DA VIGA (MODELO N300) ....................... 90

FIGURA 5.25 - DEFORMAÇõES DA ARMADURA LONGITUDINAL DA VIGA AO LONGO DO EIXO (MODELO N300).

FIGURA 5.26 - DEFORMAÇÕES DA ARMADURA LONGITUDINAL DO PILAR NA REGIÃO NODAL (MODELO N200). 
FIGURA 5.27 - DEFORMAÇÕES DA ARMADURA LONGITUDINAL DO PILAR AO LONGO DO EIXO CAUSADAS PELA FORÇA NORMAL: (A) FACE EXTERNA E (B) FACE INTERNA (MODELO N200). 92

FIGURA 5.28 - DEFORMAÇÕES DA ARMADURA LONGITUDINAL DO PILAR AO LONGO DO EIXO APÓS CARREgAmento da Viga: (A) FACE EXTERna e (B) FACE INTERna (Modelo N200). ...................... 92

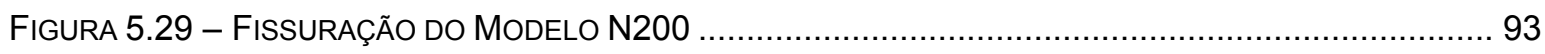

FIGURA 5.30 - DEFORMAÇÕES DO ESTRIBO NA REGIÃO DO NÓ (MODELO N200). ................................. 93

FIGURA 5.31 - DEFORMAÇÕES DOS ESTRIBOS DO PILAR (MODELO N200) ......................................... 94

FIGURA 5.32 - DEFORMAÇÕES DOS ESTRIBOS DA VIGA (MODELO N200) ......................................... 94

FIGURA 5.33 - DEFORMAÇÕES DA ARMADURA LONGITUDINAL DA VIGA (MODELO N200) ....................... 95

FIGURA 5.34 - DEFORMAÇÕES DA ARMADURA LONGITUDINAL DA VIGA AO LONGO DO EIXO (MODELO N200). .95

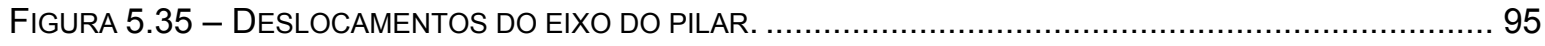

FIGURA 5.36 - DEFORMAÇÕES DAS BARRAS COMPRIMIDAS NA INTERFACE VIGA-PILAR. ....................... 97

FIGURA 5.37 - DEFORMAÇÕES DOS ESTRIBOS NA REGIÃO NODAL................................................ 98

FIGURA 5.38 - ESQUEMA DA SOLICITAÇÃO DO ESTRIBO E DA PARCELA DO CONCRETO.......................... 98

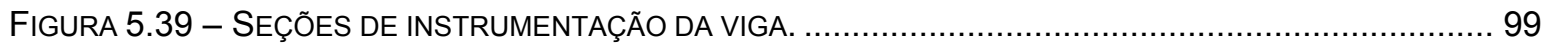

FIgURA 5.40 - DEFORMAÇÃO DA ARMADURA LONGITUDINAL DA VIGA VS. FORÇA NO PILAR (SEÇÃO 2)... 100

FIGURA 5.41 - DEFORMAÇÃO DA ARMADURA LONGITUDINAL DA VIGA VS. FORÇA NO PILAR (SEÇÃO 3)... 100

FIGURA 5.42 - ESQUEMA DAS DEFORMAÇÕES DA VIGA CAUSADAS PELA FLEXÃO DO PILAR................... 101

FIGURA 5.43 - DEFORMAÇÃO DA ARMADURA LONGITUDINAL DA VIGA VS. FORÇA NO PILAR (SEÇÃO 1)... 101

FIGURA 5.44 - DEForMAÇÃo dA ARMADURA LONGITUdINAL DA VIGA VS. FORÇA NA VIGA (SEÇÃO 1).... 102

FIGURA 5.45 - DEFORMAÇÃO DA ARMADURA LONGITUDINAL DA VIGA VS. FORÇA NA VIGA (SEÇÃO 2).... 102

FIGURA 5.46 - DEFORMAÇÃO DA ARMADURA LONGITUDINAL DA VIGA VS. FORÇA NA VIGA (SEÇÃO 3).... 102

FIGURA 5.47 - DEFORMAÇÃO DA DOBRA DAS BARRAS DA VIGA VS. FORÇA NO PILAR. ........................ 103

FIGURA 5.48 - DEFORMAÇÃO DA DOBRA DAS BARRAS DA VIGA VS. FORÇA A VIGA. ............................. 103

FIGURA 5.49 - SEÇÕES DE INSTRUMENTAÇÃO DO PILAR. ....................................................... 104

FIGURA 5.50 - DEFORMAÇÃO dA ARMADURA LONGITUDINAL DO PILAR VS. FORÇA NO PILAR (SEÇÃO 1). 104

FIGURA 5.51 - DEFORMAÇÃO DA ARMADURA LONGITUDINAL DO PILAR VS. FORÇA NO PILAR (SEÇÃO 5). 105

FIGURA 5.52 - DEFORMAÇÃO DA ARMADURA LONGITUDINAL DO PILAR VS. FORÇA NO PILAR (SEÇÃO 2). 105

FIGURA 5.53 - DEFORMAÇÃO DA ARMADURA LONGITUDINAL DO PILAR VS. FORÇA NO PILAR (SEÇÃO 4). 106

FIGURA 5.54 - DEFORMAÇÃo dA ARMADURA LONGITUDINAL DO PILAR VS. FORÇA NO PILAR (SEÇÃO 3). 106

FIGURA 5.55 - DEFORMAÇÃO DO ESTRIBO DO PILAR ACIMA DO NÓ VS. FORÇA NA VIGA........................ 107

FIGURA 6.1 - PONTOS DE DIFICULDADE DE GERAÇÃO DA MALHA DE ELEMENTOS FINITOS..................... 111

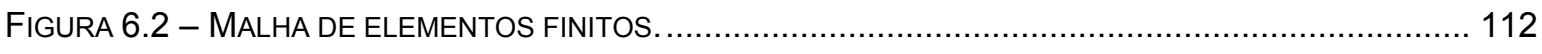

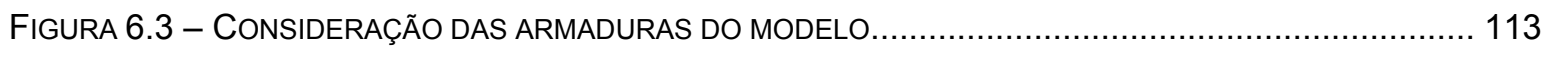

FIGURA 6.4 - SUPERFÍCIE TEÓRICA PROPOSTA POR KUPFER \& GERSTLE (1973)............................. 115

FIGURA 6.5 - DIAGRAMA TENSÃO-DEFORMAÇÃO PARA O CONCRETO (CEB-FIP, 1990)...................... 116

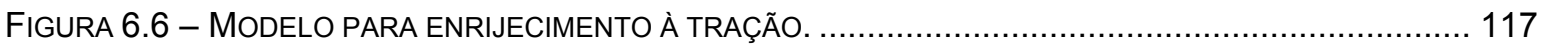


FIGURA 6.7 - CONDIÇÕES DE CONTORNO DO MODELO NUMÉRICO. ........................................... 118

FIGURA 6.8 - DEFORMAÇÕES DA ARMADURA NA POSIÇÃO DO EXTENSÔMETRO E11 (N200). ................ 119

FIGURA 6.9 - DEFORMAÇÕES DA ARMADURA NA POSIÇÃO DO EXTENSÔMETRO E11 (N300). ................ 119

FIGURA 6.10 - DEFORMAÇÕES DA ARMADURA NA POSIÇÃO DO EXTENSÔMETRO E11 (N400)............... 120

FIGURA 6.11 - DEFORMAÇÕES DO ESTRIBO LOCALIZADO NA REGIÃO NODAL (N200). ....................... 120

FIGURA 6.12 - DEFORMAÇÕES DO ESTRIBO LOCALIZADO NA REGIÃO NODAL (N300). ......................... 120

FIGURA 6.13 - DEFORMAÇÕES DO ESTRIBO LOCALIZADO NA REGIÃO NODAL (N400). .......................... 121

FIGURA 6.14 - DEFORMAÇÕES DA ARMADURA NA POSIÇÃO DO EXTENSÔMETRO E114 (N200)............ 121

FIGURA 6.15 - DEFORMAÇÕES DA ARMADURA NA POSIÇÃO DO EXTENSÔMETRO E114 (N300)............ 121

FIGURA 6.16 - DEFORMAÇÕES DA ARMADURA NA POSIÇÃO DO EXTENSÔMETRO E114 (N400)............. 122

FIGURA 6.17 - DEFORMAÇÕES DA ARMADURA NA POSIÇÃO DO EXTENSÔMETRO E17 (N200)............... 122

FIGURA 6.18 - DEFORMAÇÕES DA ARMADURA NA POSIÇÃO DO EXTENSÔMETRO E17 (N300)............... 122

FIGURA 6.19 - DEFORMAÇÕES DA ARMADURA NA POSIÇÃO DO EXTENSÔMETRO E17 (N400)............... 123

FIGURA 6.20 - DEFORMAÇÕES DO ESTRIBO LOCALIZADO ACIMA DA REGIÃO NODAL (N200). ............... 123

FIGURA 6.21 - DEFORMAÇÕES DO ESTRIBO LOCALIZADO ACIMA DA REGIÃO NODAL (N300). ................ 123

FIGURA 6.22 - DEFORMAÇÕES DO ESTRIBO LOCALIZADO ACIMA DA REGIÃO NODAL (N400). ................ 124

FIGURA 6.23 - DEFORMAÇÕES DO ESTRIBO LOCALIZADO ABAIXO DA REGIÃO NODAL (N200)................ 124

FIGURA 6.24 - DEFORMAÇÕES DO ESTRIBO LOCALIZADO ABAIXO DA REGIÃO NODAL (N300)................ 124

FIGURA 6.25 - DEFORMAÇÕES DO ESTRIBO LOCALIZADO ABAIXO DA REGIÃO NODAL (N400)............... 125

FIGURA 6.26 - DEFORMAÇÕES DA ARMADURA NA POSIÇÃO DO EXTENSÔMETRO E111 (N200). ............ 125

FIGURA 6.27 - DEFORMAÇÕES DA ARMADURA NA POSIÇÃO DO EXTENSÔMETRO E111 (N300). ............ 126

FIGURA 6.28 - DEFORMAÇÕES DA ARMADURA NA POSIÇÃO DO EXTENSÔMETRO E111 (N400). ............ 126

FIGURA 6.29 - VARIAÇÃO DA FORÇA NORMAL - ESTRIBO LOCALIZADO NA REGIÃO NODAL.................... 127

FIGURA 6.30 - VARIAÇÃO DA FORÇA NORMAL - ESTRIBO LOCALIZADO ACIMA DO NÓ. .......................... 127

FIGURA 6.31 - VARIAÇÃO DA FORÇA NORMAL - ESTRIBO LOCALIZADO ABAIXO DO NÓ........................... 128

FIGURA 6.32 - VARIAÇÃO DA FORÇA NORMAL - ARMADURA TRACIONADA DA VIGA (E114)................ 128

FIGURA 6.33 - VARIAÇÃO DA FORÇA NORMAL - TENSÕES PRINCIPAIS NO CONCRETO ( $v=0,0$ E v=0,2). 129

FIGURA 6.34 - VARIAÇÃO DA FORÇA NORMAL - TENSÕES PRINCIPAIS NO CONCRETO ( $v=0,6$ E v=0,8). 129

FIGURA A.1 - PROPRIEDADES DA SUPERFÍCIE DO CONCRETO COM TEOR DE ARGAMASSA IDEAL............ 146

FIGURA A.2 - ASPECTO HOMOGÊNEO DO CONCRETO COM TEOR DE ARGAMASSA IDEAL........................ 146

FIGURA A.3 - ASPECTO COMPACTO E COESO DO CONCRETO COM TEOR DE ARGAMASSA IDEAL............. 147

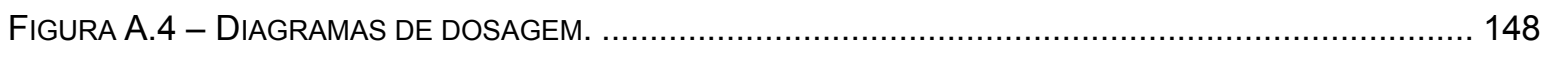

FIGURA B.1 - DISTRIBUIÇÃO DAS TENSÕES DE ADERÊNCIA NO ENSAIO DE ARRANCAMENTO. ................ 149

FIGURA B.2 - GEOMETRIA DO MODELO (A) E CONSIDERAÇÃO DA INTERFACE AÇO-CONCRETO (B)........... 150

FIgURA B.3 - DISCRETIZAÇÕES ADOTADAS PARA OS MODELOS NUMÉRICOS: TRIDIMENSIONAL (A)

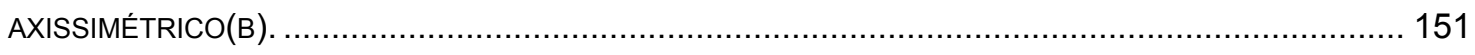

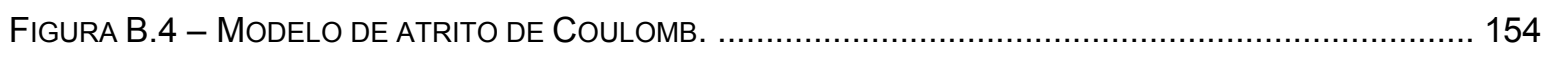


FIGURA B.5- ESQUEMA DE ENSAIOS DO MODELO EXPERIMENTAL (A) E CONSIDERAÇÕES PARA O MODELO NUMÉRICO (B). 155

FIGURA B.6- TENSÕES INICIAIS AO LONGO DA BARRA NO MODELO TRIDIMENSIONAL (A) E NO MODELO AXISSIMÉTRICO (B) $\operatorname{COM} \mu=0,4 \mathrm{E} P=3 \mathrm{KN} / \mathrm{CM}^{2}$. 156

Figura B.7- Diagrama Tensão de ADERÊNCIA Vs. Deslizamento PARA O MOdELO TRIDIMENSIONAL (A) E PARA O MODELO AXISSIMÉTRICO (B) COM $\mu=0,4 \mathrm{E} P=3 \mathrm{kN} / \mathrm{CM}^{2}$. 156

FIGURA B.8- VARIAÇÃO DA TENSÃO DE ADERÊNCIA NA REGIÃO DE CONTATO DEVIDO AO CONFINAMENTO $\left(\mu=0,4 \mathrm{E} P=3 \mathrm{KN} / \mathrm{CM}^{2}\right)$ 157

FIGURA B.9- MUDANÇA DE DIREÇÃO DAS TENSÕES DE ADERÊNCIA NA REGIÃO DO CONTATO PRÓXIMO AO CARREGAMENTO. $\left(\mu=0,4 \mathrm{E} P=3 \mathrm{kN} / \mathrm{CM}^{2}\right)$. 157

FIGURA B.10- VARIAÇÃO DAS TENSÕES DE ADERÊNCIA AO LONGO DO COMPRIMENTO DA BARRA COM $\mu=$ $0,4 \mathrm{E} P=3 \mathrm{KN} / \mathrm{CM}^{2}$. 158

Figura B.11- Diagrama Tensão de aderÊncia VS. Deslizamento extraído dos Resultados EXPERIMENTAIS DE FERNANDES (2000). 158

Figura B.12- DiagRama TENSÃO DE ADERÊNCIA VS. DESLIZAMENTO COM CONFINAMENTO DE $1 \mathrm{KN} / \mathrm{CM}^{2}$ (A), $\operatorname{COM} 2 \mathrm{KN} / \mathrm{CM}^{2}$ (B) E COM $3 \mathrm{KN} / \mathrm{CM}^{2}$ (C). 159 


\section{LISTA DE TABELAS}

TABELA 3.1 - VALORES SUGERIDOS PARA $\alpha_{2}$ 52

TABELA 3.2 - VALORES DE. $\gamma$ DE ACORDO COM A CLASSIFICAÇÃO DO NÓ. …....................................... 54

TABELA 4.1 - PROPRIEDADES DO CONCRETO FRESCO …........................................................ 70

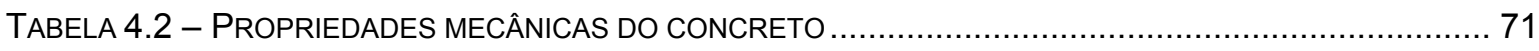

TABELA 4.3 - PROPRIEDADES MECÂNICAS DAS ARMADURAS ...................................................... 72

TABELA 4.4 - RELAÇÃO DOS INSTRUMENTOS DE MEDIÇÃO DE DESLOCAMENTOS E DEFORMAÇÕES ........... 77

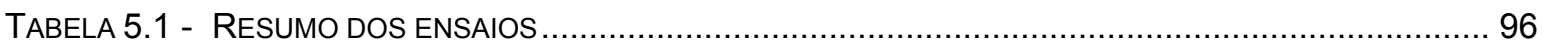

TABELA 5.2 - FoRÇAS ÚlTIMAS: EXPERIMENTAL VS. MODELOS TEÓRICOS .......................................... 108

TABELA 6.1 - QUANTIDADE DE ELEMENTOS UTILIZADOS NO MODELO NUMÉRICO ............................... 113

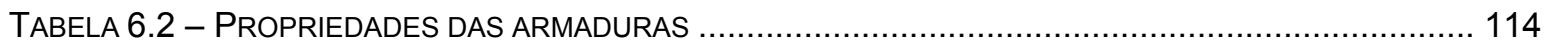

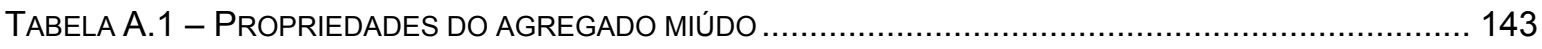

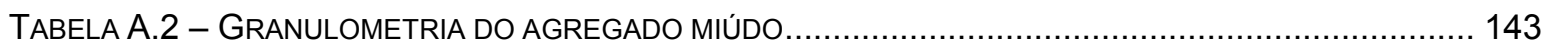

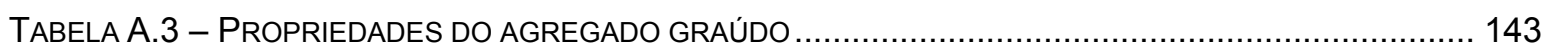

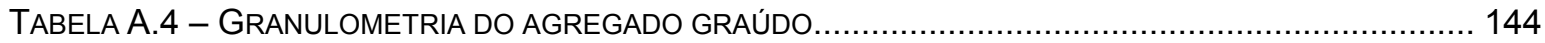

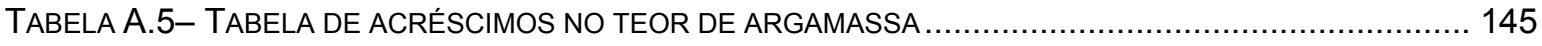

TABELA B.1 - QUANTIDADE DE ELEMENTOS UTILIZADOS PARA CADA MODELO NUMÉRICO. ....................... 152

TABELA B.2 - VALORES ADOTADOS PARA OS MATERIAIS COM COMPORTAMENTO LINEAR ....................... 152 


\title{
SUMÁRIO
}

\author{
RESUMO
}

.. $\mathrm{V}$

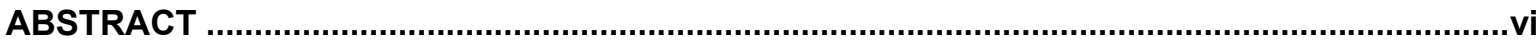

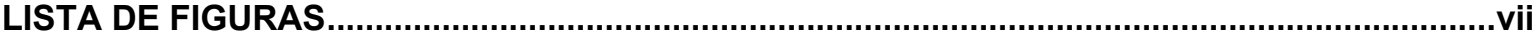

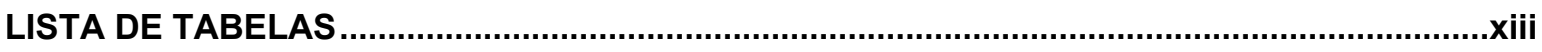

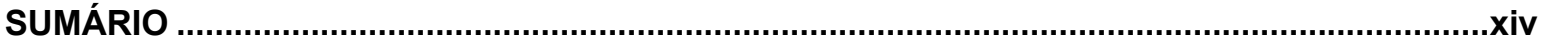

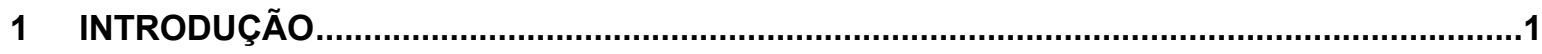

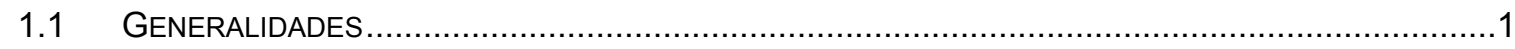

1.2 OBJETIVO

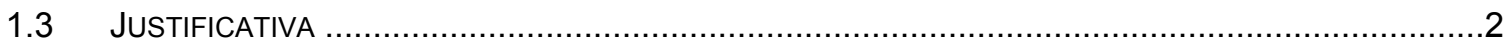

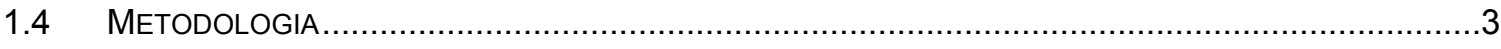

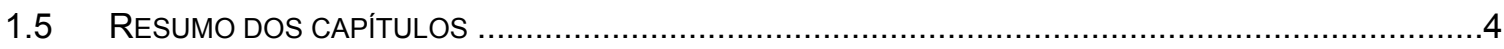

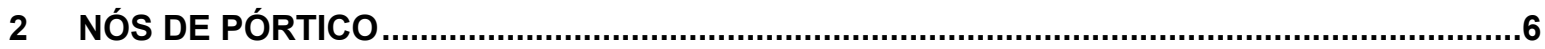

2.1 DEFINIÇÃO

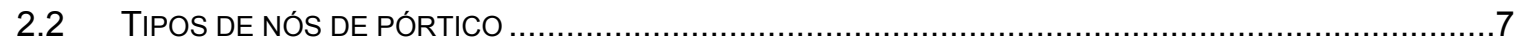

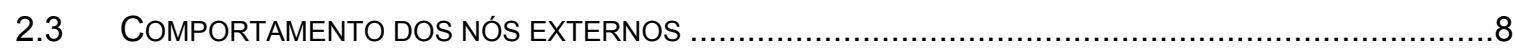

2.4 VARIÁVEIS QUE INFLUENCIAM O COMPORTAMENTO DOS NÓS DE PÓRTICO................................. 12

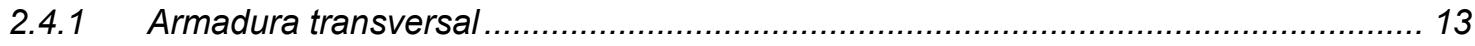

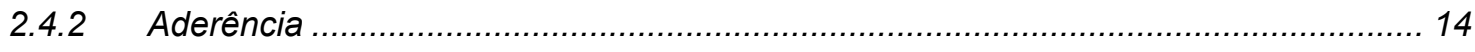

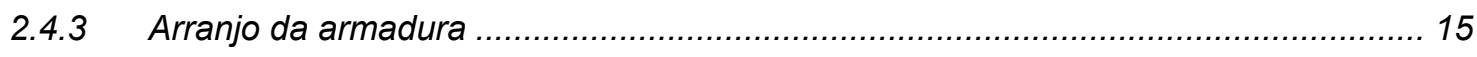

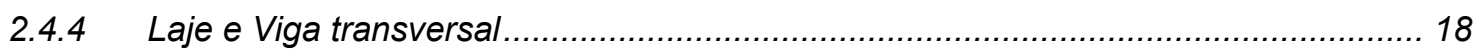

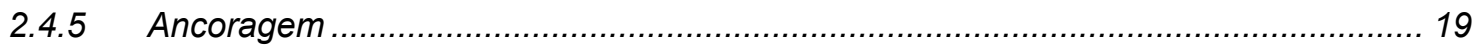

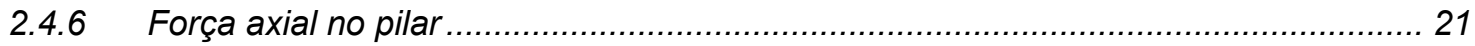




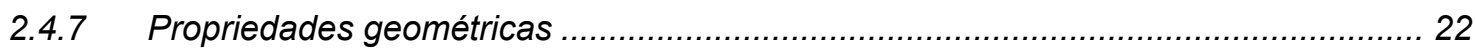

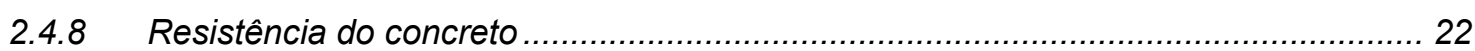

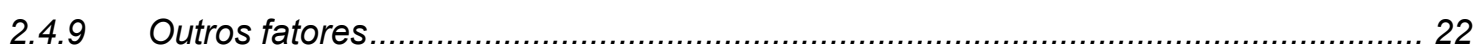

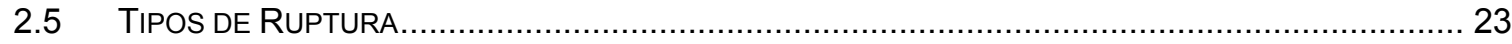

2.6 COMPORTAMENTO DOS NÓS SOB CARREGAMENTO CÍCLICO .............................................. 23

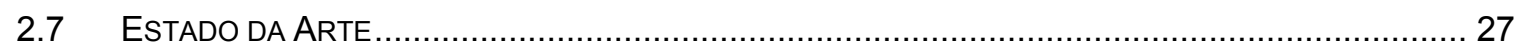

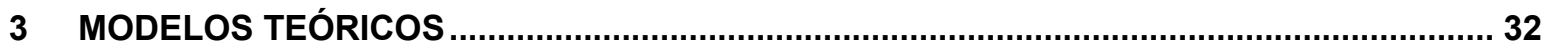

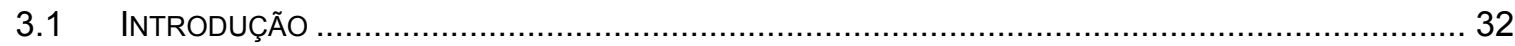

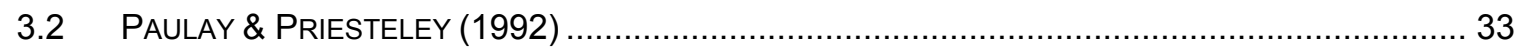

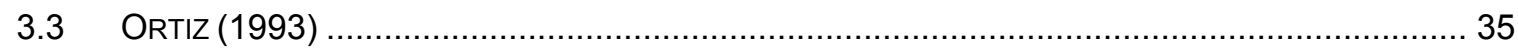

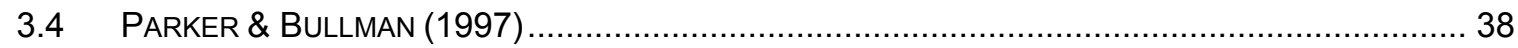

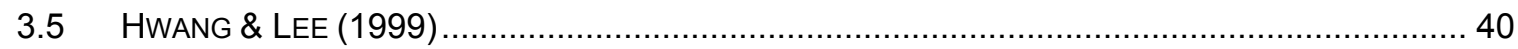

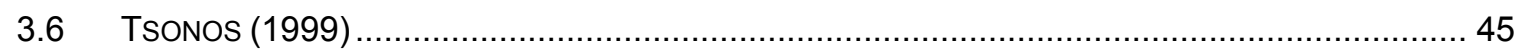

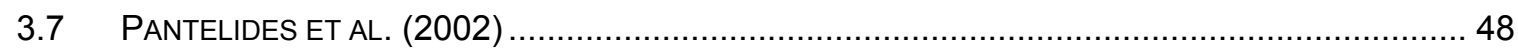

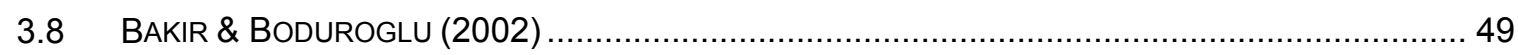

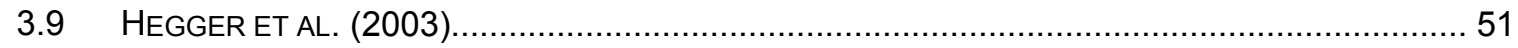

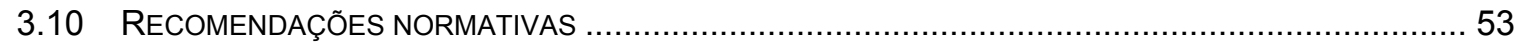

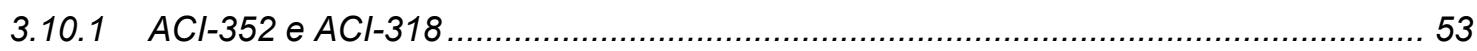

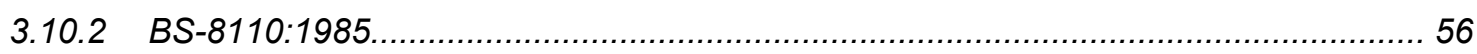

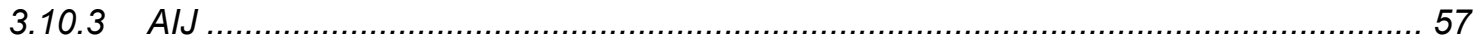

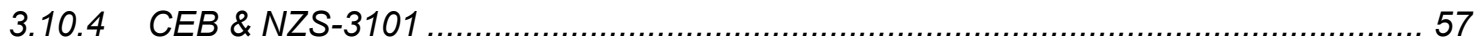

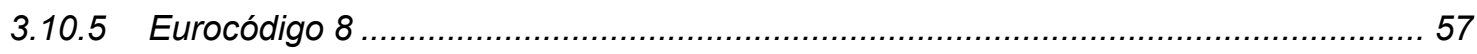

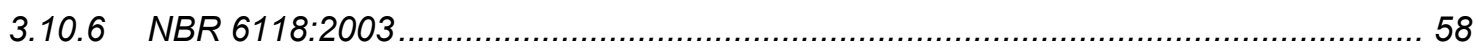

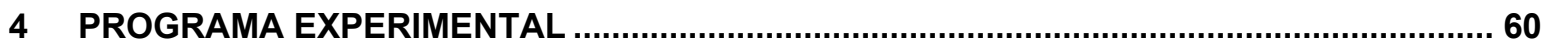

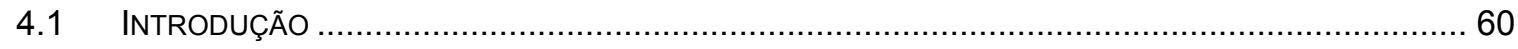

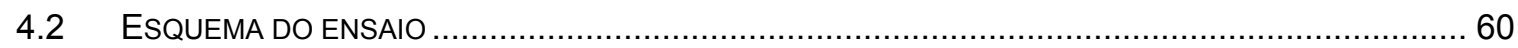

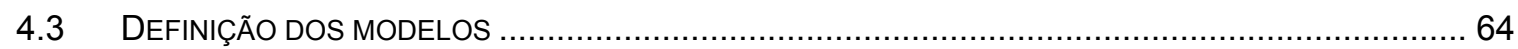

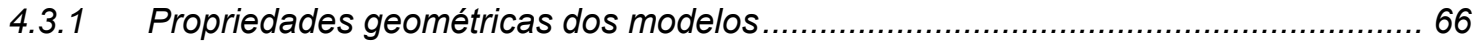

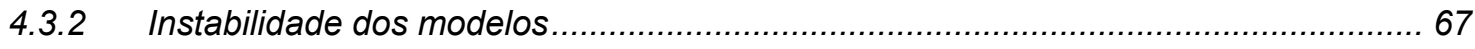

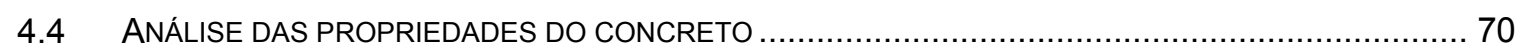

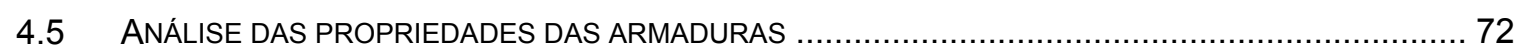

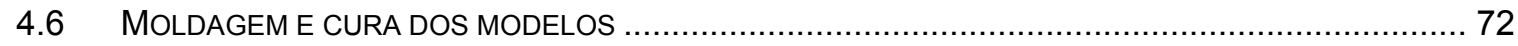

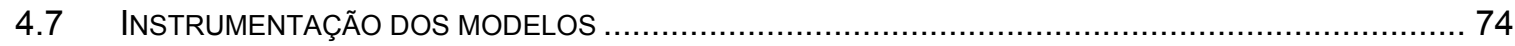

5 COMPORTAMENTO DOS MODELOS E ANÁLISE DOS RESULTADOS............................. 78

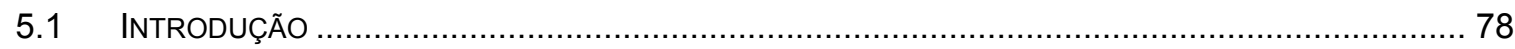




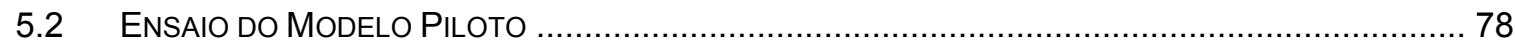

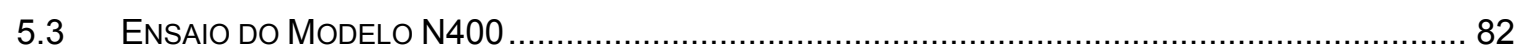

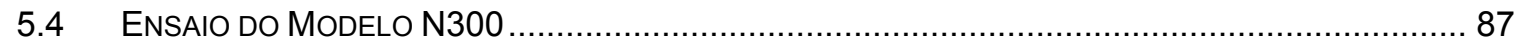

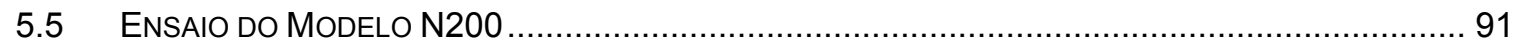

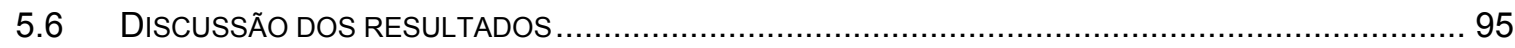

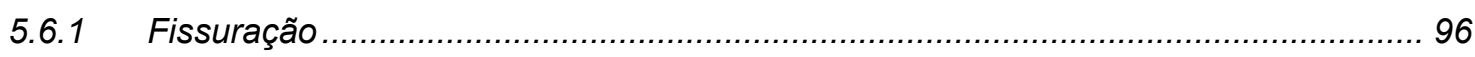

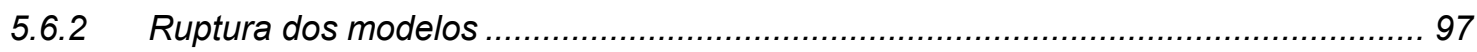

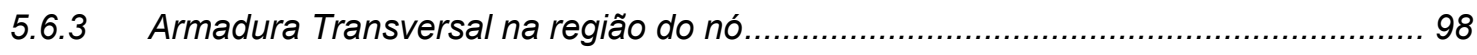

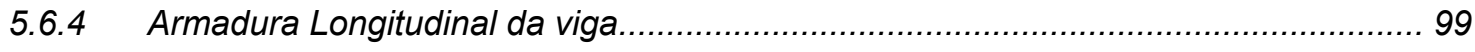

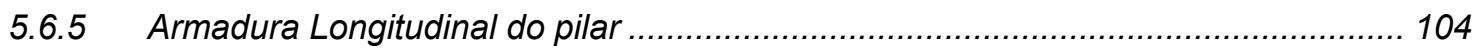

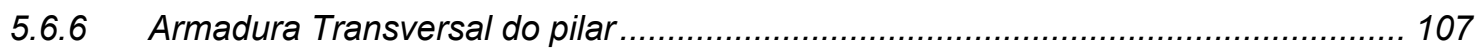

5.7 RESUltAdOS EXPERIMENTAIS VS. MOdELOS TEÓRICOS ................................................. 107

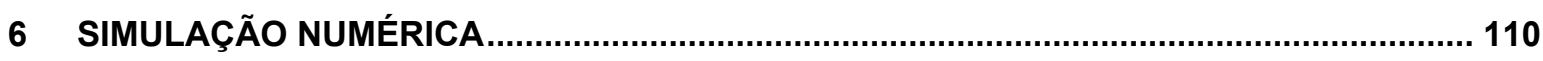

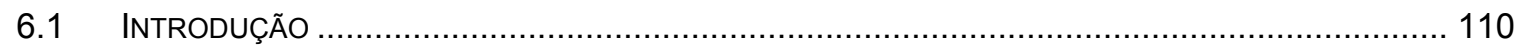

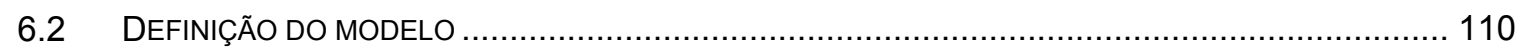

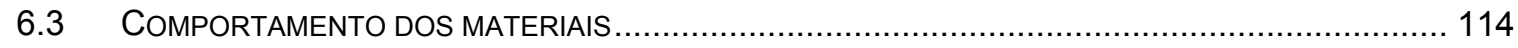

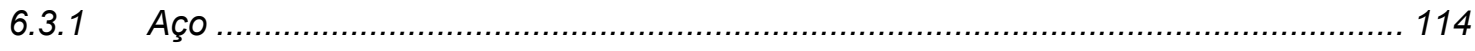

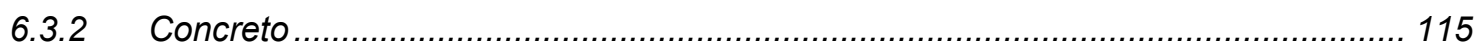

6.4 CONDIÇÕES DE CONTORNO E CARREGAMENTO ............................................................ 117

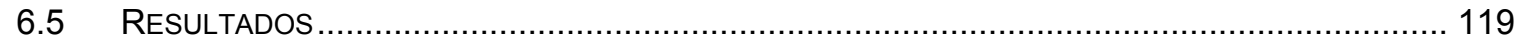

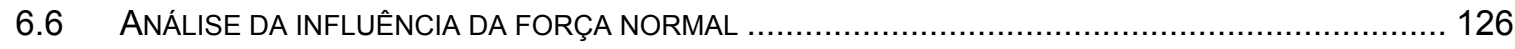

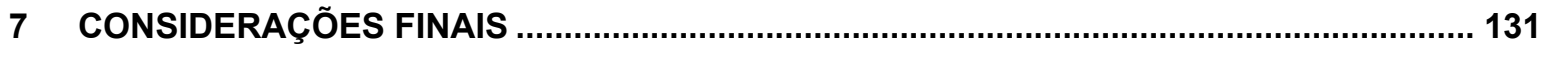

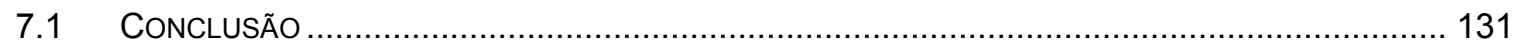

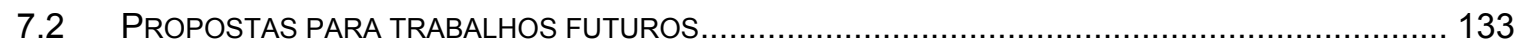

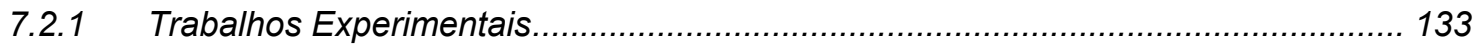

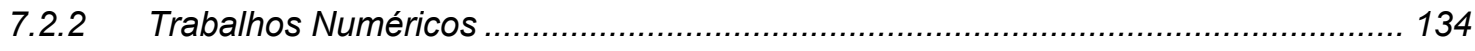

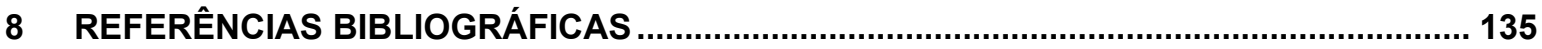

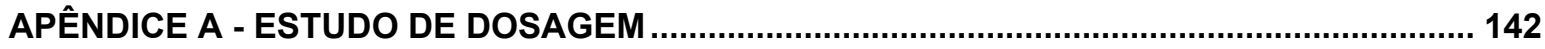

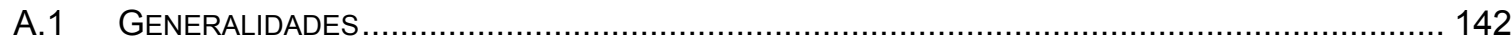

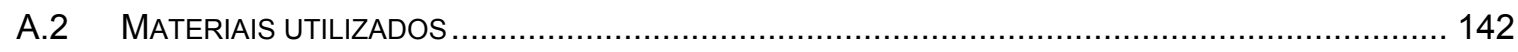

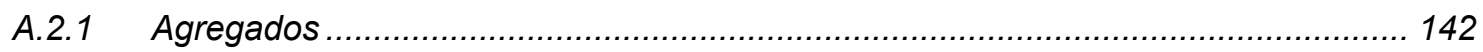

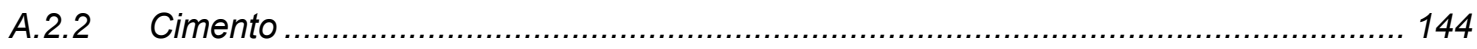

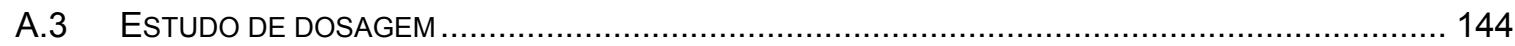




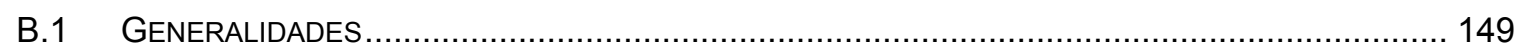

B.2 Modelo EXPERIMENTAL ENSAIAdo POR FERNANDES (2000) …........................................ 150

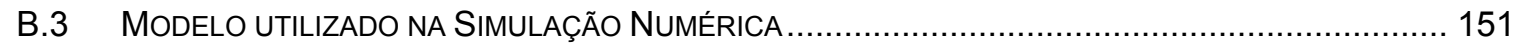

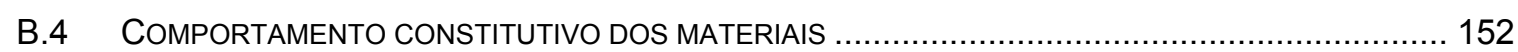

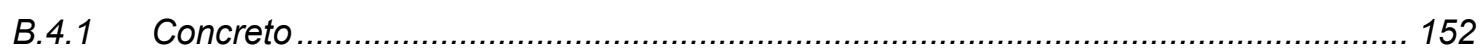

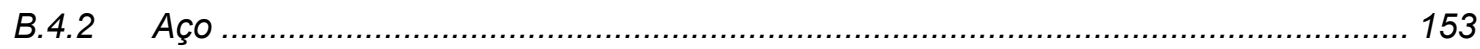

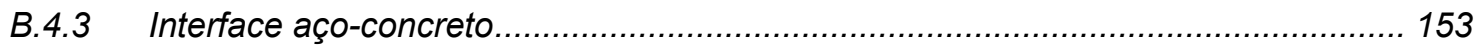

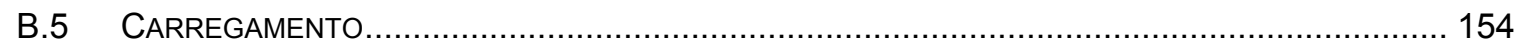

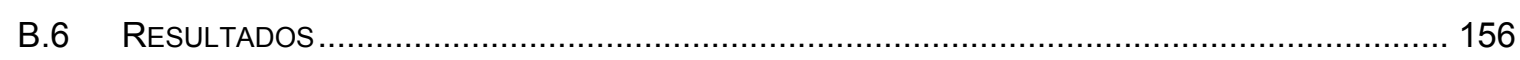




\section{INTRODUÇÃO}

\subsection{Generalidades}

Os nós de pórtico em estruturas de concreto armado são regiões bastante complexas tanto do ponto de vista de projeto como de execução. Qualquer mudança de direção do eixo de uma estrutura provoca uma mudança na direção dos esforços internos e, em conseqüência, gera esforços adicionais modificando inteiramente a distribuição das tensões. O principal objetivo do dimensionamento do nó é a transferência destas tensões da melhor maneira possível. De acordo com Park e Paulay (1975) até os anos 70 acreditava-se que a resistência do nó fosse pelo menos igual à da peça com menor capacidade resistente (viga ou pilar). Todavia, investigações experimentais demonstram que nem sempre esta hipótese é verdadeira.

A norma norte-americana ACl-352 (1976) indicava que os nós de pórtico apresentavam comportamento similar ao das vigas quando sujeito a esforços de cisalhamento, porém em 1985 suas recomendações foram revisadas e passaram considerar que o comportamento dos nós é significativamente diferente do comportamento das vigas.

Os nós devem ser tão resistentes quanto as peças ligadas por eles. Um projeto deve ser capaz de prevenir ruptura frágil por cisalhamento do nó, manter a integridade deste, reduzir a degradação da rigidez minimizando a fissuração e evitar a perda da aderência entre o aço e o concreto. O nó deve ser projetado para que, caso ocorra colapso, esta se dê pela formação de rótula na viga, pois este é um tipo de ruína com aviso prévio. 
Segundo Park e Paulay (1975) os requisitos essenciais para um comportamento satisfatório dos nós são:

1. Um nó deve apresentar comportamento sob carga de serviço igual aos elementos por ele ligados.

2. Um nó deve apresentar resistência suficiente para suportar a combinação de cargas mais desfavorável que os membros ligados possam suportar.

3. A resistência do nó não deve governar a resistência da estrutura, e seu comportamento não deve impedir que os elementos ligados desenvolvam toda as suas capacidades.

4. O arranjo das armaduras na ligação não deve dificultar sua colocação e compactação do concreto durante a execução.

Desde 1968 inúmeras foram as pesquisas a respeito da análise de nós sob carregamento cíclico, porém poucos são os estudos considerando a ligação viga-pilar sob carga monotônica.

\subsection{Objetivo}

O objetivo desta pesquisa é estudar a influência da força normal no comportamento estrutural de nós de pórtico externos de concreto armado sob a ação de carga monotônica, por meio de simulação numérica, utilizando o aplicativo $A B A Q U S^{\circledR}$, e de análise experimental.

\subsection{Justificativa}

Nós de pórticos de concreto armado são regiões críticas em virtude de diversos aspectos como: a grande quantidade de barras das armaduras, por se tratar de uma região muitas vezes de dimensões reduzidas, acarretando uma difícil concretagem; altas tensões de aderência, por ser uma região de inversão de esforços; dificuldade no arranjo das barras da viga; perda de rigidez da ligação causada por ciclos de carregamento 
advindos do vento, sismos, máquinas entre outros. Diversas pesquisas já foram realizadas sobre o assunto, porém em virtude do grande número de variáveis envolvidas e à sua complexidade ele ainda não foi esgotado.

Dentre as variáveis envolvidas, a força normal aplicada ao pilar, foi observada por diversos autores, porém existem muitas divergências de opiniões sobre a influência dela no comportamento do nó. Alguns autores afirmam que a força normal não tem influência nos mecanismos de transferência de esforços solicitantes do nó, outros afirmam que ela melhora o comportamento destes mecanismos.

Do ponto de vista teórico, o critério de ruptura de Coulomb, bastante difundido no meio científico, afirma que não há ruína se a tensão de cisalhamento não ultrapassar um valor dado pela equação ( 1.1 ):

$$
\tau=C+\sigma^{*} \mu
$$

sendo $c$ e $\mu$ constantes do material e $\sigma$ a tensão normal ao plano de cisalhamento.

Portanto, tensões de compressão transversais às armaduras devem ser benéficas, já que promovem um confinamento das barras e por conseguinte, melhoram as condições de aderência das mesmas. No caso dos nós de pórtico, a aderência é apenas umas das variáveis que definem o comportamento da ligação, e assim sua capacidade resistente. Assim sendo, a aplicação de cargas axiais de compressão nos nós externos de pórtico, modifica o comportamento destes elementos.

Por conseguinte, este trabalho procura definir a variação do comportamento do nó de pórtico externo sujeito à aplicação de diferentes valores de força normal, por meio de análise experimental e simulação numérica.

\subsection{Metodologia}

Foi realizada uma extensa pesquisa bibliográfica, com o objetivo de entender melhor o comportamento dos nós de pórtico, buscar modelos de dimensionamento e definição de esforços, verificar as principais dificuldades encontradas nos estudos experimentais e analisar como as normas abordam o assunto. 
Realizada esta etapa da pesquisa de levantamento de informações, elaborou-se um protótipo para ensaio no qual foram mantidas constantes todas as propriedades geométricas e de arranjo de armadura. Com isso foram ensaiados quatro modelos com forças normais adimensionais de 0,5; 0,65; 0,87 e 0,9.

Paralelamente a esta etapa do trabalho foi simulado numericamente um nó de pórtico externo, utilizando o aplicativo $A B A Q U S^{\circledR}$, com as mesmas propriedades do modelo experimental, com o intuito de comparação de resultados e análise da ligação para um intervalo maior de valores de força normal. Além disso, foram realizados estudos numéricos sobre o comportamento da interface aço-concreto, por meio de modelos de arrancamento, para a aplicação no modelo do nó de pórtico. No entanto isto não foi possível, porque se conseguiu pequenos progressos nesta simulação da aderência e ao se considerar o contato no modelo do nó de pórtico, o acréscimo desta não linearidade adicional foi seguida de problemas de convergência.

\subsection{Resumo dos capítulos}

No Capítulo 1, introduz-se de maneira resumida o assunto dos nós de pórtico apresentando o objetivo do trabalho e sua justificativa juntamente com a metodologia utilizada no desenvolvimento das atividades.

Nos Capítulos 2 e 3, apresenta-se uma revisão bibliográfica sobre nós de pórtico com ênfase para nós externos, sendo que no Capítulo 2 descreve-se sobre as variáveis que influenciam o comportamento dos nós, o comportamento da ligação sob carregamentos cíclicos além de um estado da arte abordando de maneira resumida os principais trabalhos publicados sobre o assunto. Já no Capítulo 3, apresenta-se modelos teóricos sugeridos na bibliografia para o dimensionamento de nós de pórtico, juntamente com algumas recomendações normativas.

No Capítulo 4, descreve-se o programa experimental com detalhes da elaboração e construção do modelo, das estruturas de reação, dos carregamentos aplicados e dos instrumentos utilizados nos ensaios, além das dificuldades encontradas durante todo o processo.

No Capítulo 5, descreve-se o comportamento de cada modelo durante o ensaio e apresenta-se a análise dos resultados experimentais comparando-os com aqueles 
encontrados na literatura e com as previsões de força última obtidas dos modelos teóricos.

No Capítulo 6, mostra-se todos os passos realizados para a simulação numérica do nó de pórtico externo, desde a concepção do modelo, comportamento dos materiais utilizados, discretização da malha, condições de contorno, carregamentos aplicados, até os resultados finais obtidos.

No Capítulo 7, faz-se as considerações finais do trabalho com a apresentação das conclusões desta pesquisa e descreve-se algumas sugestões para trabalhos futuros. 


\section{NÓS DE PÓRTICO}

\subsection{Definição}

A expressão "nó" define a região de concorrência entre vigas e pilares. Usualmente a palavra ligação também é utilizada para se referir ao encontro destes elementos. Porém o ACl-352 (1991) faz uma diferenciação destes dois termos da seguinte forma: "Nó" é definido como a porção do pilar dentro da maior altura das vigas que concorrem na ligação (Figura 2.1) e "Ligação" é o nó acrescido dos pilares, vigas e lajes adjacentes a esta região. Como usualmente estes termos se confundem, neste trabalho, não se fará diferenciação entre eles.
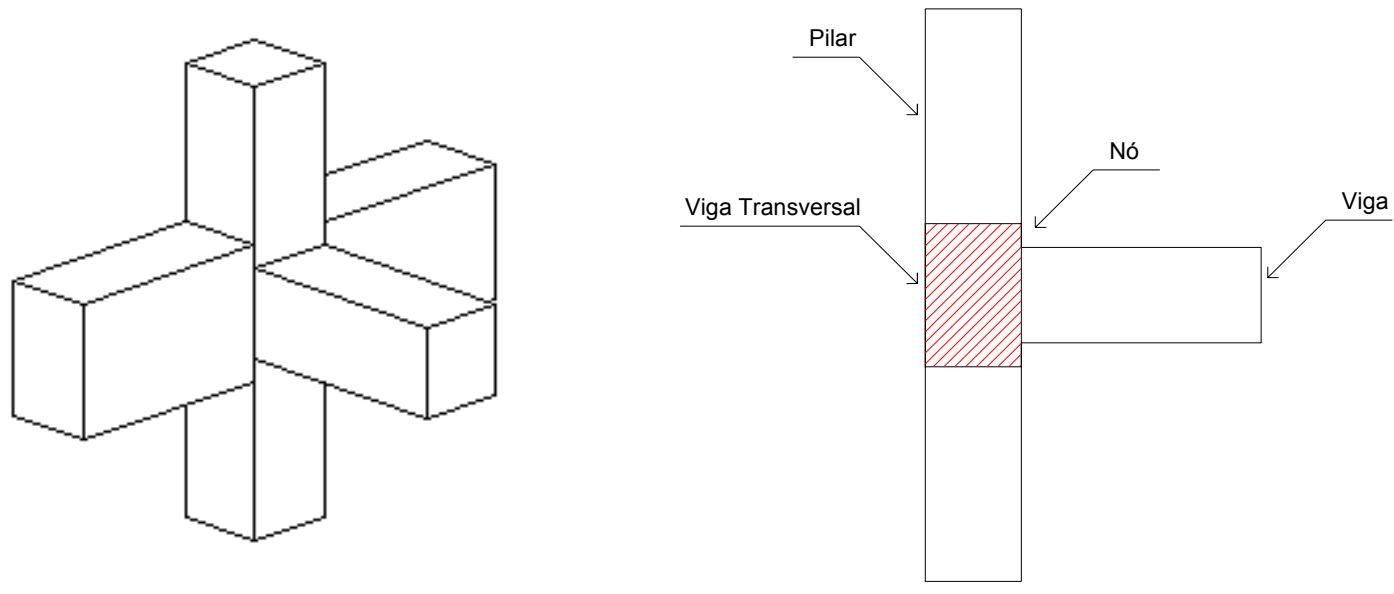

Figura 2.1 - Definição de nó de pórtico. 


\subsection{Tipos de nós de pórtico}

Na literatura há diversas classificações para os nós de pórtico. Serão citadas nesta seção as mais comumente encontradas.

Segundo Paulay \& Priestley, a classificação dos nós pode ser feita levando-se em conta as diferenças observadas nos mecanismos de ancoragem da armadura da viga, dividindo os nós em dois grupos: externos (Figura 2.2(a) à (f)) e internos (Figura 2.2(g) à (j)). Nessa figura, as lajes não são desenhadas a fim de facilitar a visualização.

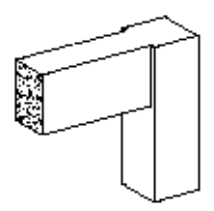

a)

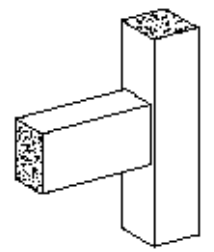

d)

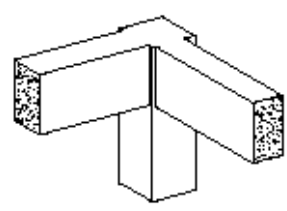

b)

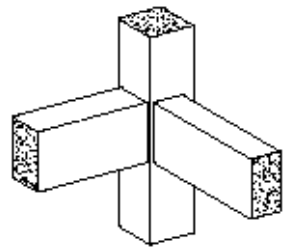

e)

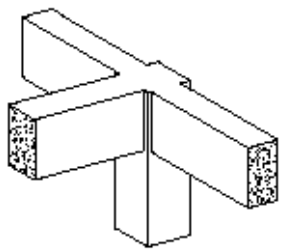

C)

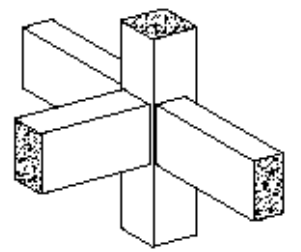

f)

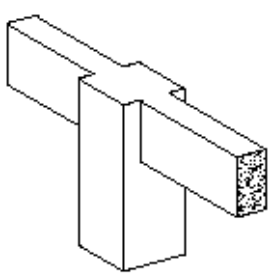

g)

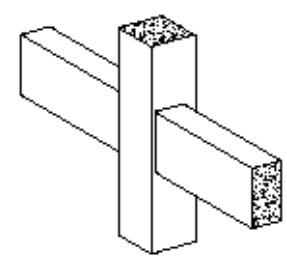

i)

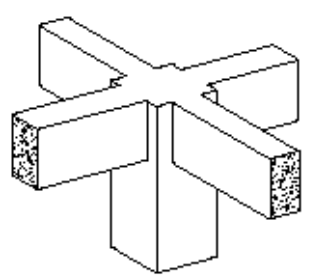

h)

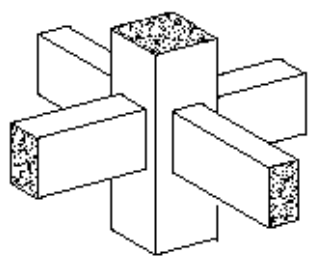

j)

Figura 2.2 - Geometrias usuais de nós.

Fonte: Alva, G. S. (2004) 
O ACl-352 classifica as ligações, segundo as condições de carregamento e deformabilidade dos seus elementos, em dois tipos distintos:

- Tipo 1: São as ligações onde os elementos não apresentam deformações plásticas significantes.

- Tipo 2: São as ligações onde os elementos estão sujeitos a deformações alternadas dentro de uma escala plástica e requerem dissipação de energia.

De maneira simplificada, pode-se classificar os nós de pórtico de concreto armado, em edifícios, em quatro tipos: ligação viga de cobertura - pilar interno, ligação viga de cobertura - pilar externo, ligação viga - pilar interno e ligação viga - pilar externo (Figura 2.3).

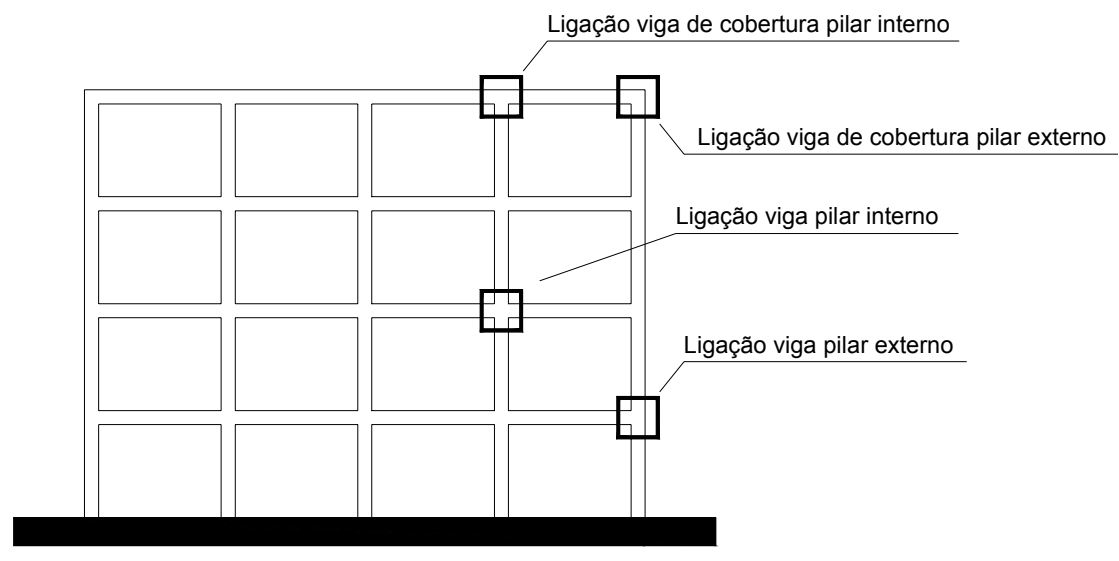

Figura 2.3 - Tipos de ligações de concreto armado em edifícios.

Fonte: Barbosa, L. A. G.; Almeida, P. A O (2001)

Este trabalho abrangerá apenas o caso da ligação viga - pilar externo, denominado simplesmente como nó externo.

\subsection{Comportamento dos nós externos}

Os esforços solicitantes nos nós externos provêm da viga e do pilar, desta maneira, dependem das combinações das ações nestes elementos. Sendo assim, esta ligação pode estar submetida a diferentes conjuntos de esforços como mostra a Figura 2.4 . 


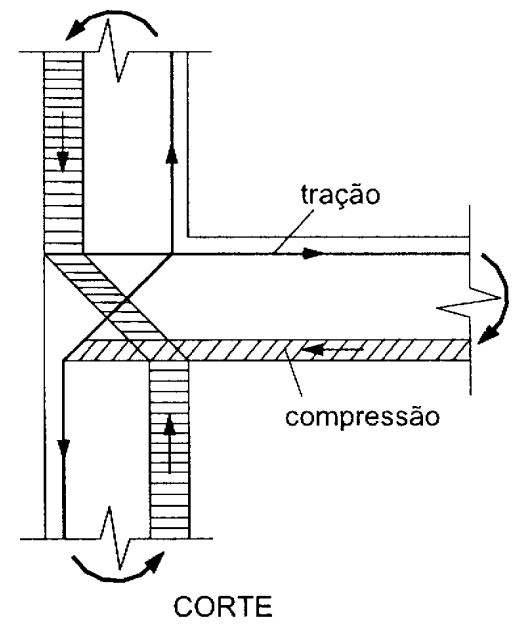

a)

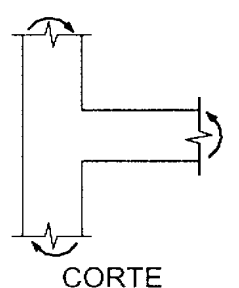

b)

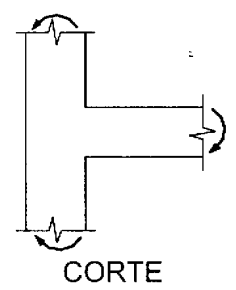

c)

Figura 2.4 - Possíveis esforços atuantes na ligação viga-pilar.

Fonte: Leonhardt, F.; Mönnig E. (1977)

Considerando os esforços mostrados na Figura 2.5, como os atuantes no nó, Ortiz (1993) explicou o comportamento dos nós pelo equilíbrio de forças.

Equilíbrio Horizontal:

$\mathrm{V}_{\mathrm{jh}}=\mathrm{T}_{\mathrm{v}}-\mathrm{V}_{\mathrm{ps}}=\mathrm{C}_{\mathrm{v}}-\mathrm{V}_{\mathrm{pi}}$

Equilíbrio Vertical:

$\mathrm{V}_{\mathrm{jv}}=\mathrm{F}_{\mathrm{si}}+\mathrm{F}_{\mathrm{ii}}+\mathrm{C}_{\mathrm{pi}}-\mathrm{V}_{\mathrm{v}}=\mathrm{F}_{\mathrm{se}}+\mathrm{F}_{\mathrm{ie}}+\mathrm{C}_{\mathrm{ps}}$

O equilíbrio horizontal no nó é atingido com a força de compressão advinda da viga se encontrando com a força cortante do pilar na biela diagonal.

O equilíbrio vertical é analisado em cada lado do nó. Em ambos os casos o equilíbrio se dá pela equação ( 2.2 ). Quando o nó é solicitado, as barras do pilar da face interior transferem tensões para o concreto por forças diagonais (Figura 2.6- Det. 1). Estas forças de transferência não são consideradas como parte da biela diagonal principal. Esta ação é ajudada pelos estribos, porém, as fissuras de flexão que abrem o canto do nó podem se prolongar pelas barras perturbando o efeito de aderência, 
principalmente se não houver estribo no nó. Desta forma, a aderência é mudada para a parte mais baixa do nó onde o concreto está altamente comprimido.

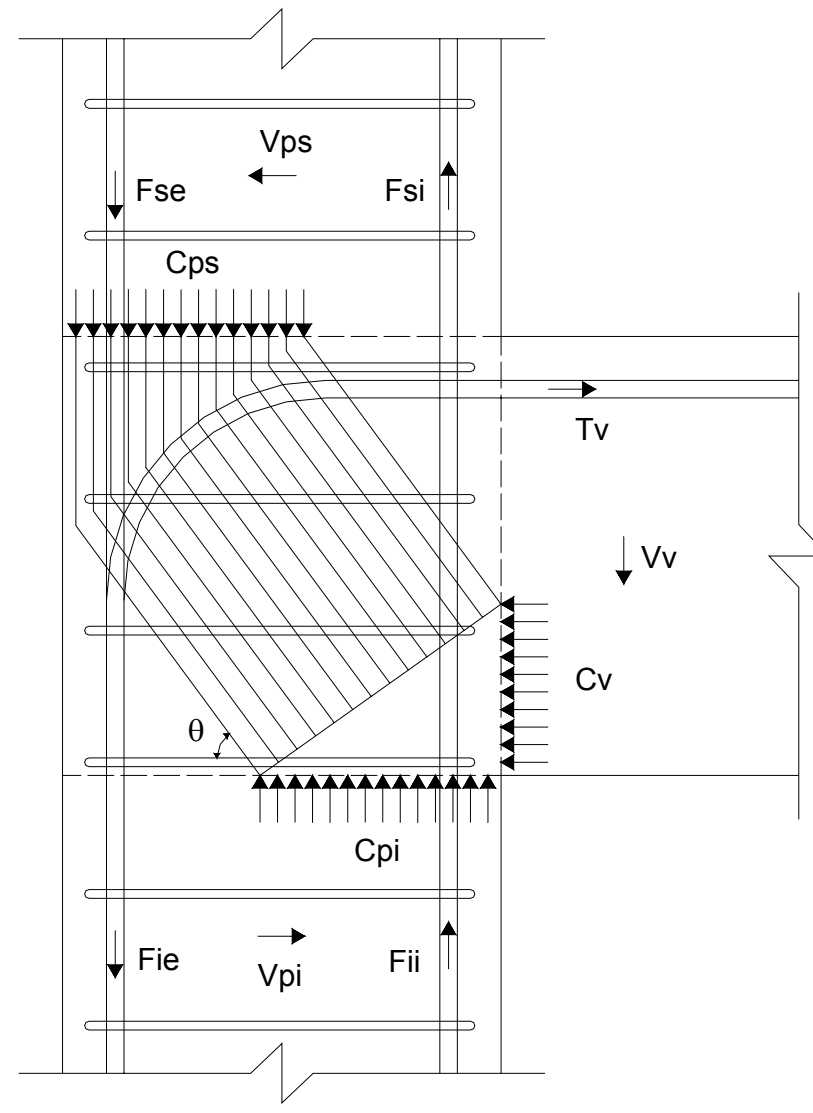

Figura 2.5 - Biela diagonal e forças no nó.

Fonte: Ortiz, I. R. (1993)

$D^{*} \operatorname{sen} \theta+V_{v}=F_{s i}+F_{i i}+C_{p i}$

O lado externo do nó apresenta um comportamento mais complexo. Os ensaios realizados por Ortiz (1993) mostraram que a área de aço da dobra das barras da viga sobrepõe a área de aço do pilar, ou seja, parte do esforço advindo do pilar é absorvido por esta porção de barra. Desta maneira a ancoragem da dobra das armaduras da viga no nó se dá por dois mecanismos: uma fração é feita pela transferência de tensões de compressão das barras do pilar e a outra fração é realizada pelo cobrimento onde as forças de arrancamento são equilibradas pela resistência à tração do concreto por causa da aderência (Figura 2.7). Como o núcleo do nó é mais rígido que o cobrimento, altas 
tensões de aderência são geradas na face das barras voltada para o cobrimento, principalmente quando não há estribos.

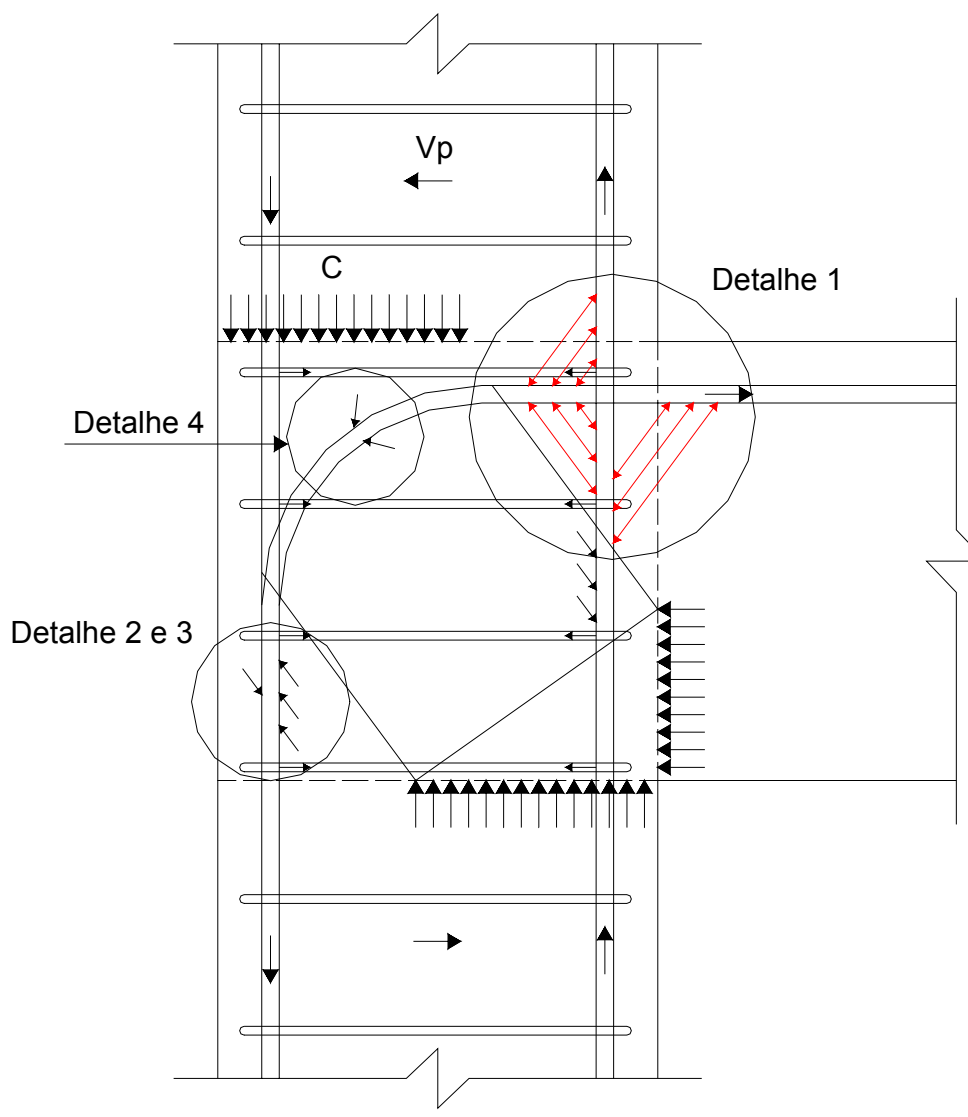

Figura 2.6 - Mecanismo de transferência de tensões.

Fonte: Ortiz, I. R. (1993)

As forças horizontais resultantes da ação da biela são resistidas pelas barras longitudinais do pilar em flexão entre dois estribos (Figura 2.7). Portanto, a presença de estribos permite ao lado externo do nó trabalhar em toda sua altura, amarrando as barras verticais com o núcleo e ajudando também na ação de aderência.

O equilíbrio horizontal é atingido pela interação da biela diagonal com as barras da viga e a força cortante do pilar. Os estribos ajudam levando as forças horizontais da parte externa e mais baixa da biela para o lado interno do nó, e de lá a biela transfere estas forças para a região superior. Na região superior os estribos trabalham do mesmo modo, aumentando a aderência das barras do pilar e prevenindo a abertura de fissuras. 


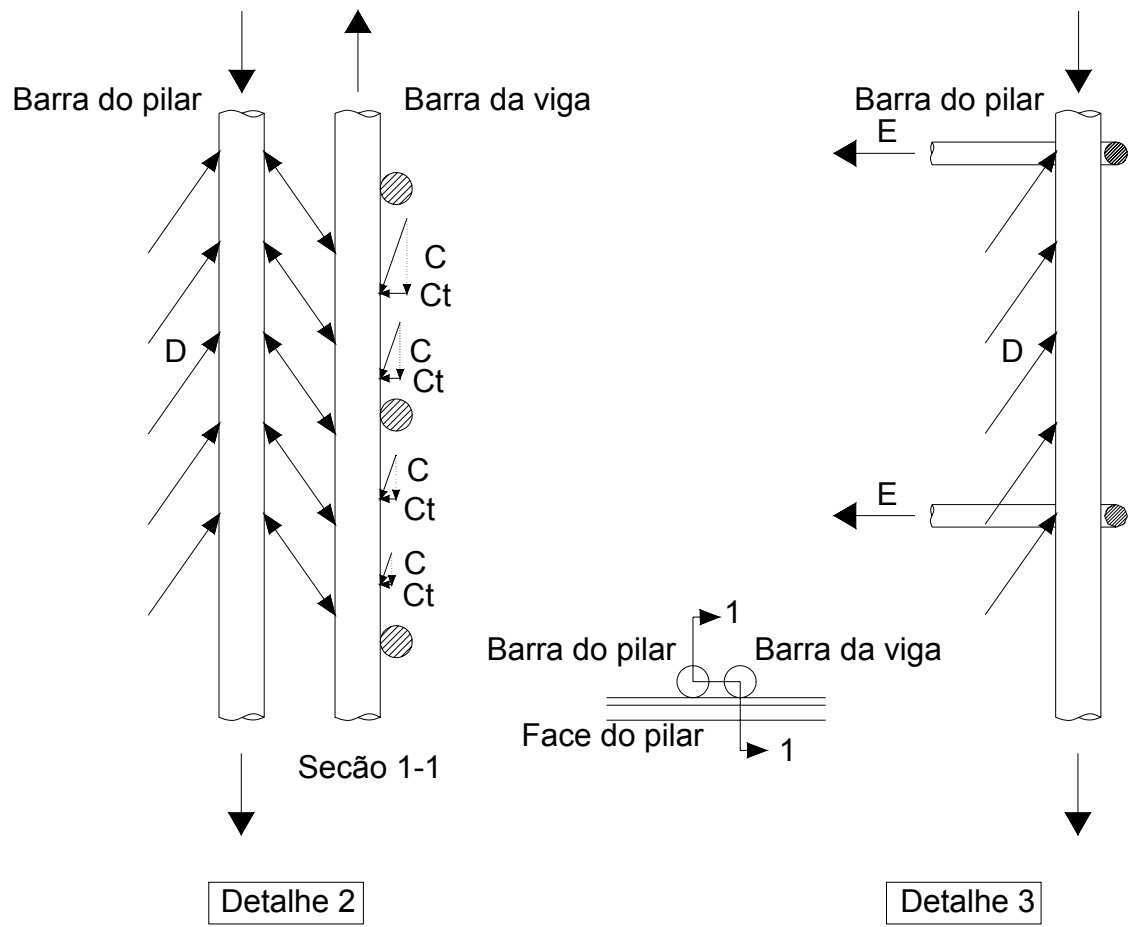

Figura 2.7 - Mecanismo de transferência de tensões (Detalhes 2 e 3).

Fonte: ORTIZ, I. R. (1993)

Sem a presença de estribos no nó, as barras longitudinais não suportam as forças horizontais que tendem a empurrá-las para fora do cobrimento. As forças de tração no cobrimento ficam acima da resistência do concreto, então as fissuras da diagonal aumentam, correm para o topo do nó e seguem as barras do pilar. A ruína ocorre pela incapacidade do nó resistir a estas forças horizontais.

\subsection{Variáveis que influenciam o comportamento dos nós de pórtico}

Segundo Leonhardt e Mönnig (1977) qualquer mudança de direção do eixo de uma estrutura provoca uma mudança na direção dos esforços internos e, em conseqüência, esforços transversais ao eixo, que modificam inteiramente a distribuição das tensões. 
Esta mudança de direção faz com que o nó de pórtico apresente um comportamento bastante complexo, já que há um elevado gradiente de tensões em uma área relativamente pequena. Este comportamento é influenciado por diversas variáveis como:

- a ancoragem;

- a carga axial no pilar;

- a resistência do concreto;

- o grau de confinamento;

- as propriedades geométricas do nó;

- o efeito da laje;

- a presença de vigas transversais;

- o arranjo da armadura;

- e outros.

\subsubsection{Armadura transversal}

A presença de armadura transversal no nó aumenta a resistência da ligação (Ehsani \& Wight, 1985; Ortiz, 1993; Scott et al., 1999; Hegger et al., 2003). Porém, existe um limite, onde o acréscimo desta armadura não provoca grandes modificações (Ortiz, 1993).

Os ensaios realizados por Ortiz (1993) mostraram que os estribos são realmente solicitados apenas após a fissuração, e aqueles localizados próximos da armadura longitudinal da viga absorvem tensões desta. Todavia, se não há estribos no nó, a tendência é que ocorra a separação com ruptura do cobrimento das barras do pilar. Resumidamente, nos nós sem estribos quando as tensões transversais atingem a resistência à tração do concreto, fissuras abrem ao longo da biela diagonal e as tensões internas sofrem um rearranjo. A biela diagonal é separada em duas partes, porém sem ter atingido a tensão limite, sendo assim capaz de resistir a um aumento da força cortante. Entretanto com o aumento do carregamento, fissuras começam a surgir no topo da biela e a região do cobrimento se rompe. Desta maneira, incapaz de distribuir as tensões, o nó rompe. No caso dos nós com estribos, a tendência de abertura de fissuras é resistida pela armadura e as tensões podem se propagar por toda a biela diagonal. Novas fissuras se abrem, contudo de forma controlada pelos estribos. 
Outro ponto relevante diz respeito aos estribos do pilar acima do nó, eles têm um papel importante nesta região, pois são altamente solicitados nas proximidades da ruína. Ortiz (1993) recomenda a utilização de pelo menos dois estribos na região do nó.

\subsubsection{Aderência}

A aderência é a condição fundamental para a existência do material concreto armado. De um modo geral, ela garante que a deformação da armadura seja igual à das fibras vizinhas do concreto. O comportamento da aderência é influenciado pela resistência à compressão do concreto, diâmetro das barras, grau de confinamento entre outros. Desta forma, a aderência apresenta uma influência direta, sobre os nós de pórtico, pois sem ela todos os mecanismos de transmissão de esforços ficam impedidos de atuar.

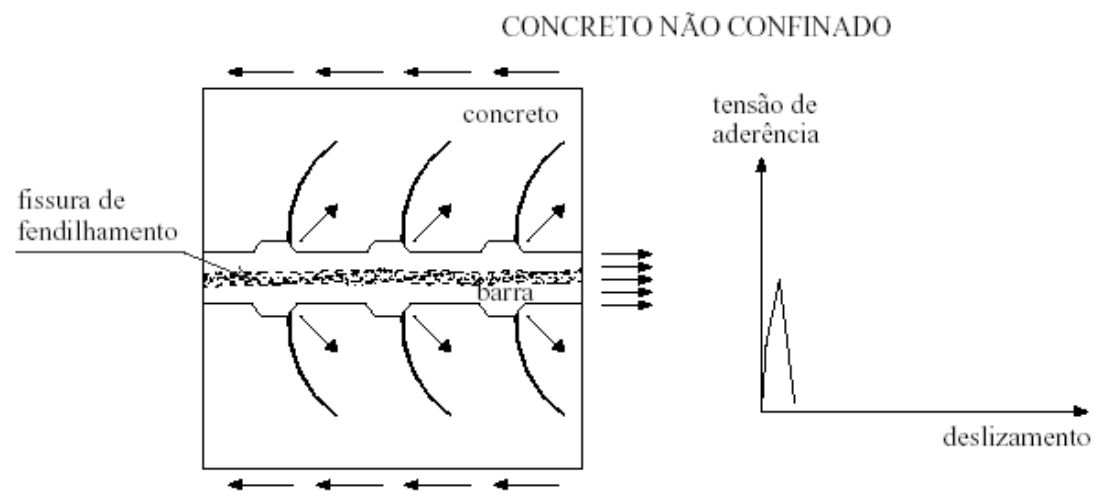

(a)

\section{CONCRETO CONFINADO}
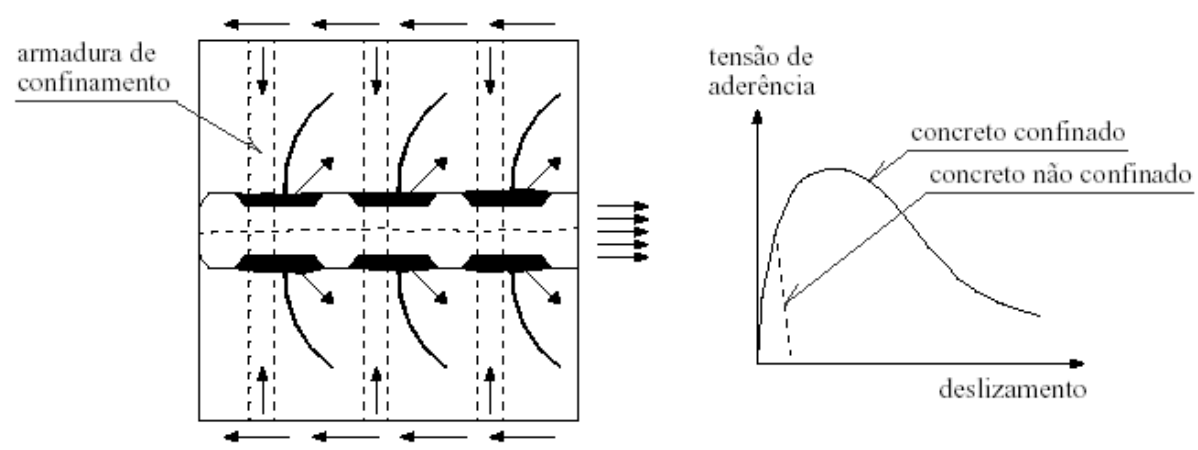

(b)

Figura 2.8 - Ruptura da aderência por: (a) fissuração por fendilhamento em concreto não confinado; (b) arrancamento em concreto confinado.

Fonte: Fernandes, R. M. (2000) 
A aderência é composta por três parcelas: adesão, atrito e resistência mecânica. A resistência mecânica é a principal das três parcelas. A ação das mossas no concreto produz fissuras inclinadas e após a fissuração as tensões são transferidas do aço para o concreto pela compressão inclinada. A componente radial deste sistema de forças simula uma tensão interna no concreto que causa a tendência de ruptura. O confinamento evita a propagação e a abertura destas fissuras (Figura 2.8).

De acordo com as observações feitas por Popov (1984), nos nós sujeitos a carregamento cíclico os problemas com a aderência se tornam mais críticos, pois a alternância dos esforços solicitantes provocam perda de aderência inicial e aumenta gradativamente conforme o número de ciclos aplicados (Figura 2.9).

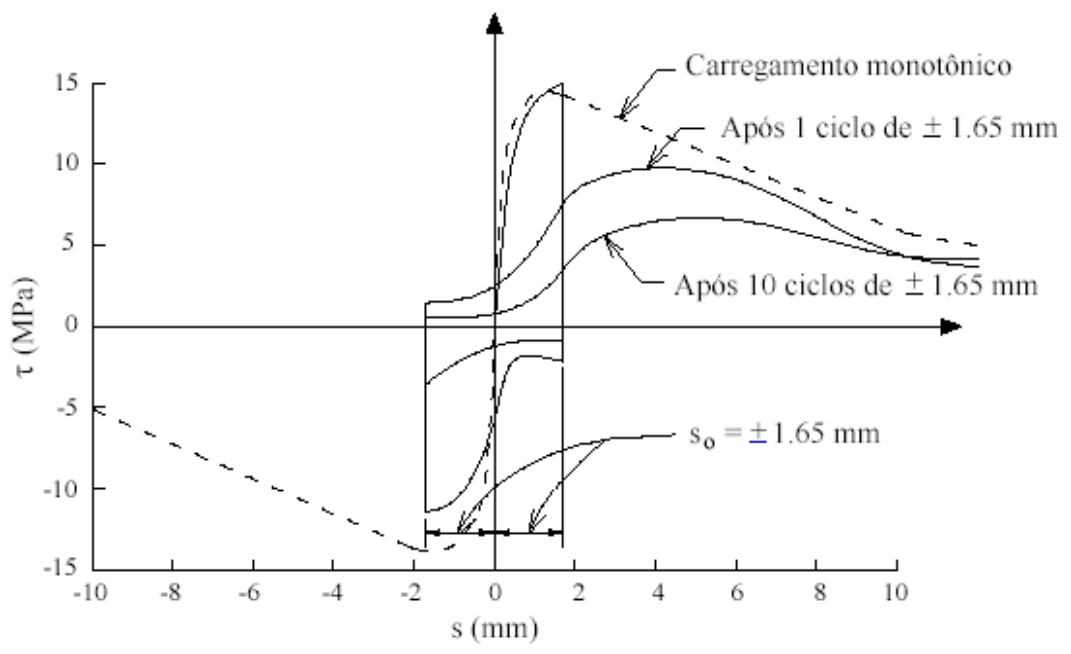

Figura 2.9 - Curva experimental tensão de aderência-deslizamento para ação cíclica alternada em barra de $8 \mathrm{~mm}$ Fonte: Popov, E. P. (1984).

\subsubsection{Arranjo da armadura}

Os arranjos das armaduras nos nós de pórticos são estudados em diversas pesquisas tais como: Taylor - 1974 apud Ortiz, 1993; Kordina - 1984 apud Ortiz, 1993; Scott, 1996; Murty et al., 1998; Scott et al., 1999. Além da sua grande influência na resistência ao cisalhamento e no modo de ruína da ligação, é de fundamental importância quanto aos aspectos construtivos. 
Scott (1996) analisou três diferentes detalhes de armadura no nó como mostra a Figura 2.10.

Tipo A

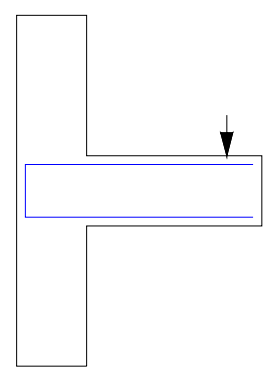

Tipo B

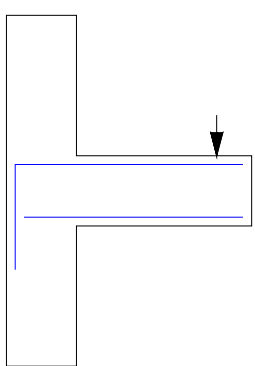

Tipo C

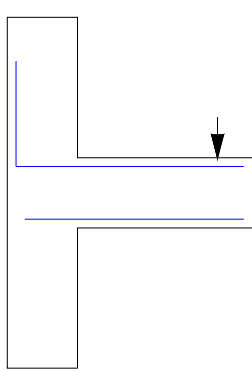

Figura 2.10 - Detalhes ensaiados por Scott, R. H. (1996).

Os detalhes tipo B e tipo A apresentaram um acréscimo gradual das deformações de tração, na dobra da barra da viga, e um aumento substancial no carregamento entre a fissuração e a ruptura.

A primeira curvatura da armadura e a parte vertical são regiões onde há maior transferência de forças da barra para o concreto, porém esta transferência é igual e pequena para todos os detalhes antes da fissuração. Após a fissuração o detalhe tipo $B$ perde a capacidade de desenvolver tensões de aderência na curvatura, desta maneira a parte vertical aumenta sua parcela de transferência de forças de maneira suave e controlada. O detalhe tipo $\mathrm{C}$ evita o desenvolvimento de tensões na parte vertical por causa da flexão do pilar, então a transferência de forças adicionais aumenta a tensão de aderência ao redor da curvatura. A capacidade de resistir a estas tensões por parte do concreto é limitada, então ocorre a ruptura repentina com rápida propagação de tensões ao longo do trecho vertical. O detalhe tipo $A$ depois da fissuração é capaz de transferir forças para o concreto pela combinação de maiores tensões de aderência no topo do gancho, desenvolvendo tensões primeiramente na parte vertical e conforme vai aumentando a tração, a parte inferior do gancho começa a absorver tensões da mesma forma.

Murty et al. (1998) estudaram três tipos de arranjos das armaduras para o nó externo (Figura 2.11). Observaram com seus ensaios que o melhor comportamento foi alcançado pelo detalhe onde a dobra da barra da viga ultrapassava o fundo da mesma. Este arranjo apresentou maior força de fissuração e ruína. Dentre os três detalhes 
observou que a barra dobrada para cima apresentou o pior comportamento como era esperado.

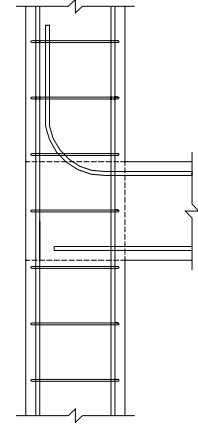

Modelo BDT

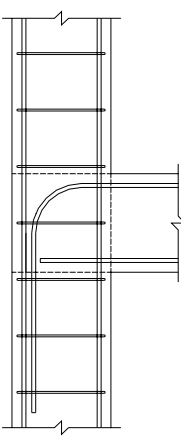

Modelo BDB

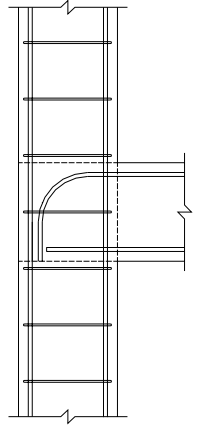

Modelo BDW

Figura 2.11 - Modelos ensaiados por Murty et al.

Fonte: Adaptado de Murty et al. (1998)

Scott et al (1999) ensaiaram 30 modelos de nós externos. Nestes modelos dentre outras variáveis, o arranjo da armadura foi analisado utilizando-se os detalhes tipo A e B estudados por Scott (1996). Observaram que o detalhe tipo B se comporta melhor, pois transfere as cargas para o pilar de melhor maneira, porém fissura antes do tipo $A$. Já o detalhe tipo A não transfere as tensões para o pilar de maneira satisfatória, pois absorve as tensões para dentro do nó, porém sua fissuração é mais controlada, pois apresenta maior quantidade de aço na conexão o que proporciona maior rigidez. Como resultado deste estudo foram sugeridos os seguintes fatores para o cálculo da tensão última de cisalhamento:

$$
\begin{aligned}
& V_{u}=\alpha^{*} \beta^{*} \gamma^{*} \sqrt{f_{c k}} \\
& \beta=0,42 *\left(3.2-\frac{h_{v}}{h_{p}}\right) \\
& \gamma=0,02 *\left(50+f_{c}\right)
\end{aligned}
$$

Onde $\alpha=1,0$ para o detalhe em dobra a $90^{\circ}$ e $\alpha=0,82$ para o dealhe em $\mathrm{U}$, os valores de $\beta$ são limitados em $1,4 \leq \beta \leq 2,0$ e a tensão axial no pilar é limitada pelo menor dos valores: $f_{c} \leq 20 M P a$ ou $0,4 \mathrm{f}_{\mathrm{ck}}$. 


\subsubsection{Laje e Viga transversal}

Uma das variáveis que afeta o comportamento do nó de pórtico é a presença da laje (Figura 2.12), porém poucas são as pesquisas considerando sua influência. Durrani et al. (1987) estudaram os nós de pórtico considerando a presença de laje e viga transversal simultaneamente. Observou-se que o comprimento da região onde forma a rótula de flexão é dependente da espessura da laje. Outro aspecto observado foi que os modelos com a presença da laje tiveram um acréscimo de 60 a $70 \%$ em sua rigidez. Porém a perda de rigidez não foi afetada pela variação da espessura da laje. Os modelos com laje dissiparam $40 \%$ a mais de energia que àqueles sem laje. Comparando os modelos com e sem viga transversal observou-se que a presença desta provoca um aumento de $25 \%$ na rigidez da ligação. Quando as vigas transversais atingem a resistência à fissuração por torção, a deformação da armadura do nó aumenta rapidamente indicando perda de confinamento. Um ponto negativo é que a presença da laje induz efeitos de torção aumentando o cisalhamento no nó.

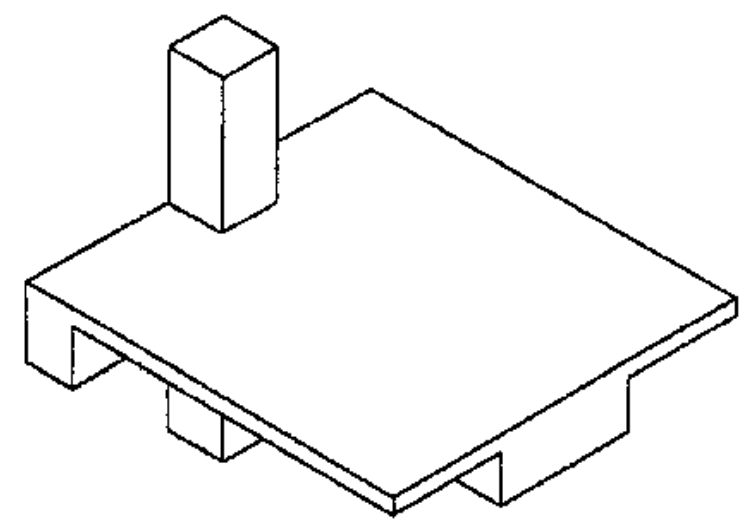

Figura 2.12 - Ligação com a presença de laje e viga transversal.

Fonte: Adaptado de Lafave, J. M. \& Wight, J. K. (1999)

Paultre et al. (1989) observaram em seus ensaios que a armadura da laje contribui significativamente, aumentando a resistência da viga e reduzindo a ductilidade a momentos negativos.

Lafave \& Wight (1999) analisaram ligações com a presença de laje e viga transversal. A principal característica dos seus modelos era que a largura da viga principal era maior que a do pilar. As observações feitas foram que a ligação se comporta bem com relações $b_{\text {viga }} / b_{\text {pilar }}$ superiores a três e quando mais de $2 / 3$ da armadura a flexão da viga 
principal está ancorada fora do núcleo do pilar. A participação da laje é maior nas ligações com vigas largas.

Meinheit \& Jirsa (1981), Ehsani \& Wight (1985), Kitayama et al. (apud Tsonos, 2002) também investigaram o efeito das vigas transversais no comportamento de nós. Eles concluíram que a presença deste elemento melhora consideravelmente o comportamento do nó. Por outro lado, Cheung et al. (apud Tsonos, 2002) não encontraram evidências em seus ensaios, de que a presença de vigas transversais provocasse um confinamento significativo no nó durante a aplicação de carregamento sísmico bidirecional. A influência da presença da laje nas vigas transversais ainda não é claramente compreendida.

\subsubsection{Ancoragem}

A ancoragem das barras nos nós externos é bastante problemática, pois as barras tracionadas da viga se encontram em uma região desfavorável onde há a predominância de tensões de tração. Desta forma, a aderência entre a armadura e o concreto envolvente é deficiente. Além disso, outro problema encontrado normalmente pelos projetistas diz respeito à falta de espaço para um alojamento eficiente, em virtude desta região ser normalmente muito pequena.

Patton (apud Park \& Paulay, 1975) em seus ensaios em nós externos construiu modelos onde a viga apresentava uma pequena extensão além do pilar, com intuito de melhorar as condições de ancoragem, fazendo com que esta fosse solicitada em uma região mais favorável (Figura 2.13).
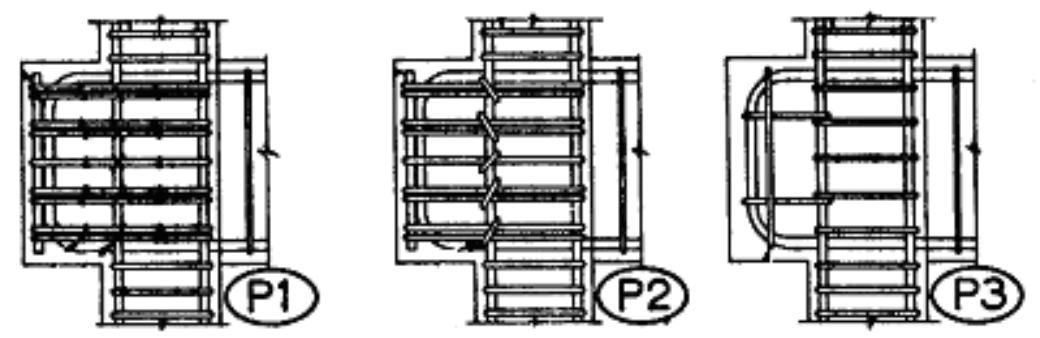

Figura 2.13 - Modelos, com viga estendida além dos limites do pilar, ensaiados por Patton (1972). Fonte: Adaptado de Park \& Paulay (1975) 
Marques \& Jirsa (1975) ensaiaram 22 modelos simulando nós externos, e avaliaram a capacidade de ancoragem das barras longitudinais da viga com diversos graus de confinamento. Para isso variaram a força axial aplicada no pilar, a taxa de armadura transversal e a espessura do cobrimento.

Com estes ensaios Marques e Jirsa (1975) observaram que só ocorre o escorregamento da parte horizontal da barra. Em todos os modelos a dobra teve um pequeno escorregamento apenas no instante da ruptura. Com relação às tensões na barra notaram que a tensão na dobra é baixa, aumentando rapidamente no instante da ruptura. As dobras de $90^{\circ}$ tendem a ser mais rígidas que os ganchos (escorregamento menor). Também concluíram que a força axial do pilar é desprezível no comportamento de aderência das armaduras, no entanto vale ressaltar que foram aplicadas forças muito baixas. A presença de estribos não tem influência no que diz respeito à carga de fissuração, porém modelos com estribos apresentaram força de ruína maior. A redução do cobrimento reduz a resistência e a deformação. Os estribos no nó parecem ser mais benéficos se o espaçamento for igual ou menor que o raio do gancho.

Soroushian et al. (1988) analisaram o comportamento das dobras a $90^{\circ} \mathrm{em}$ nós externos por meio de ensaios em sete modelos. As dobras a $90^{\circ}$ resistem às forças de arrancamento e evitam grandes rotações. A Figura 2.14 mostra os mecanismos resistentes no gancho. O aumento da força de arrancamento faz com que os modelos expandam, pois a dobra induz altas tensões de compressão e por causa do efeito de Poisson resultam em deformações laterais. Soroushian et al. (1988) observaram que a resistência ao arrancamento cresce com o aumento do diâmetro da barra, mas este é menor que o correspondente aumento da força de escoamento da barra. Outro ponto observado foi que o confinamento influencia no comportamento da dobra, pelo contrário a resistência do concreto nada exerce sobre esta.

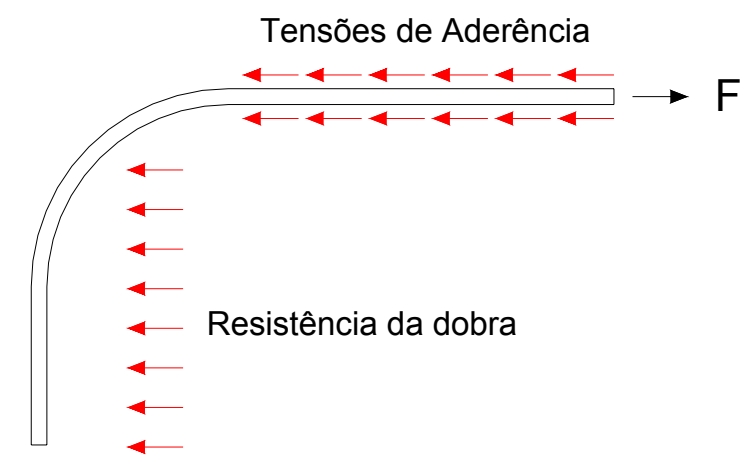

Figura 2.14 - Mecanismos resistentes da barra longitudinal da viga. 
Os ensaios realizados por Ortiz (1993) mostraram que em virtude da alta fissuração do nó próximo da ruína, a ancoragem pode ser considerada com confiabilidade apenas no trecho reto do comprimento das armaduras longitudinais da viga até a curvatura da barra, desconsiderando a dobra.

\subsubsection{Força axial no pilar}

A força normal advinda do pilar ajuda no confinamento do nó. Porém, afirmar que esta força aumenta a resistência do nó não é um consenso entre todos os pesquisadores.

Em suas análises Parker \& Bullman (1997) concluíram que a força axial influencia o comportamento dos nós de pórtico mudando apenas o modo de colapso da ligação. Bakir \& Boduroglu (2002) realizaram uma análise paramétrica com dados experimentais de diversos autores, e afirmaram que a força normal não tem influência na resistência última dos nós de pórtico, porém apesar da normalização feita pelos autores para que nenhuma variável influenciasse na avaliação do efeito de outra variável, a variabilidade dos modelos experimentais analisados era muito grande. Todavia Scott et al. (1999) obteve um aumento de $40 \%$ na resistência de seus modelos quando sujeito a uma tensão axial de $40 \%$ do valor da resistência à compressão do concreto. Hwang \& Lee (1999) consideram que a força axial no pilar tem efeito benéfico na resistência ao cisalhamento, pois ela aumenta as dimensões da biela, contudo altas forças axiais aceleram a degradação da ligação. Hegger et al. (2003) por meio de seus ensaios observaram que para tensões axiais no pilar superiores a $40 \%$ da resistência do concreto a capacidade do nó começa a ser reduzida.

Como visto, há duas linhas de raciocínio, uma delas concordando com o fato de que o carregamento axial no pilar provoca um acréscimo na resistência do nó até um certo limite, e a outra afirmando que as tensões normais no pilar não têm qualquer influência na resistência do nó, exceto no modo de ruína da ligação.

Porém, analisando os parâmetros que influenciam o comportamento do nó, chegase facilmente a conclusão que a força normal exerce alguma influência na ligação, pois ela melhora o confinamento e as condições de ancoragem. Entretanto as verdadeiras incógnitas, com relação à força normal, são os ganhos ou as perdas provocados pela variação da sua intensidade. 


\subsubsection{Propriedades geométricas}

O tamanho do nó é uma das variáveis mais importantes, pois ela controla a intensidade de tensão na biela diagonal. Segundo Alva (2004), nós de pórtico com alturas de viga significativamente maiores que as alturas do pilar possuem um comportamento menos favorável frente a ações cíclicas, em particular frente às de origem sísmica. Se fosse este o caso, sob uma ação cíclica intensa, rótulas plásticas provavelmente se desenvolveriam nos pilares antes que nas vigas, comportamento indesejável na filosofia usual de projeto.

\subsubsection{Resistência do concreto}

A resistência do concreto, juntamente com as propriedades geométricas, é uma das variáveis fundamentais no comportamento dos nós de pórtico, pois é a responsável pela integridade da biela. Algumas normas e autores consideram que a resistência ao cisalhamento do nó é proporcional a raiz quadrada da resistência do concreto.

$\mathrm{Na}$ atualidade a busca por concretos de alta resistência vem crescendo cada vez mais. Conseqüentemente, a aplicação destes concretos nos nós de pórtico vem sendo pesquisada cada vez mais (Ha et al., 1992; Scott et al., 1999). Algumas pesquisas mostram que concretos de alta resistência aumentam a capacidade dos nós, porém devese ter muito cuidado com a ductilidade da ligação, principalmente no caso de carregamentos cíclicos.

\subsubsection{Outros fatores}

Entre outros fatores que influenciam o comportamento dos nós pode-se citar:

1. A utilização de concreto com fibras principalmente para melhorar as propriedades de ductilidade da ligação.

2. A utilização de ancoragem das barras da viga por meio de mecanismos de placa, evitando assim o grande número de barras da armadura.

3. A relação entre as capacidades resistentes à flexão dos elementos. 


\subsection{Tipos de Ruptura}

Segundo Barbosa e Almeida (2001) existem, basicamente, cinco possibilidades de ruptura do nó sob carregamento.

1. Ruptura por tensão diagonal de tração $\rightarrow$ ocorre quando as tensões de tração oriundas do momento fletor não forem resistidas pelas armaduras.

2. Ruptura por tensões de tração normais às armaduras principais $\rightarrow$ ocorre no concreto por tensões de fendilhamento, por causa da mudança de direção das barras da armadura principal tracionada.

3. Ruptura por escoamento das armaduras principais $\rightarrow$ é causada pelo escoamento da armadura dentro da ligação. Esta ruptura causa grandes deformações no nó e como conseqüência ocasiona a ruptura por esmagamento do concreto nas zonas comprimidas.

4. Ruptura por ancoragem insuficiente $\rightarrow$ nos carregamentos cíclicos aumentam-se ainda mais os riscos desta ruptura.

5. Ruptura por esmagamento do concreto nas zonas comprimidas $\rightarrow$ acontece quando o concreto dentro do nó possui uma resistência à compressão menor que a resistência dos elementos estruturais que a eles se unem.

\subsection{Comportamento dos nós sob carregamento cíclico}

As ações cíclicas ou dinâmicas atuantes nas estruturas podem ter diversas origens, dependendo da finalidade e das condições a que essas estruturas são expostas. Entre as diversas origens das solicitações cíclicas, encontra-se a ação de cargas móveis, de pontes rolantes, de ondas marítimas, de pressões hidrostáticas variáveis, de sismos, de vento, de variações de temperatura e de umidade, impacto e de máquinas sujeitas à vibração. As cargas cíclicas são definidas pela variação de amplitude de um determinado parâmetro, tal como a tensão, podendo haver também a inversão de sinal (sentido).

O comportamento dos nós de pórtico se torna mais crítico sob a aplicação de carregamento cíclico, pois o nó começa a apresentar perda de rigidez e deficiência nas ancoragens, já que a aderência fica bastante prejudicada por causa da fadiga provocada 
pela alternância de carregamento. A ductilidade passa a ser uma das propriedades mais importantes da ligação sujeita a carregamentos cíclicos.

As variáveis normalmente investigadas são: a perda de rigidez da ligação, a eficiência dos arranjos das armaduras, os modos de ruptura, a resistência do concreto e a deformabilidade do nó. Grande parte dos resultados experimentais já obtidos provém de ensaios com controle de deslocamento, o que é usual em simulações de carregamento cíclico (Figura 2.15). Os modelos físicos utilizados na maioria dos casos constituem-se de ligações isoladas (sem a presença de laje e sem a presença de paredes estruturais). Os resultados experimentais obtidos são geralmente apresentados por meio de diagramas Força vs. Deslocamento.

Um dos primeiros estudos sobre o comportamento das ligações viga-pilar foi feito pelos pesquisadores Hanson e Connor (1967) motivados pela preocupação com as ações sísmicas. Eles analisaram o comportamento da ligação sob carregamento cíclico reverso, e demonstraram a influência benéfica da presença de estribos na região nodal sob tal carregamento.
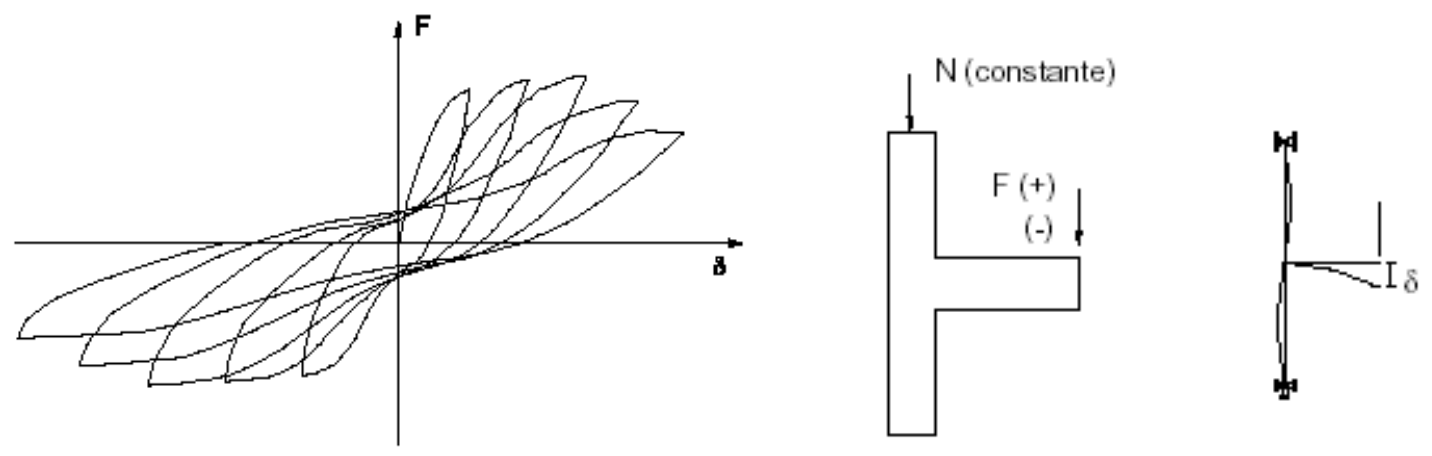

(a)

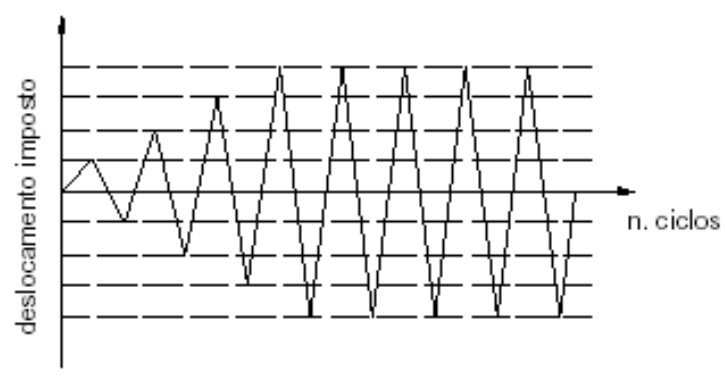

(b)

Figura 2.15 - Diagramas utilizados para a apresentação de dados experimentais: Força vs. Deslocamento (a) e Histórico do carregamento (b).

Fonte: Alva, G. S. (2004) 
A partir de então, diversas foram as pesquisas buscando a melhor compreensão do comportamento dos nós de pórtico, principalmente frente às ações cíclicas.

Ehsani \& Wight (1985) analisaram nós externos sujeitos a carregamento sísmico, e observaram que a deterioração do concreto no nó por causa das altas tensões de cisalhamento afeta as condições de ancoragem. Assim sendo, a maior causa de perda de rigidez do nó é a perda de aderência tanto nas barras da viga como do pilar. Com relação à armadura transversal, concluíram que o acréscimo da taxa de estribos só apresenta valor significante caso o índice de resistência à flexão (relação entre a soma das capacidades resistentes dos pilares e a capacidade resistente da viga), seja superior a unidade.

Para assegurar a integridade estrutural durante um terremoto, a estrutura deve ser capaz de dissipar uma enorme quantidade de energia, já que os esforços solicitantes gerados no nó são bastante elevados. Para resistir a estas altas tensões, normalmente o espaçamento dos estribos é reduzido, causando congestionamento de armaduras nesta região. Gefken \& Ramey (1989) estudaram a utilização de fibras no concreto com o objetivo de aumentar o espaçamento dos estribos e, observaram que a adição de fibras torna a ligação mais dúctil e possibilita o aumento do espaçamento dos estribos sem perda de resistência.

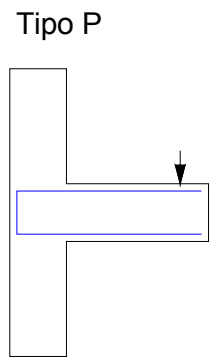

Tipo Q

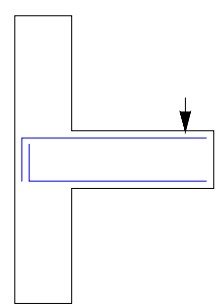

Tipo R

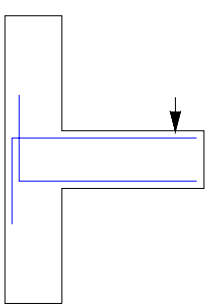

Tipo S

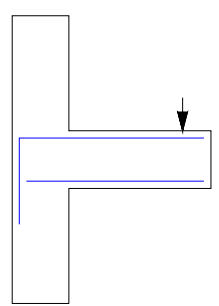

(a) Detalhes das armaduras da viga

Tipo 1

Sem estribos

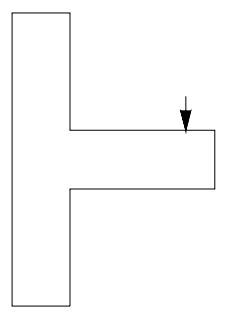

Tipo 2

Estribos abertos

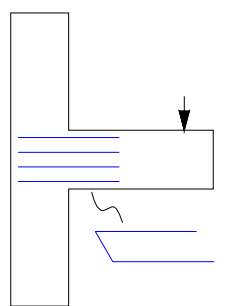

Tipo 3

Estribos fechados

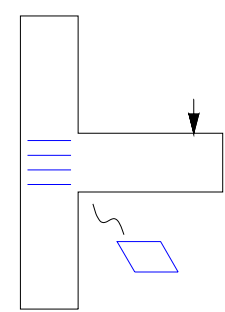

(b) Detalhes dos estribos no nó

Figura 2.16 - Detalhes das armaduras dos modelos de Murty et al. (2003). 
Murty et al. (2003) ensaiaram nós externos sob carregamento sísmico variando o arranjo da armadura (Figura 2.16). Em seus resultados, observaram que em nós com volume reduzido, é difícil manter a tensão de cisalhamento horizontal abaixo das especificações das normas. Como resultado disso, a fissuração do nó ocorrerá antes dos membros ligados atingirem sua capacidade. Dentre os detalhes analisados o que apresentou melhor comportamento foi o tipo R2. Este resultado é bastante atraente analisando os aspectos construtivos, pois a utilização de estribos abertos em uma extremidade facilita a execução da ligação.

Ha et al. (1992) analisaram o comportamento dos nós de pórtico com concretos de alta resistência, variando o arranjo da armadura na ligação (Figura 2.17). Eles observaram que é possível movimentar a rótula plástica na viga acrescentando-se armaduras intermediárias num comprimento de $1,5^{*} \mathrm{~h}$ à partir da face do pilar. $\mathrm{O}$ dimensionamento de estruturas com concreto de alta resistência utilizando as recomendações do $\mathrm{ACl}$ apresenta baixa segurança. Estes concretos podem se tornar perigosos se apresentarem baixa ductilidade.

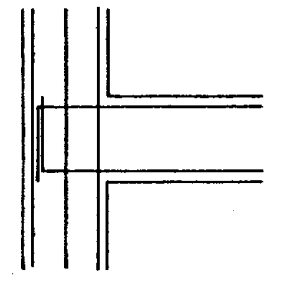

(a)

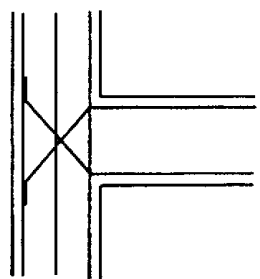

(c)

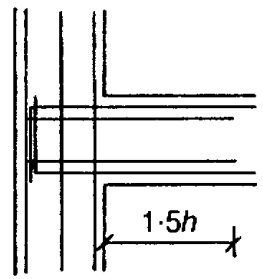

(d)

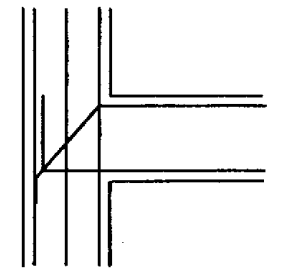

(b)

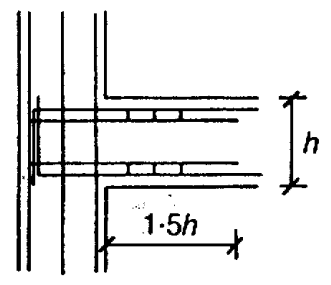

(e)

Figura 2.17 - Detalhes das armaduras dos modelos de Ha et al. (1992). Fonte: Ha et al. (1992)

Ehsani \& Wight (1990) analisaram um grande número de ligações viga-pilar ensaiadas por eles e por outros autores e, utilizando-se de um índice para quantificar a absorção de energia e condições de dissipação em elementos de concreto armado proposto por Hwang \& Scibner (apud Ehsani \& Wight, 1990), apresentaram um simples 
dimensionamento da quantidade de estribos para confinamento do nó a ser utilizada para que o comportamento dúctil fosse atingido.

Tsonos (2004) estudou a influência do efeito P- $\Delta$, causada pela mudança simultânea da força axial no pilar e o deslocamento lateral da ligação. Os resultados experimentais e teóricos demonstraram que a variação da carga axial e o efeito P$\Delta$ causam uma rápida deterioração da resistência durante terremotos. Barras inclinadas podem ser uma alternativa para a redução do desfavorável efeito causado por estes fenômenos. Ensaios mostram que a presença de barras inclinadas no nó introduz um novo mecanismo de transferência de tensões.

Como avaliação do comportamento dos nós sob carregamento cíclico, podem ser utilizados modelos teóricos que abordam conceitos de dano e plasticidade. Alva (2004) fez uma análise numérica utilizando o modelo simplificado de dano e plasticidade proposto por Picon \& Flórez-López (2000). Em seu estudo, concluiu que este modelo apresenta um bom desempenho na simulação da ligação. Em particular, apresentando bons resultados quanto à força máxima aplicada à ligação e na consideração do decréscimo da resistência por causa da ação cíclica. Uma das principais vantagens deste modelo é a facilidade de implementação computacional, requerendo-se para a sua aplicação um pequeno número de parâmetros, cujo significado mecânico é bem claro.

\subsection{Estado da Arte}

HANSON, N. W.; CONNER, H. W. (1967)

Um dos primeiros trabalhos sobre o comportamento de nós de pórtico. Avaliaram a influência de ações sísmicas nos nós.

PATTON, R. N. (1972)

Ensaiou modelos onde a viga apresentava uma pequena extensão além do pilar, com intuito de melhorar as condições de ancoragem, fazendo com que esta fosse solicitada em uma região mais favorável. 
TAYLOR, H.P.J. (1974)

Analisou o comportamento dos nós de pórtico com variação na configuração do detalhamento da armadura.

MARQUES, J. L. G.; JIRSA, J. O. (1975)

Ensaiaram 22 modelos simulando nós externos, e avaliaram a capacidade de ancoragem das barras longitudinais da viga com diversos graus de confinamento.

MEINHEIT, D. F.; JIRSA, J. O. (1981)

Analisaram a resistência ao cisalhamento de ligações viga-pilar. Observaram que a presença de vigas transversais melhora o comportamento da ligação.

KORDINA, K. (1984)

Analisou o comportamento dos nós de pórtico com variação na configuração do detalhamento da armadura.

POPOV, E.P. (1984)

Analisou o comportamento da aderência sob carregamento cíclico.

EHSANI, M.R.; WIGHT, J.K. (1985)

Analisaram nós externos sujeitos a carregamento sísmico, e observaram que a deterioração do concreto no nó em virtude das altas tensões de cisalhamento afeta as condições de ancoragem.

DURRANI, A. J.; ASCE, A. M.; ZERBE, H. E. (1987)

Estudaram os nós de pórtico considerando a presença de laje e viga transversal simultaneamente

SOROUSHIAN, P.; OBASEKI, K.; NAGI, M.; ROJAS, M. C. (1988) Analisou o comportamento da dobra a $90^{\circ}$ na ancoragem das barras longitudinais das vigas em nós externos. 
PAULTRE, P.; CASTELE, D.; RATTRAY, S.; MITCHELL, D. (1989)

Observaram que a armadura da laje contribui significantemente, aumentando a resistência da viga e reduzindo a ductilidade a momentos negativos.

GEFKEN, P. R.; RAMEY, M. R. (1989)

Estudaram a utilização de fibras no concreto com o objetivo de aumentar o espaçamento dos estribos.

EHSANI, M.R.; WIGHT, J.K. (1990)

Apresentaram um simples dimensionamento para o confinamento do nó considerando um índice de dissipação de energia.

CHEUNG, P. C.; PAULAY, T.; PARK, R. (1991)

Não encontraram evidências, em seus ensaios, de que a presença de vigas transversais provocasse um confinamento significante no nó durante a aplicação de carregamento sísmico bidirecional.

KITAYAMA, K.; OTANI, S.; AOYAMA, H. (1991)

Analisaram o comportamento dos nós internos. Observaram que a presença de vigas transversal melhora o comportamento da ligação.

HA, G. J.; KIM, J. K.; CHUNG, L. (1992)

Analisaram o comportamento dos nós de pórtico submetidos a carregamento cíclico com a utilização de concretos de alta resistência.

ORTIZ, I. R. (1993)

Estudou os modelos de bielas e tirantes para estruturas de concreto armado, com o objetivo de melhorar o entendimento sobre a forma e a resistência das bielas. Analisou vigas curtas e nós externos. Propôs um modelo de biela e tirantes e um método de dimensionamento para nós externos.

TSONOS, A. G.; TEGOS, I. A.; PENELIS, G. G. (1994)

Analisaram a influência da força normal em nós externos sob carregamento cíclico. 
SCOTT, R. H. (1996)

Por meio de ensaios de 17 modelos avaliou a distribuição de deformações e de tensões de aderência nos nós.

PARKER, D. E.; BULLMAN, P. J. M. (1997)

Propuseram um modelo que se baseia na formulação para o dimensionamento de peças submetidas a força cortante considerando uma inclinação crítica para a biela do nó.

MURTY, D. S. R.; SASTRY, S. G.; LAKSHMI, P. N. V. A. P. P.; RAO, D. L. N. (1998). Estudou o arranjo das armaduras longitudinais da viga no nó externo.

SCOTT, R. H.; HAMIL, S. J.; BAGLIN, P. S. (1999)

Analisaram o comportamento do nó externo, por meio de 30 modelos experimentais com a utilização de concreto de alta resistência.

HWANG, S. J.; LEE, H. J. (1999)

Apresentou um modelo teórico considerando a compatibilidade de deformações e as leis constitutivas dos materiais.

LAFAVE, J. M.; WIGHT, J. K. (1999)

Analisaram ligações com a presença de laje e viga transversal. A principal particularidade dos seus modelos era que a largura da viga principal era maior que a do pilar.

TSONOS, A. G. (1999)

Estudou métodos para reforço em nós externos e demonstrou uma formulação teórica considerando o comportamento biaxial do concreto.

BARBOSA, L. A. G.; ALMEIDA, P. A. O. (2001)

Estudou nós de canto avaliando seu comportamento quanto a esforços solicitantes que provocam abertura e fechamento.

PANTELIDES, C. P.; HANSEN, J.; NADAULD, J.;REAVELEY, L. D. (2002)

Estudou os nós externos sob carregamento sísmico e propôs um modelo de bielas e tirantes. 
BAKIR, P. G.; BODUROGLU, H. M. (2002)

Fizeram uma análise paramétrica das variáveis que influenciam o nó externo.

MURTY, D. S. R; DURGESH, C. R.; BAJPAI, K. K. e JAIN, S. K. (2003)

Ensaiaram nós externos sob carregamento sísmico variando o arranjo da armadura.

HEGGER, S. J.; SHERIF, A.; ROESER, W. (2003)

Analisaram os fatores que influenciam o comportamento dos nós quanto ao cisalhamento e apresentaram uma formulação considerando a utilização de coeficientes relacionados as variáveis influentes.

ALVA, G. M. S. (2004)

Realizou um estudo Teórico-Experimental do comportamento de nós de pórtico de concreto armado submetidos a ações cíclicas.

TSONOS, A. G. (2004)

Estudou a influência do efeito $P-\Delta$, causada pela mudança simultânea da força axial no pilar e o deslocamento lateral da ligação. 


\section{MODELOS TEÓRICOS}

\subsection{Introdução}

A análise de estruturas de concreto armado por meio de modelos de treliça foi introduzida pela primeira vez por Ritter e Mörsch. A partir da analogia clássica da treliça tornou-se possível a representação do comportamento estrutural de diversos elementos pouco compreendidos anteriormente por meio de modelos de bielas e tirantes. Nestes modelos, as bielas representam regiões de tensões de compressão e os tirantes regiões de tensões de tração.

Para efeito de aplicação do modelo, pode-se dividir a estrutura em regiões contínuas e descontínuas. As regiões contínuas são denominadas de regiões tipo $B$, nestas as deformações apresentam comportamento linear na seção transversal. As regiões descontínuas são denominadas de regiões tipo $D$, e nelas as hipóteses de Bernoulli não são válidas.

Os nós de pórtico são regiões do tipo $D$, ou seja, os métodos convencionais de dimensionamento não são aplicáveis a eles. Desta forma, os modelos de bielas e tirantes tornam-se interessante pela facilidade de aplicação e compreensão do comportamento estrutural.

Neste capítulo serão apresentados modelos que analisam a distribuição de forças, tensões e deformações na região nodal. Dentre eles, os modelos de bielas e tirantes são os que mais aparecem na literatura. 


\subsection{Paulay \& Priesteley (1992)}

Paulay \& Priesteley (1992) consideram que a transferência das tensões cisalhantes dentro do nó é feita por dois mecanismos: o da biela diagonal e o de treliça (equação ( 3.1 )).

$V_{j h}=V_{c h}+V_{s h}$

Onde $V_{c h}$ é a parcela horizontal da resistência da biela diagonal e $V_{s h}$ é parcela da força cortante resistida pela armadura transversal disposta no nó.

A componente horizontal do mecanismo da biela diagonal é definida pela equação abaixo.

$V_{c h}=C_{v}+\Delta T_{c}-V_{p}$

Onde $\Delta T_{c}$ é a fração da força de compressão que age na armadura inferior da viga, introduzida pela biela por meio da aderência e $V_{p}$ é a força cortante no pilar.

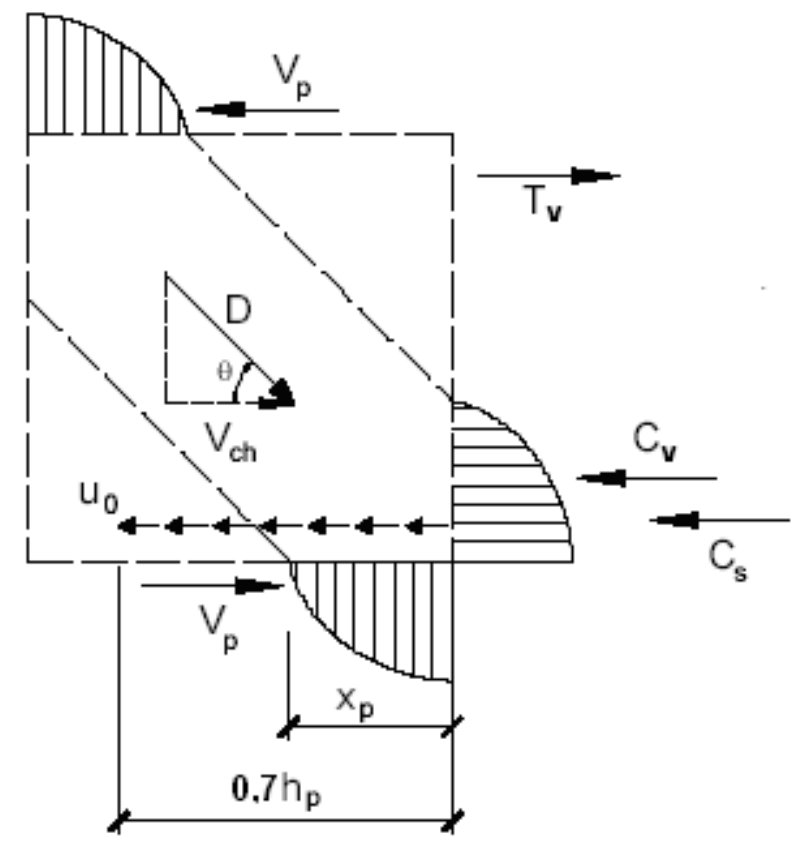

Figura 3.1 - Esforços considerados por Paulay \& Priesteley (1992). 
A parcela $\Delta T_{c}$ é definida por meio de uma força distribuída em um comprimento de ancoragem efetivo equivalente a $70 \%$ da altura do pilar (Figura 3.1) e assume-se que a transferência efetiva desta força, por aderência, para a biela ocorre somente em $80 \%$ da região comprimida do pilar, como mostra as equações ( 3.3 ) e ( 3.4 ).

$$
\begin{aligned}
& \Delta T_{c}=u_{o}^{*}\left(0,8^{*} x_{p}\right) \\
& u_{o}=\frac{C_{s}}{0,7^{*} h_{p}}
\end{aligned}
$$

Onde $C_{s}$ é a força na armadura comprimida da viga e $x_{p}$ é a dimensão da zona comprimida do pilar. A altura comprimida do pilar pode ser considerada de maneira simplificada pela equação abaixo.

$$
x_{p}=\left(0,25+0,85 * \frac{N}{f_{c}^{\prime} * A_{g}}\right) * h_{p}
$$

Onde $A_{g}$ é a área bruta da seção do pilar e $N$ é a força normal que age no pilar.

Desta forma, tem-se a equação ( 3.6 ) definindo o valor de $V_{c h}$.

$$
V_{c h}=C_{v}+\left(\frac{C_{s}}{0,7^{*} h_{p}}\right) *\left(0,8^{*} x_{p}\right)-V_{p}
$$

Conhecida a parcela referente à resistência oferecida pela biela, chega-se facilmente àquela que deverá ser resistida pela armadura transversal, se necessária, pela equação ( 3.7 ).

$$
V_{s h}=V_{j h}-V_{c h}=C_{s} *\left(0,7-\frac{N}{f_{c}^{\prime} * A_{g}}\right)
$$

Para evitar a ruptura frágil da biela comprimida considera-se que a tensão cisalhante no nó, não deve ultrapassar o valor de $25 \%$ da resistência à compressão ou 9,0 MPa. 


\subsection{Ortiz (1993)}

Com base em sua investigação experimental em nós externos sob carga monotônica, Ortiz (1993) propôs um procedimento de cálculo para o dimensionamento dos nós externos, partindo dos valores de momento fletor, força cortante e força normal nas faces do nó, calculados por meio da análise estrutural.

Neste seu procedimento o ângulo da biela é dado por:

$\theta=\arctan \left(\frac{\mathrm{V}_{\mathrm{jh}}}{\mathrm{V}_{\mathrm{jv}}}\right)$

Onde as forças cortantes $\bigvee_{\text {jh }}$ e $\bigvee_{j v}$ são calculadas pelo equilíbrio horizontal e pelo vertical respectivamente como apresentado no capítulo 2.

Tendo-se os valor da inclinação da biela chega-se ao esforço resistido por ela:

$D^{*} \cos \theta=V_{j h}$

Próximo da ruína do nó, este desenvolve toda sua capacidade resistente. Segundo o Código Modelo CEP-FIP (1990), a resistência de projeto de uma região sob compressão uniaxial pode ser determinada por meio de um diagrama simplificado de tensões uniformes para o concreto, ao longo de toda a altura, de bielas e banzos comprimidos. Desta forma, considera-se a tensão média de uma região fissurada para o cálculo da força cortante resistido pelo nó:

$$
\begin{aligned}
& \mathrm{f}_{\mathrm{cd} 2}=0,60 *\left(1-\frac{\mathrm{f}_{\mathrm{ck}}}{250}\right) * \mathrm{f}_{\mathrm{cd}} \\
& \mathrm{V}_{\mathrm{jd}}=\mathrm{f}_{\mathrm{cd} 2}{ }^{*} \mathrm{~b}_{\mathrm{c}}{ }^{*} \mathrm{w}{ }^{*} \cos \theta
\end{aligned}
$$

De acordo com os resultados dos seus ensaios, Ortiz (1993) concluiu que o valor da largura da biela, $w$, equivale a $45 \%$ do valor máximo possível para a mesma para 0 caso de nós sem estribos (Figura 3.2). 


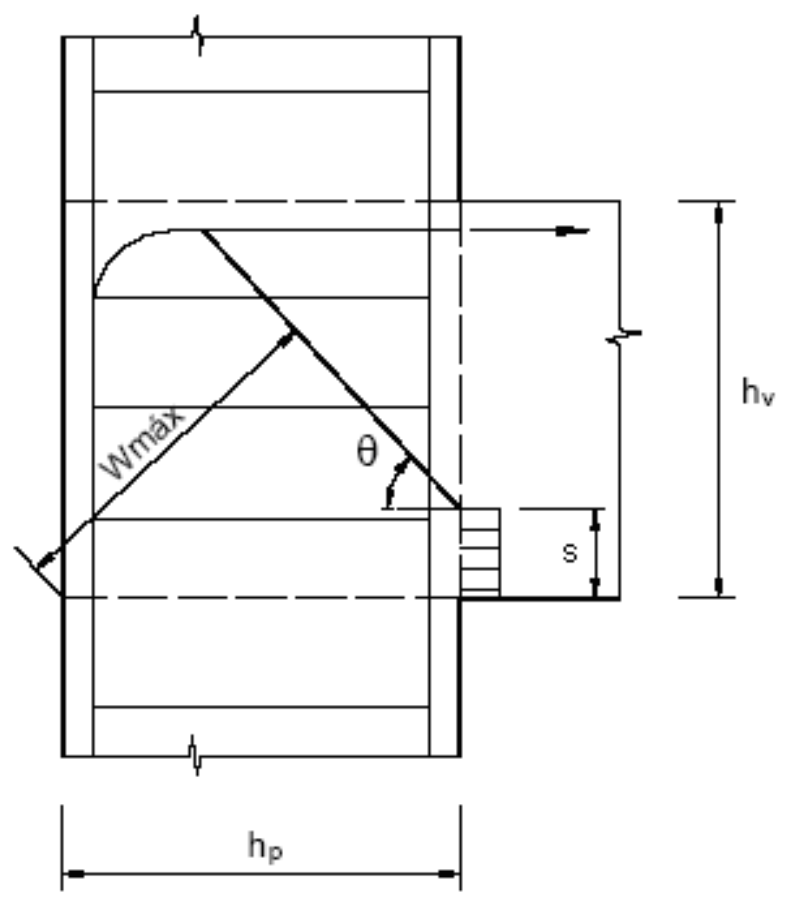

Figura 3.2 - Largura máxima disponível para a biela segundo Ortiz (1993).

Fonte: Alva, G. S. (2004)

$\mathrm{w}_{\text {máx }}=\mathrm{h}_{\mathrm{p}}{ }^{*} \operatorname{sen} \theta+\mathrm{s}{ }^{*} \cos \theta$

Todavia, vale salientar que não é possível que a largura da biela atinja $w_{\text {máx }}$ já que as dimensões do nó ficam limitadas pelas armaduras do pilar.

Nos nós com a utilização de estribos, Ortiz (1993) observou em seus ensaios que ocorreu um aumento na largura da biela, haja vista que a presença de estribos produz um maior confinamento no nó, sendo assim este desenvolve uma maior resistência. Como se torna possível a aplicação de maiores cargas, no instante da ruína a largura da biela será maior que nos nós sem a presença de estribos. O acréscimo da largura da biela fica definido como:

$$
\delta w=\frac{A_{s w}{ }^{*} f_{y w}}{f_{c d 2}{ }^{*} b_{c}{ }^{*} \cos \theta}
$$


Desta maneira, a largura da biela dos nós com estribos fica definida pela equação ( 3.14 ). O valor da capacidade resistente dos nós com estribos é calculado da mesma maneira que para aqueles sem a presença de estribos.

$$
w=0,45^{*} w_{\text {máx }}+\frac{A_{s w}{ }^{*} f_{y w}}{f_{c d 2}{ }^{*} b_{c}{ }^{*} \cos \theta}<w_{\text {máx }}
$$

Outra observação feita por Ortiz (1993) nos seus ensaios foi que o acréscimo de estribos ao nó, não aumenta sua capacidade resistente à partir de um certo valor. Desta forma, reorganizando a equação ( 3.14 ) tem-se:

$$
A_{s w}<\frac{0,55^{*} w_{\text {máx }}{ }^{*} f_{c d 2}{ }^{*} b_{c}{ }^{*} \cos \theta}{f_{y}}
$$

Como resultado das observações feitas em seu estudo, por meio de análises experimentais em 7 modelos de nós externos, Ortiz (1993) propôs o modelo de bielas e tirantes apresentado na Figura 3.3.

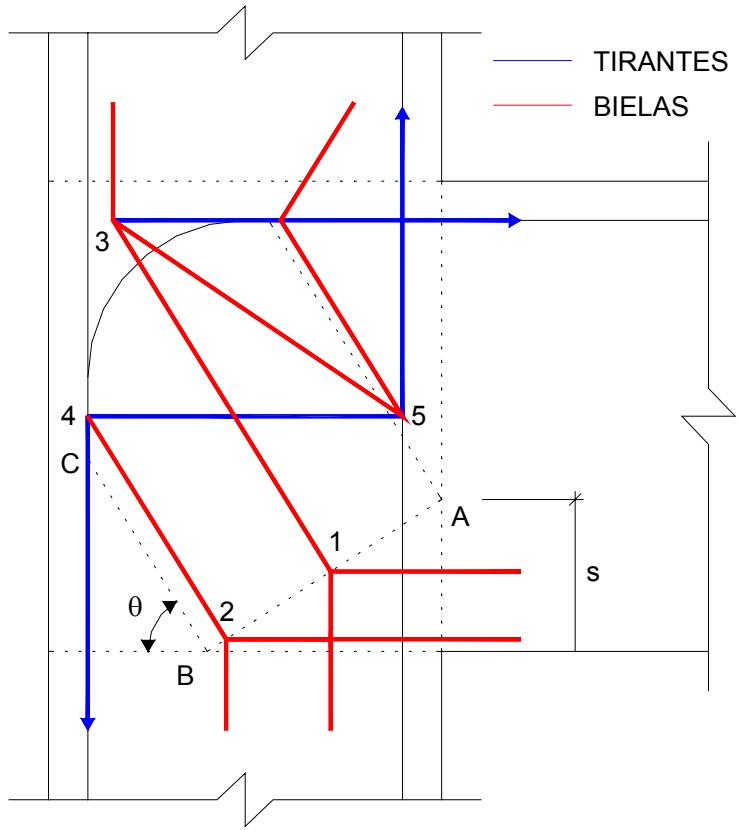

Figura 3.3 - Modelo de bielas e tirantes proposto por Ortiz (1993).

Fonte: ORTIZ, I. R. (1993) 


\subsection{Parker \& Bullman (1997)}

Parker e Bullman (1997) propuseram um modelo para o dimensionamento de nós de pórtico externos, considerando uma inclinação crítica para a biela de modo que sua rigidez seja máxima. Esta inclinação é o valor que maximiza a equação ( 3.16 ).

$$
\begin{aligned}
& f(\theta)=(1-\gamma * \tan (\theta)) * \operatorname{sen}^{2}(\theta) * \cos ^{2}(\theta) \\
& \gamma=\frac{a_{v}}{d_{p}} \\
& a_{v}=0,8 * d_{v}-0,8 * R
\end{aligned}
$$

Onde $R$ é o raio de curvatura da dobra das barras da viga e $d_{p}$ e $d_{v}$ são as alturas úteis do pilar e da viga respectivamente.

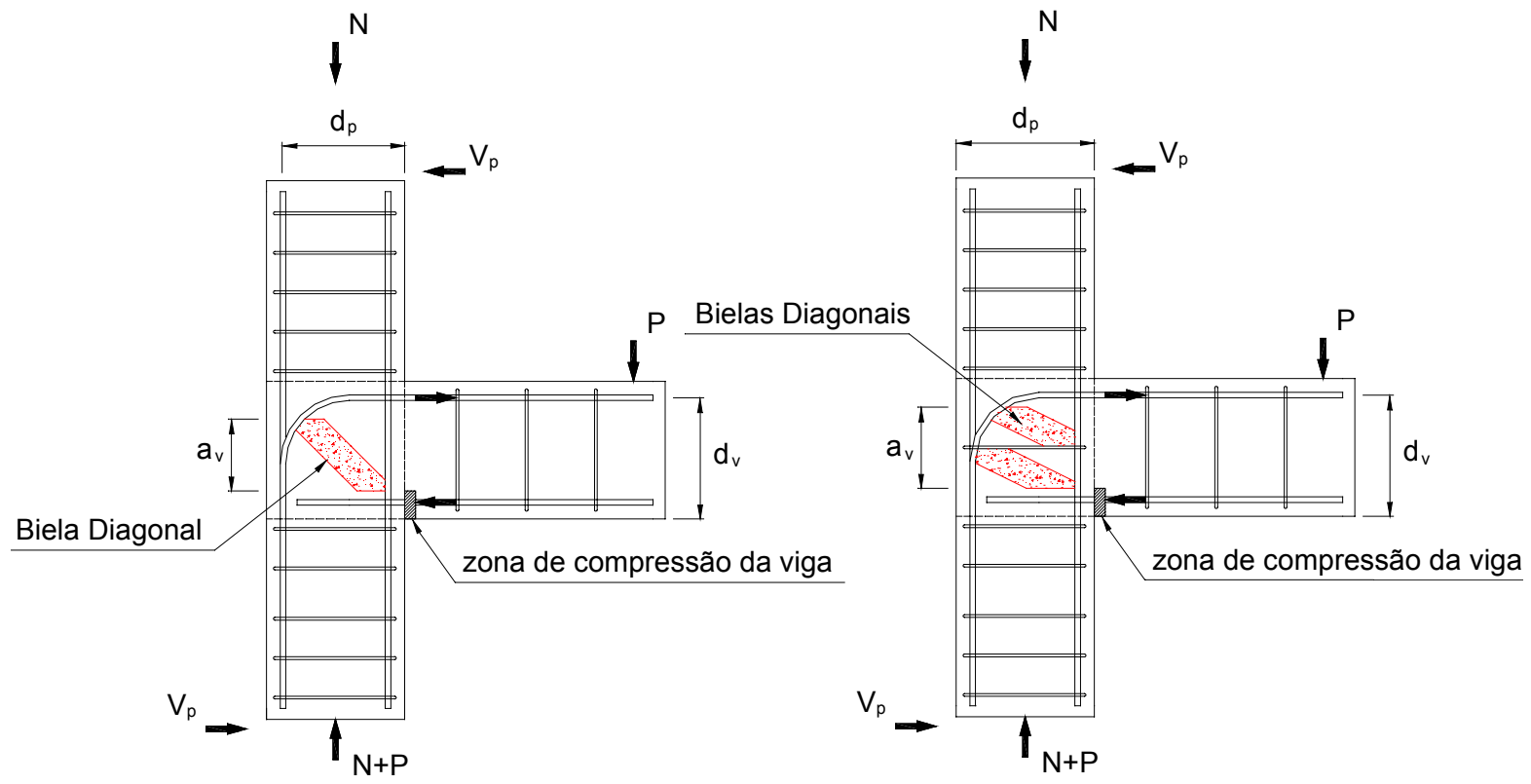

Figura 3.4 - Variáveis envolvidas no modelo de Parker \& Bullman (1997).

Fonte: Parker \& Bullman (1997) 
Aplicando-se o método iterativo de Newton, a solução da equação ( 3.16 ) é:

$$
\begin{array}{ll}
\gamma<0,5 & \tan \theta_{\text {crit }}=1-\frac{\gamma}{2} \\
\gamma>0,5 & \tan \theta_{\text {crit }}=\frac{1}{2^{*} \gamma}+\frac{\gamma^{2}-0,75}{6^{*} \gamma^{3}+2,5^{*} \gamma}
\end{array}
$$

Com a inclinação da biela diagonal conhecida, a força cortante que age no nó é limitada pela equação ( 3.20 ) referente a influência da armadura longitudinal do pilar e da força normal.

$$
V_{1}=\left(\left(A_{s}\right)_{\text {pilar }}^{*} f_{y}+N\right) * \tan \theta_{\text {crit }}
$$

Caso não haja estribos no nó a resistência da biela de concreto é definida, pela equação ( 3.21 ).

$$
\begin{aligned}
& V_{2}=\alpha^{*} \beta^{*} f_{c}^{*}\left(b_{w}\right)_{\text {pilar }} *(d)_{\text {pilar }} \\
& \alpha=\frac{\left(1-\tan \theta_{\text {crit }}\right)}{\left(\tan \theta_{\text {crit }}+\frac{1}{\tan \theta_{\text {crit }}}\right)} \\
& \beta=0,7-\frac{f_{c}}{200} \geq 0,5
\end{aligned}
$$

Caso haja estribos no nó a resistência é limitada pelas equações ( 3.24 ) e ( 3.25 ), onde a segunda controla a tensão nas bielas que se formam entre os estribos.

$$
\begin{aligned}
& V_{3}=V_{2}+A_{s w}{ }^{*} f_{y w} *\left(\frac{a_{v}}{s_{v}}-1\right) \\
& V_{4}=\chi^{*} V_{2} \\
& \chi=\frac{\left(0,9 *(d)_{\text {pilar }}-s_{v}{ }^{*} \tan \theta_{\text {crit }}\right)}{\left((d)_{\text {pilar }}-a_{v}{ }^{*} \tan \theta_{\text {crit }}\right)} \geq 1
\end{aligned}
$$


Onde $s_{v}$ é o espaçamento entre os estribos no nó.

\subsection{Hwang \& Lee (1999)}

Hwang e Lee (1999) propuseram um modelo um pouco mais completo, pois além do equilíbrio de forças, consideraram a compatibilidade de deslocamentos e as leis constitutivas dos materiais.

Em suas pesquisas consideraram o comportamento do nó baseado em três mecanismos (Figura 3.5): a biela diagonal, treliça com mecanismo horizontal e treliça com mecanismo vertical.

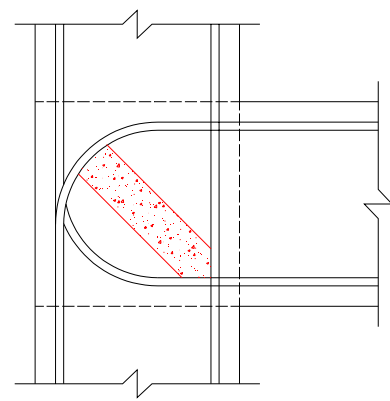

Biela diagonal principal

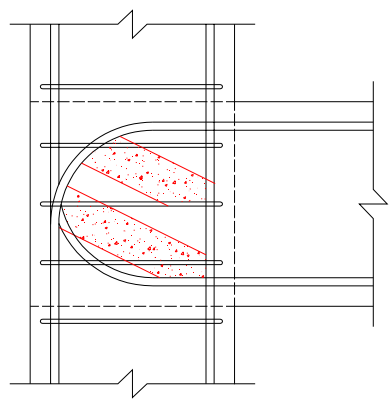

Mecanismo de treliça horizontal Mecanismo de treliça vertical

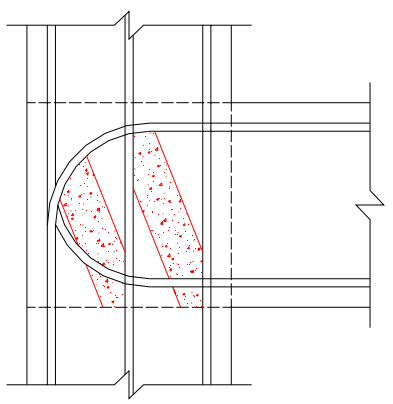

Figura 3.5 - Mecanismos resistentes no nó externo (1999).

Fonte: Hwang, S. J.; Lee, H. J. (1999)

Com a consideração destes mecanismos Hwang e Lee (1999) propuseram o modelo de bielas e tirantes apresentado na Figura 3.6.

O ângulo da biela diagonal é definido pela equação ( 3.27 ).

$$
\theta=\arctan \left(\frac{h_{v}}{h_{p}^{\prime \prime}}\right)
$$

Onde $h_{v}$ " e $h_{p}$ " são as distâncias entre os centros geométricos das armaduras da viga e do pilar respectivamente na região do nó. 


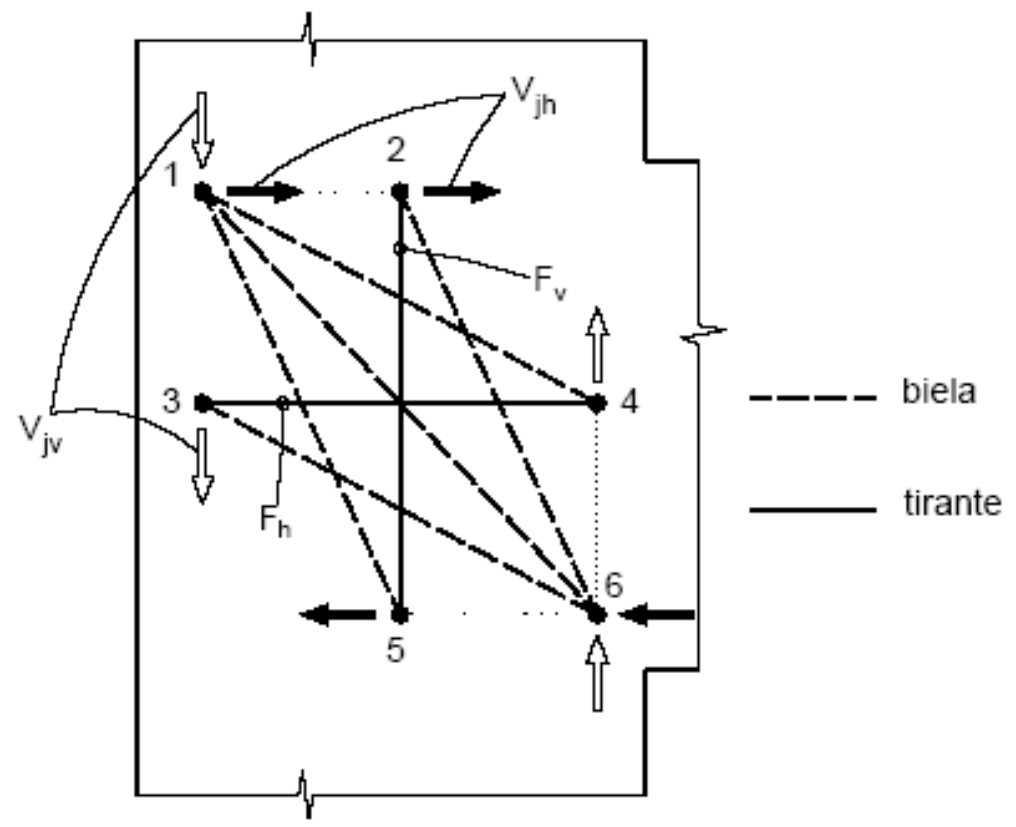

Figura 3.6 - Modelo de bielas e tirantes de Hwang e Lee (1999).

Fonte: Hwang, S. J. ; Lee, H. J. (1999)

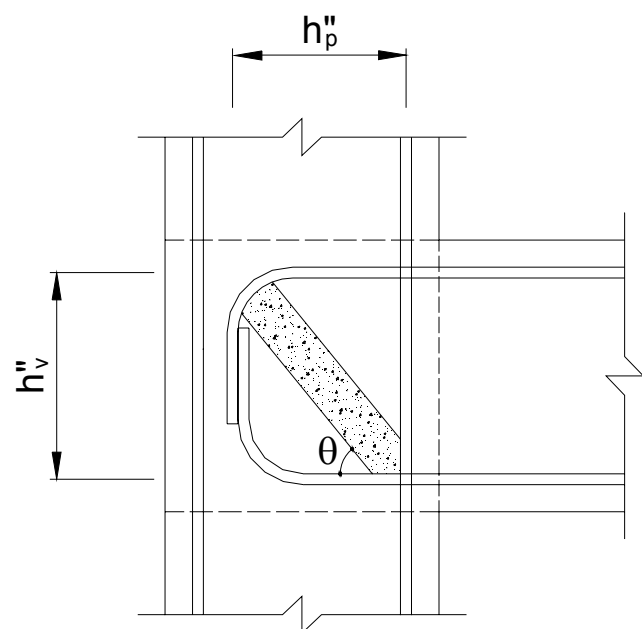

Figura 3.7 - Inclinação da biela diagonal para o modelo de Hwang \& Lee (1999).

Do equilíbrio de forças as parcelas vertical e horizontal do esforço cortante no nó ficam definidas da seguinte forma:

$V_{j h}=D^{*} \cos (\theta)+F_{h}+F_{v}{ }^{*} \cot (\theta)$ 
$V_{j v}=D^{*} \operatorname{sen}(\theta)+F_{h}^{*} \tan (\theta)+F_{v}$

Os valores $F_{h}$ e $F_{v}$ são assumidos como sendo:

$F_{h}=\gamma_{h}{ }^{*} V_{j h} \rightarrow \gamma_{h}=\frac{2 * \tan (\theta)-1}{3} \rightarrow 0 \leq \gamma_{h} \leq 1$

$F_{v}=\gamma_{v}{ }^{*} V_{j v} \rightarrow \gamma_{v}=\frac{2{ }^{*} \cot (\theta)-1}{3} \rightarrow 0 \leq \gamma_{v} \leq 1$

Onde $\gamma_{h}$ é a fração da força cortante horizontal transferida para os estribos horizontais com a ausência de estribos verticais e $\gamma_{v}$ é a fração da força cortante vertical transferida para os estribos verticais com a ausência de estribos horizontais. Estas frações consideram que para $\theta \geqslant \arctan (2)$ a força cortante horizontal é toda transferida para os estribos horizontais e para $\theta \leqslant \arctan (1 / 2)$ os estribos horizontais não absorvem força alguma.

Baseados nas equações ( 3.28 ), ( 3.30 ) e ( 3.31 ), taxas da força cortante horizontal, $R_{d}, R_{h}$ e $R_{v}$, resistida pelos mecanismos diagonal, vertical e horizontal, podem ser definidas pelas equações ( 3.32 ), ( 3.34 ) e ( 3.33 ). A Figura 3.8 ilustra as taxas da força cortante resistida pelos três mecanismos.

$$
\begin{aligned}
& \mathrm{R}_{\mathrm{d}}=\frac{\left(1-\gamma_{\mathrm{h}}\right){ }^{*}\left(1-\gamma_{\mathrm{v}}\right)}{1-\gamma_{\mathrm{h}}{ }^{*} \gamma_{\mathrm{v}}} \\
& \mathrm{R}_{\mathrm{h}}=\frac{\gamma_{\mathrm{h}}{ }^{*}\left(1-\gamma_{\mathrm{v}}\right)}{1-\gamma_{\mathrm{h}}{ }^{*} \gamma_{\mathrm{v}}} \\
& \mathrm{R}_{\mathrm{v}}=\frac{{\gamma_{\mathrm{v}}}^{*}\left(1-\gamma_{\mathrm{v}}\right)}{1-\gamma_{\mathrm{h}}{ }^{*} \gamma_{\mathrm{v}}}
\end{aligned}
$$




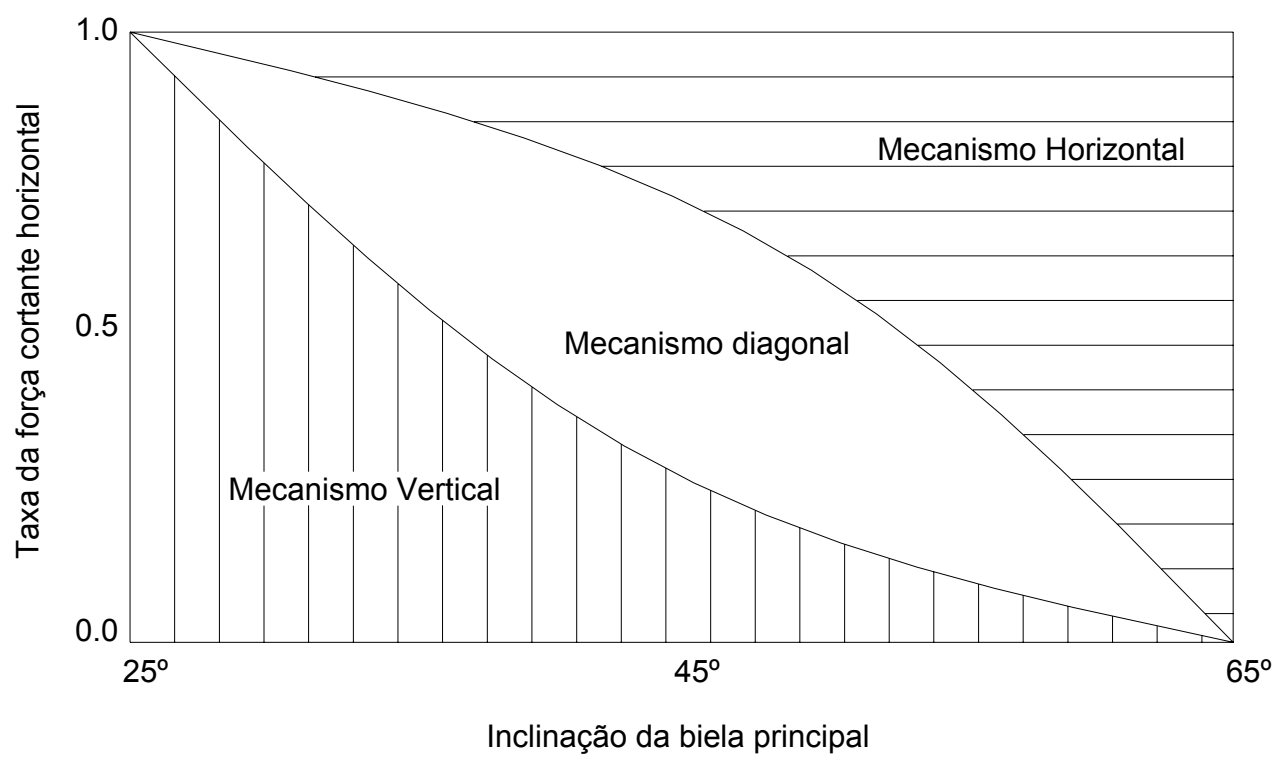

Figura 3.8 - Taxas de resistência.

Fonte: Hwang, S. J. ; Lee, H. J. (1999)

Para avaliar se a resistência do nó ao esmagamento é atingida a tensão máxima na região nodal é dada por:

$$
\sigma_{d, \text { max }}=\frac{1}{A_{b}} *\left\{D+\frac{\cos \left(\theta-\tan ^{-1}\left(\frac{h_{v}^{\prime \prime}}{2^{*} h_{p}^{\prime \prime}}\right)\right)}{\cos \left(\tan ^{-1}\left(\frac{h_{v}^{\prime \prime}}{2^{*} h_{p}^{\prime \prime}}\right)\right)} F_{h}+\frac{\cos \left(\tan ^{-1}\left(\frac{2^{*} h_{v}^{\prime \prime}}{h_{p}^{\prime \prime}}\right)-\theta\right)}{\operatorname{sen}\left(\tan ^{-1}\left(\frac{2^{*} h_{v}^{\prime \prime}}{h_{p}^{\prime \prime}}\right)\right)} * F_{v}\right\}
$$

Onde $A_{b}$ é a área da biela diagonal principal e definida pela equação ( 3.36 ).

$$
A_{b}=h_{b}^{*} b_{b}
$$

Onde $h_{b}$ e $b_{b}$ são a largura e a espessura efetiva da biela respectivamente.

A largura da biela pode ser calculada pela equação ( 3.37 ), ou estimada como sendo igual a largura da zona comprimida do pilar que pode ser aproximada pela equação ( 3.5 ). A espessura efetiva da biela é definida como no ACl-318. 


$$
h_{\text {biela }}=\sqrt{\left(x_{L N}\right)_{\text {viga }}^{2}+\left(x_{L N}\right)_{\text {pilar }}^{2}}
$$

Onde $x_{L N}$ é a largura da zona comprimida.

A relação tensão vs. deformação do concreto é reduzida por um fator $\zeta$, em função da região da biela ser uma zona fissurada com esforços de tração (Figura 3.9). Para facilitar a análise é considerado que a direção da biela coincide com uma das direções principais.

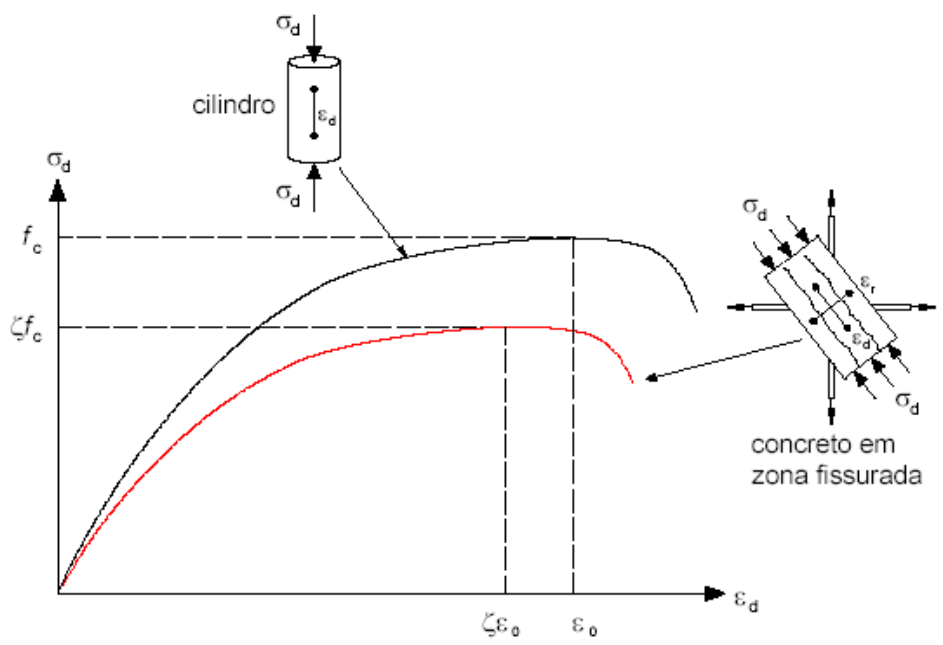

Figura 3.9 - Relação tensão vs. deformação considerada por Hwang \& Lee (1999).

Fonte: Alva, G. S. (2004)

$$
\begin{aligned}
& \sigma_{d}=\zeta^{*} f_{c} *\left[2 *\left(\frac{\varepsilon_{d}}{\zeta^{*} \varepsilon_{0}}\right)-\left(\frac{\varepsilon_{d}}{\zeta^{*} \varepsilon_{0}}\right)^{2}\right] \text { para } \frac{\varepsilon_{d}}{\zeta^{*} \varepsilon_{0}} \leq 1 \\
& \zeta=\frac{5,8}{\sqrt{f_{c}}} * \frac{1}{\sqrt{1+400^{*} \varepsilon_{r}}} \leq \frac{0,9}{\sqrt{1+400^{*} \varepsilon_{r}}} \\
& \varepsilon_{0}=-0,002-0,001^{*}\left(\frac{f_{c}-20}{80}\right) \text { para } 20 \leq f_{c} \leq 100 \mathrm{MPa}
\end{aligned}
$$

Com a consideração das direções principais, a compatibilidade de deformações é expressa por:

$$
\varepsilon_{\mathrm{r}}=\varepsilon_{\mathrm{h}}+\left(\varepsilon_{\mathrm{h}}-\varepsilon_{\mathrm{d}}\right) * \cot ^{2}(\theta)
$$


$\varepsilon_{\mathrm{r}}=\varepsilon_{\mathrm{v}}+\left(\varepsilon_{\mathrm{h}}-\varepsilon_{\mathrm{d}}\right) * \tan ^{2}(\theta)$

Onde $\varepsilon_{\mathrm{v}}$ e $\varepsilon_{\mathrm{h}}$ são as deformações das armaduras vertical e horizontal, $\varepsilon_{\mathrm{d}}$ a deformação das fibras de concreto na direção da diagonal e $\varepsilon_{r}$ na direção perpendicular à diagonal.

O valor da força cortante resistida pelo nó é calculado por um algoritmo no qual incrementos de força cortante são aplicados até atingir-se a convergência pelas relações descritas anteriormente. Por meio de 63 modelos ensaiados por outros pesquisadores, verificou-se que a formulação proposta representa de forma eficiente o comportamento do fenômeno que acontece nos nós externos.

\subsection{Tsonos (1999)}

Tsonos (1999) estudou métodos para reforço de nós de pórtico por meio de injeção de resina epoxy. Para isto demonstra uma formulação teórica bastante interessante. Considera dois mecanismos resistentes no nó (Figura 3.10). Primeiramente as tensões de cisalhamento são resistidas pela biela diagonal e em segundo lugar pelo mecanismo de bielas e tirantes formado pelas barras verticais e horizontais no nó. Ambos os mecanismos dependem da resistência do núcleo de concreto.
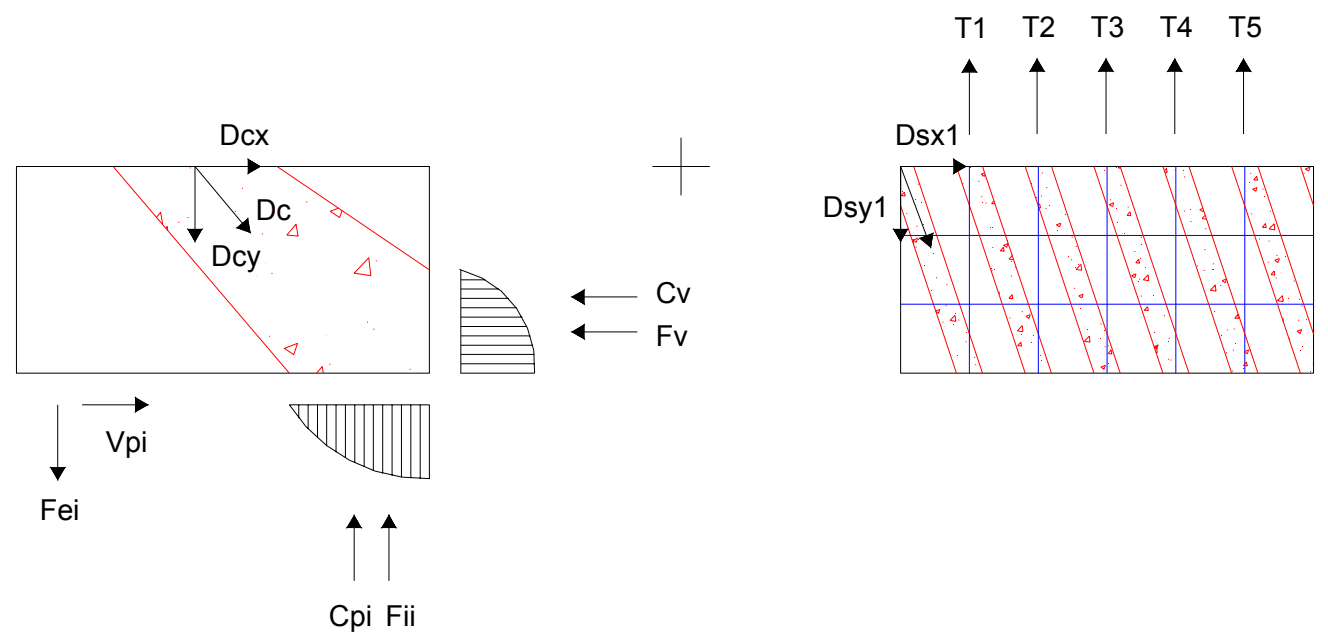

Figura 3.10 - Mecanismos resistentes no nó.

Fonte: Tsonos, A. G (1999) 
O equilíbrio de forças nas direções horizontal e vertical define a força cortante que age no nó.

$$
\begin{aligned}
& D_{c x}+\left(D_{v x} 1+\ldots+D_{c x} n\right)=V_{j h} \\
& D_{c y}+\left(T 1+\ldots+T 5+D_{v y} 1+\ldots+D_{c y} n\right)=V_{j v}
\end{aligned}
$$

As tensões, normal e de cisalhamento uniformemente distribuída na seção do nó são dadas por:

$$
\begin{gathered}
\sigma=\frac{V_{j v}}{h_{p}{ }^{*} b_{v}} \\
\tau=\frac{V_{j h}}{h_{p}{ }^{*} b_{v}}
\end{gathered}
$$

Para facilitar a manipulação das equações, define-se $\alpha$ como a relação entre as tensões normal e de cisalhamento.

$$
\begin{aligned}
& \sigma=\frac{\mathrm{V}_{\mathrm{jv}}}{\mathrm{V}_{\mathrm{jh}}}{ }^{*} \tau \\
& \frac{\mathrm{h}_{\mathrm{v}}}{\mathrm{h}_{\mathrm{p}}}=\frac{\mathrm{V}_{\mathrm{jv}}}{\mathrm{V}_{\mathrm{jh}}}=\alpha \\
& \sigma=\alpha^{*} \tau
\end{aligned}
$$

Onde, $h_{p}$ e $b_{v}$ são a altura e a base do núcleo do nó respectivamente.

As máximas tensões principais dadas pelo círculo de Mohr são:

$$
\sigma_{\mathrm{I}, \mathrm{II}}=\frac{\sigma}{2} \pm \frac{\sigma}{2} * \sqrt{1+\frac{4^{*} \tau^{2}}{\sigma^{2}}}
$$

Do diagrama de comportamento do concreto sob tensões biaxiais (Figura 3.11) tem-se as relações: 


$$
\begin{aligned}
& 10 * \frac{\sigma_{I}}{f_{c}}+\left(\frac{\sigma_{I I}}{f_{c}}\right)^{5}=1 \\
& f_{c}=k * f_{c}^{\prime} \\
& k=1+\frac{\rho_{s}{ }^{*} f_{y h}}{f_{c}^{\prime}}
\end{aligned}
$$

Onde $f_{c}$ leva em conta o aumento de resistência relativo ao confinamento, $f_{c}^{\prime}$ é a resistência à compressão do concreto, $\rho_{\mathrm{s}}$ é a taxa de armadura transversal e $f_{y h}$ é a resistência de escoamento da armadura transversal.

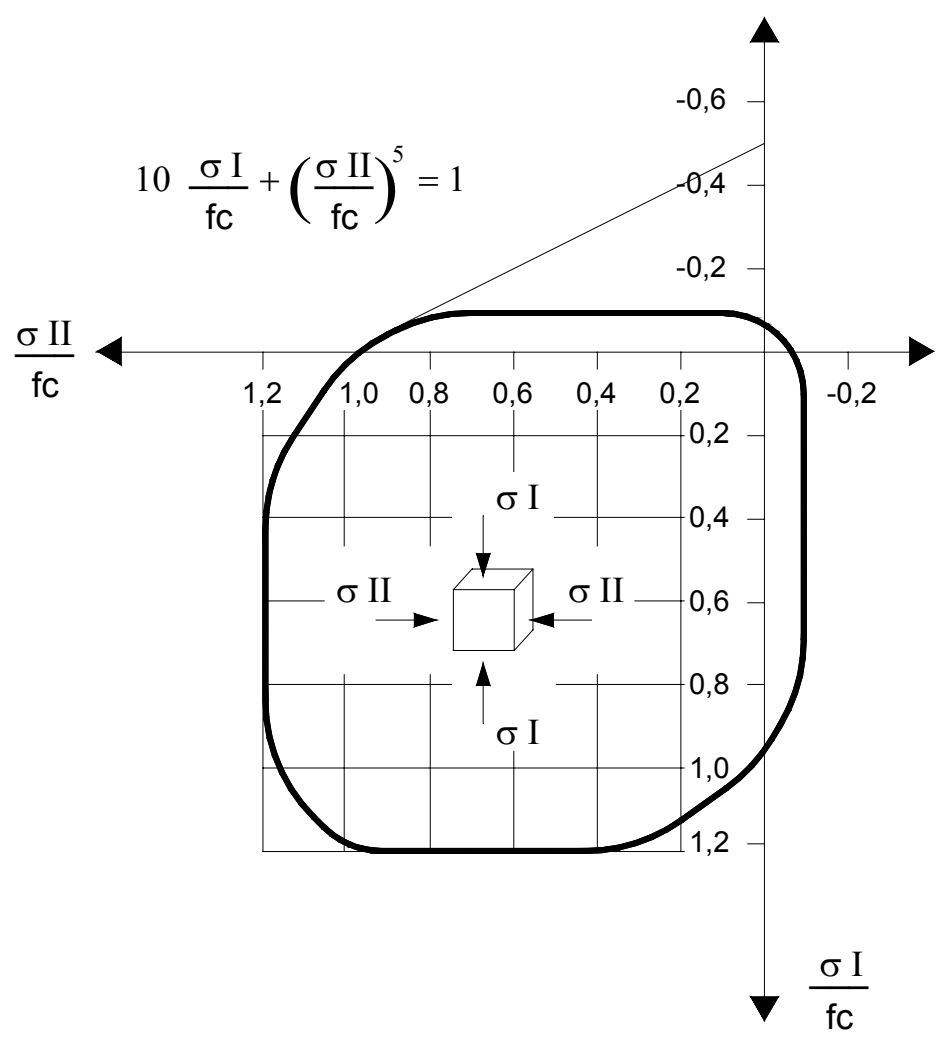

Figura 3.11 - Comportamento do concreto sob tensões biaxiais.

Fonte: TSONOS, A. G (1999)

Como observado por outros pesquisadores há uma proporção entre a resistência ao cisalhamento do nó e a resistência à compressão do concreto. 
$\tau=\gamma^{*} \sqrt{f_{c}^{\prime}}$

Substituindo as equações ( 3.49 ), ( 3.50 ) e ( 3.54 ) na equação ( 3.51 ) tem-se:

$\left[\frac{\alpha^{*} \gamma}{2 * \sqrt{f_{c}}} *\left(1+\sqrt{1+\frac{4}{\alpha^{2}}}\right)\right]^{5}+\frac{5^{*} \alpha^{*} \gamma}{\sqrt{f_{c}}} *\left(\sqrt{1+\frac{4}{\alpha^{2}}}-1\right)=1$

Assumindo as relações dadas pelas equações ( 3.56 ) e ( 3.57 ) tem-se:

$x=\frac{\alpha^{*} \gamma}{2 * \sqrt{f_{c}}}$

$\psi=\frac{\alpha^{*} \gamma}{2 * \sqrt{f_{c}}} * \sqrt{1+\frac{4}{\alpha^{2}}}$

$(x+\psi)^{5}+10 * \psi-10 * x=1$

A resolução do sistema formado pelas equações ( 3.56 ), ( 3.57 ) e ( 3.58 ) retorna o valor da resistência ao cisalhamento do nó.

\subsection{Pantelides et al. (2002)}

Por causa de deficiências observadas, como falta de confinamento, em estruturas projetadas antes do meio dos anos 70 e a observação dos severos danos e até mesmo o colapso de nós de pórtico causados em terremotos por projeto inadequado, Pantelides et al. (2002) estudaram os nós de pórtico externo sem a utilização de estribos no nó, buscando exatamente este comportamento de falta de confinamento. Para isso, variaram o detalhamento do nó e o módulo da força normal aplicada no pilar. Como resultado afirmaram que três parâmetros são suficientes para descrever o comportamento do nó: rotação plástica, resistência ao cisalhamento e abertura de fissuras.

Por meio de suas análises, propuseram o modelo de bielas e tirantes apresentado na Figura 3.12. 
Nos ensaios realizados houve basicamente duas formas de ruptura: por cisalhamento e por escorregamento.

Pode-se observar que a presença de altas forças axiais é benéfica em termos de resistência ao cisalhamento, porém torna a ligação menos dúctil e faz com que esta dissipe menos energia. Concluíram que a resistência do nó varia com a carga axial.

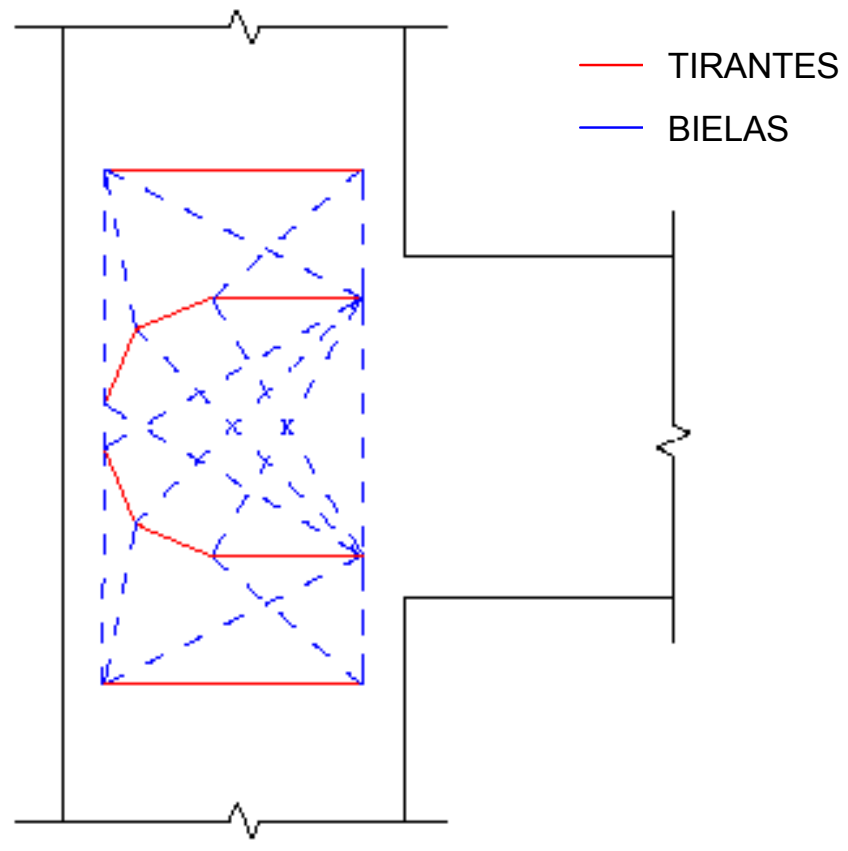

Figura 3.12 - Modelo de bielas e tirantes proposto por Pantelides et al. (1999).

Fonte: Pantelides, C. P. et al. (1999)

\subsection{Bakir \& Boduroglu (2002)}

Bakir e Boduroglu (2002) fizeram uma investigação paramétrica, com o objetivo de avaliar as variáveis que têm influência significante na resistência do nó, com resultados de 58 ensaios, com carregamento monotônico, realizados por outros autores.

Analisando a resistência do concreto, confirmaram aquilo que outros já haviam observado, a resistência ao cisalhamento do nó é proporcional a raiz quadrada da resistência à compressão do concreto.

Com relação à taxa de armadura do pilar observaram que a resistência ao cisalhamento independe desta variável, no caso de nós com ruptura por cisalhamento, 
porém nós com menores taxas de armadura do pilar e com tensão axial aplicada são mais susceptíveis a formação de rótula no pilar, e conseqüentemente possuem menor resistência ao cisalhamento.

Observando a armadura da viga $\left(A_{s v}\right)$ Bakir e Boduroglu (2002) notaram que há um aumento exponencial da resistência do nó com a taxa de armadura. $O$ arranjo da armadura da viga tem muita influência no comportamento do nó, sendo que nós com ancoragem em gancho à $90^{\circ}$ são mais eficientes que em gancho à $180^{\circ}$. Além disso, o raio de curvatura e o comprimento da fração vertical do gancho à $90^{\circ}$ também aumentam a resistência do nó se tomados maiores que $8 \phi$ e $26 \phi$, respectivamente.

Analisando as dimensões do nó, observaram que a resistência diminui exponencialmente em relação a altura da viga e a largura do pilar.

Com estas relações Bakir e Boduroglu (2002) propõem a equação ( 3.59 ) para prever a resistência do nó sem estribos. Quando há a presença de estribos a resistência fica aumentada de uma parcela referente a estes (equação ( 3.60 )), porém com um coeficiente minorador $\alpha$ que leva em consideração a taxa de estribos. Para alta quantidade de estribos $(\rho>0,55 \%) \alpha=0,37$, para média quantidade $(0,30 \%<\rho<0,55 \%)$ $\alpha=0,6$ e para baixa quantidade $(\rho<0,30 \%) \alpha=0,664$.

$V_{c h}=\frac{0,71^{*} \beta^{*} \gamma *\left(100 * \frac{A_{s v}}{b_{v}{ }^{*} d_{v}}\right)^{0,4289} *\left(\frac{b_{p}+b_{v}}{2}\right) * h_{p} * \sqrt{f_{c}}}{\left(\frac{h_{v}}{h_{p}}\right)^{0,61}}$

$V_{j h}=V_{c h}+\alpha^{*} A_{s w}^{*} f_{y w}$

Onde $\beta=0,85$ para nós com detalhe de gancho à $180^{\circ}$ e $\beta=1,0$ para gancho à $90^{\circ}$ e $\gamma=$ 1,37 para barras inclinadas no nó e $\gamma=1,00$ para os outros casos.

Com relação à carga axial no pilar, foi observado que ela não influencia a resistência do nó, porém influencia o modo de ruptura.

Para confirmar a confiabilidade do estudo paramétrico Bakir e Boduroglu (2002) desenvolvem as equações básicas da mecânica dos sólidos no nó, comprovando a influência das variáveis analisadas na parametrização. 


\subsection{Hegger et al. (2003)}

Hegger et al. (2003) analisou os fatores que influenciam o comportamento dos nós de pórtico quanto ao cisalhamento, e concluiu com os resultados dos ensaios que a resistência do nó diminui com sua esbeltez, e que ela depende da armadura transversal do nó. Outro ponto observado foi que há um aumento da resistência do nó com a taxa de armadura do pilar.

Como conseqüência, propôs um modelo de cálculo para a previsão da força de ruptura e a forma de ruptura.

Como proposto por outros autores, a resistência ao cisalhamento é considerada como composta por duas parcelas: a referente ao concreto e à armadura.

$V_{j h}=V_{c h}+V_{s h}$

Para levar em consideração os diversos fatores que influenciam o comportamento do nó externo Hegger et al. (2003) utilizaram quatro coeficientes, cada um relacionado com um fenômeno.

$$
\begin{aligned}
& V_{c h}=\alpha_{1}{ }^{*} A^{*} B^{*} C^{*} b_{j}{ }^{*} h_{p} \\
& V_{s h}=\alpha_{2}{ }^{*} A_{s w, e f}{ }^{*} f_{y w}
\end{aligned}
$$

Onde $b_{j}$ espessura do nó, $h_{p}$ é a largura do pilar, $A_{s w, e f}$ é a área de aço transversal efetiva localizada acima da região comprimida da viga, $\alpha_{1}$ está relacionado com a eficiência da ancoragem das barras da viga $\left(\alpha_{1}=0,85\right.$ para gancho à $180^{\circ}$ e $\alpha_{1}=0,95$ para gancho à $\left.90^{\circ}\right), \alpha_{2}$ está relacionado com a eficiência da armadura transversal (Tabela 3.1), A leva em conta a esbeltez do nó (equação ( 3.64 )), B leva em conta a taxa de armadura do pilar (equação ( 3.65 )) e C está relacionado com a resistência do concreto (equação ( 3.66 )). 
Tabela 3.1 - Valores sugeridos para $\alpha_{2}$.

\begin{tabular}{|ccc|}
\hline Detalhe & Estribos fechados & Estribos abertos \\
\hline Gancho à $90^{\circ}$ & 0,6 & 0,7 \\
\hline Gancho à $180^{\circ}$ & 0,5 & 0,6 \\
\hline
\end{tabular}

Fonte: HEGGER, J. et al. (2003)

$A=1,2-0,3 * \frac{h_{v}}{h_{p}} \ldots . . . .0,75 \leq \frac{h_{v}}{h_{p}} \leq 2,0$

$B=1,0+\frac{\rho_{p}-0,5}{7,5} \ldots . . . .0,5 \leq \rho_{c} \leq 2,0$

$C=2 * \sqrt[3]{f_{c}^{\prime}} \ldots . . \ldots 30 \leq f_{c}^{\prime} \leq 100 M P a$

A parcela de resistência ao cisalhamento referente ao concreto definida pela equação ( 3.61 ) é limitada por um valor máximo (equação ( 3.67 )) que depende principalmente do tipo de ancoragem, da força axial do pilar e da esbeltez da ligação.

$V_{\max }=\gamma_{1}{ }^{*} \gamma_{2}{ }^{*} \gamma_{3}{ }^{*} 0,25 * f_{c}^{\prime *} b_{j}{ }^{*} h_{p} \leq 2{ }^{*} V_{c}$

Onde $\gamma_{1}=1,2$ para ancoragem com placa e $\gamma_{1}=1,0$ para ancoragem com gancho, $\gamma_{2}$ está relacionado com a carga axial no pilar (equação ( 3.68 )) e $\gamma_{3}$ leva em conta a esbeltez do nó (equação ( 3.69 )).

Hegger et al. (2003) observaram que para a força axial do pilar muito alta, ou seja, $\sigma_{\mathrm{c}} \geq 0,4 \mathrm{f}_{\mathrm{c}}{ }^{\prime}$, há uma redução na resistência do nó.

$$
\begin{aligned}
& \gamma_{2}=1,5-1,2 * \frac{\sigma_{p i l}}{f_{c}^{\prime}} \leq 1,0 \\
& \gamma_{3}=1,9-0,6 * \frac{h_{v}}{h_{p}} \leq 1,0
\end{aligned}
$$




\subsection{Recomendações normativas}

Diversas são as normas que abordam o dimensionamento de nós de pórtico, entre elas podem-se citar: as normas norte-americanas ACl-318 e ACl-352, a japonesa $\mathrm{AlJ}$, a britânica BS8110, a neozelandesa NZS-3101.

De um modo geral, o dimensionamento dos nós de pórtico é baseado em modelos de bielas e tirantes, porém não há um consenso, entre as normas, sobre os mecanismos resistentes considerados. A principal diferença encontrada entre elas diz respeito à contribuição do mecanismo de treliça na transferência das tensões de cisalhamento. Nem todas as normas apresentam a armadura transversal como responsável por uma parcela da resistência do nó, pelo contrário, considerando que ela contribua apenas no confinamento do nó.

\subsubsection{ACl-352 e ACl-318}

O ACl-352 apresenta recomendações específicas para o projeto de ligações monolíticas viga-pilar de concreto armado. Nele há menções: sobre concretos de alta resistência, quanto à contribuição na resistência ao cisalhamento das armaduras da laje, sobre a ancoragem por meio de placas, sobre ligações com vigas excêntricas e no caso de vigas mais largas que o pilar.

Neste código o nó é tratado como parte do pilar e projetado como uma região crítica. Como apresentado anteriormente, a norma norte-americana classifica os nós de pórtico em dois grupos: tipo 1 e tipo 2 .

A resistência ao cisalhamento do nó é verificada apenas na direção horizontal pelas seguintes equações:

$$
\begin{aligned}
& \phi^{*} V_{j h} \geq V_{u} \\
& V_{j h}=0,083^{*} \gamma^{*} \sqrt{f_{c}^{\prime}}{ }^{*} b_{j}{ }^{*} h_{p}
\end{aligned}
$$

Onde $\phi=0,85$ e $b_{j}$ é a espessura efetiva da biela tomada como o menor dos valores seguintes. 


$$
\begin{gathered}
b_{p} \\
\frac{b_{p}+b_{v}}{2} \\
b_{v}+\sum \frac{m^{*} b_{p}}{2}
\end{gathered}
$$

Para nós onde a excentricidade entre o pilar e a viga exceder $b_{d} / 8, \mathrm{~m}=0,3$; para os outros casos $\mathrm{m}=0,5$. A constante $\gamma$ depende da classificação do nó segundo a Tabela 3.2. Embora o nó possa ser projetado para resistir ao cisalhamento em duas direções horizontais perpendiculares, somente um valor de $\gamma$ é selecionado.

No caso de nós com vigas nas duas direções a força cortante horizontal pode ser verificada em cada lado separadamente. Sabe-se que na realidade o nó está sujeito a um comportamento biaxial, porém estudos mostram que a consideração de comportamento uniaxial subestima de $10 \%$ a $35 \%$ a capacidade da ligação.

Com relação a armadura transversal o $\mathrm{ACl}-352$ recomenda a consideração de uma quantidade mínima de estribos no nó para evitar o rompimento do cobrimento da armadura, logo melhorar as condições de aderência no nó, e promover algum confinamento para garantir a integridade do concreto.

Tabela 3.2 - Valores de $\gamma$ de acordo com a classificação do nó.

\begin{tabular}{|lll|}
\hline \multicolumn{1}{|c|}{ Classificação } & Tipo da Ligação \\
\hline A. Nós com Pilar Contínuo & 24 & 20 \\
A1. Nós confinados em suas 4 faces verticais & 20 & 15 \\
A2. Nós confinados em três faces verticais ou & & 12 \\
em duas faces opostas & 15 & 15 \\
A3. Outros casos & 20 & 12 \\
\hline B. Nós com Pilar Descontínuo & 15 & 8 \\
A1. Nós confinados em suas 4 faces verticais & & \\
A2. Nós confinados em três faces verticais ou & 12 & \\
em duas faces opostas & & \\
A3. Outros casos & & \\
\hline
\end{tabular}

Fonte: $\mathrm{ACl}-352$ 
No caso dos nós tipo 1, deve haver pelo menos duas camadas de estribos e o espaçamento entre eles deve ser inferior a $30 \mathrm{~cm}$. Caso o nó resista a forças laterais não sísmicas este espaçamento deve ser inferior a $15 \mathrm{~cm}$.

Para os nós do tipo 2, é definido que a área dos estribos no nó deva ser pelo menos igual a:

$$
A_{s w}=0,3 * \frac{s_{h}{ }^{*} h^{\prime *} f_{c}^{\prime}}{f_{y h}} *\left(\frac{A_{g}}{A_{c}}-1\right)
$$

E não menor que:

$$
A_{s w}=0,09 * \frac{s_{h} * h^{\prime \prime} f_{c}^{\prime}}{f_{y h}}
$$

Onde $s_{h}$ é o espaçamento dos estribos, $h$ " é a dimensão do núcleo do pilar perpendicular a armadura transversal, $A_{g}$ é a área da seção bruta do pilar e $A_{c}$ é a área do pilar delimitada pelos estribos, sendo medida pela porção externa destes elementos. $O$ espaçamento dos estribos para estes nós não deve ser superior aos valores de: $15 \mathrm{~cm}$, seis vezes o diâmetro das barras longitudinais do pilar ou três quartos da menor dimensão do pilar no caso do nó resistir a ações sísmicas laterais, caso contrário este espaçamento não deve exceder $20 \mathrm{~cm}$ ou um terço da menor dimensão do pilar.

O comprimento de ancoragem das barras longitudinais é diferenciado de acordo com a classificação do tipo do nó, assim como com os estribos, porém sempre maior que $15 \mathrm{~cm}$ ou $8 \phi$.

Para os nós do tipo 1 o comprimento de ancoragem é dado por:

$$
\ell_{b}=\frac{f_{y}^{*} \phi}{4,2 * \sqrt{f_{c}^{\prime}}}
$$

Para os nós do tipo 2 o comprimento de ancoragem é dado por: 


$$
\ell_{b}=\frac{1,25^{*} f_{y}{ }^{*} \phi}{6,2 * \sqrt{f_{c}^{\prime}}}
$$

A norma norte-americana trata também do uso de placas de ancoragem, particularmente em regiões com excesso de armadura e apresenta esta solução como uma solução viável sem problemas significativos de projeto. Segundo o $\mathrm{ACl}$ a distância das placas de ancoragem e das pernas verticais das dobras a $90^{\circ}$ até os estribos deve ser de no mínimo $5 \mathrm{~cm}$ com o intuito de promover bielas diagonais dentro do núcleo do nó.
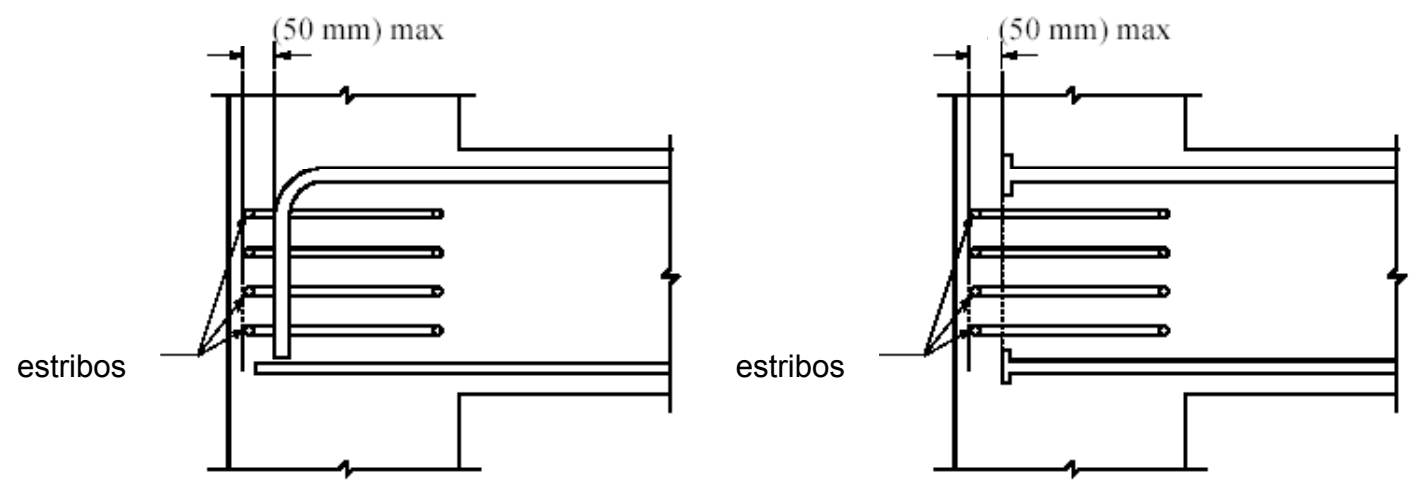

Figura 3.13 - Posicionamento das placas de ancoragem e das dobras a $90^{\circ}$.

Fonte: ACl-352

\subsubsection{BS-8110:1985}

A norma britânica não apresenta uma equação específica para o cálculo da resistência ao cisalhamento dos nós, ela considera simplesmente uma expressão para a verificação de peças submetidas a forças cortante e normal simultaneamente (equações ( $3.77)$, ( 3.78 ) e ( 3.79$))$.

$$
\begin{aligned}
& V_{j d}=\left(v_{c}+0,75 * \frac{N}{A_{g}} * \frac{V^{*} d}{M}\right) * b^{*} d+A_{s w} * f_{y w} *\left(\frac{d}{s_{v}}\right) \\
& V_{j d} \leq b^{*} d^{*} \sqrt{f_{c}} \\
& V_{j d} \leq 6,25^{*} b^{*} d
\end{aligned}
$$


Onde $v_{c}$ é a resistência ao cisalhamento de projeto para o concreto armado, $V$ é a força cortante de projeto, $M$ é o momento de projeto e $s_{V}$ é o espaçamento da armadura transversal.

\subsubsection{AlJ}

De acordo com o modelo japonês, o único mecanismo confiável é a biela principal. Os estribos são considerados apenas como armadura de confinamento, da mesma maneira que o tratamento feito pelo $\mathrm{ACl}$. Segundo o AlJ, a resistência ao cisalhamento assume o seguinte valor:

$$
\tau_{n}=k{ }^{*} f_{c}
$$

Onde $k=0,3$ para nós internos e $k=0,18$ para nós externos.

\subsubsection{CEB \& NZS-3101}

O código da Nova Zelândia e o CEB seguem basicamente a mesma formulação. Eles consideram dois mecanismos de transferência de tensões: o da biela diagonal e o de treliça, no qual são consideradas as forças cortantes verticais e horizontais. No mecanismo da biela considera-se que a força axial no pilar melhora o comportamento da ligação, pois reduz sua inclinação. A tensão de cisalhamento máxima é calculada assumindo que a tensão da armadura longitudinal da viga seja igual a $1,25^{\star} f_{y}$ e é limitada a $0,2^{*} f_{c}^{\prime}$ para evitar a ruptura por compressão da biela diagonal.

\subsubsection{Eurocódigo 8}

O Eurocódigo 8 apresenta a seguinte equação para a determinação da resistência ao cisalhamento de cálculo para os nós de pórtico: 
$V_{j d}=0,525 * f_{c}^{2 / 3 *} b_{j}^{*} h_{p}$

Assim como o ACl e o AIJ, o Eurocódigo 8 considera a armadura transversal no nó apenas com propriedade de confinamento.

\subsubsection{NBR 6118:2003}

A norma brasileira não traz muitas informações com relação ao dimensionamento de nós de pórtico, apenas comenta, no capítulo 21 sobre regiões especiais, que em decorrência da mudança de direção dos elementos da estrutura, a resistência do conjunto depende da resistência à tração do concreto e da disposição da armadura.

Algumas especificações são recomendadas, entre elas pode-se citar as referentes ao comprimento de ancoragem, à utilização de estribos em toda altura do pilar inclusive no encontro com vigas e lajes e a limitação do diâmetro interno de curvatura das barras longitudinais dobradas a $90^{\circ}$ em $10 \phi$ para CA-25, 15 $\phi$ para CA-50 e 18 $\phi$ para CA-60, o comprimento de $8 \phi$ para as dobras à $90^{\circ}$. Contudo, nenhum modelo de cálculo para a verificação da capacidade resistente dos nós de pórtico é apresentado.

Quanto à ancoragem, a norma brasileira define um comprimento de ancoragem básico, que equivale ao comprimento reto de barra necessário para ancorar a força nessa barra. Este comprimento é dado pela equação abaixo.

$$
\ell_{b}=\alpha * \frac{\phi}{4} * \frac{f_{y d}}{f_{b d}}
$$

Onde $\alpha=1,0$ para barras com ponta reta e $\alpha=0,7$ para barras com gancho e $f_{b d}$ é a resistência de aderência de cálculo e é dada pela equação seguinte:

$$
f_{b d}=\eta_{1}{ }^{*} \eta_{2}{ }^{*} \eta_{3}{ }^{*} f_{c t d}
$$

Onde $\eta_{1}, \eta_{2}$ e $\eta_{3}$ são coeficientes que levam em consideração a conformação superficial das barras, o posicionamento com relação as regiões de boa e má aderência e o diâmetro das barras ancoradas, respectivamente e seus valores são tomados da seguinte maneira: 
$\eta_{1}=1,0$ para barras lisas;

$\eta_{1}=1,4$ para barras entalhadas;

$\eta_{1}=2,25$ para barras nervuradas;

$\eta_{2}=1,0$ para situações de boa aderência;

$\eta_{2}=0,7$ para situações de má aderência;

$\eta_{3}=1,0$ para $\phi<32 \mathrm{~mm}$;

$\eta_{3}=(132-\phi) / 100$ para $\phi \geq 32 \mathrm{~mm}$.

No caso de apoios extremos, a norma brasileira recomenda que as barras devam ser ancoradas a partir da face do apoio, com comprimentos iguais ou superiores ao maior dos seguintes valores:

- $\ell_{\mathrm{b}}$

$-(r+5,5 \phi)$

- $60 \mathrm{~mm}$.

Onde r é o raio de curvatura da armadura tracionada da viga.

Caso o cobrimento, no plano normal ao gancho, seja maior que $70 \mathrm{~mm}$ e as ações acidentais não ocorram com grande freqüência com seu valor máximo, o primeiro dos três valores pode ser desprezado. 


\section{PROGRAMA EXPERIMENTAL}

\subsection{Introdução}

O programa experimental se dividiu basicamente em três fases: a definição dos modelos a serem ensaiados, as análises das propriedades dos materiais e os ensaios das ligações. Na primeira etapa foram levantadas as possíveis dificuldades e limitações encontradas para a realização do ensaio proposto. Depois foi realizada a análise das propriedades dos materiais por meio de estudo de dosagem para o concreto e ensaio de resistência à tração para as barras das armaduras. Finalmente, foi ensaiado o modelo piloto seguido dos três modelos definitivos.

\subsection{Esquema do ensaio}

O procedimento geral do ensaio da ligação constitui na aplicação de uma força normal no pilar até a intensidade desejada, mantendo-a constante a partir daí, então se aplica uma força na viga até a ruína.

O ensaio foi realizado na posição horizontal, pois segundo Alva (2004) esta posição apresentaria mais vantagens, em especial na montagem e no monitoramento.

$\mathrm{Na}$ posição horizontal, o cilindro hidráulico e o atuador servo-controlado, responsáveis pela aplicação da força normal no pilar e da força concentrada na extremidade da viga, foram suportados por pilares metálicos, aos quais foram conectados barras inclinadas de travamento para reduzir os deslocamentos laterais. Os pilares 
metálicos e as barras de travamento foram fixados na laje de reação, em canaletas dispostas a cada $1,25 \mathrm{~m}$.

A força aplicada na extremidade da viga produz um binário nas duas extremidades do pilar, que garante o equilíbrio global da ligação. As forças de reação correspondentes ao binário são paralelas aos eixos das canaletas (Figura 4.1).

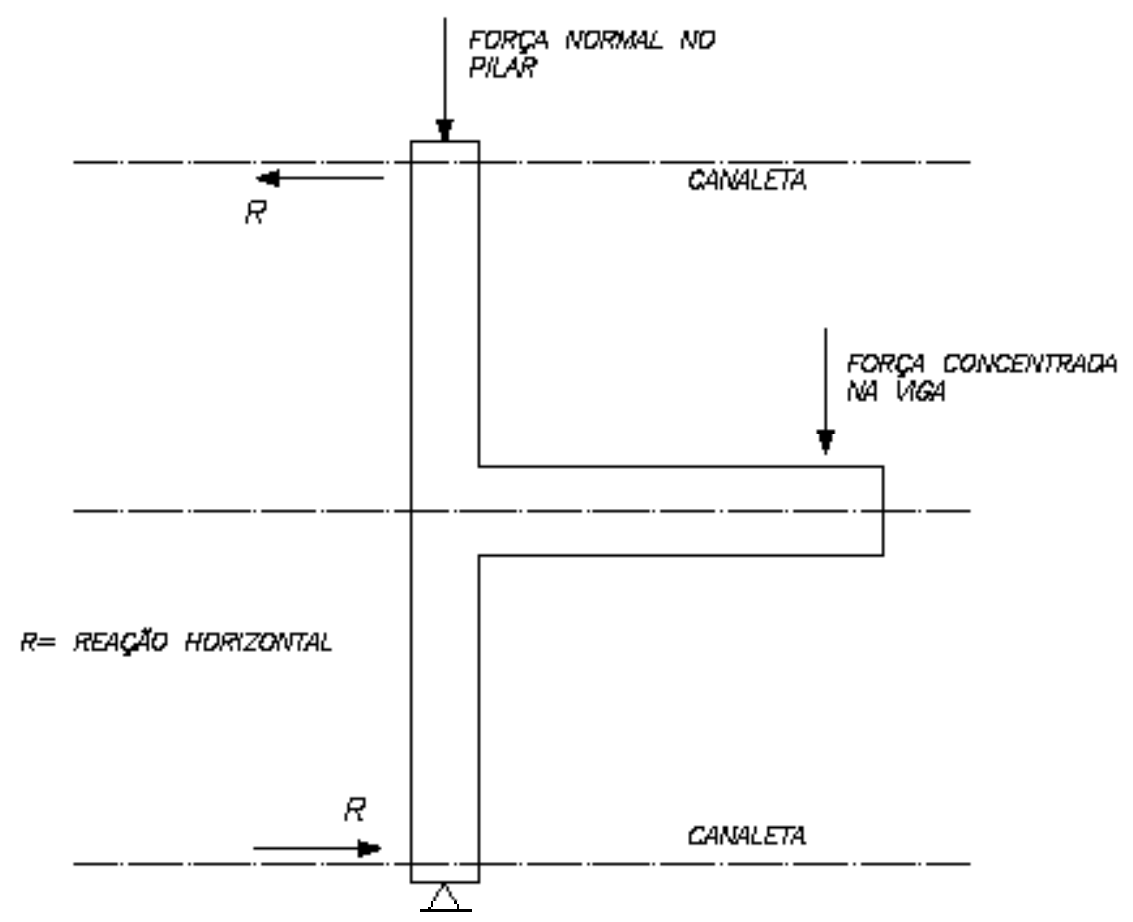

Figura 4.1 - Equilíbrio estático da ligação viga-pilar de extremidade.

Fonte: Alva (2004)

Entretanto, por razões do próprio sistema de fixação dos elementos estruturais na laje de reação, não há restrição aos deslocamentos na direção das canaletas. Por esse motivo, foi utilizado um quadro horizontal auto-equilibrado (Figura 4.6), projetado por Alva (2004), para impedir os deslocamentos ao longo dessas canaletas. As figuras seguintes ilustram o posicionamento detalhado da ligação viga-pilar em relação aos diversos dispositivos e equipamentos. 


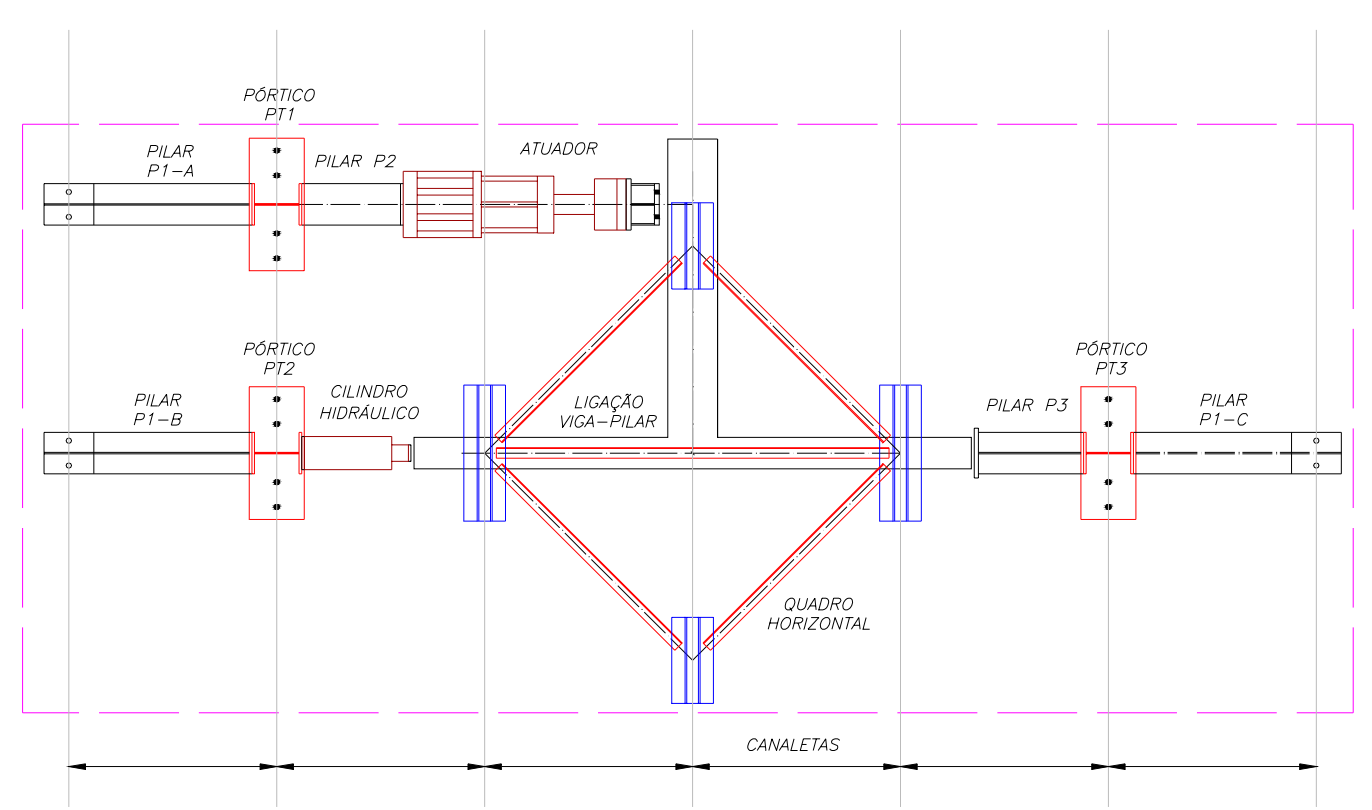

Figura 4.2 - Posicionamento da ligação e dos dispositivos de ensaio (Vista superior).

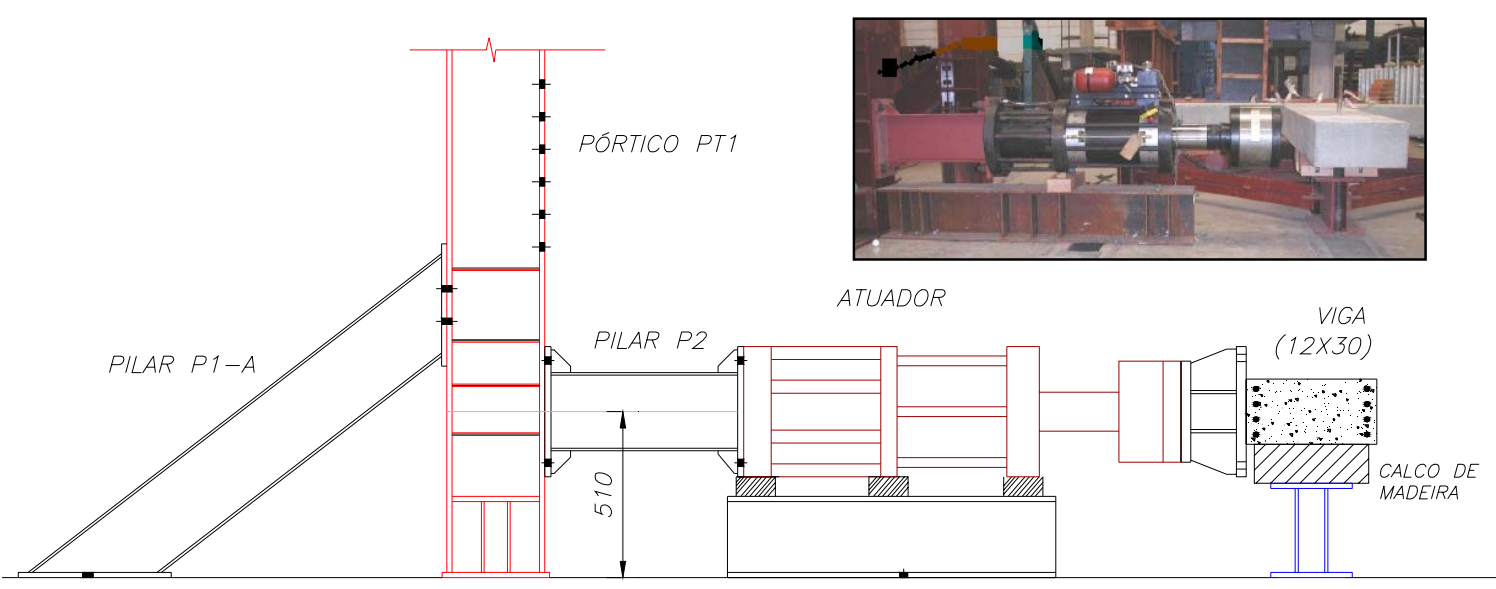

Figura 4.3 - Posicionamento da ligação e dos dispositivos de ensaio: Eixo do Atuador.

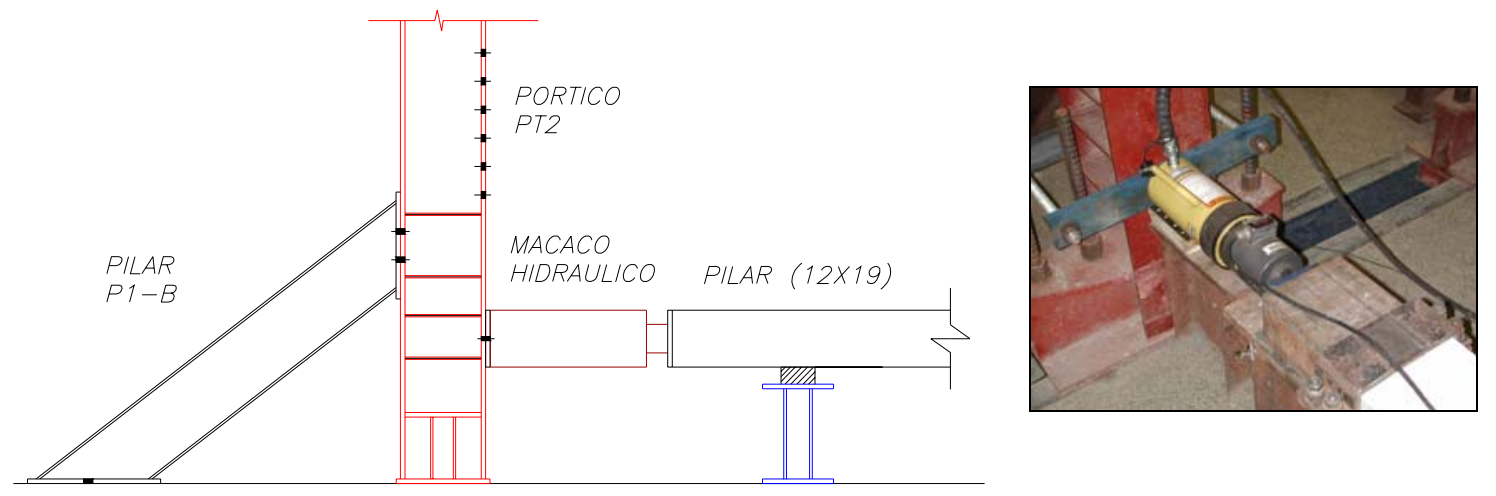

Figura 4.4 - Posicionamento da ligação e dos dispositivos de ensaio: Eixo do cilindro hidráulico (topo do pilar). 


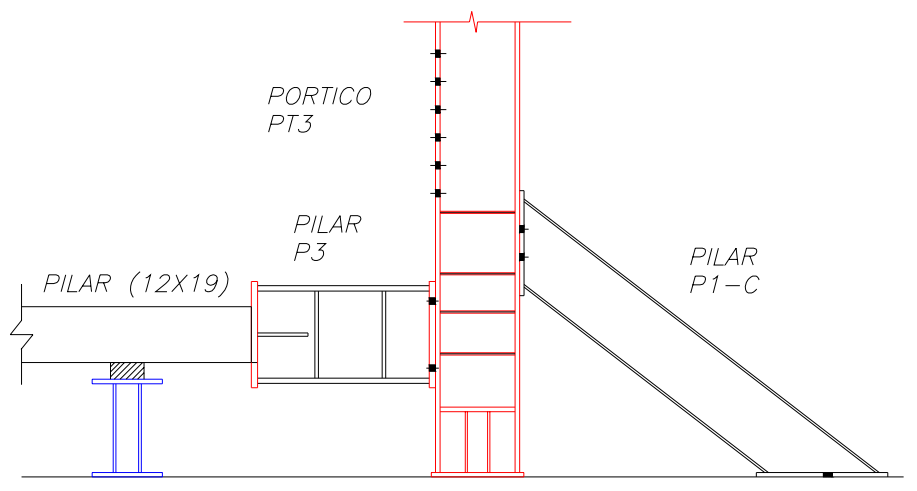

Figura 4.5 - Posicionamento da ligação e dos dispositivos de ensaio: Eixo do cilindro hidráulico (base do pilar).

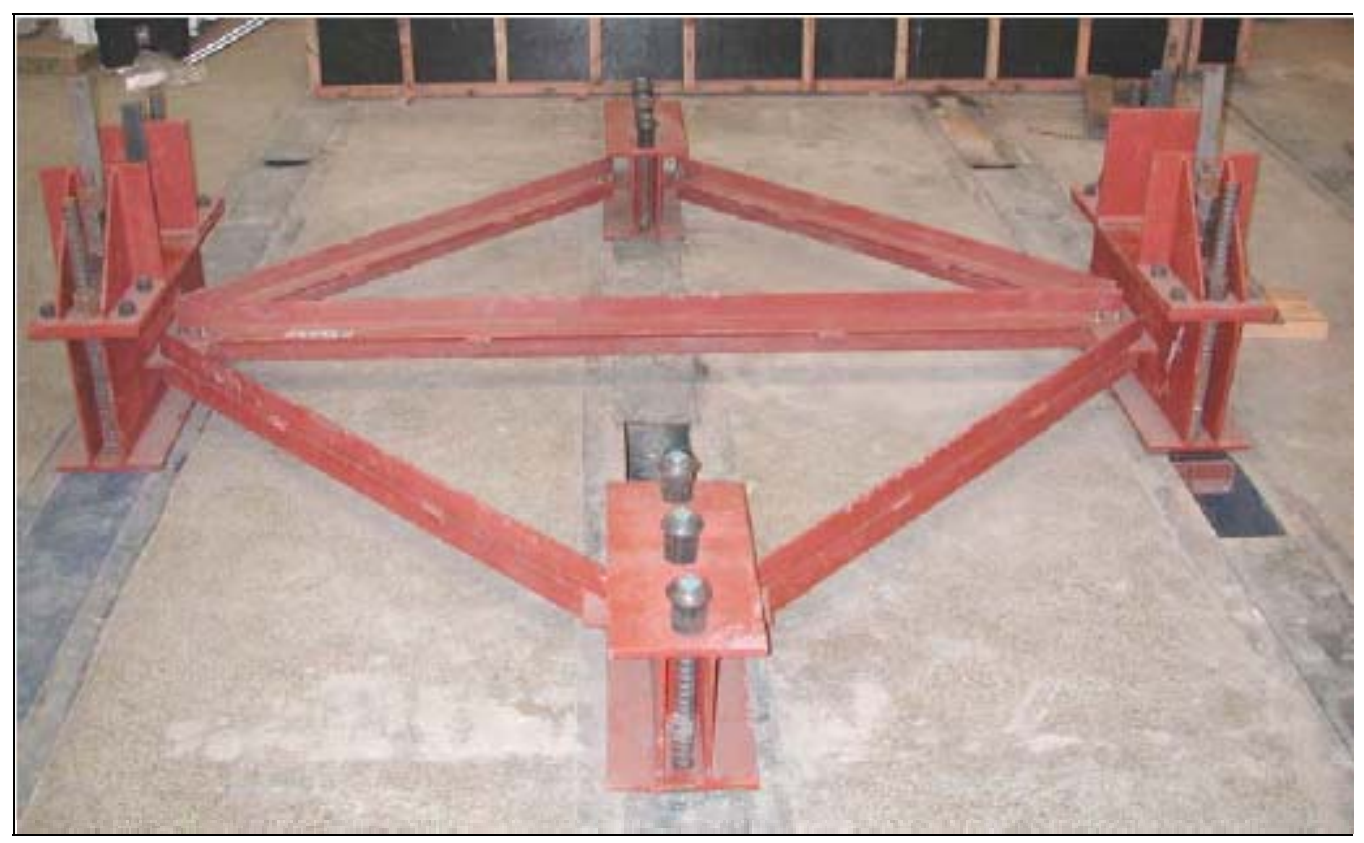

Figura 4.6 - Quadro horizontal auto-equilibrado.

O apoio lateral dos pilares em suas extremidades foi garantido por um dispositivo metálico, semelhante a um pára-choque.

Os equipamentos de aplicação de forças, como o atuador servo-controlado e o macaco hidráulico foram fixados em pilares metálicos. Barras inclinadas foram conectadas a esses pilares para o travamento na direção de aplicação da força (Figura 4.7). 


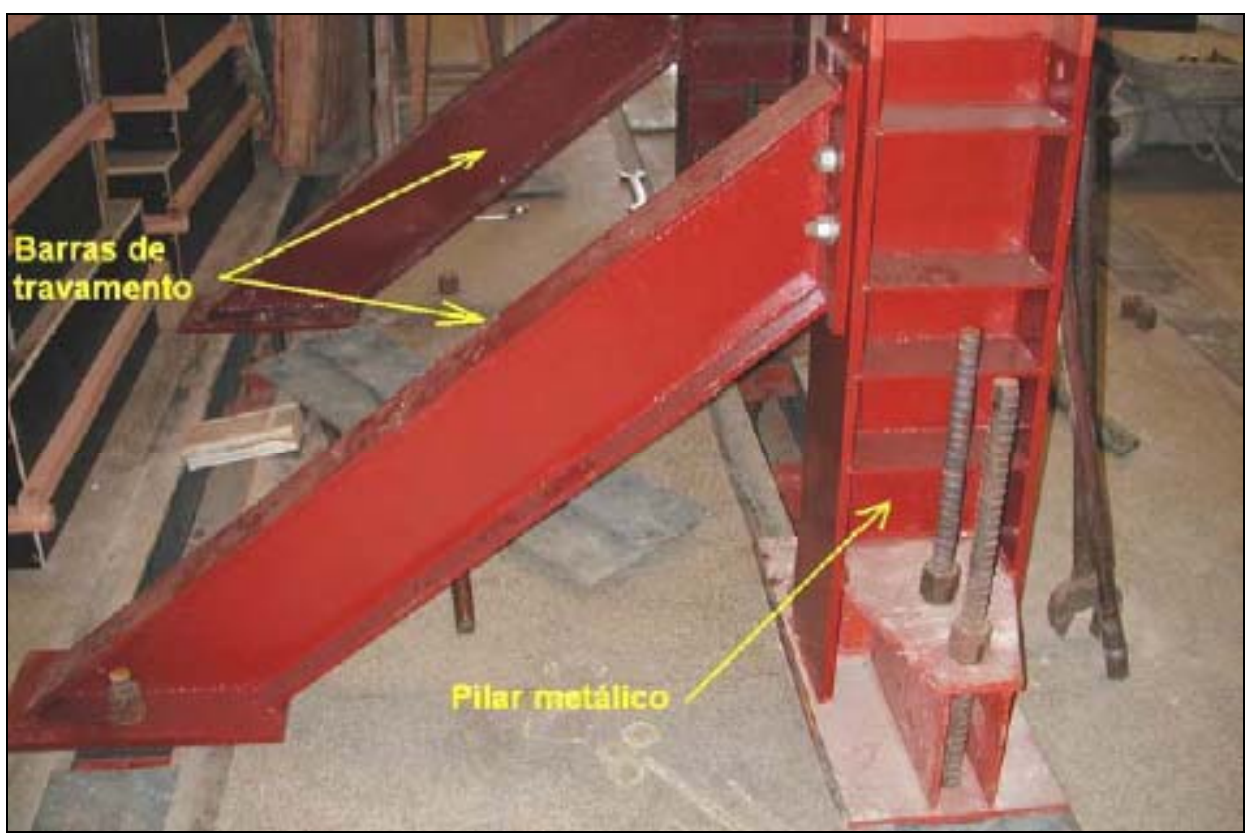

Figura 4.7 - Pilar metálico para fixação do equipamento e as barras inclinadas de travamento.

\subsection{Definição dos modelos}

A força normal aplicada em pilares é usualmente definida de maneira adimensional (equação ( 4.1 )). Observou-se na literatura que a maioria dos estudos realizados, com nós de pórtico externo, envolvendo aplicação de força normal no pilar, utilizaram valores entre 0,1 e 0,4. Contudo, na prática é comum se encontrar pilares com valores de força normal superiores a unidade. O grande problema encontrado na representação experimental destas ligações é a limitação quanto a capacidade resistente dos equipamentos disponíveis para a realização dos ensaios.

$v=\frac{N}{A_{g}{ }^{*} f_{c}}$

Como a principal variável a ser analisada nesta pesquisa é a força normal aplicada no pilar, foi necessário verificar a capacidade de carga do pórtico de reação. Para esta verificação foi utilizada a seguinte configuração para o pórtico de reação: 


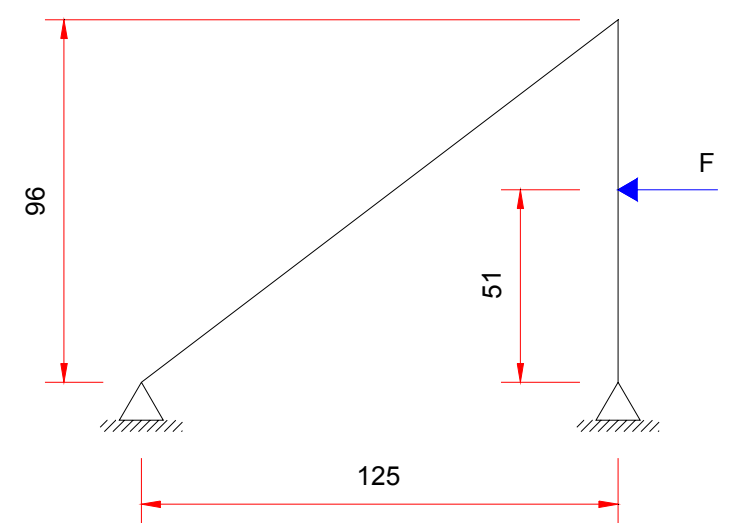

Figura 4.8 - Configuração do pórtico de reação (Figura 4.7) para verificação da capacidade de suporte.

A variável limitante do valor de $F$ foi a força cortante no pilar metálico do pórtico de reação. Desta forma, ficou definido que $450 \mathrm{kN}$ é a máxima força normal que se poderá aplicar no pilar dos modelos a serem ensaiados. Adotou-se como $50 \mathrm{kN}$ a máxima força a ser aplicada na viga, sendo assim a força a normal no topo do pilar ficou limitada a $400 \mathrm{kN}$.

A NBR 6118:2003 considera concretos com resistência à compressão variando de $20 \mathrm{MPa}$ à $50 \mathrm{MPa}$, admitindo a resistência de $15 \mathrm{MPa}$ apenas para utilização em fundações. Nesta pesquisa, como se pretende alcançar um valor alto para a força normal, foi escolhida a classe C20 para o concreto a ser utilizado nas ligações.

Com a força normal máxima a ser aplicada no pilar e com a resistência à compressão do concreto definidas, a área da seção do pilar é a única variável que pode ser modificada para se conseguir definir altos valores para $v$ na ligação.

A norma brasileira limita a dimensão dos pilares em $19 \mathrm{~cm}$, permitindo em casos especiais a consideração de dimensões entre $19 \mathrm{~cm}$ e $12 \mathrm{~cm}$ desde que as ações a serem consideradas no dimensionamento sejam multiplicadas por um coeficiente adicional, porém em qualquer caso, não se permite pilar com seção transversal de área inferior a $360 \mathrm{~cm}^{2}$. Seguindo as recomendações da norma a máxima força normal que se conseguiria aplicar nesta pesquisa seria de 0,55. Como o objetivo deste trabalho é analisar a influência da força normal nos nós externos, optou-se por uma seção transversal em desacordo com as recomendações da norma para a seção mínima do pilar, para se poder avaliar valores mais altos de força normal. Desta forma, foram definidos 3 modelos de ensaio $(v=0,50 ; 0,65 ; 0,87)$ mais o modelo piloto $(v=0,9)$. 


\subsubsection{Propriedades geométricas dos modelos}

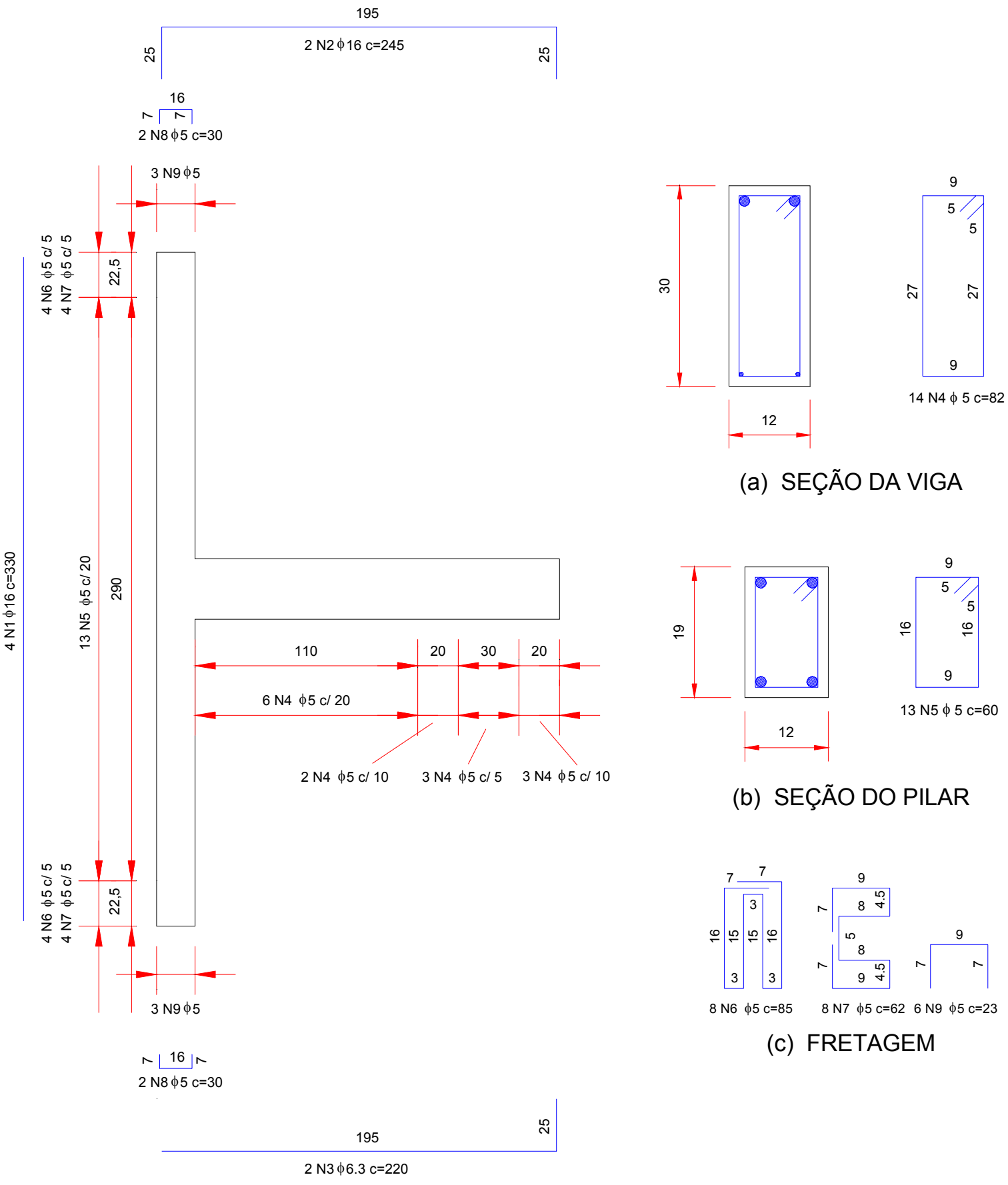

(a) EM PLANTA

Figura 4.9 - Propriedades geométricas dos modelos a serem ensaiados. 


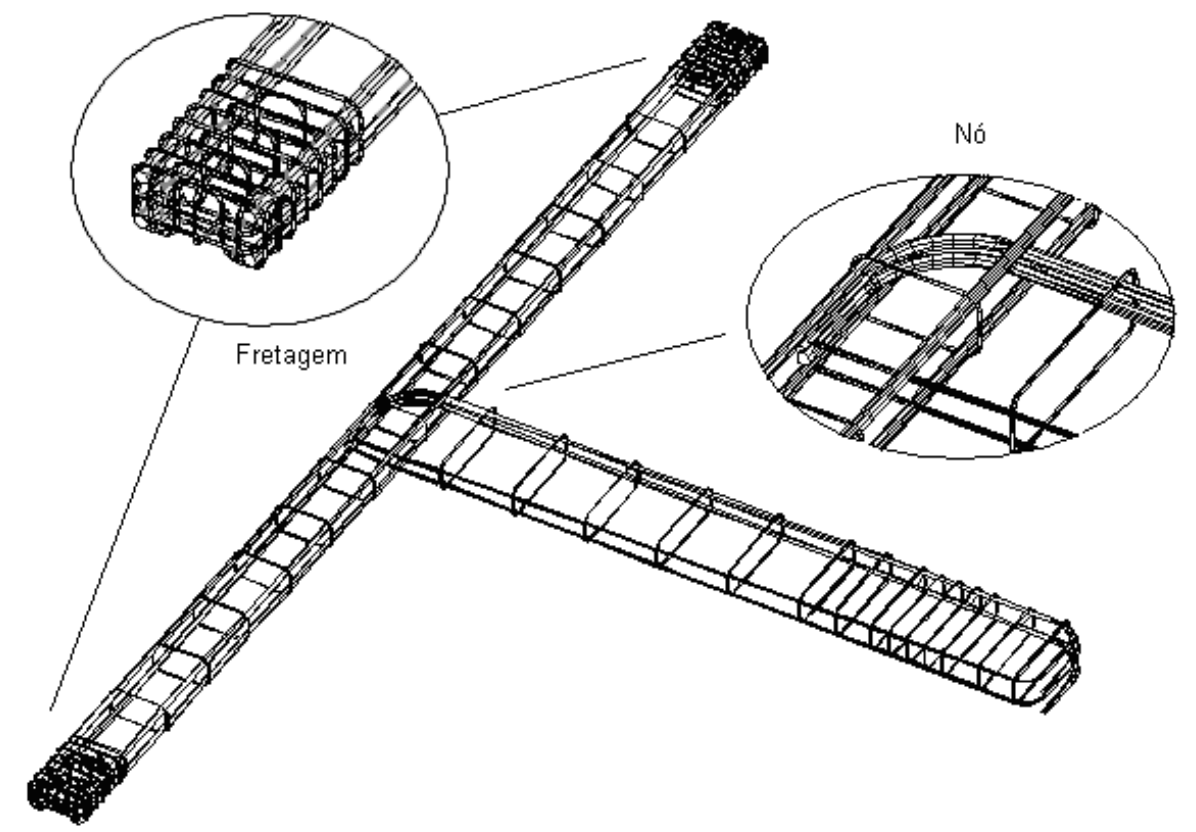

Figura 4.10 - Detalhe das armaduras do modelo.

\subsubsection{Instabilidade dos modelos}

Como os modelos ensaiados eram muito esbeltos na direção normal ao plano do ensaio, apresentando um índice de esbeltez igual a 96, foram utilizados apoios auxiliares para se diminuir o comprimento de flambagem da peça nesta direção. Para o ensaio piloto utilizou-se um par de tirantes (Figura 4.12) conseguindo com isto uma redução de $45 \%$ no índice de esbeltez.
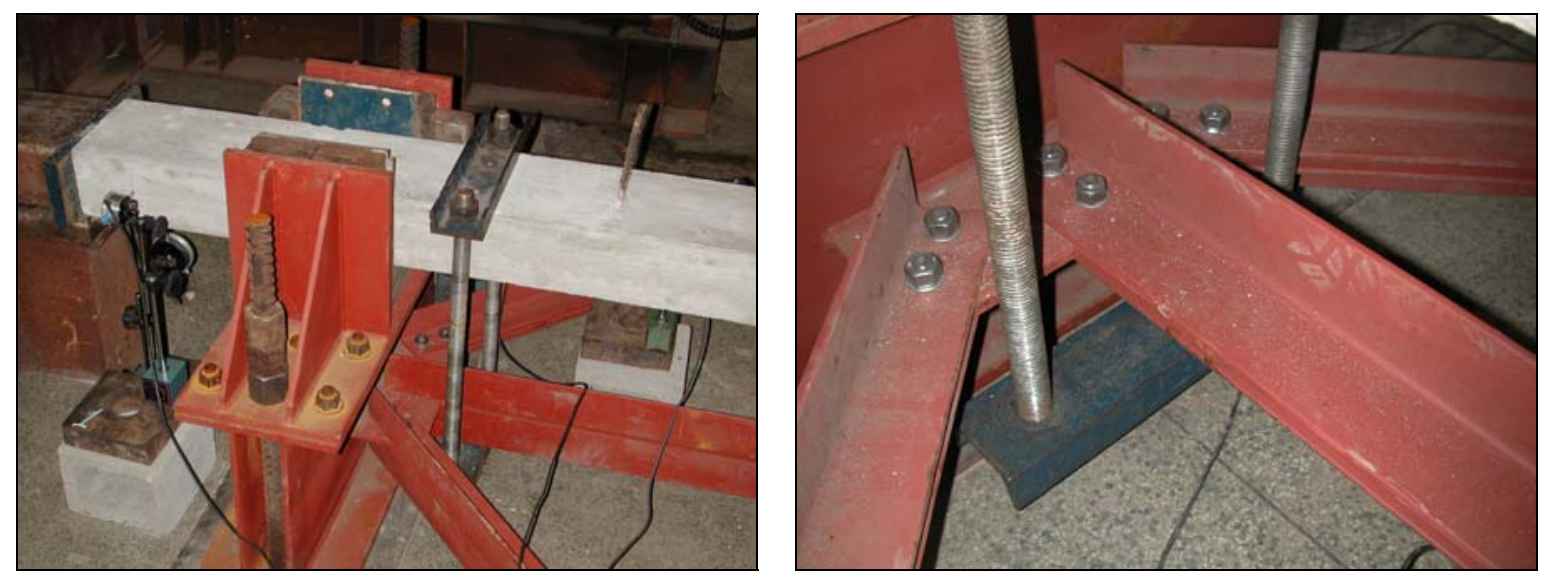

Figura 4.11 - Posição de fixação dos tirantes. 
Estes tirantes foram fixados no modelo com a utilização de dois perfis metálicos. Um dos perfis foi colocado na superfície superior do modelo e o outro foi apoiado nas cantoneiras, pertencentes ao quadro horizontal auto-equilibrado, posicionadas abaixo do modelo (Figura 4.11).
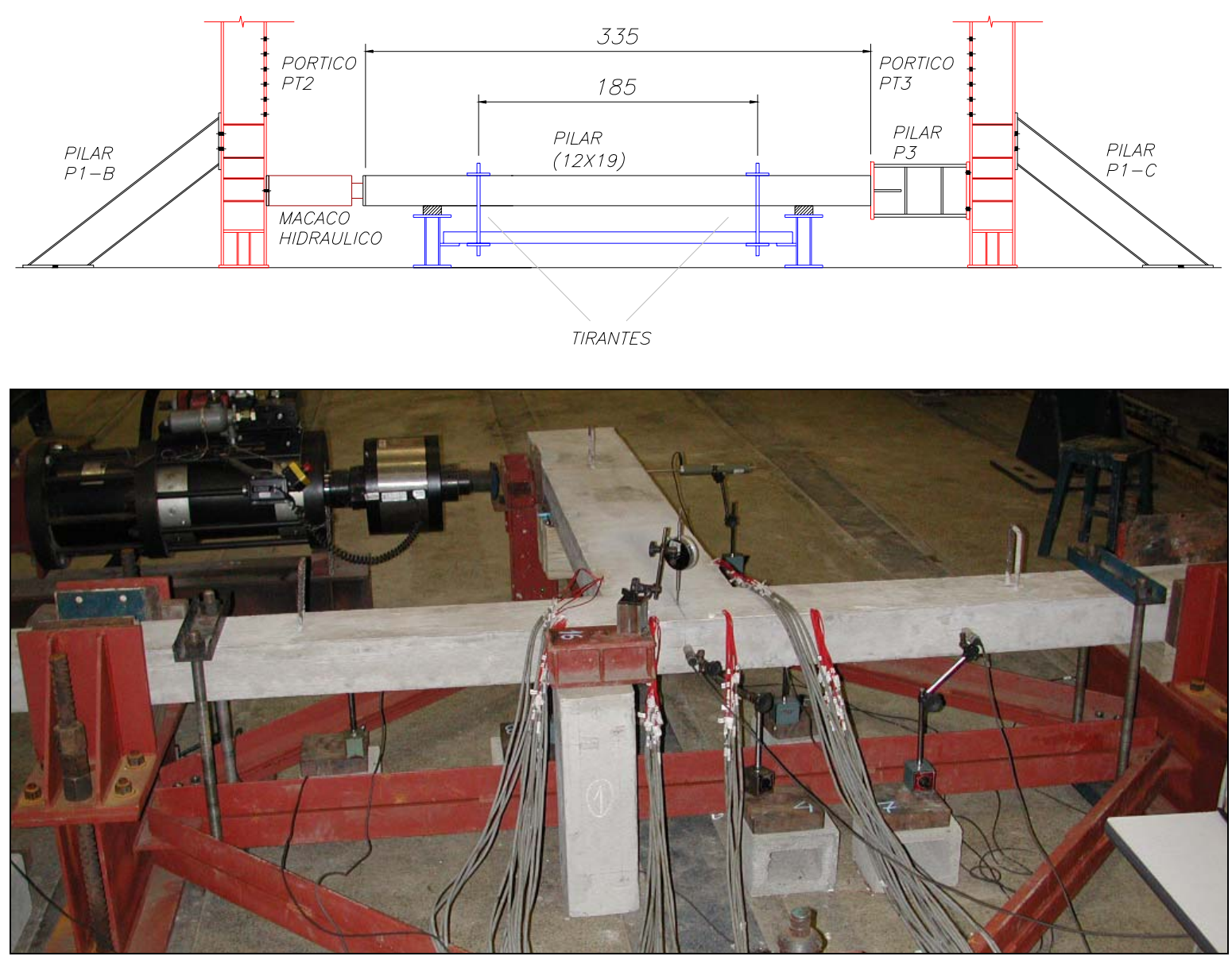

Figura 4.12 - Tirantes utilizados para a redução do índice de esbeltez da peça (Ensaio Piloto).

Porém verificou-se que mesmo com a utilização de dois tirantes, o esforço de segunda ordem, gerado na ligação, possuía uma relevante influência no comportamento do modelo, levando-o à ruptura por causa da flexão oblíqua. Conseqüentemente, para os ensaios definitivos foram adicionados mais dois tirantes e dois calços no esquema de ensaio (Figura 4.13), reduzindo o índice de esbeltez máximo para $25 \%$ do valor inicial. 

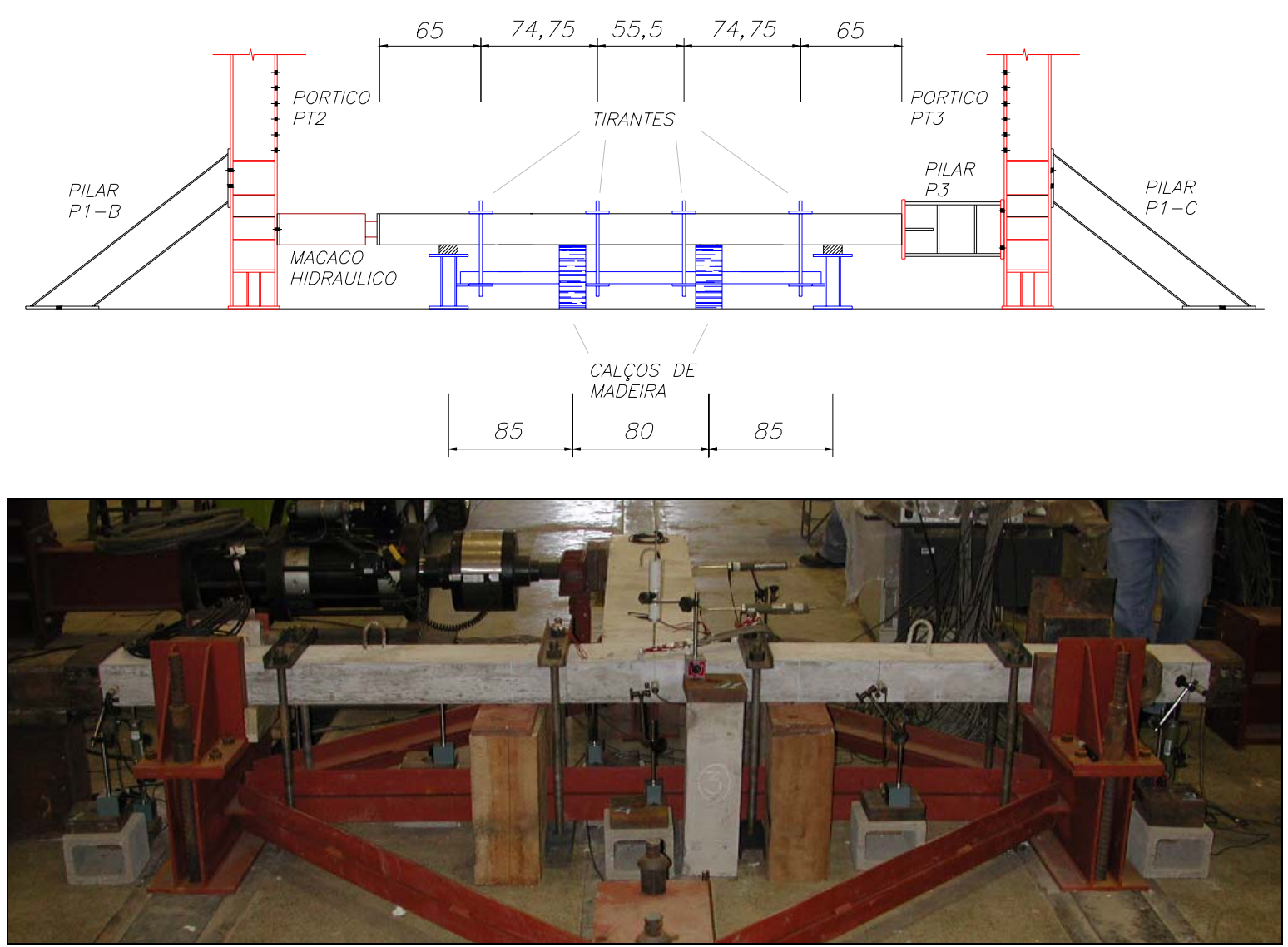

Figura 4.13 - Apoios utilizados para a redução do índice de esbeltez da peça (Ensaio Definitivo).

Além dos apoios auxiliares apresentados acima, nos ensaios definitivos, foram utilizadas rótulas nos pontos de aplicação de força com a intenção de reduzir ainda mais os esforços de segunda ordem (Figura 4.14).
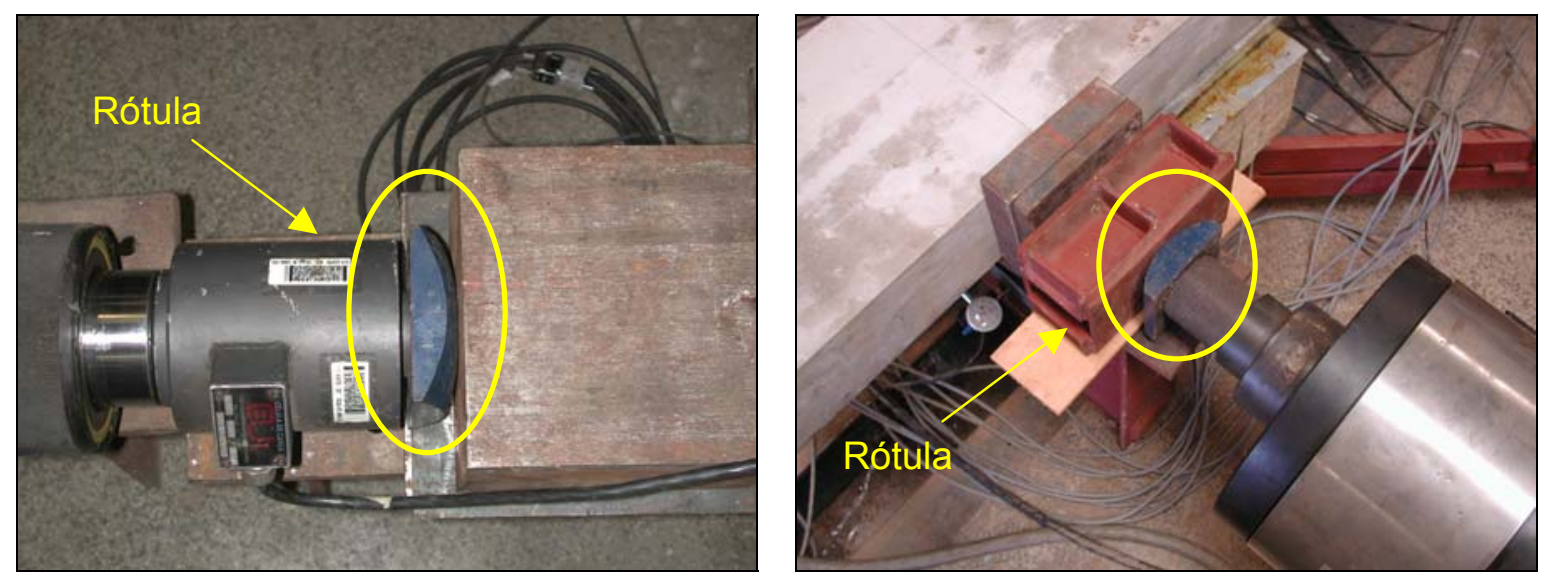

Figura 4.14 - Rótulas utilizadas nos pontos de aplicação de força. 


\subsection{Análise das propriedades do concreto}

Como explicado anteriormente, a resistência à compressão do concreto é de fundamental importância para que se consigam as forças normais esperadas na ligação. Assim sendo, para se ter melhor controle da resistência do concreto no ensaio, optou-se por fazer um estudo de dosagem, com os materiais disponíveis. Este estudo está detalhado no Apêndice A. Desta forma, as propriedades definidas para o concreto utilizado nos modelos estão apresentadas na Tabela 4.1.

Inicialmente, pretendia-se ensaiar os modelos com a idade de 28 dias, porém por causa da disponibilidade de um período no laboratório, decidiu-se ensaiar os modelos com a idade de 9 dias, já que havia sido feito o estudo de dosagem e por isso não haveria maiores problemas na modificação do traço.

Tabela 4.1 - Propriedades do concreto fresco.

\begin{tabular}{|c|c|}
\hline \multicolumn{1}{|c|}{ Traço } & $1: 3,25: 3,21$ \\
\hline Abatimento do tronco de cone $(\mathrm{mm})$ & $80 \pm 10$ \\
\hline Consumo de cimento $\left(\mathrm{kg} / \mathrm{m}^{3}\right)$ & 287,42 \\
\hline Relação água cimento & 0,8634 \\
\hline & \\
\hline & \\
\hline & \\
\hline
\end{tabular}

De cada modelo concretado foram moldados oito corpos-de-prova para realizar ensaios de compressão e módulo de elasticidade (quatro corpos-de-prova) e, ensaios de tração diametral (quatro corpos-de-prova) para a definição das propriedades do material. Para o modelo piloto foram moldados apenas quatro corpos-de-prova por causa de erro 
no cálculo do volume de concreto a ser produzido, desta forma foram realizados apenas os ensaios de compressão e módulo de elasticidade. As propriedades referentes ao concreto de cada modelo são apresentadas na Tabela 4.2.

Tabela 4.2 - Propriedades mecânicas do concreto.

\begin{tabular}{|c|c|c|c|c|c|}
\hline Modelo & $N^{0}$ de cps & Idade (dias) & $\overline{f_{c}(\mathrm{MPa})}$ & $E_{c}(\mathrm{MPa})$ & $\mathrm{f}_{\mathrm{t}}(\mathrm{MPa})$ \\
\hline \multirow{4}{*}{ Piloto } & \multirow{4}{*}{4} & \multirow{4}{*}{9} & 17,81 & - & - \\
\hline & & & 19,71 & 22485,30 & - \\
\hline & & & 19,98 & 22762,20 & - \\
\hline & & & 19,47 & 22044,50 & - \\
\hline \multirow{4}{*}{ N400 } & \multirow{4}{*}{8} & \multirow{4}{*}{9} & 22,36 & $\overline{-}$ & 1,587 \\
\hline & & & 22,09 & - & 1,731 \\
\hline & & & 20,82 & 22104,80 & 1,915 \\
\hline & & & 16,86 & 25464,70 & 1,680 \\
\hline \multirow{4}{*}{ N300 } & \multirow{4}{*}{8} & \multirow{4}{*}{8} & 20,05 & - & 1,270 \\
\hline & & & 20,03 & - & 1,840 \\
\hline & & & 20,24 & 25464,70 & 1,854 \\
\hline & & & 21,30 & 25464,70 & 2,004 \\
\hline \multirow{4}{*}{ N200 } & \multirow{4}{*}{8} & \multirow{4}{*}{8} & 21,89 & - & 2,306 \\
\hline & & & 22,68 & - & 2,052 \\
\hline & & & 21,40 & 25464,70 & 1,882 \\
\hline & & & 21,49 & 25464,70 & 2,464 \\
\hline
\end{tabular}

No dia do ensaio, pouco antes de sua realização, era feito o ensaio à compressão simples, sem medição das deformações para o cálculo de módulo de elasticidade, para definir a força normal que iria ser aplicada para se atingir o valor adimensional especificado. No modelo piloto foi ensaiado apenas um corpo-de-prova antes do ensaio, porém para os outros modelos optou-se por ensaiar dois corpos-de-prova. 


\subsection{Análise das propriedades das armaduras}

Foram realizados ensaios de tração em corpos-de-prova das barras das armaduras a serem utilizadas nos modelos, para os diâmetros de 16,0 mm, 6,3 mm e 5,0 $\mathrm{mm}$, com o objetivo de se conhecer seus diagramas tensão vs. deformação. Para cada diâmetro ensaiou-se 2 corpos-de-prova (Tabela 4.3).

Tabela 4.3 - Propriedades mecânicas das armaduras.

\begin{tabular}{|c|c|c|c|c|c|}
\hline Corpo-de-prova & Diâmetro $(\mathrm{mm})$ & $\mathrm{E}_{\mathrm{s}}(\mathrm{MPa})$ & $\mathrm{f}_{\mathrm{y}}(\mathrm{MPa})$ & $\varepsilon_{\mathrm{y}}(\% \mathrm{o0})$ & $\mathrm{f}_{\mathrm{u}}(\mathrm{MPa})$ \\
\hline CP1 & 5,0 & 205761,32 & 681,00 & 5,31 & 778,00 \\
\hline CP2 & 5,0 & 205761,32 & 688,00 & 5,34 & 734,00 \\
\hline CP3 & 6,3 & 205761,32 & 555,00 & 2,70 & 647,00 \\
\hline CP4 & 6,3 & 205761,32 & 570,00 & 2,77 & 650,00 \\
\hline CP5 & 16,0 & 205761,32 & 510,00 & 2,48 & 657,00 \\
\hline CP6 & 16,0 & 205761,32 & 520,00 & 2,53 & 660,00 \\
\hline
\end{tabular}

\subsection{Moldagem e cura dos modelos}

Os modelos foram moldados em fôrmas de madeira compostas por duas partes separadas: o pilar e a viga (Figura 4.15).

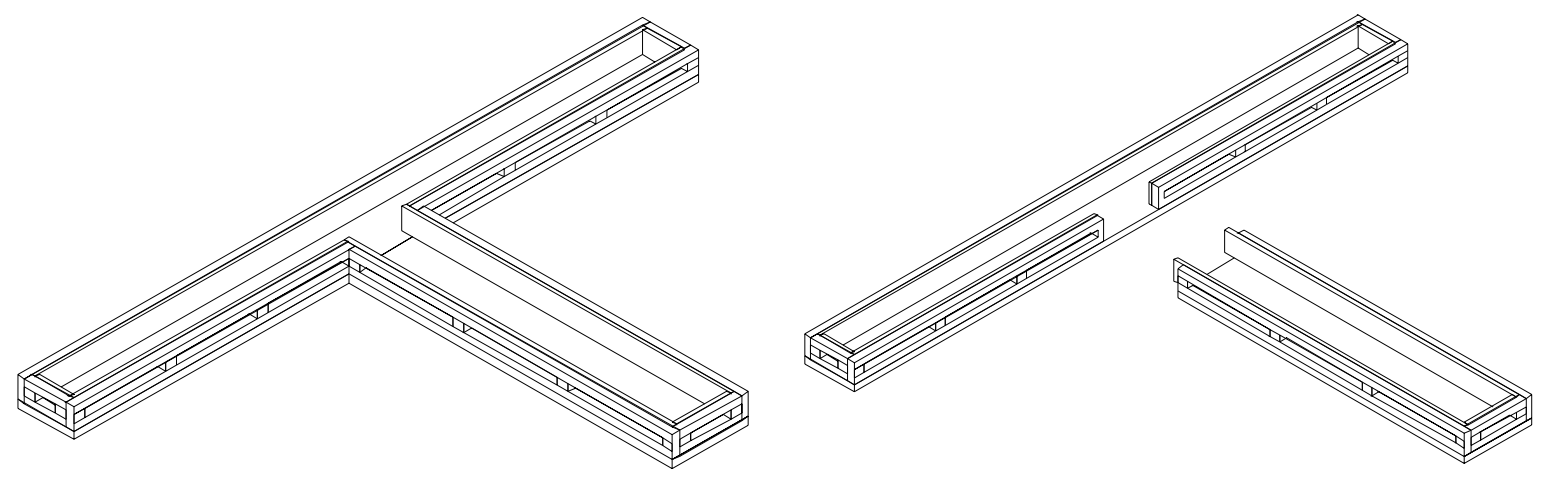

Figura 4.15 - Fôrmas de madeira. 
No modelo piloto notou-se que era necessário um cuidado especial na fixação das duas partes da fôrma. Após a concretagem, observou-se um desvio do eixo da viga em relação ao pilar, isto ocorreu provavelmente por causa de um toque do carrinho de mão na fôrma, e como as partes não estavam devidamente fixadas, elas se deslocaram. Sendo assim, nos modelos seguintes, foram acrescentadas travas na fôrma de maneira a evitar o deslocamento relativo (Figura 4.16).
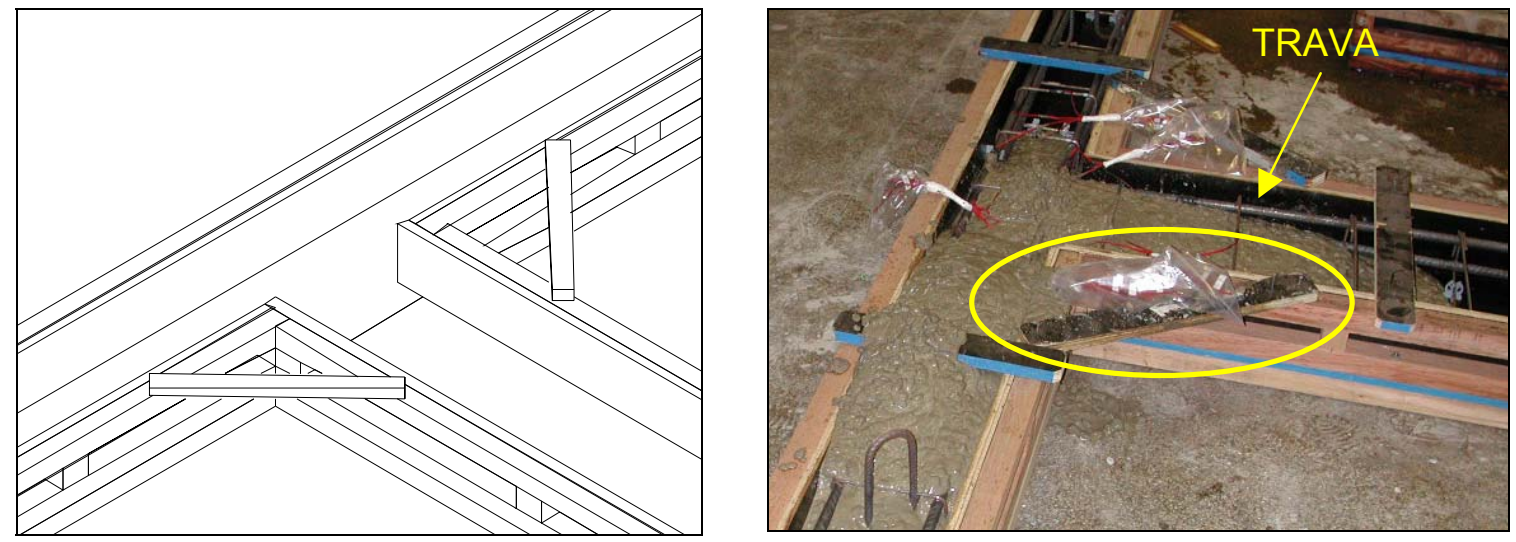

Figura 4.16 - Travas para evitar movimento relativo entre as partes da fôrma.

O processo de cura dos modelos foi feito por meio da permanência de espumas umedecidas na superfície do modelo por três dias (Figura 4.17).
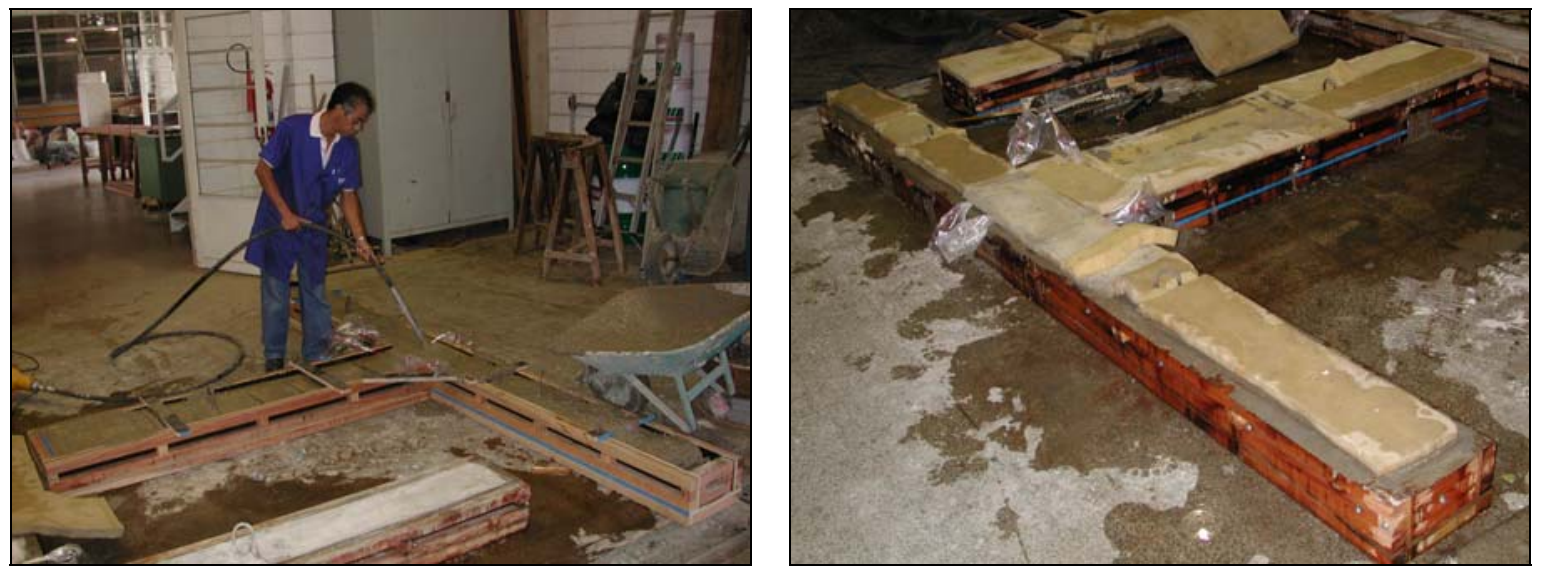

Figura 4.17 - Moldagem e cura dos modelos. 


\subsection{Instrumentação dos modelos}

No modelo piloto foi empregada uma densa instrumentação a fim de se minimizar a utilização desta nos outros modelos. Por causa disto, foram empregados alguns transdutores mecânicos, já que não havia canais suficientes no dispositivo para a aquisição de dados. Nos modelos definitivos, reduziu-se praticamente pela metade o número de extensômetros, conseqüentemente não foram utilizados os transdutores mecânicos.

A Figura 4.18 mostra os transdutores de deslocamento posicionados no plano da ligação viga-pilar. Os transdutores T1 e T9 tiveram a função de monitorar os deslocamentos no topo e na base do pilar. No ensaio piloto não foi utilizado o transdutor T6. Os transdutores T2 e T8 foram utilizados para medir os deslocamentos laterais do pilar. Os transdutores T3 e T5 tiveram a função de medir a rotação da ligação. O transdutor T4 foi empregado para o monitoramento do deslocamento lateral do eixo da viga. Os transdutores T5 e T6 tiveram a função de medir os deslocamentos na viga.

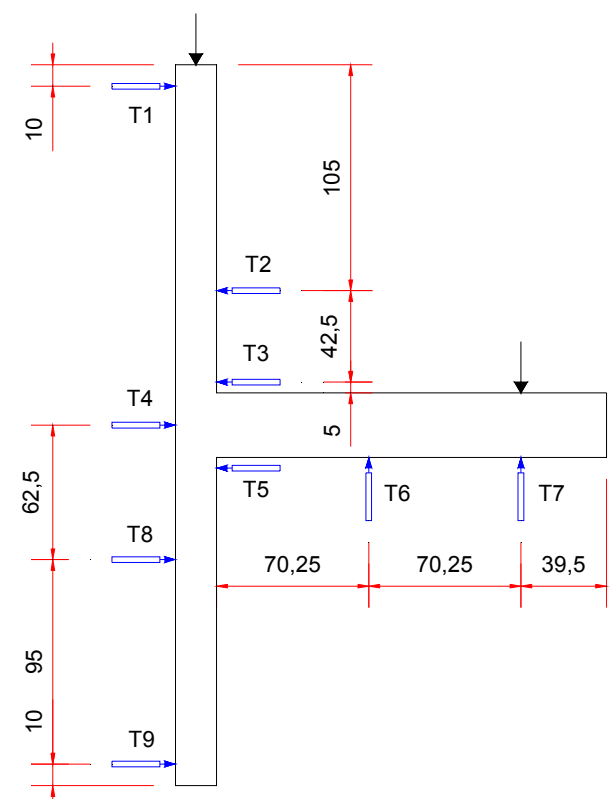

Figura 4.18 - Posicionamento dos transdutores de deslocamentos horizontais na ligação vigapilar. 


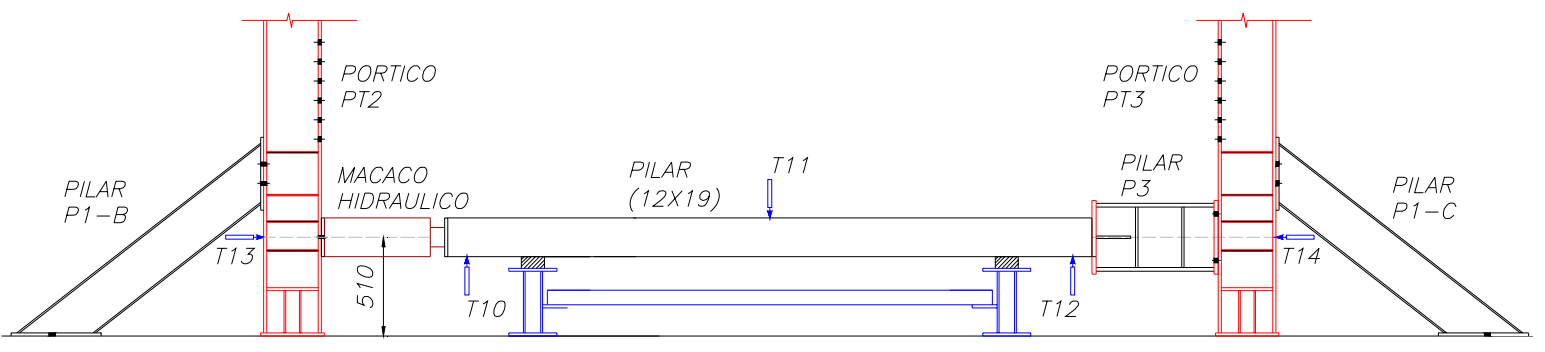

Figura 4.19 - Posicionamento dos transdutores de deslocamentos no pilar do eixo do macaco hidráulico e dos transdutores de deslocamentos verticais na ligação viga-pilar.

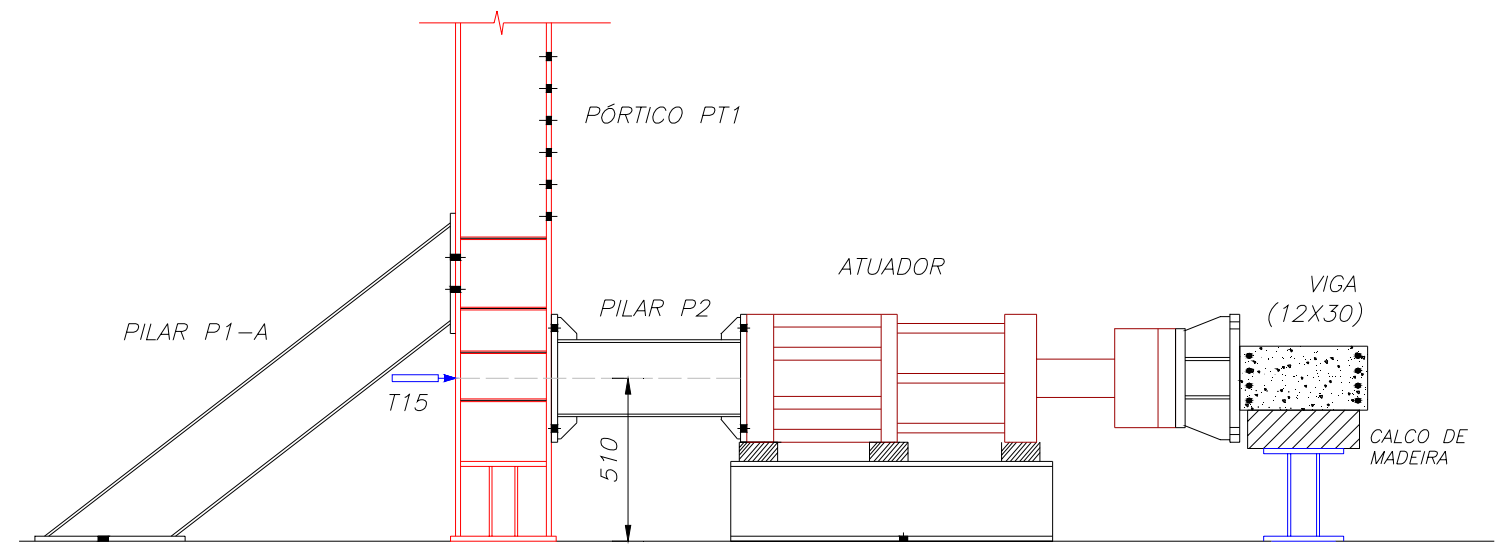

Figura 4.20 - Transdutores posicionados no pilar do eixo do atuador.

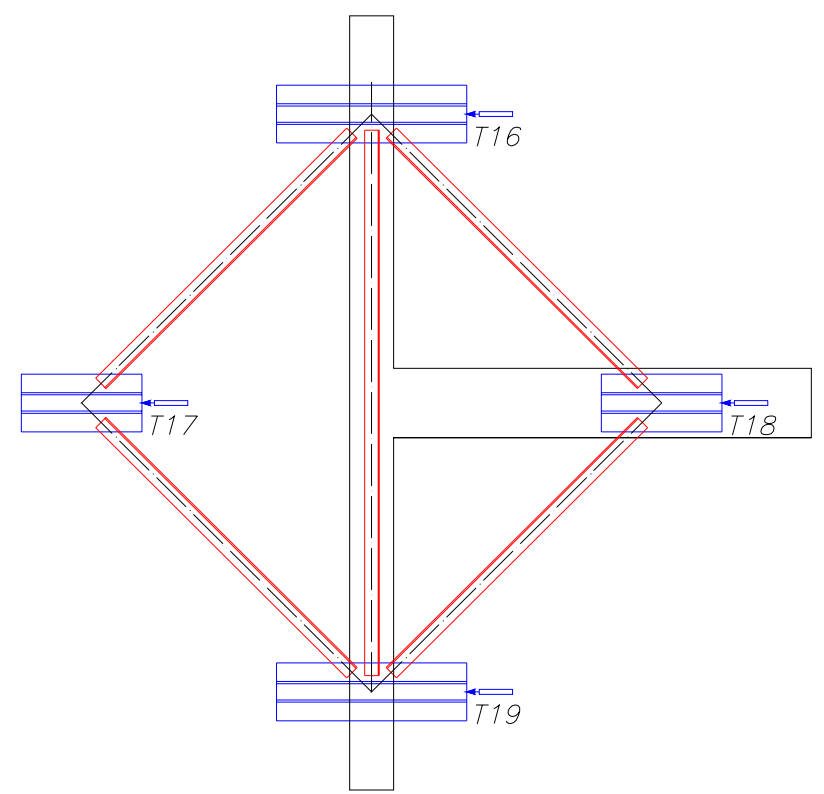

Figura 4.21 - Transdutores posicionados no quadro horizontal. 
Os transdutores T10, T11 e T12 serviram para medir os deslocamentos verticais do pilar, principalmente durante a aplicação da força normal (no modelo piloto utilizou-se transdutores mecânicos nestas posições). O transdutor T11 era retirado antes do início da aplicação da força na viga, pois como estava localizado em uma região que teria intensa fissuração e possível ruptura de concreto, poderia ser danificado.

Os transdutores T13 e T14 foram empregados para o monitoramento dos deslocamentos dos pilares metálicos da estrutura de reação localizados no eixo do macaco hidráulico.

O transdutor T15 monitorou os deslocamentos do pilar metálico localizado no eixo do atuador (no modelo piloto utilizou-se um transdutor mecânico nesta posição). Os transdutores T16 a T19 tiveram a função de monitorar o quadro horizontal.

Para medir as deformações nas barras das armaduras da ligação, foram utilizados extensômetros elétricos de resistência uniaxiais. Todas armaduras principais da viga e do pilar foram instrumentadas. No caso dos estribos, a instrumentação foi feita no estribo do nó e em dois estribos: acima e abaixo do nó e na direção da viga (Figura 4.22).

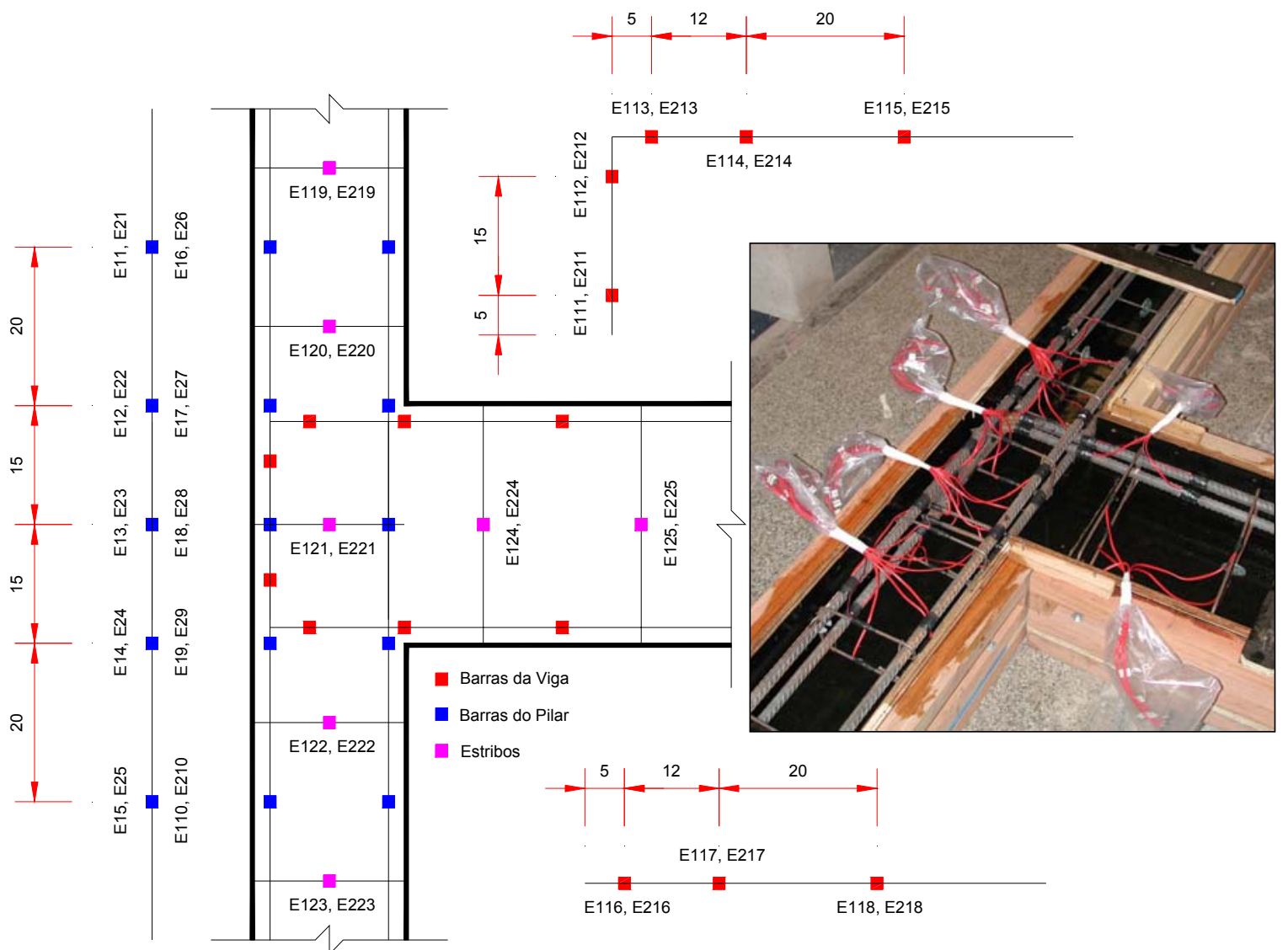

Figura 4.22 - Posicionamento dos extensômetros. 
Os extensômetros foram nomeados segundo a Figura 4.23.

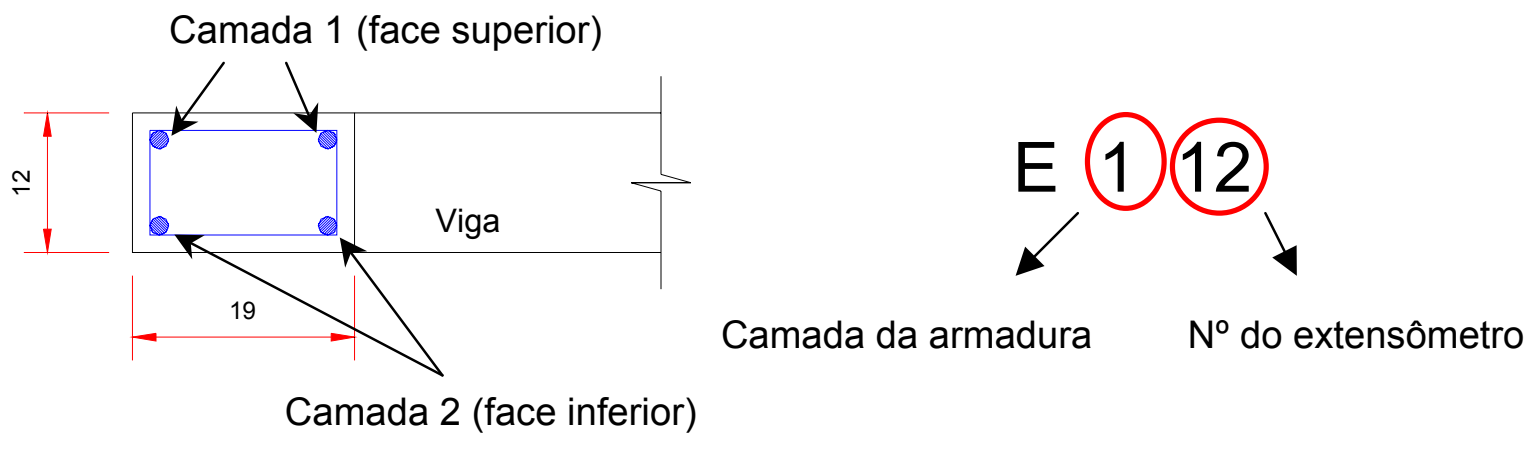

Figura 4.23 - Nomeação dos extensômetros

Nos modelos definitivos a camada 2 apresentou apenas os extensômetros: E23, E28 e E221, referente aos pontos dentro do nó, pois com o enrijecimento dos elementos por meio dos tirantes e apoios auxiliares, teoricamente, as deformações das barras da camada 1 devem ser iguais as da camada 2.

As especificações dos instrumentos de medição utilizados nos ensaios encontram-se na Tabela 4.4.

Tabela 4.4 - Relação dos instrumentos de medição de deslocamentos e deformações.

\begin{tabular}{|c|c|c|c|}
\hline Instrumento & Marca/Modelo/Sensibilidade & $\begin{array}{l}\text { Posição } \\
\text { (Piloto) }\end{array}$ & $\begin{array}{c}\text { Posição } \\
\text { (Definitivos) }\end{array}$ \\
\hline $\begin{array}{l}\text { Transdutor: } \\
\text { Curso de } 10 \mathrm{~mm}\end{array}$ & $\begin{array}{c}\text { KYOWA/DTH-A10 } \\
\text { Sensibilidade: } 0,001 \mathrm{~mm}\end{array}$ & $\begin{array}{c}\text { T1 à T5 } \\
\text { T7 e T8 } \\
\text { T11 à T14 }\end{array}$ & $\begin{array}{c}\text { T1 à T5 } \\
\text { T8 e T9 } \\
\text { T16 à T19 }\end{array}$ \\
\hline $\begin{array}{l}\text { Transdutor: } \\
\text { Curso de } 50 \mathrm{~mm}\end{array}$ & $\begin{array}{c}\text { KYOWA/DT-50A } \\
\text { Sensibilidade: } 0,02 \mathrm{~mm}\end{array}$ & T9 e T10- & T10 à T15 \\
\hline $\begin{array}{c}\text { Transdutor: } \\
\text { Curso de } 100 \mathrm{~mm}\end{array}$ & $\begin{array}{c}\text { KYOWA/DT-50A } \\
\text { Sensibilidade: } 0,03 \mathrm{~mm}\end{array}$ & T6 & T6 e T7 \\
\hline $\begin{array}{l}\text { Transdutor Mecânico: } \\
\text { Curso de } 50 \text { mm }\end{array}$ & $\begin{array}{c}\text { MITUTOYO/3058E } \\
\text { Sensibilidade: } 0,01 \mathrm{~mm}\end{array}$ & T15 à T18 & - \\
\hline Extensômetros elétricos & $\begin{array}{c}\text { KYOWA/KFG-5-120-C1-11 } \\
\text { Sensibilidade: } 1 \mu \varepsilon\end{array}$ & $\begin{array}{l}\text { Todas as } \\
\text { armaduras }\end{array}$ & $\begin{array}{c}\text { Todas as } \\
\text { armaduras }\end{array}$ \\
\hline
\end{tabular}




\section{COMPORTAMENTO DOS MODELOS E ANÁLISE DOS RESULTADOS}

\subsection{Introdução}

O ensaio de cada modelo se dividiu basicamente em três etapas. Inicialmente era realizado escorvamento do pilar, ou seja, uma força da ordem de $10 \%$ da carga última da peça era aplicada com o objetivo de acomodar a estrutura reduzindo as folgas existentes entre o modelo e a estrutura de reação. Após esta etapa, era iniciada a aplicação da força normal no pilar. Ao atingir o valor especificado iniciava-se o carregamento da viga.

Na proximidade da ruína a estrutura acomodava, ou seja, não se conseguia mais aumentar o valor da força aplicada na viga. Esta força permanecia constante e as deformações aumentavam rapidamente. O ensaio era paralisado quando a força começava a decrescer.

\subsection{Ensaio do Modelo Piloto}

Anteriormente à execução do ensaio da ligação, realizou-se o ensaio de compressão simples em um dos corpos-de-prova moldados. Apesar da resistência do concreto ter resultado ligeiramente inferior ao esperado, decidiu-se aplicar a força normal de $400 \mathrm{kN}(v=0,9)$.

O ensaio iniciou com o escorvamento do modelo, após esta etapa o pilar começou a ser carregado, controlando-se os deslocamentos e fazendo medições nos transdutores 
mecânicos a cada 50 kN. Ao atingir 200 kN observou-se um vazamento na mangueira do atuador que aplicava a força no pilar, desta forma o pilar teve de ser descarregado, para a troca da mangueira. Resolvido o problema, iniciou-se o carregamento do pilar, fazendo-se o mesmo controle de deslocamentos anterior. Ao se atingir a carga de $300 \mathrm{kN}$, a extremidade do pilar contrária à aplicação da força teve o concreto esmagado, ocorrendo a ruptura de praticamente todo o cobrimento da região da fretagem (Figura 5.1). Isto se deu provavelmente por causa da utilização de uma almofada de neoprene na região. Como a almofada não foi dimensionada, sua deformação foi acentuada, causando uma concentração de tensões nos cantos da seção. Esta conclusão se dá pelo fato de nada ter acontecido com a outra extremidade do pilar que não possuía a almofada. Conseqüentemente o pilar teve de ser descarregado.
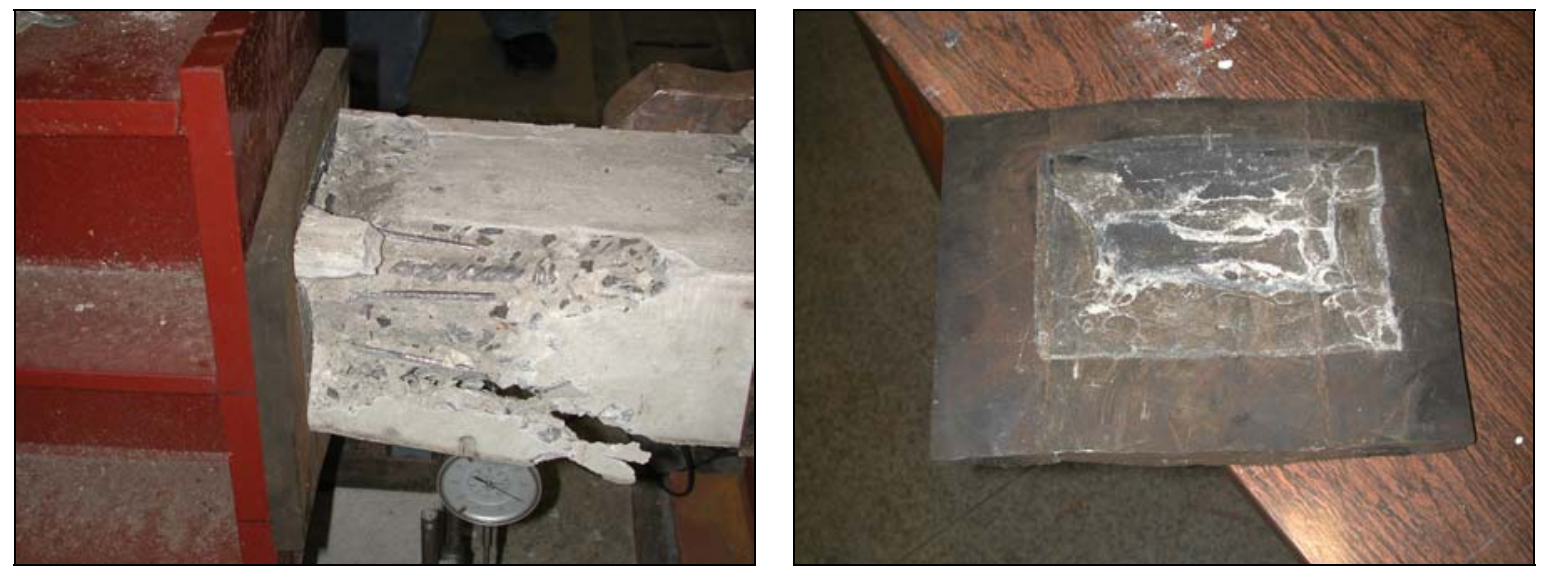

Figura 5.1 - Ruptura da extremidade do pilar por concentração de tensões.

Como o dano foi concentrado apenas na extremidade do pilar, o restante do elemento estava íntegro, então foi raspado o concreto danificado para aumentar a região de contato e colocado uma camisa metálica na extremidade danificada (Figura 5.2). Nos modelos definitivos, para evitar a ocorrência deste problema, decidiu-se não utilizar o neoprene, apoiando o pilar diretamente sobre a placa metálica da estrutura de reação e, optou-se pelo emprego das camisas metálicas nas duas extremidades do pilar.

Após estes procedimentos o pilar foi novamente carregado, ao atingir 250 kN ocorreu uma acomodação da região onde foi realizado o reforço (a carga caiu à $200 \mathrm{kN}$ ), porém decidiu-se continuar a aplicação da força até atingir o valor de esperado $400 \mathrm{kN}$. 

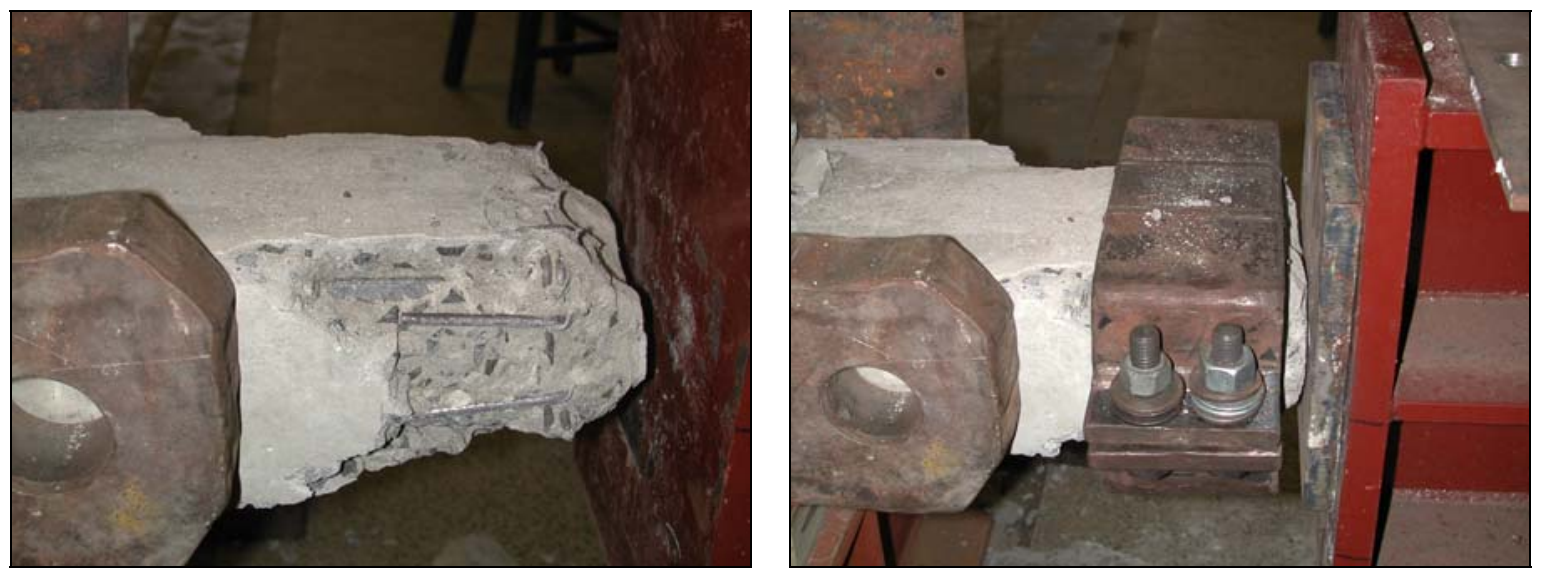

Figura 5.2 - Correção da superfície da extremidade do pilar e reforço com camisa metálica.

Ao fim desta etapa, foi observada uma grande flecha no pilar, da ordem de 6,5 $\mathrm{mm}$ e as deformações das barras do pilar, em uma mesma seção, apresentavam uma grande diferença $(\Delta \varepsilon \approx 0,7 \%$, Figura 5.3 ), indicando o surgimento de esforços de flexão nas duas direções da seção do pilar.
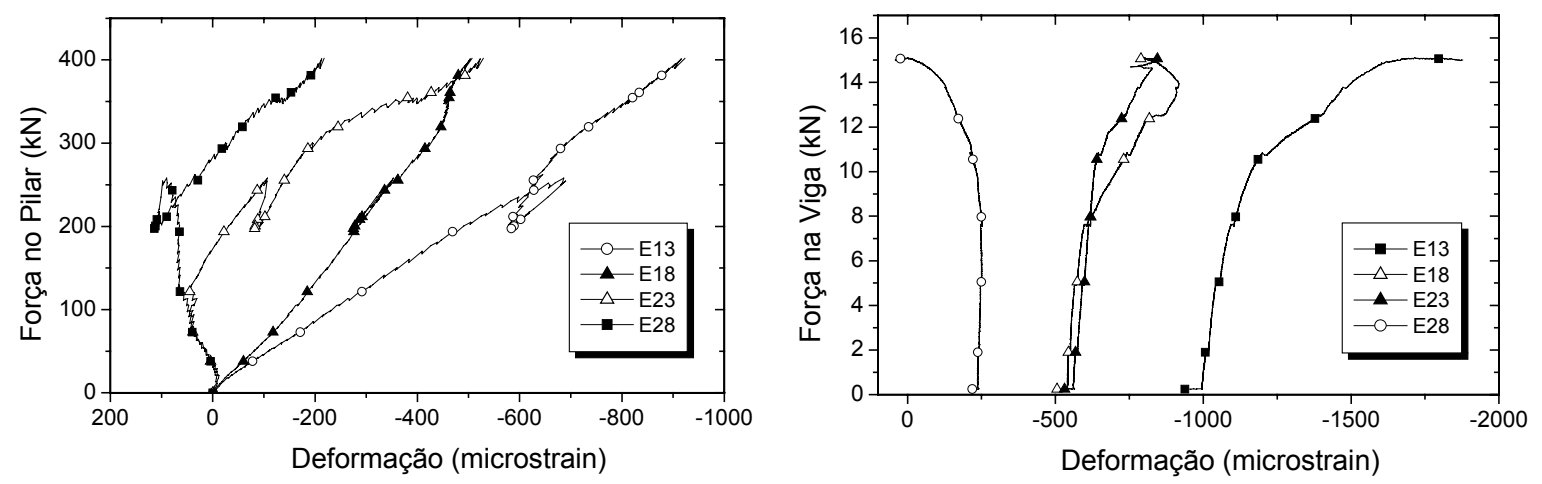

Figura 5.3 - Deformações da armadura longitudinal do pilar na região nodal (Modelo Piloto).

Seguindo a seqüência dos procedimentos do ensaio, iniciou-se o carregamento da viga. Com a força de $12 \mathrm{kN}$ sendo aplicada no balanço o modelo começou a fissurar na interface viga-pilar e na região das barras do pilar de maneira muito rápida atingindo a ruptura aos $15 \mathrm{kN}$ (Figura 5.4). 

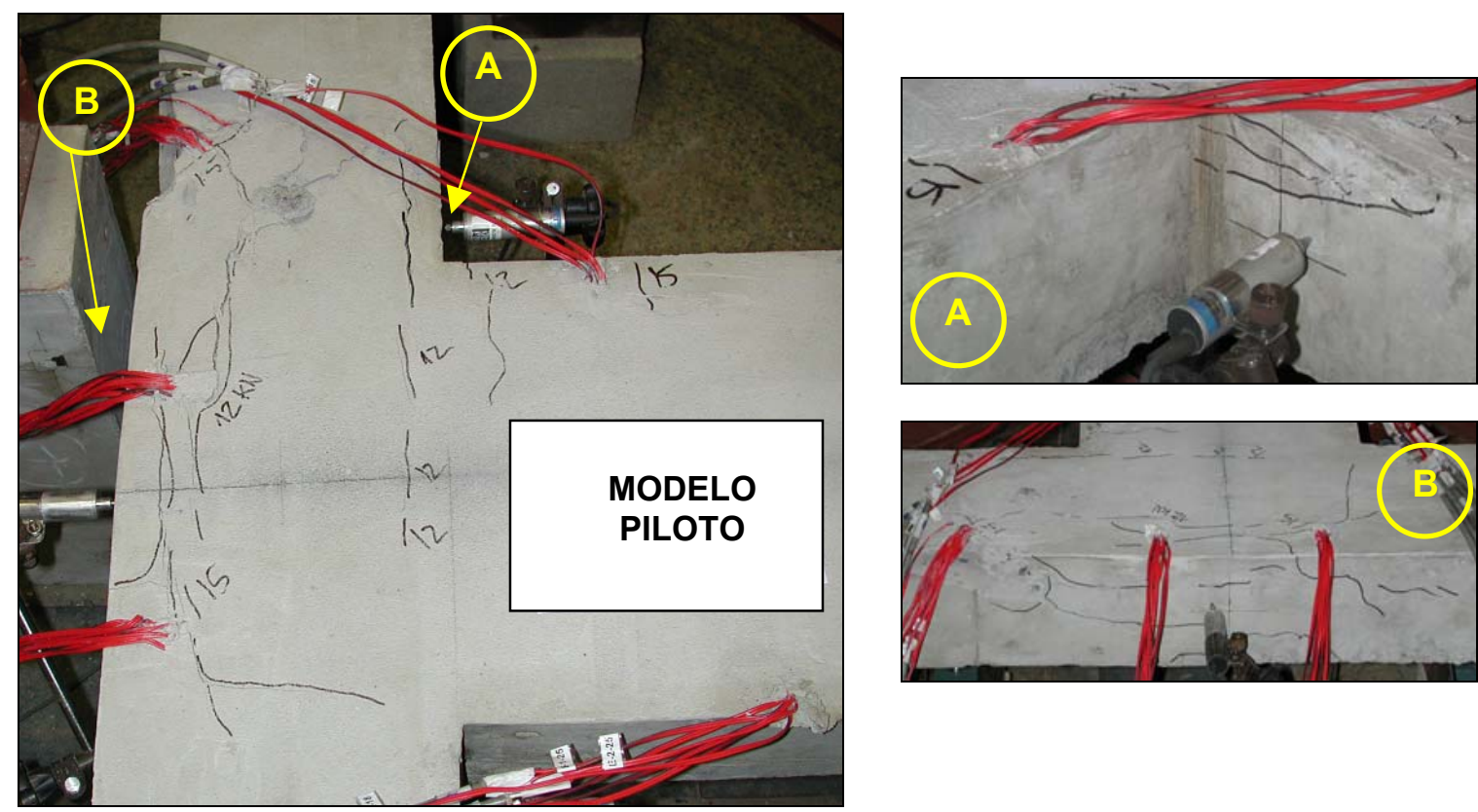

Figura 5.4 - Fissuração do modelo piloto.

O esperado era o surgimento de uma fissura diagonal no nó, indicando ruptura da biela, porém isto não aconteceu. O estribo localizado no nó apresentou uma pequena deformação só no instante da ruína (Figura 5.5). Os resultados, por meio das deformações diferenciadas das armaduras do pilar em uma determinada seção (Figura $5.3 b)$, apontaram que a ruptura ocorreu por causa da flexão oblíqua no pilar, pois o surgimento de momentos adicionais, na direção do eixo da viga (x) e na direção normal ao plano de ensaio $(z)$, reduziram a capacidade resistente do pilar na direção de interesse do ensaio, levando uma das barras do pilar ao escoamento (Figura 5.6).
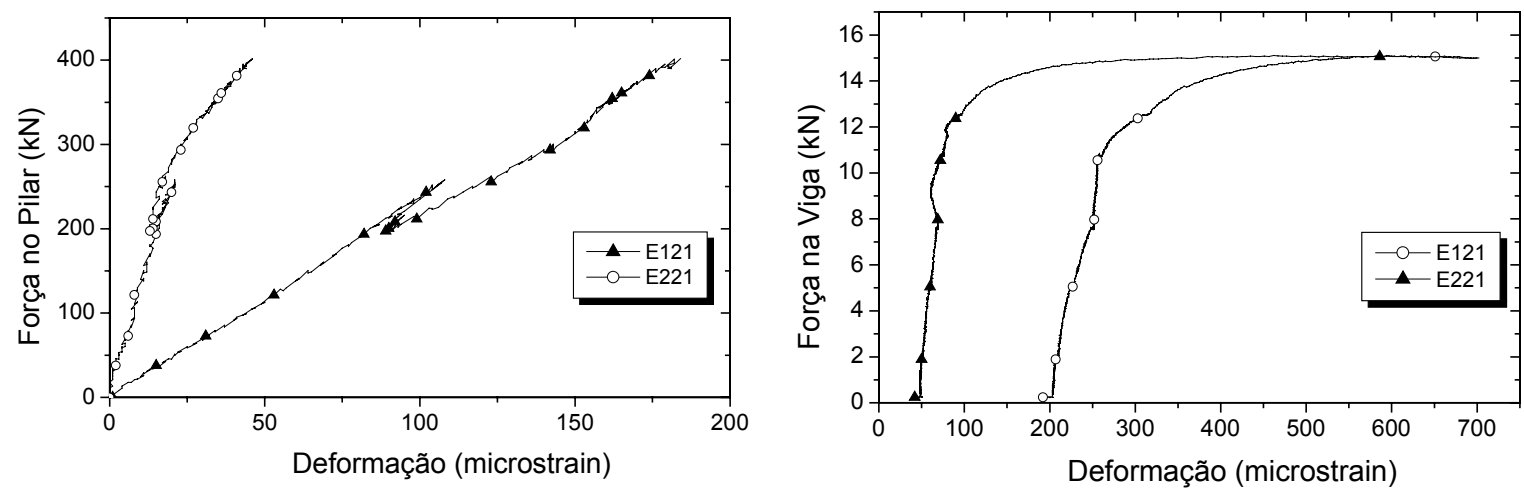

Figura 5.5 - Deformações do estribo na região nodal. 


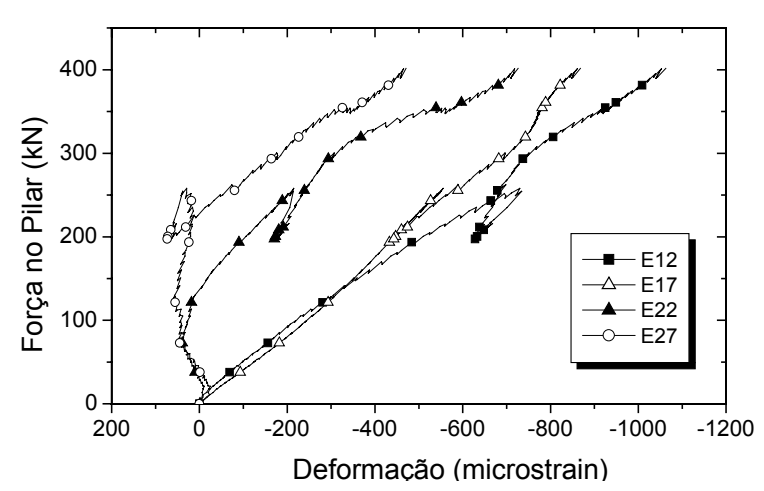

(a)

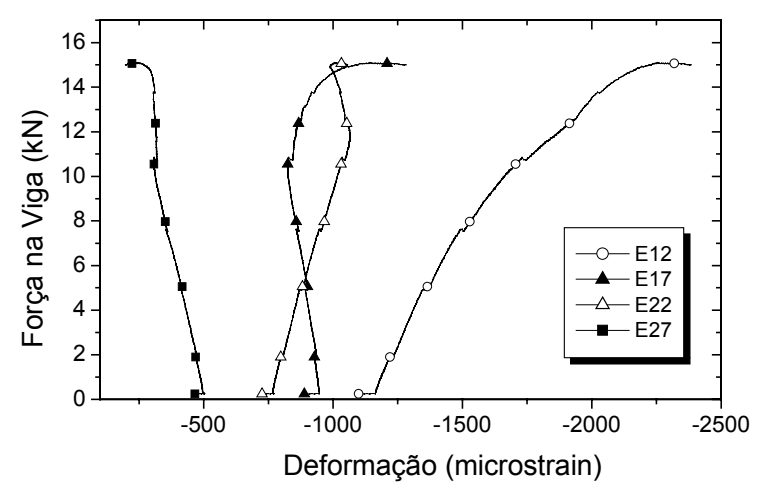

(b)

Figura 5.6 - Deformações das barras longitudinais do pilar na seção onde ocorreu a ruptura (Modelo Piloto).

Desta maneira, os resultados obtidos deste ensaio não puderam ser aproveitados para a análise do comportamento do nó, porém foram de fundamental importância para a definição de dispositivos mais eficientes para a realização do ensaio.

\subsection{Ensaio do Modelo N400}

Assim como no ensaio piloto, anteriormente ao início do experimento realizou-se o ensaio de compressão simples. Com o resultado obtido foi decidida a aplicação da força máxima, ou seja, uma força normal de $400 \mathrm{kN}(v=0,87)$, já que os resultados obtidos pelo modelo piloto não puderam ser aproveitados para efeito de análise do nó.

A peça se comportou de maneira satisfatória, a utilização de camisas metálicas na cabeça do pilar evitou que esta rompesse e a utilização de apoios intermediários também foi bastante eficaz.

Ao atingir a força de $400 \mathrm{kN}$ no pilar, a flecha era da ordem de $0,5 \mathrm{~mm}$ e as deformações das barras apresentavam divergências bem menores que no modelo piloto $(\Delta \varepsilon \approx 0,35 \%$, Figura 5.7), o que comprova a eficiência dos apoios intermediários. A Figura 5.8 apresenta a variação do comportamento das barras do pilar ao longo do eixo em relação à força normal, e a Figura 5.9 a variação em relação à força aplicada na viga. 

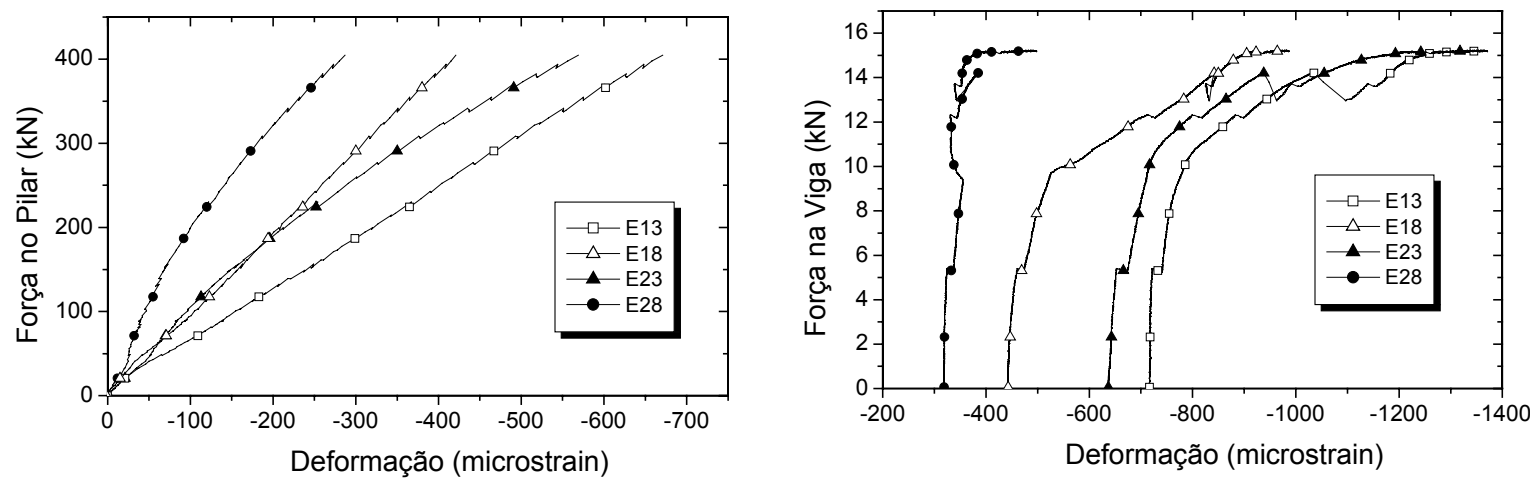

Figura 5.7 - Deformações da armadura longitudinal do pilar na região nodal (Modelo N400).

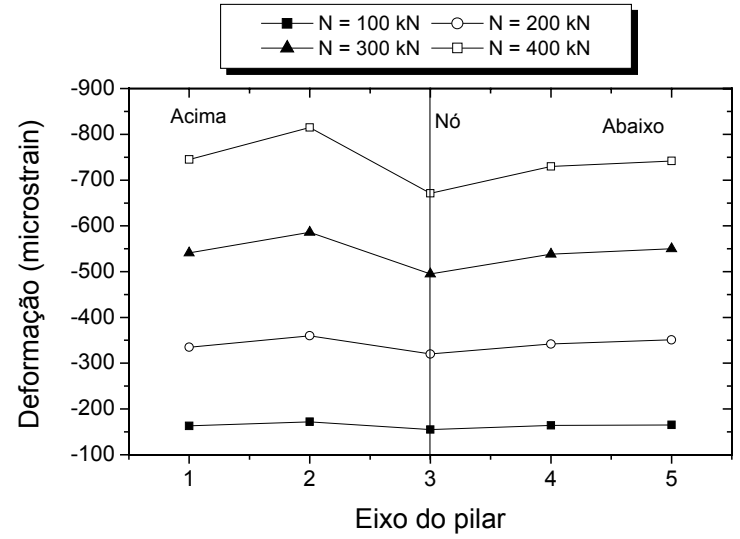

(a)

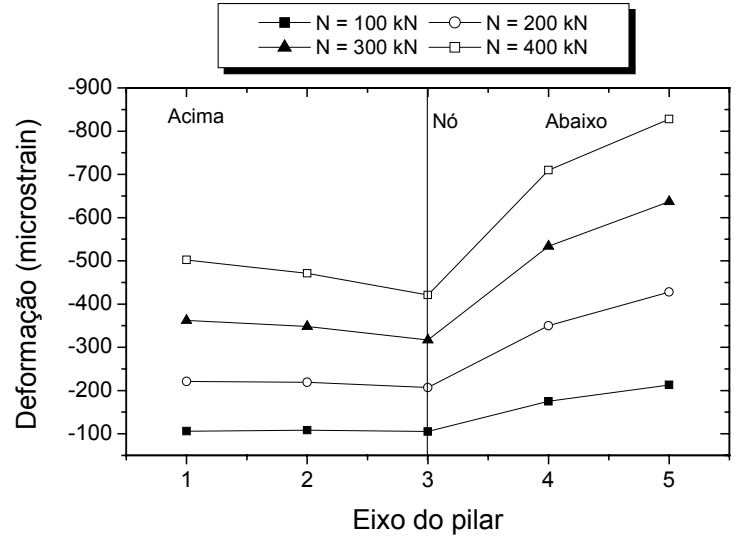

(b)

Figura 5.8 - Deformações da armadura longitudinal do pilar ao longo do eixo causadas pela força normal: (a) Face externa e (b) Face interna (Modelo N400).

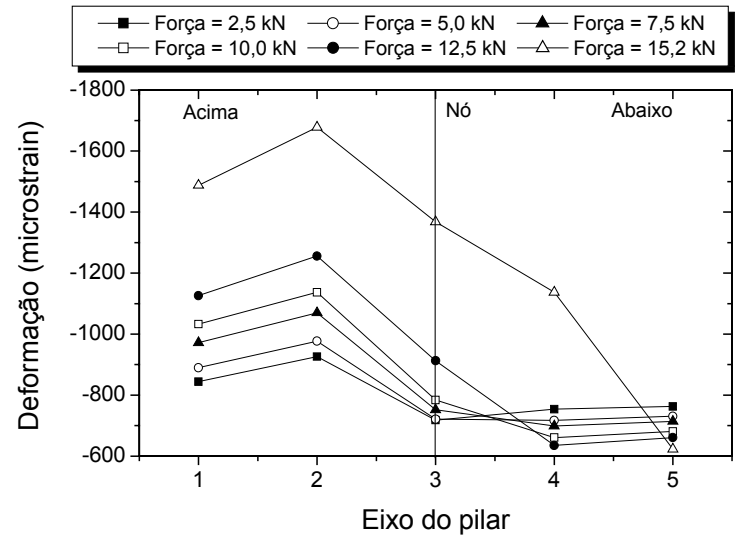

(a)

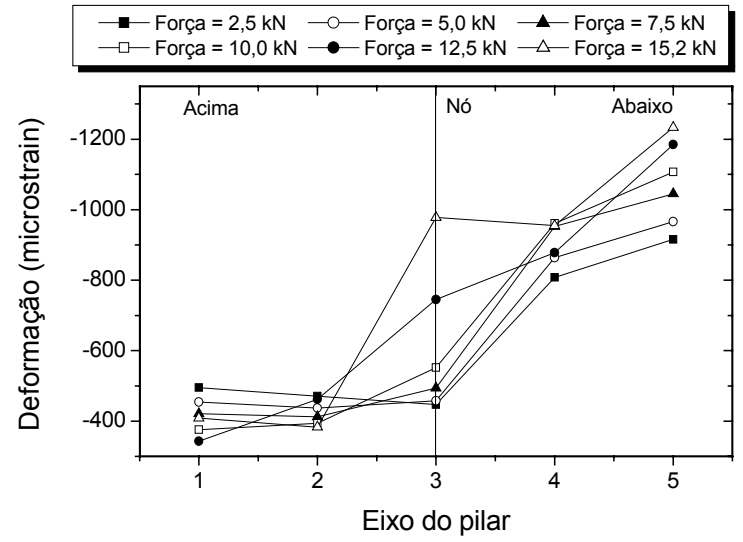

(b)

Figura 5.9 - Deformações da armadura longitudinal do pilar ao longo do eixo após carregamento da viga: (a) Face externa e (b) Face interna (Modelo N400). 
As primeiras fissuras no modelo, localizadas na viga, surgiram com a aplicação de 7 kN no balanço (Figura 5.10). A fissuração na região do nó começou somente a partir de 11 kN, aumentando a solicitação do estribo localizado no nó (Figura 5.11).
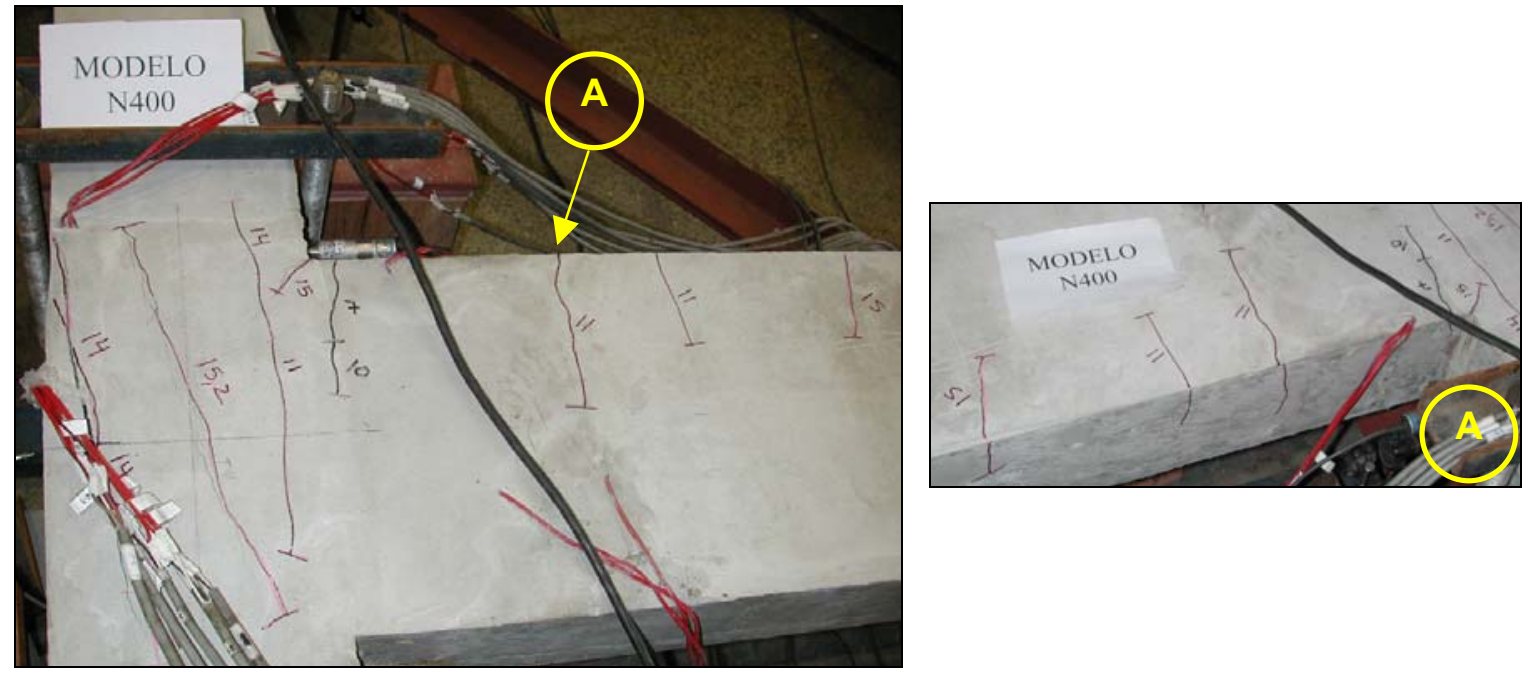

Figura 5.10 - Fissuração do Modelo N400.
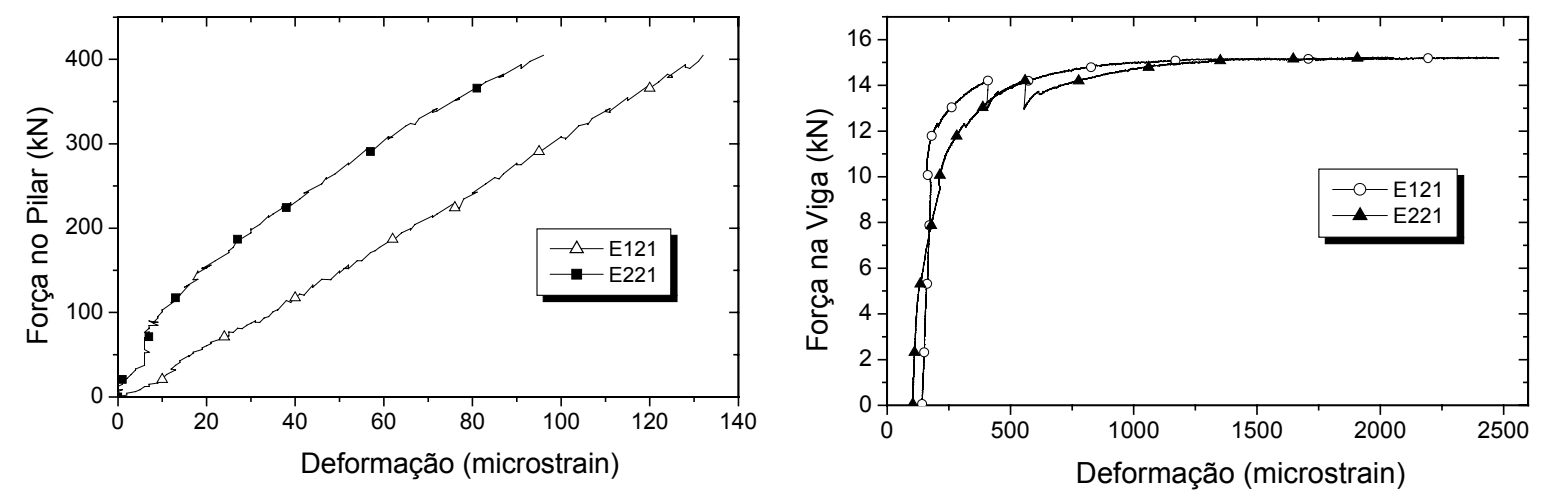

Figura 5.11 - Deformações do estribo na região nodal (Modelo N400).

Os estribos do pilar apresentaram baixas deformações, sendo aqueles localizados logo acima e abaixo do nó os mais solicitados (Figura 5.12), confirmando a observação feita por Ortiz (1993) e Leonhardt \& Mönnig (1977). 

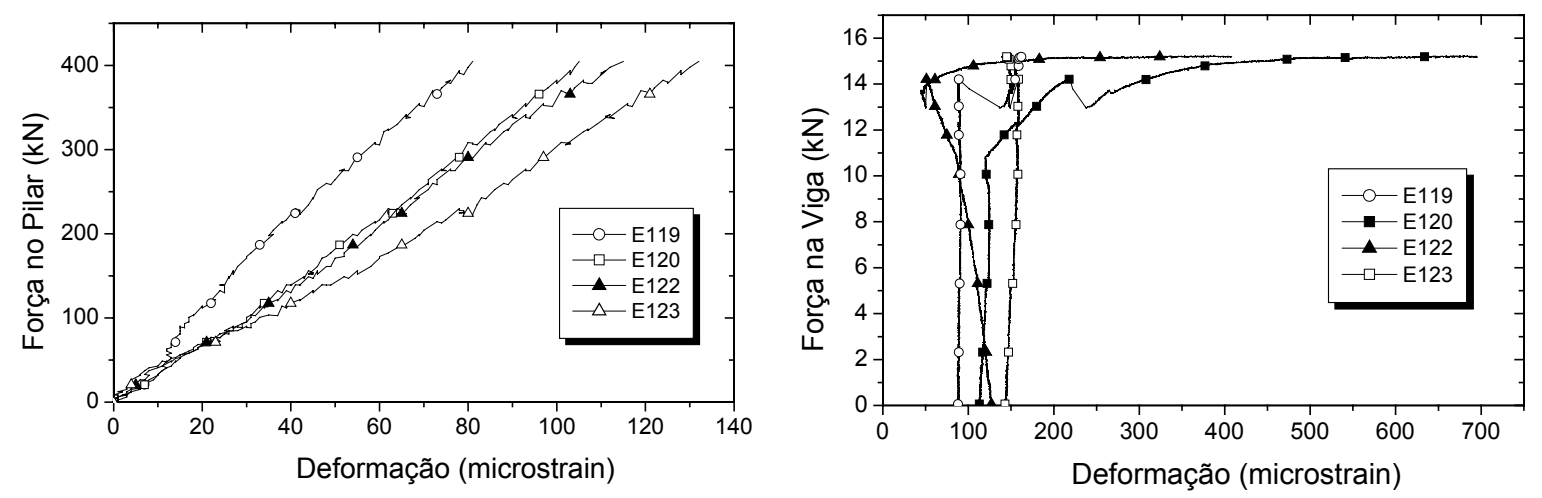

Figura 5.12 - Deformações dos estribos do pilar (Modelo N400).

Os estribos da viga apresentaram deformações desprezíveis, indicando não terem influenciado no comportamento do nó (Figura 5.13).

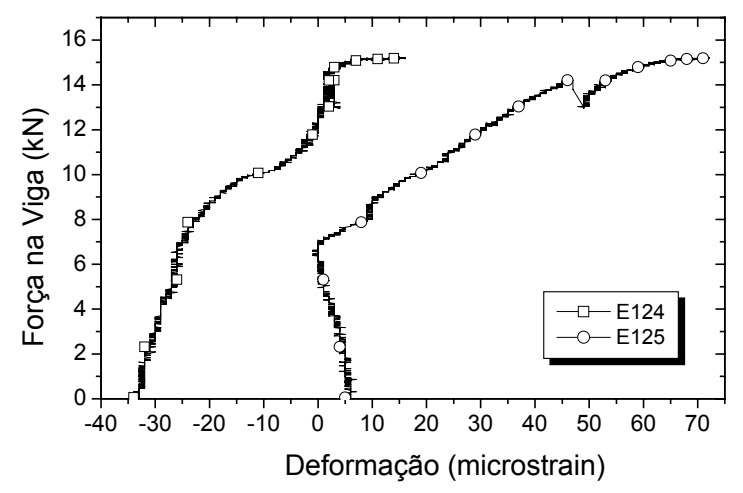

Figura 5.13 - Deformações dos estribos da viga (Modelo N400).
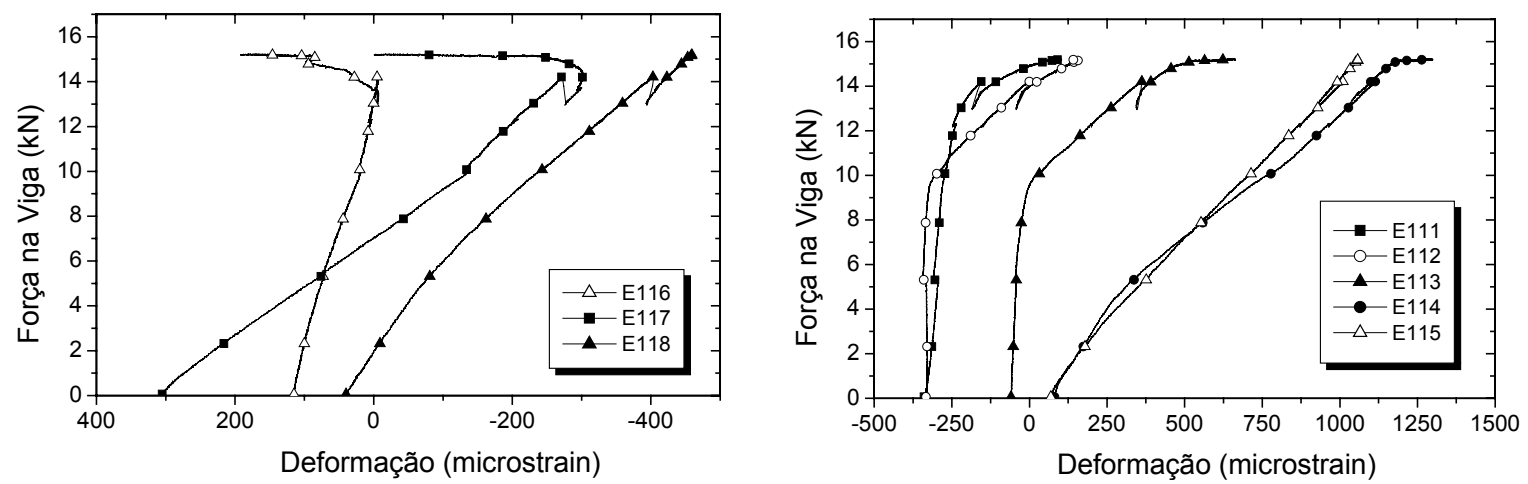

Figura 5.14 - Deformações da armadura longitudinal da viga (Modelo N400). 

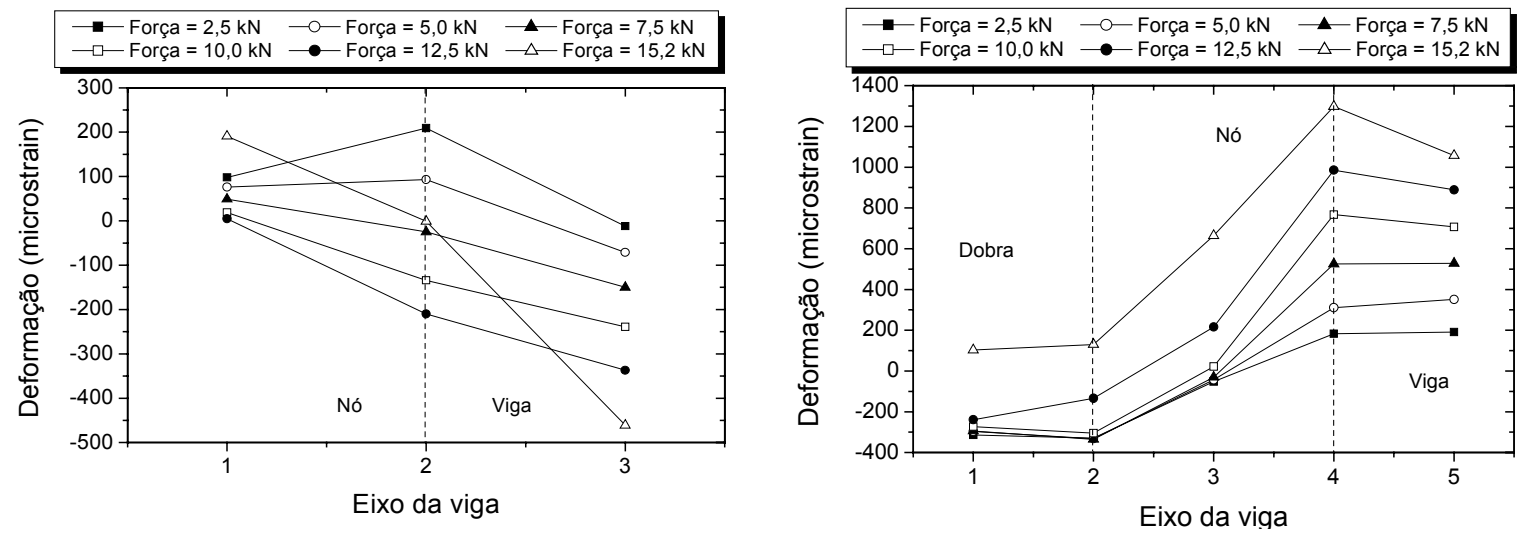

Figura 5.15 - Deformações da armadura longitudinal da viga ao longo do eixo (Modelo N400).

Com relação às barras longitudinais da viga, foi constatado que a dobra absorve uma parcela das tensões de compressão advindas do pilar (Figura 5.14), como observado por Ortiz (1993). Juntamente com a dobra, a porção das barras da viga no interior da região nodal começa a ser solicitada à tração somente a partir do início da fissuração do nó. A Figura 5.15 apresenta o comportamento das barras da viga ao longo do eixo com a variação da força aplicada no balanço.

Ao atingir $14 \mathrm{kN}$, observou-se que um dos tirantes afrouxou, provavelmente por causa da acomodação do sistema estrutural de apoio. Na proximidade da ruína da ligação surgiram fissuras, que aumentavam rapidamente, no lado externo do nó provocando a ruptura do cobrimento (Figura 5.16). Ao atingir a carga de $15,2 \mathrm{kN}$, a estrutura atingiu sua capacidade de suporte.
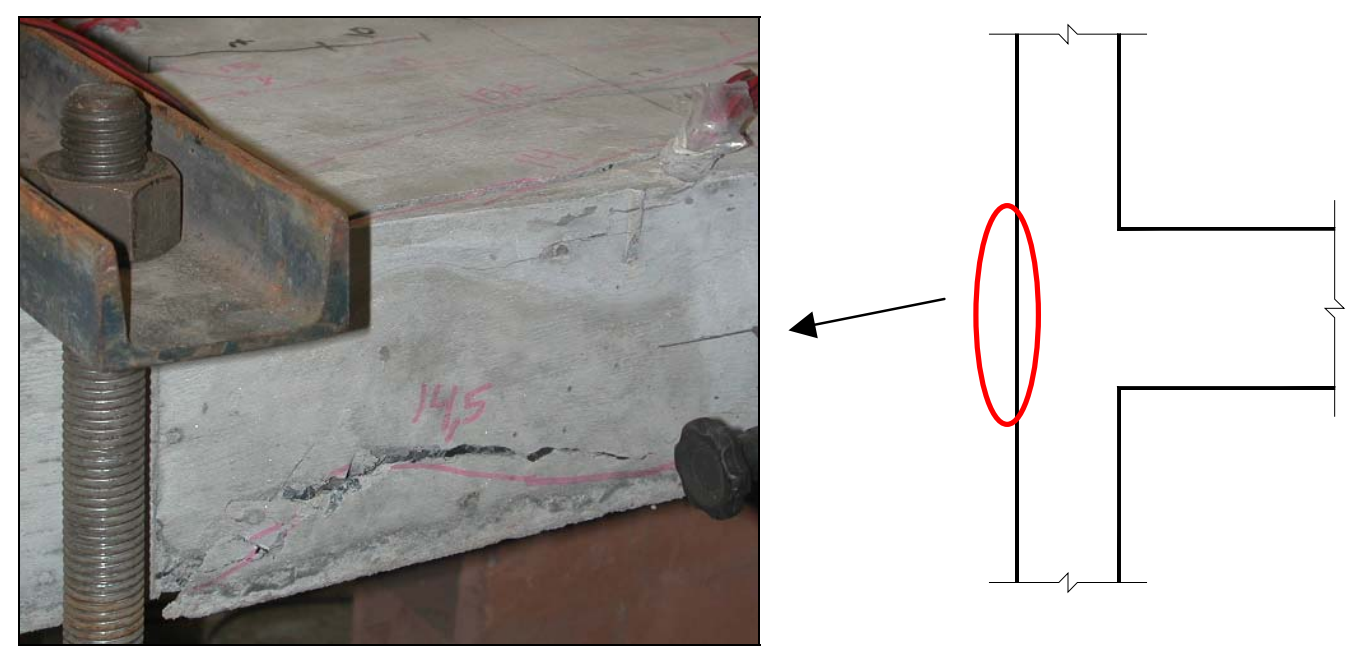

Figura 5.16 - Ruptura do cobrimento no lado externo do nó (Modelo N400). 


\subsection{Ensaio do Modelo N300}

O ensaio seria realizado com 9 dias, porém houve um adiantamento nos serviços de preparação do modelo. Desta forma, depois de observado se a resistência do concreto era satisfatória, optou-se por realizar o ensaio com a idade de 8 dias. Conhecida a resistência à compressão, decidiu-se aplicar uma força normal de 300 kN $(v=0,65)$.

Assim como no modelo N400 a peça se comportou de maneira satisfatória quanto aos problemas ocorridos no modelo piloto.
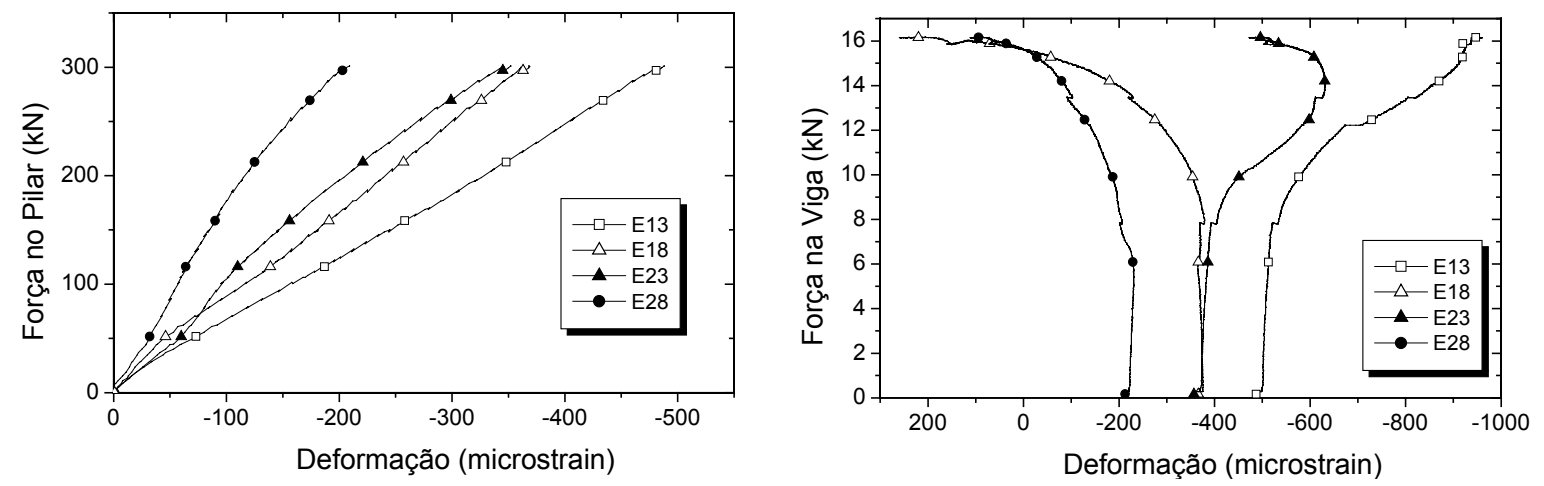

Figura 5.17 - Deformações da armadura longitudinal do pilar na região nodal (Modelo N300).

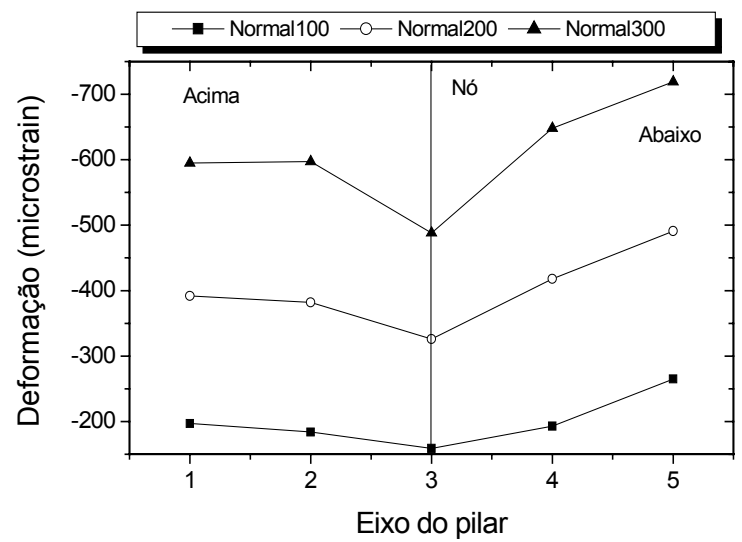

(a)

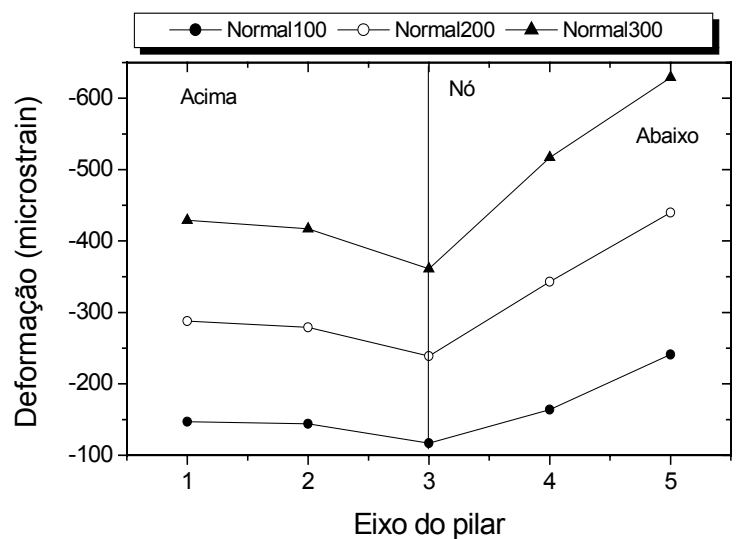

(b)

Figura 5.18 - Deformações da armadura longitudinal do pilar ao longo do eixo causadas pela força normal: (a) Face externa e (b) Face interna (Modelo N300). 


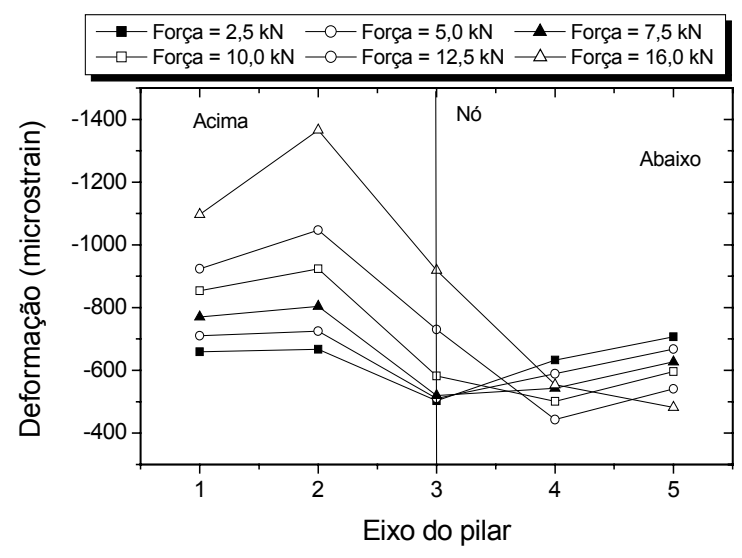

(a)

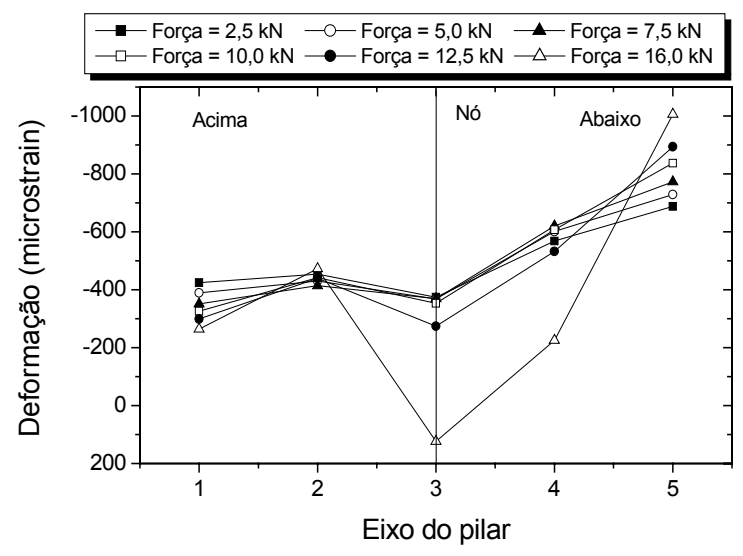

(b)

Figura 5.19 - Deformações da armadura longitudinal do pilar ao longo do eixo após carregamento da viga: (a) Face externa e (b) Face interna (Modelo N300).

Ao atingir a força de $300 \mathrm{kN}$ no pilar, a flecha era da ordem de 0,2 $\mathrm{mm}$ e as deformações das barras apresentavam divergências bem menores que no modelo piloto $(\Delta \varepsilon \approx 0,30 \%$, Figura 5.17). A Figura 5.18 apresenta a variação do comportamento das barras do pilar ao longo do eixo em relação à força normal, e a Figura 5.19 a variação em relação à força aplicada na viga.

Iniciado o carregamento da viga, as primeiras fissuras no modelo, diferentemente do modelo N400, surgiram na região do nó sobre as barras do pilar do lado interno, com a aplicação de 8,5 kN (Figura 5.21). Os estribos do nó começaram a ser realmente mobilizados após a força de $10 \mathrm{kN}$ aplicada na viga (Figura 5.20).
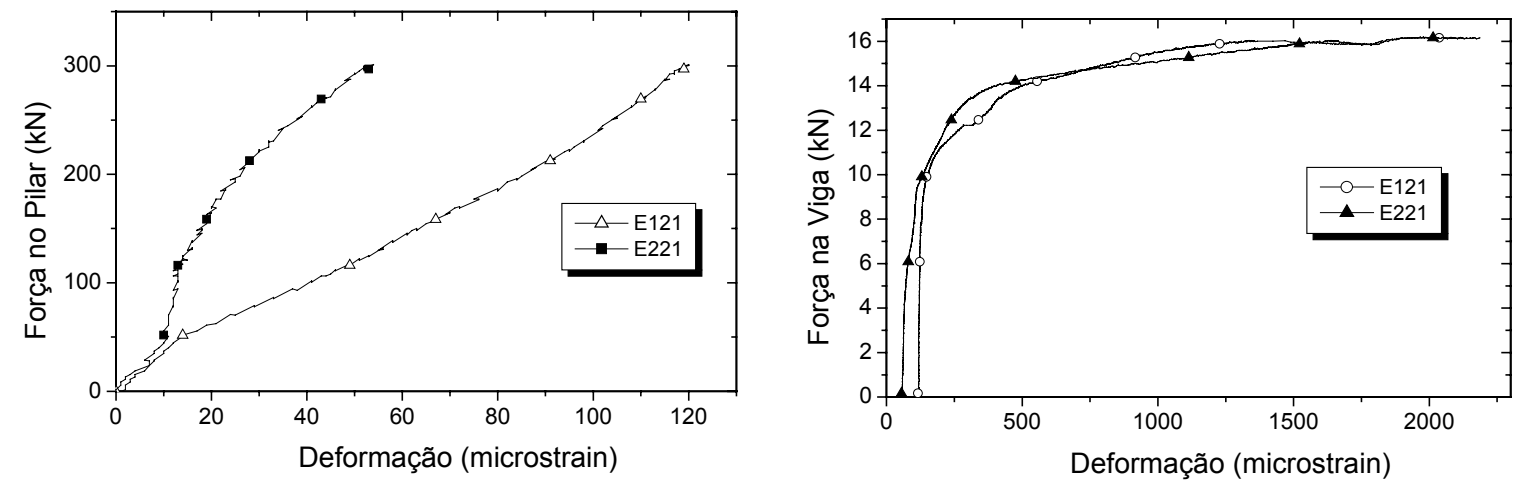

Figura 5.20 - Deformações do estribo na região do nó (Modelo N300). 

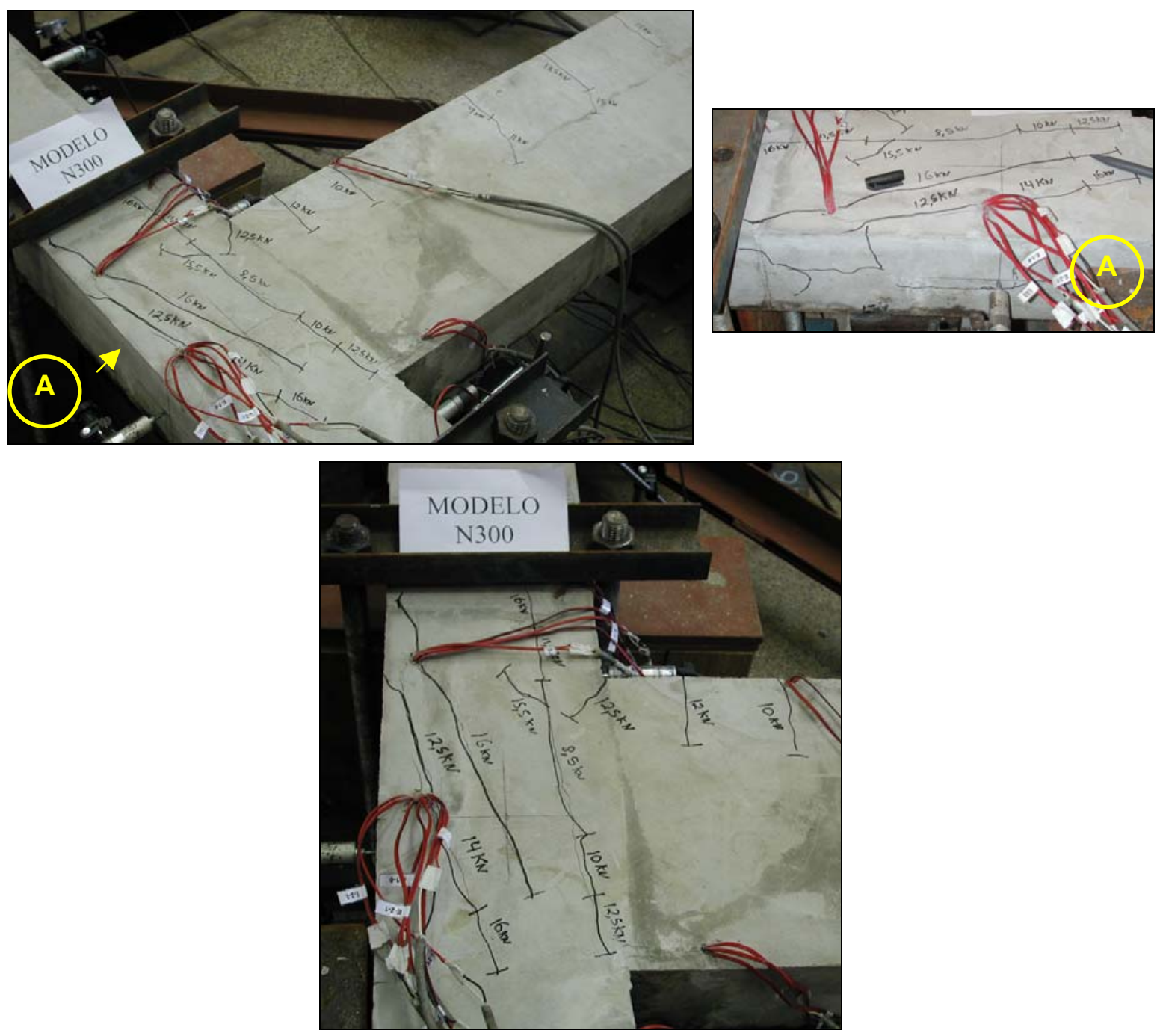

Figura 5.21 - Fissuração do Modelo N300.

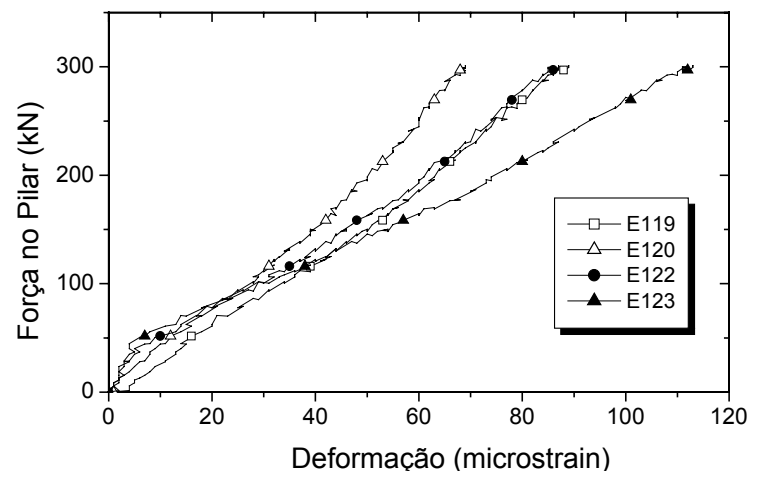

(a)

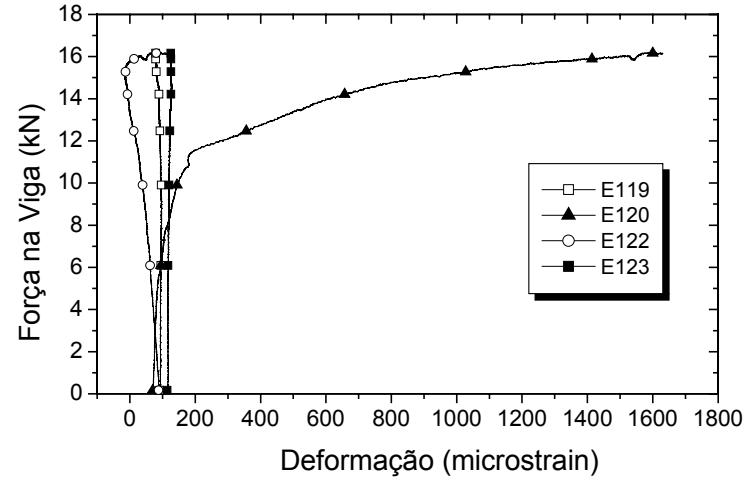

(b)

Figura 5.22 - Deformações dos estribos do pilar (Modelo N300). 
Neste modelo, na proximidade da ruptura, observa-se claramente a alta solicitação do estribo localizado logo acima do nó. Os outros estribos do pilar apresentam baixa deformação ao longo de todo o ensaio (Figura 5.22).

Assim como no modelo $\mathrm{N} 400$, os estribos da viga apresentaram deformações desprezíveis (Figura 5.23).

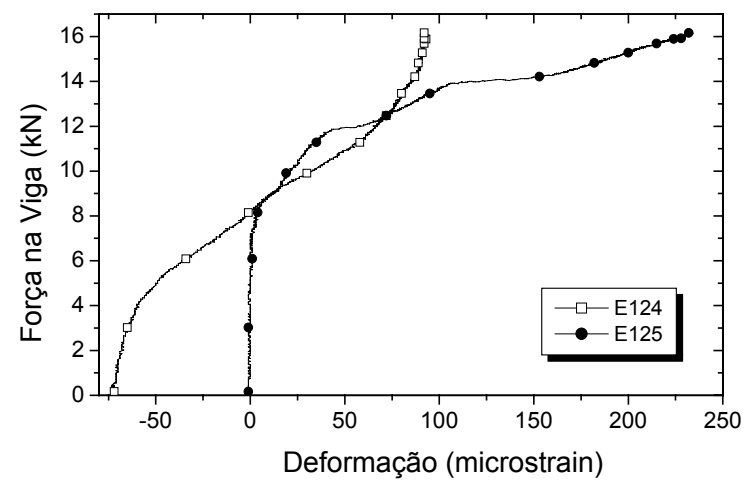

Figura 5.23 - Deformações dos estribos da viga (Modelo N300).

Com relação às barras longitudinais da viga, da mesma forma que no modelo N400, foi constatado que a parte vertical absorve uma parcela das tensões de compressão advindas do pilar (Figura 5.24), e conforme as fissuras vão surgindo no nó esta parte da barra vai sendo solicitada por tensões de tração. A Figura 5.25 apresenta o comportamento das barras da viga ao longo do eixo com a variação da força aplicada no balanço.
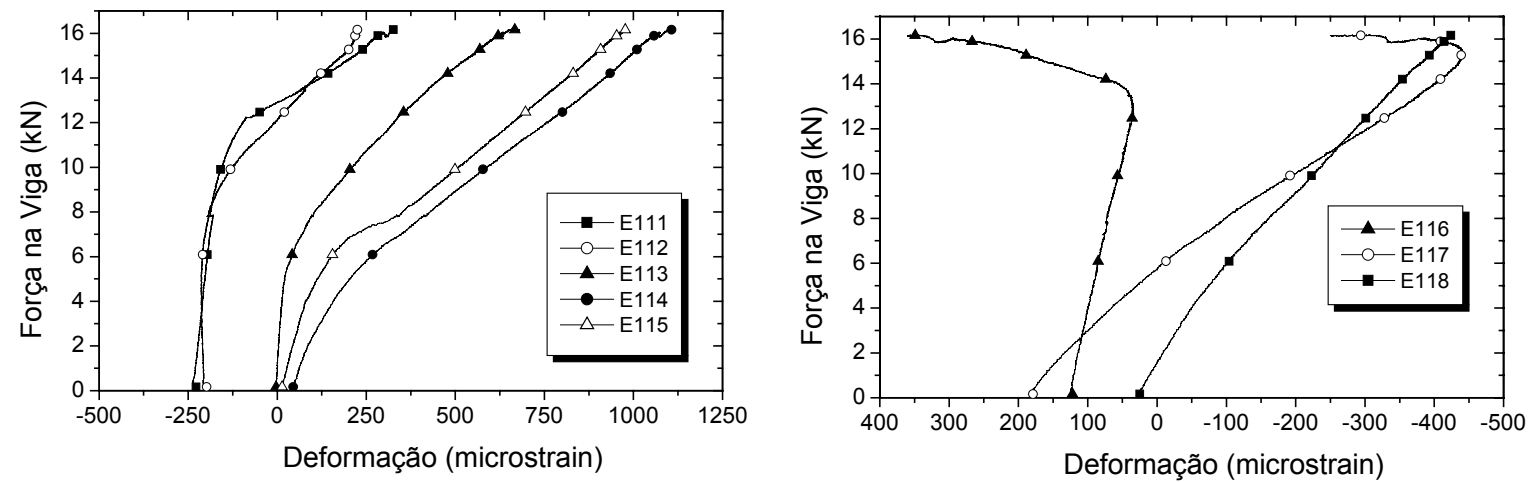

Figura 5.24 - Deformações da armadura longitudinal da viga (Modelo N300). 

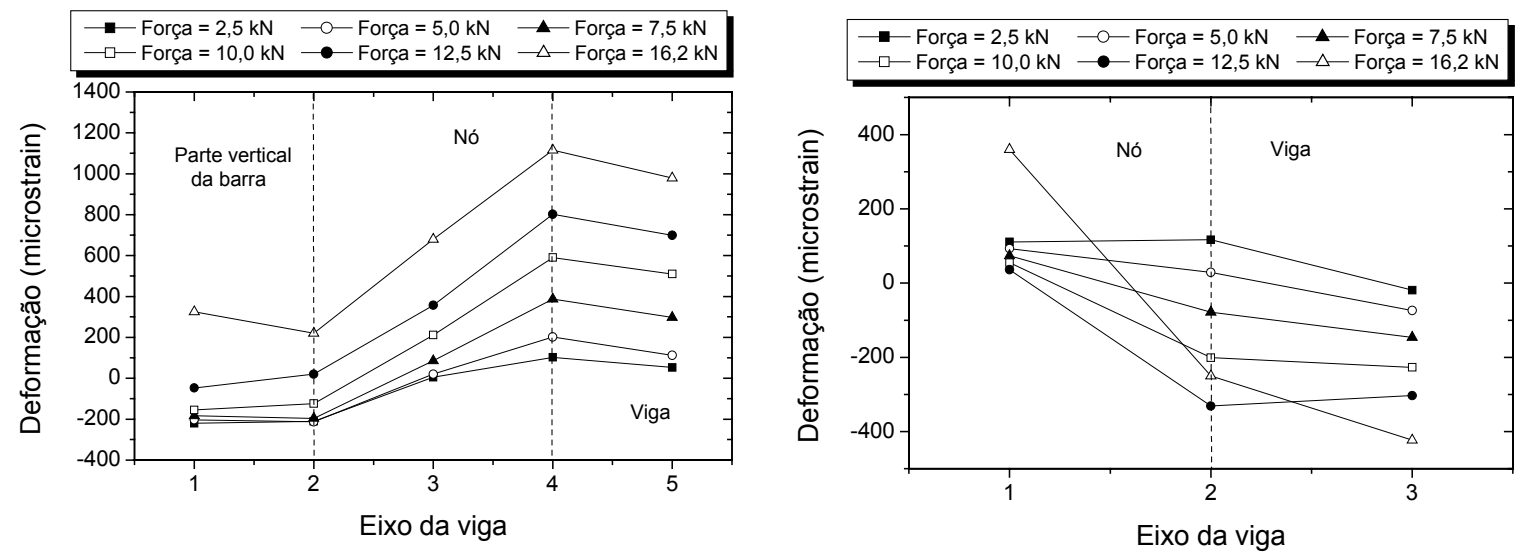

Figura 5.25 - Deformações da armadura longitudinal da viga ao longo do eixo (Modelo N300).

Observou-se um afrouxamento em um dos tirantes da mesma forma que no modelo N400. Ao atingir a carga de $16 \mathrm{kN}$, a estrutura atingiu sua capacidade de suporte.

\subsection{Ensaio do Modelo N200}

Da mesma maneira que o modelo N300, o ensaio seria realizado com 9 dias, porém houve um adiantamento nos serviços de preparação do modelo. Desta forma, depois de observado se a resistência do concreto era satisfatória, optou-se por realizar o ensaio com a idade de 8 dias. Conhecida a resistência a compressão, decidiu-se aplicar uma força normal de $250 \mathrm{kN}(v=0,5)$.
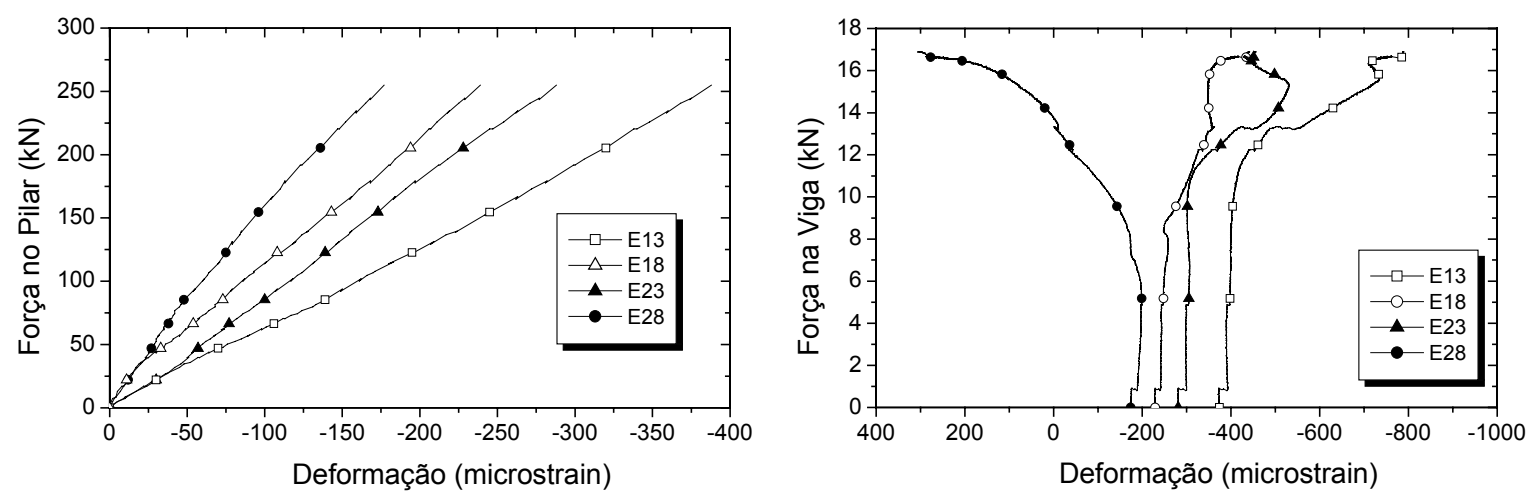

Figura 5.26 - Deformações da armadura longitudinal do pilar na região nodal (Modelo N200). 


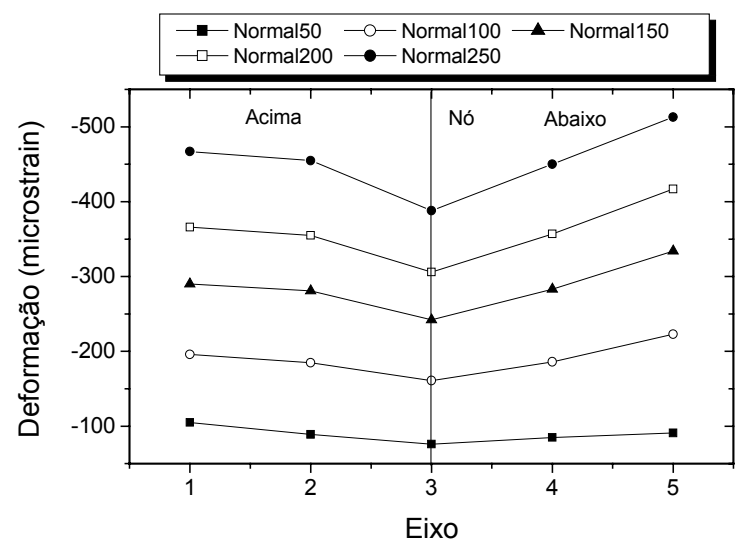

(a)

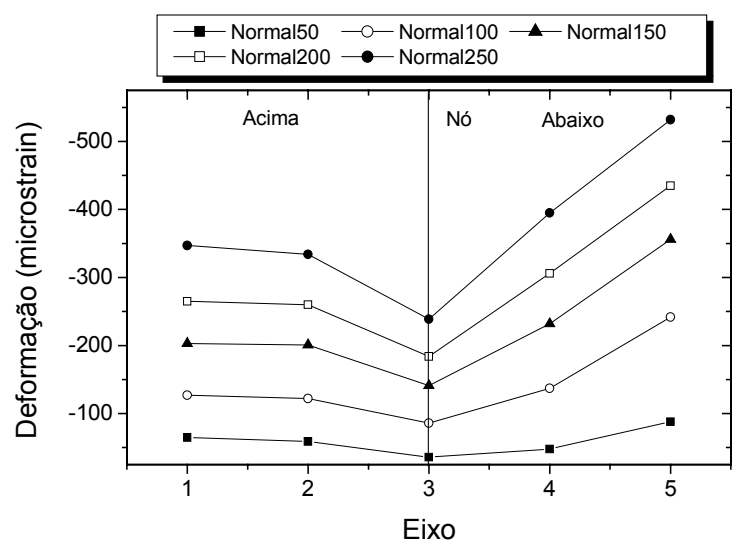

(b)

Figura 5.27 - Deformações da armadura longitudinal do pilar ao longo do eixo causadas pela força normal: (a) Face externa e (b) Face interna (Modelo N200).

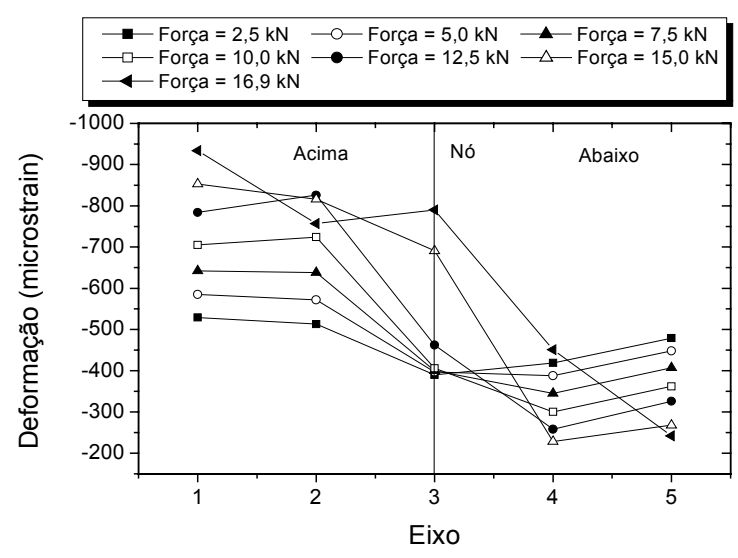

(a)

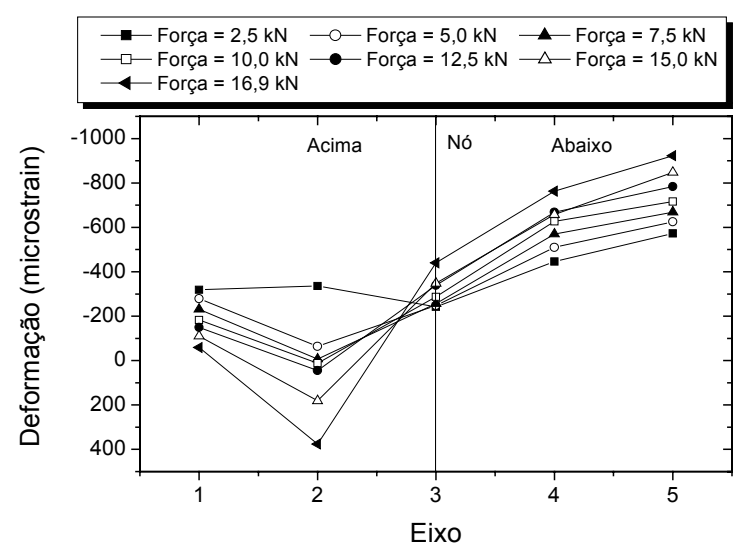

(b)

Figura 5.28 - Deformações da armadura longitudinal do pilar ao longo do eixo após carregamento da viga: (a) Face externa e (b) Face interna (Modelo N200).

Iniciado o carregamento do pilar, ao atingir a força de $250 \mathrm{kN}$, a flecha era da ordem de 0,3 mm e as deformações das barras apresentavam divergências bem menores que no modelo piloto $(\Delta \varepsilon \approx 0,20 \%$, Figura 5.26). A Figura 5.27 apresenta a variação do comportamento das barras do pilar ao longo do eixo em relação à força normal, e a Figura 5.27 a variação em relação à força aplicada na viga.

As primeiras fissuras no modelo surgiram na região do nó sobre as barras do pilar do lado interno, assim como no modelo N300, com a aplicação de 10 kN (Figura 5.29). Os estribos do nó começaram a ser realmente mobilizados após a força de $10 \mathrm{kN}$ aplicada na viga (Figura 5.30). 

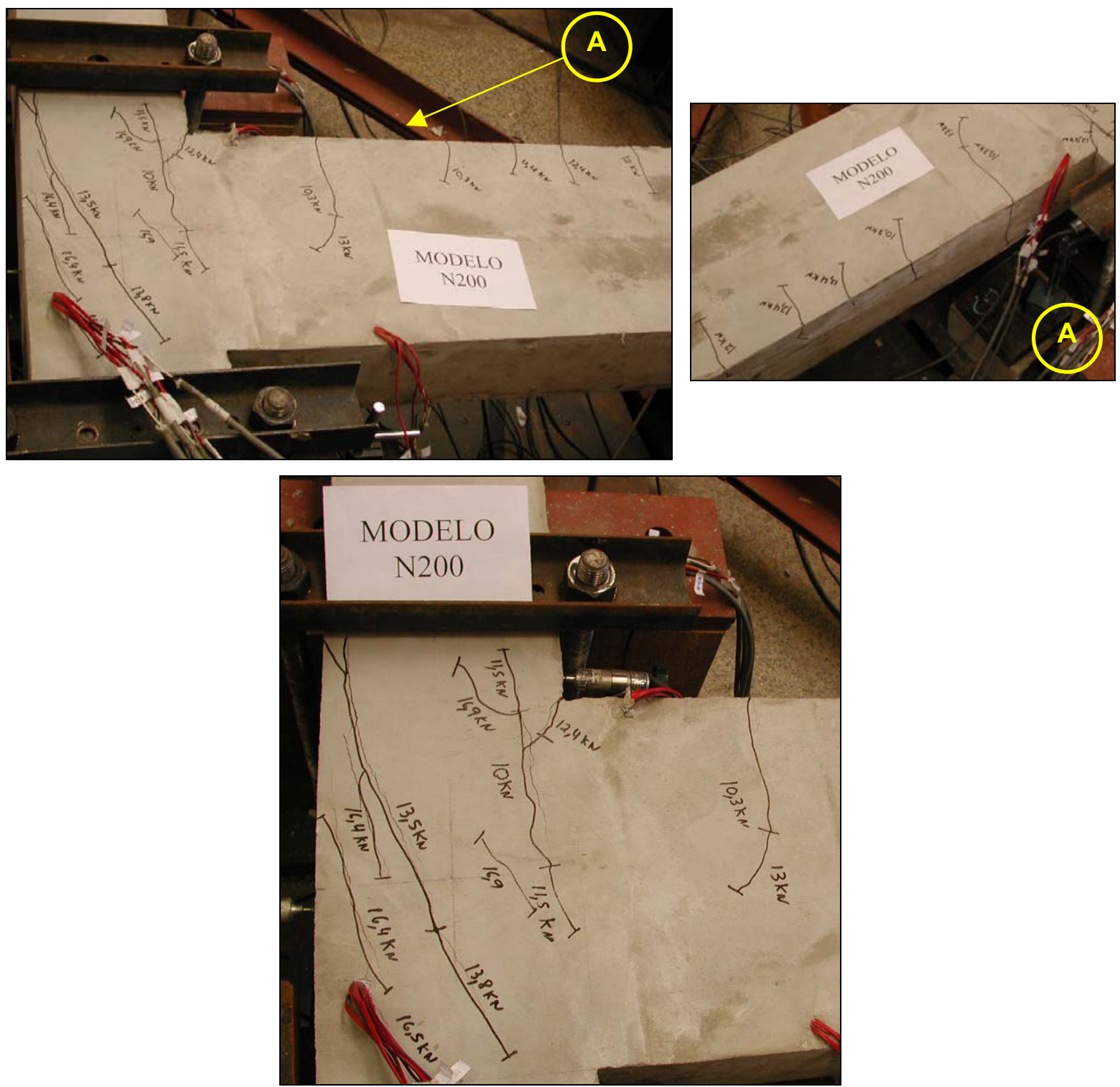

Figura 5.29 - Fissuração do Modelo N200
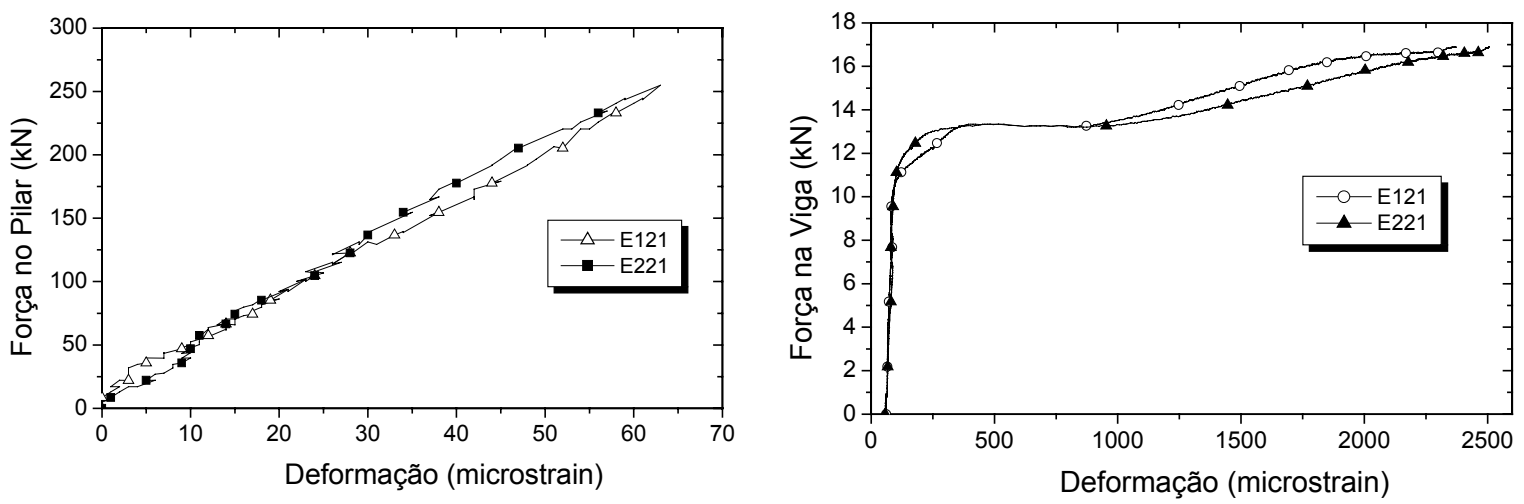

Figura 5.30 - Deformações do estribo na região do nó (Modelo N200). 
Assim como nos outros modelos, os estribos do pilar apresentaram baixas deformações, com exceção daquele localizado logo acima do nó, que na proximidade da ruptura desenvolveu maiores deformações (Figura 5.31).

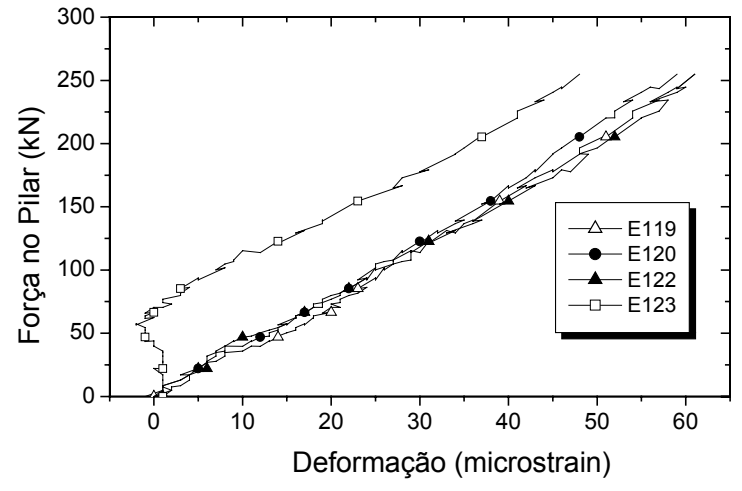

(a)

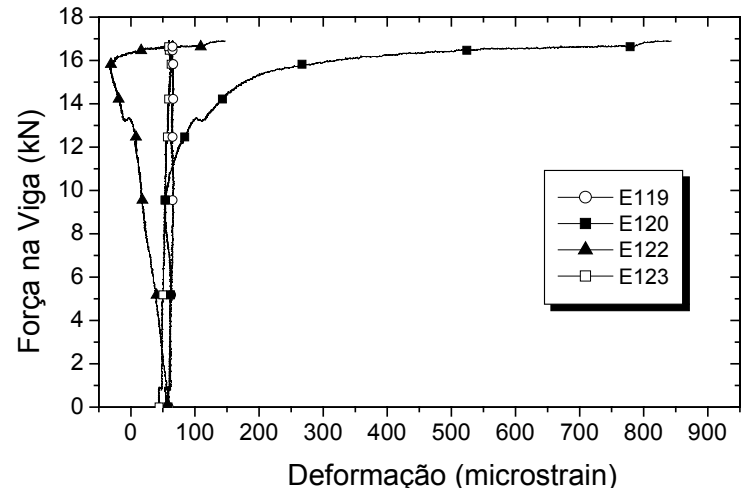

(b)

Figura 5.31 - Deformações dos estribos do pilar (Modelo N200).

Assim como nos outros modelos, as deformações dos estribos da viga foram desprezíveis (Figura 5.32).

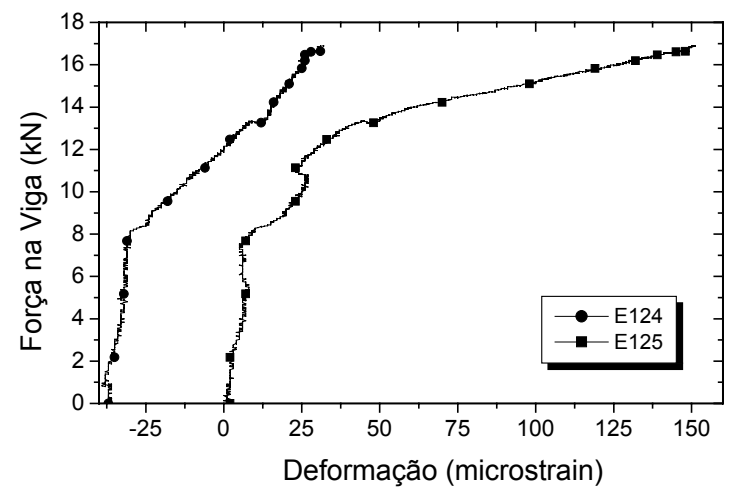

Figura 5.32 - Deformações dos estribos da viga (Modelo N200).

Com relação às barras longitudinais da viga, observou-se como nos outros modelos que a parte vertical da barra absorveu uma parcela das tensões de compressão do pilar e permaneceu sem ser solicitada à tração até o surgimento das primeiras fissuras no modelo (Figura 5.33). A Figura 5.34 apresenta o comportamento das barras da viga ao longo do eixo com a variação da força aplicada no balanço.

A força última atingida pelo modelo $\mathrm{N} 200$ foi de $16,9 \mathrm{kN}$. 

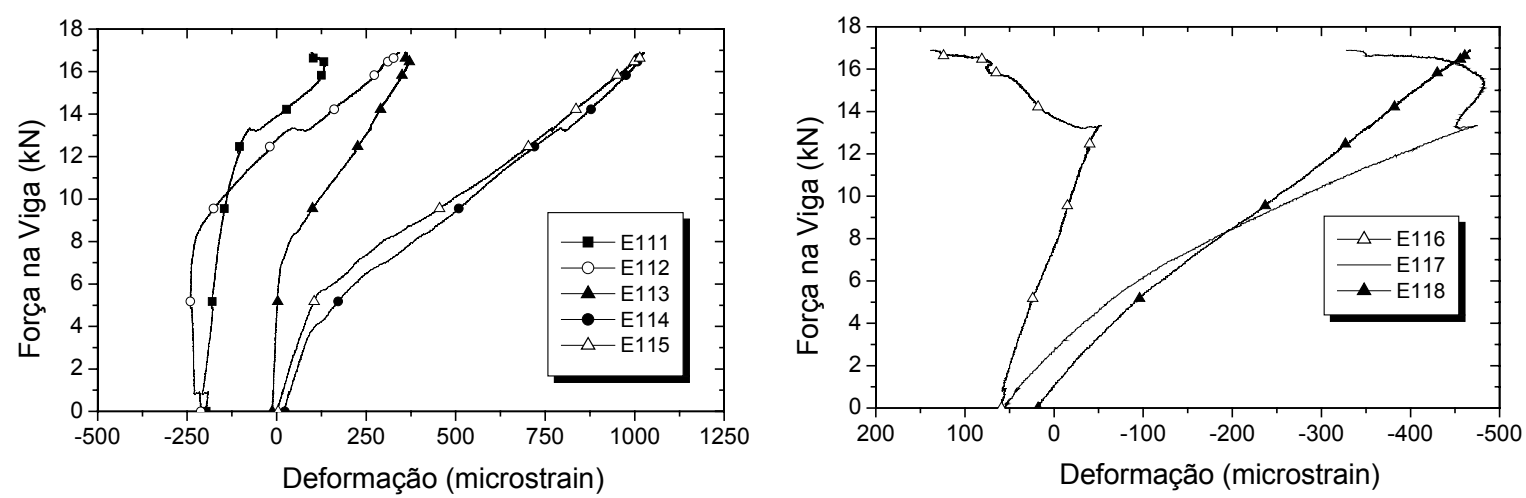

Figura 5.33 - Deformações da armadura longitudinal da viga (Modelo N200).
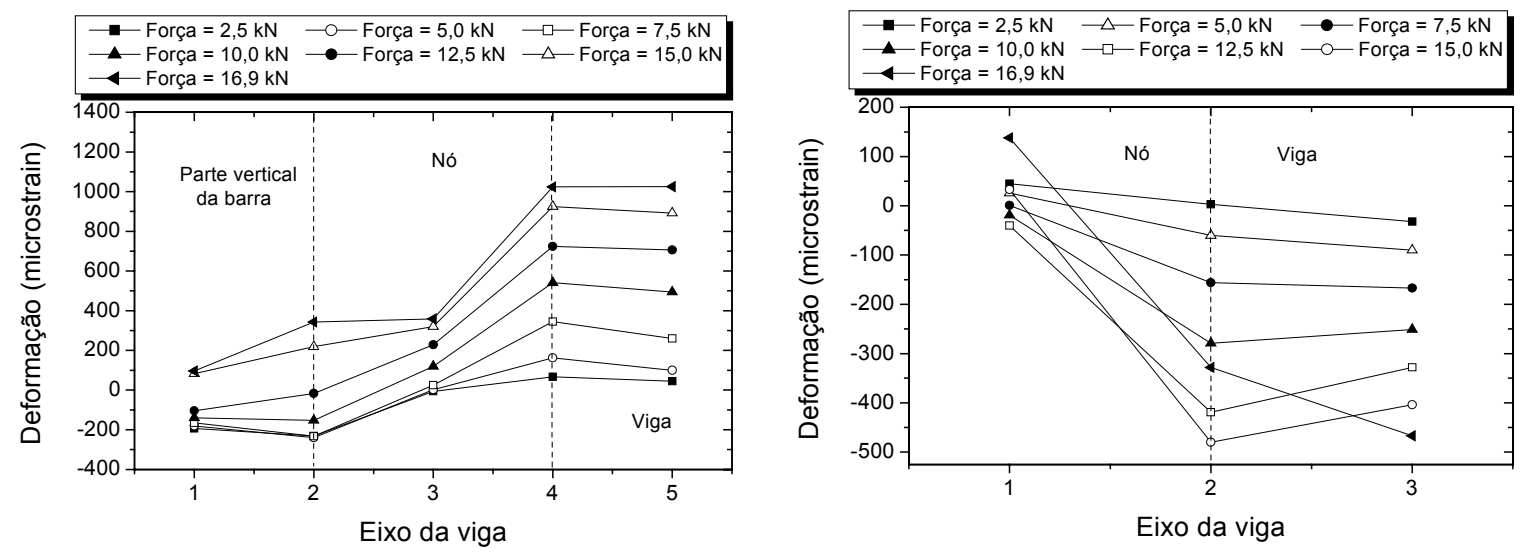

Figura 5.34 - Deformações da armadura longitudinal da viga ao longo do eixo (Modelo N200).

\subsection{Discussão dos resultados}

Neste item é feita a comparação entre os resultados obtidos em cada ensaio com o objetivo de compreender melhor o comportamento dos nós de pórtico externos, analisando cada variável observada nos experimentos.

A Tabela 5.1 apresenta um resumo do comportamento dos modelos ensaiados.
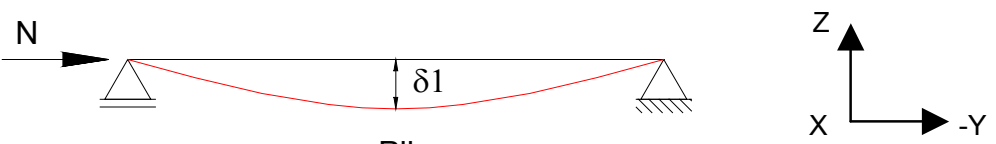

Pilar

Figura 5.35 - Deslocamentos do eixo do pilar. 
Tabela 5.1 - Resumo dos ensaios.

\begin{tabular}{|c|c|c|c|c|c|c|}
\hline Modelo & $\begin{array}{c}\mathrm{N} \\
(\mathrm{kN})\end{array}$ & $v$ & $\begin{array}{l}\Delta \varepsilon \\
(\%)\end{array}$ & $\begin{array}{c}\delta 1 \\
(\mathrm{~mm})\end{array}$ & $\begin{array}{c}\mathrm{Fr} \\
(\mathrm{kN})\end{array}$ & $\begin{array}{l}\text { Fu } \\
\text { (kN) }\end{array}$ \\
\hline Piloto & 400 & 0,99 & 0,70 & 6,50 & 12,0 & 5,0 \\
\hline$\overline{\mathrm{N} 400}$ & 400 & 0,79 & 0,35 & $-0,50$ & 11,0 & 15,2 \\
\hline N300 & 300 & 0,66 & 0,30 & 0,20 & 8,5 & 16,0 \\
\hline N200 & 250 & 0,49 & 0,20 & 0,30 & 10,0 & 16,9 \\
\hline \multicolumn{7}{|c|}{$\begin{array}{l}\delta 1 \rightarrow \text { Figura } 5.35 \\
\text { Fr e Fu } \rightarrow \text { Força de fissuração do nó e Força de ruptura, } \\
\text { respectivamente. }\end{array}$} \\
\hline
\end{tabular}

\subsubsection{Fissuração}

A influência da força normal sobre a fissuração do nó dos modelos ensaiados é observada nitidamente. $\mathrm{O}$ modelo $\mathrm{N} 400$, no qual a mais alta força normal foi aplicada, apresentou poucas fissuras, tendo estas aparecido somente na iminência da ruína. Isto se dá, porque as altas tensões de compressão no concreto geram um confinamento, que tende a retardar as primeiras fissuras e a ativação da armadura transversal. No modelo N300, como a força normal aplicada no pilar era menor, a fissuração do nó foi antecipada. Contudo, no modelo N200, apesar da pequena intensidade da força de compressão no pilar, a força de fissuração foi superior à do modelo N300. No entanto, isto deve ter ocorrido por ele apresentar uma resistência à tração cerca de $26 \%$ superior à dos outros modelos ensaiados.

De acordo com a fissuração dos modelos, nota-se que a ligação começa a ser solicitada na região interna, onde fissuras se propagam sobre as barras do pilar e abrem o canto do nó. Em seguida, por causa das altas tensões de aderência que solicitam as barras externas do pilar, surgem fissuras rompendo o cobrimento nesta região. Estas tensões de aderência aumentam de acordo com a intensidade da força de compressão do pilar, o que torna as altas forças normais prejudiciais. Desta forma, a biela diagonal fica bem delimitada pelas fissuras internas e externas, e ao atingir seu limite de compressão, rompe formando uma fissura em seu centro (Figura 5.10 e Figura 5.21). Com pequenas tensões de compressão, a fissuração central da biela inicia antes de maneira controlada, 
ativando a armadura transversal (Figura 5.29 e Figura 5.31). Este comportamento mostra que a força normal tem influência no modo de ruína do modelo, proporcionando uma ruína dúctil para baixas intensidades de força normal.

\subsubsection{Ruptura dos modelos}

Com exceção do modelo piloto que rompeu por flexão oblíqua do pilar, os outros modelos atingiram a ruína por esmagamento da biela do nó. A acomodação da força aplicada na extremidade da viga com a baixa deformação dos estribos, em todos os modelos, indica este tipo de ruptura. Outro ponto que confirma esta afirmação é o decréscimo de deformações que as barras comprimidas da viga (E117) apresentaram na região da interface viga-pilar, pois a biela do nó equilibrava a região comprimida da viga, e quando aquela começou a se degradar foi necessário que houvesse uma redistribuição de esforços como mostra a Figura 5.36.

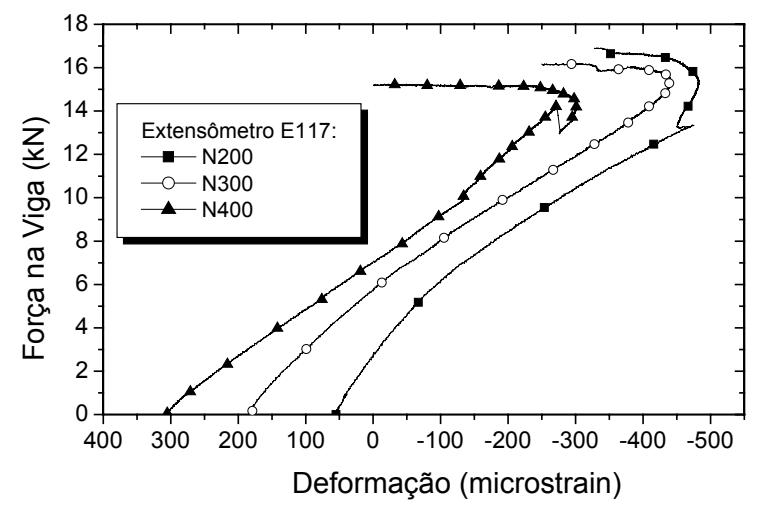

Figura 5.36 - Deformações das barras comprimidas na interface viga-pilar.

A cada $16 \%$ de acréscimo no valor da força normal adimensional houve uma redução de $5 \%$ na força de ruptura dos modelos; desta forma altas forças normais mostraram-se prejudiciais. 


\subsubsection{Armadura Transversal na região do nó}

Como a biela do nó sofreu esmagamento chegando à ruptura, os estribos localizados na região nodal não atingiram toda sua capacidade. Os gráficos força na viga vs. deformação (Figura 5.37) indicam que eles só foram realmente solicitados após a fissuração, como era de se esperar, pois até a primeira fissura mecanismos complementares ao de treliça $\left(V_{c}\right)$ resistem às tensões de tração; a partir daí ocorre uma redistribuição de esforços e esta parcela de resistência decresce enquanto a armadura transversal passa a ser solicitada mais intensamente $\left(V_{s w}\right)$ como se pode ver na Figura 5.38 .

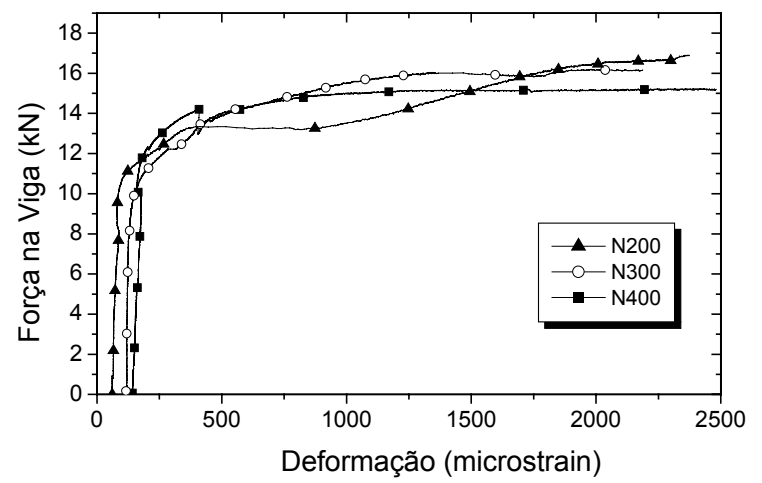

Figura 5.37 - Deformações dos estribos na região nodal.

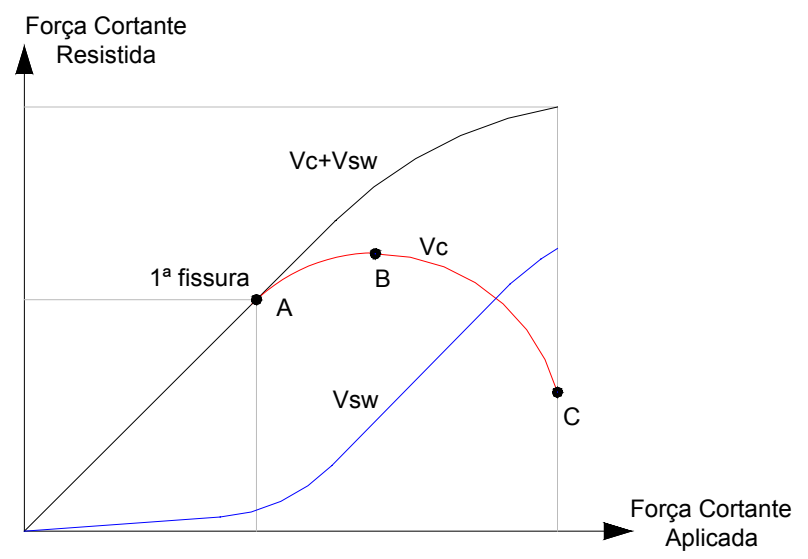

Figura 5.38 - Esquema da solicitação do estribo e da parcela do concreto.

Em todos os modelos ensaiados pode-se observar que o intervalo compreendido entre o início da fissuração no nó e a ruína do modelo foi muito curto, indicando que os 
estribos praticamente não interferiram na resistência do nó, já que apresentaram pequenas deformações. Sendo assim, pode-se dizer que os modelos teóricos que consideram a resistência do nó com armadura transversal como sendo igual à resistência do nó sem armadura transversal acrescida da parcela referente a resistência à tração dos estribos são válidos desde que a biela localizada no nó não rompa antes do escoamento dos estribos.

Segundo a analogia de treliça clássica para elementos estruturais lineares submetidos à força cortante, a resistência do elemento estrutural, numa determinada seção transversal, deve ser considerada satisfatória quando verificadas simultaneamente as condições ( 5.1 ).

$V_{s} \leq V_{R 1}$

$V_{s} \leq V_{R 2}=V_{c}+V_{s w}$

Onde $V_{s}$ é a força cortante solicitante, $V_{R 1}$ é a força cortante resistente relativa a ruína das diagonais comprimidas de concreto e $V_{R 2}$ é a força cortante resistente, relativa à ruína por tração da diagonal.

\subsubsection{Armadura Longitudinal da viga}

Para uma melhor apresentação dos resultados, foram delimitadas seções na viga exatamente sobre o posicionamento dos extensômetros nas barras superiores e inferiores (Figura 5.39).

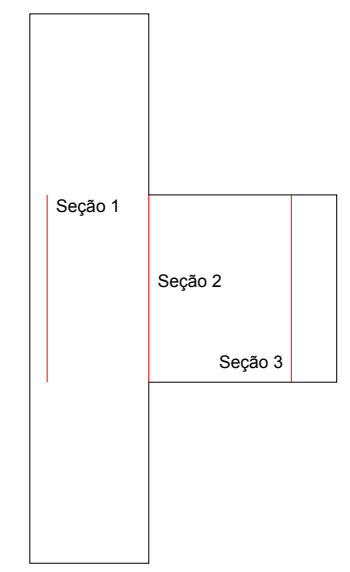

Figura 5.39 - Seções de instrumentação da viga. 
Ao se analisar as tensões nas barras longitudinais da viga notou-se que durante a aplicação da força normal no pilar, tanto as barras superiores quanto as inferiores apresentavam-se tracionadas na região externa ao nó (Figura 5.40 e Figura 5.41). Isto ocorreu, por causa da flexão do pilar (Figura 5.42). Como a região da ligação é descontínua, as hipóteses de Bernoulli que apresentam distribuição linear de deformações ao longo da seção transversal, não são válidas. Desta forma, como as faces superior e inferior da viga encontram-se tracionadas, o concreto na região central da viga deve estar comprimido para que o equilíbrio da seção seja satisfeito.
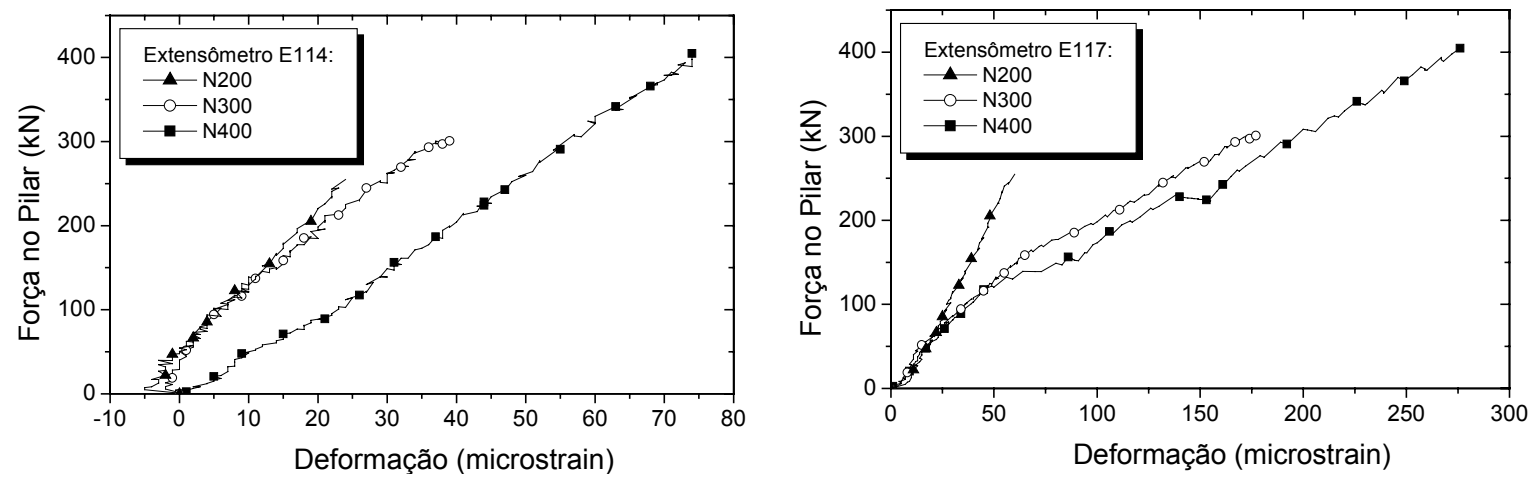

Figura 5.40 - Deformação da armadura longitudinal da viga vs. Força no pilar (Seção 2).
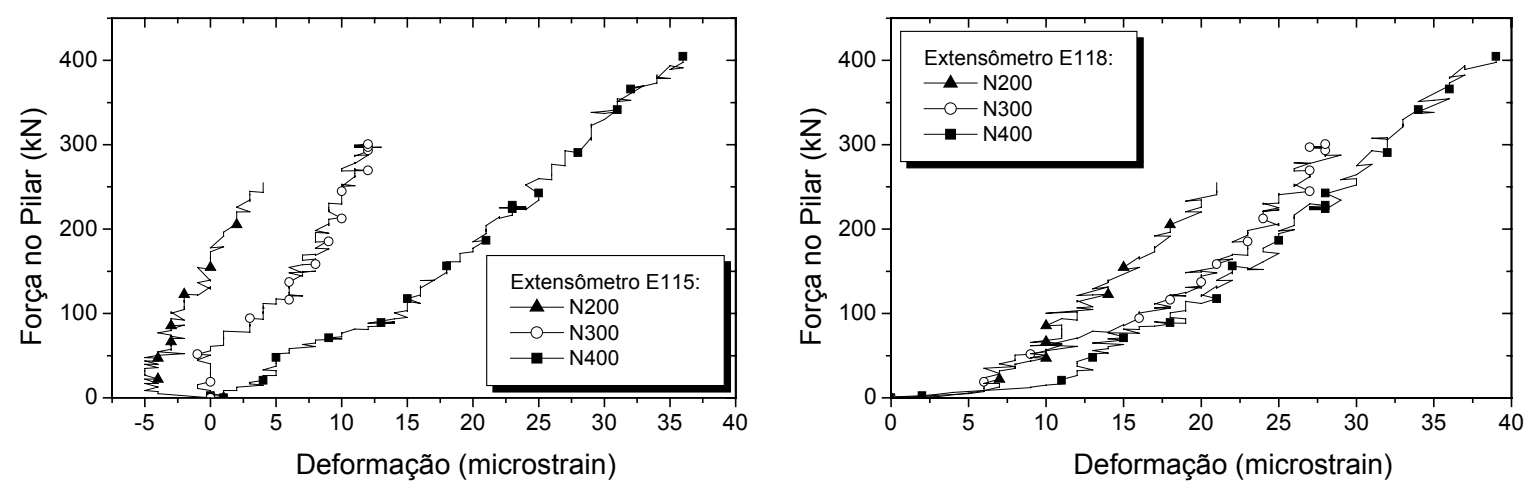

Figura 5.41 - Deformação da armadura longitudinal da viga vs. Força no pilar (Seção 3).

Segundo o princípio de Saint-Venant, há uma região definida por dimensões da mesma ordem de grandeza da seção transversal do elemento carregado, na qual se processa a regularização das tensões. Como os dois pontos de medição na viga encontravam-se dentro desta região de regularização, ou seja, distantes da face do pilar menos de $30 \mathrm{~cm}$, mesmo sem força alguma sendo aplicada na viga, os extensômetros indicaram tração das barras. Pode-se observar na Figura 5.41 que as deformações nas 
barras da viga diminuem quanto mais distante do nó, indicando a regularização das tensões.

Como visto, antes de se iniciar a aplicação da força na viga, as barras deste elemento já apresentavam uma pré-deformação, que é função do carregamento no pilar. Isto explica o fato do modelo N400 apresentar uma força de tração na barra da viga maior que dos outros modelos apesar de sua força última ser inferior a eles.

A flexão do pilar não foi simétrica em relação ao eixo da viga, pois as armaduras inferiores apresentaram-se mais tracionadas que as superiores. Desta forma, na região nodal, onde as tensões de compressão eram de valor elevado, a porção das barras superiores e inferiores se apresentou menos tracionada e no caso do modelo N400, uma ligeira compressão surgiu nas barras superiores (Figura 5.43).

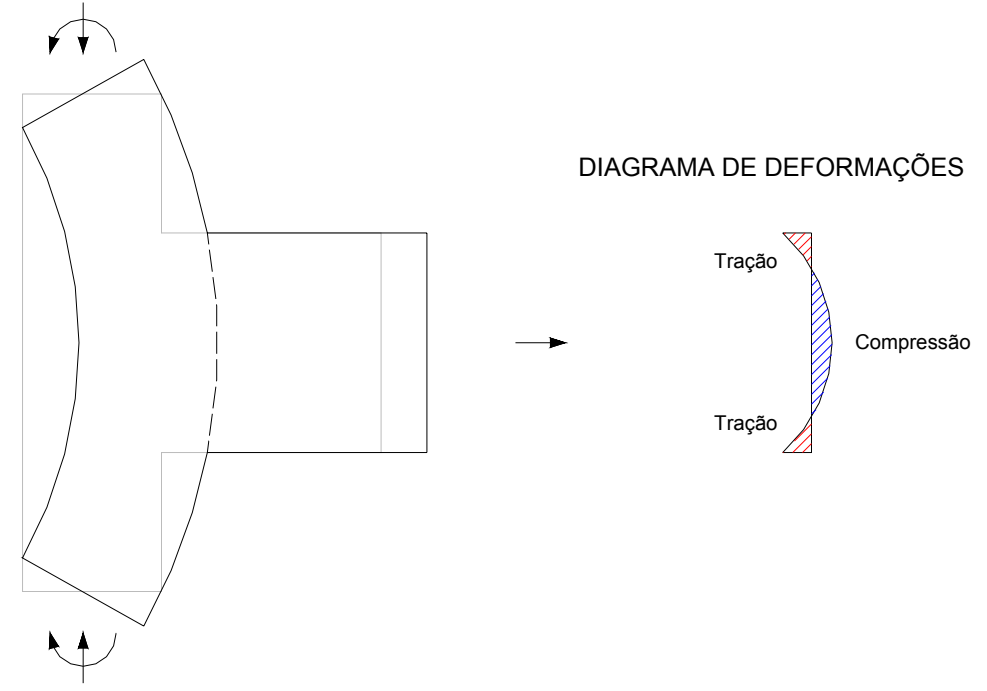

Figura 5.42 - Esquema das deformações da viga causadas pela flexão do pilar.
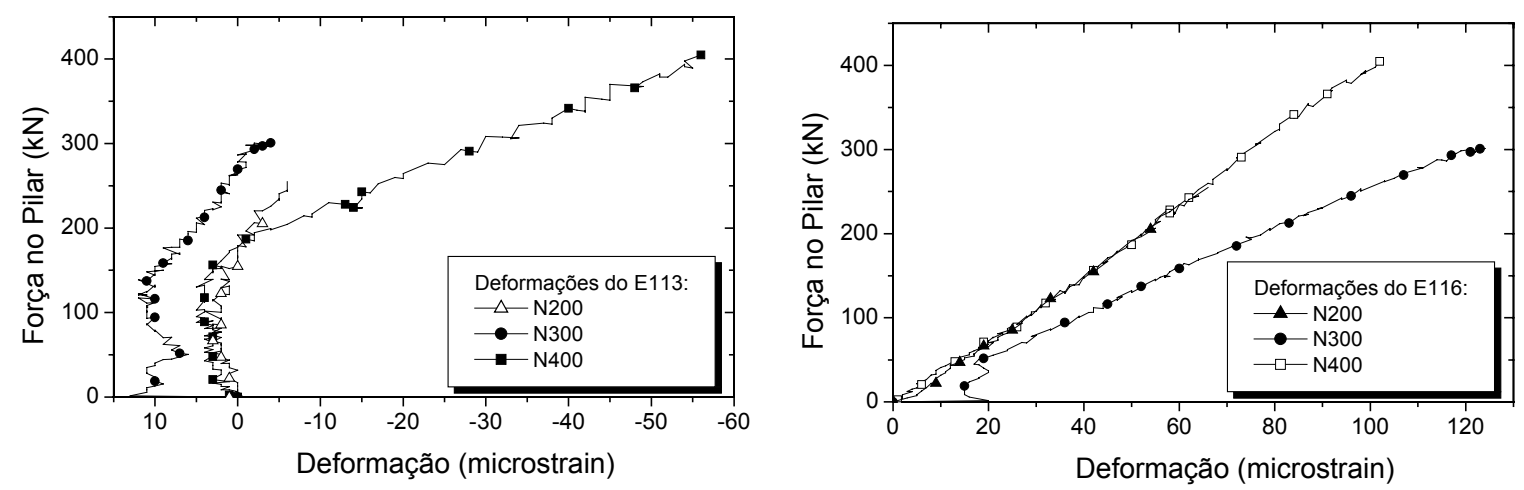

Figura 5.43 - Deformação da armadura longitudinal da viga vs. Força no pilar (Seção 1). 
Ao iniciar a aplicação da força na viga, as barras inferiores inverteram sua direção de deformação e passaram a ser comprimidas, já as barras superiores continuaram a ser tracionadas aumentando suas deformações (Figura 5.44 a Figura 5.46).
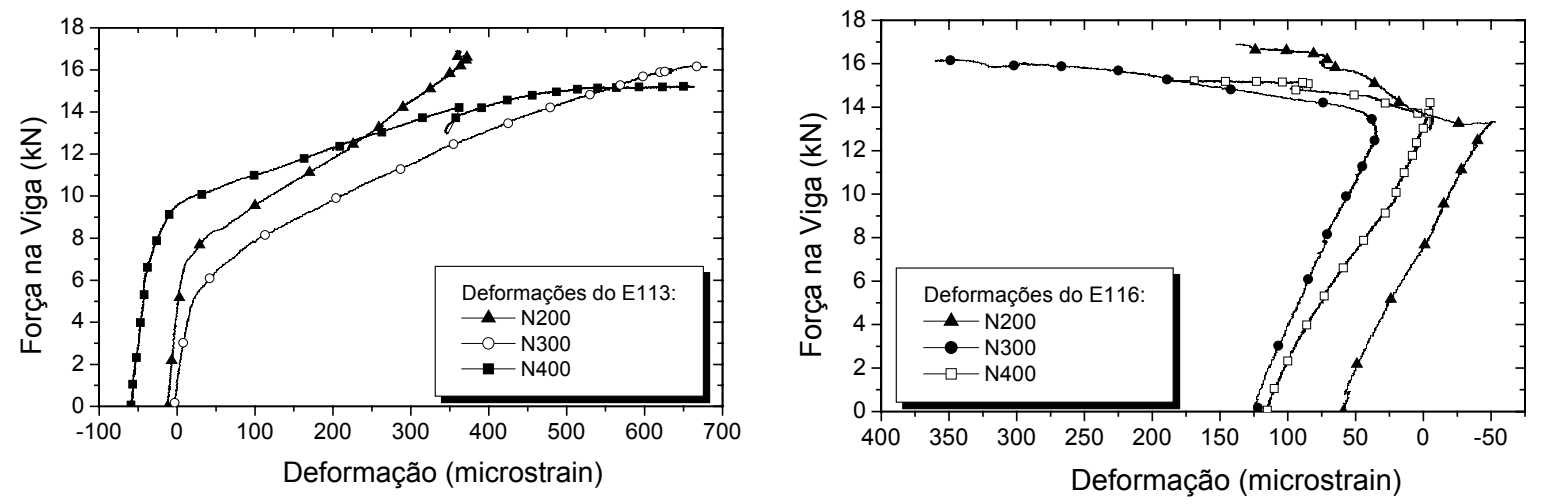

Figura 5.44 - Deformação da armadura longitudinal da viga vs. Força na viga (Seção 1).
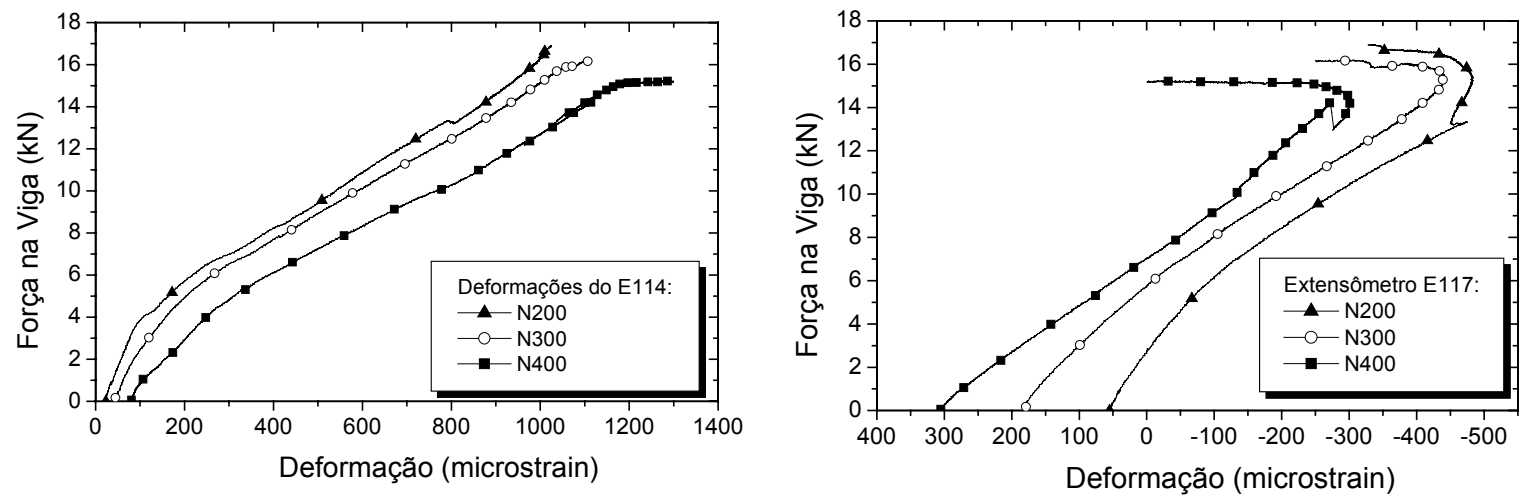

Figura 5.45 - Deformação da armadura longitudinal da viga vs. Força na viga (Seção 2).
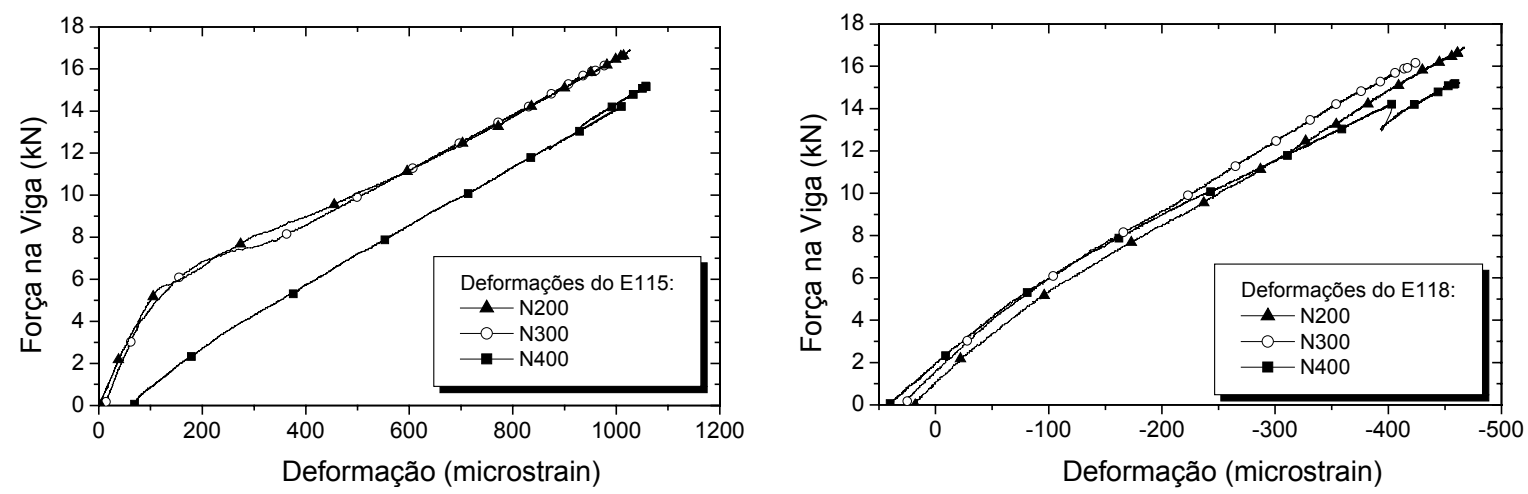

Figura 5.46 - Deformação da armadura longitudinal da viga vs. Força na viga (Seção 3). 
A ancoragem das barras da viga é diretamente influenciada pela intensidade da força de compressão do pilar e pela resistência à tração do concreto. A Figura 5.44 mostra que quanto maior a força normal e a resistência à tração do concreto, maior é a força necessária para que uma porção da armadura dentro do nó comece a ser solicitada.

A dobra das barras da viga, assim como observado por outros pesquisadores, absorve parte das tensões de compressão que solicitam o pilar (Figura 5.47).
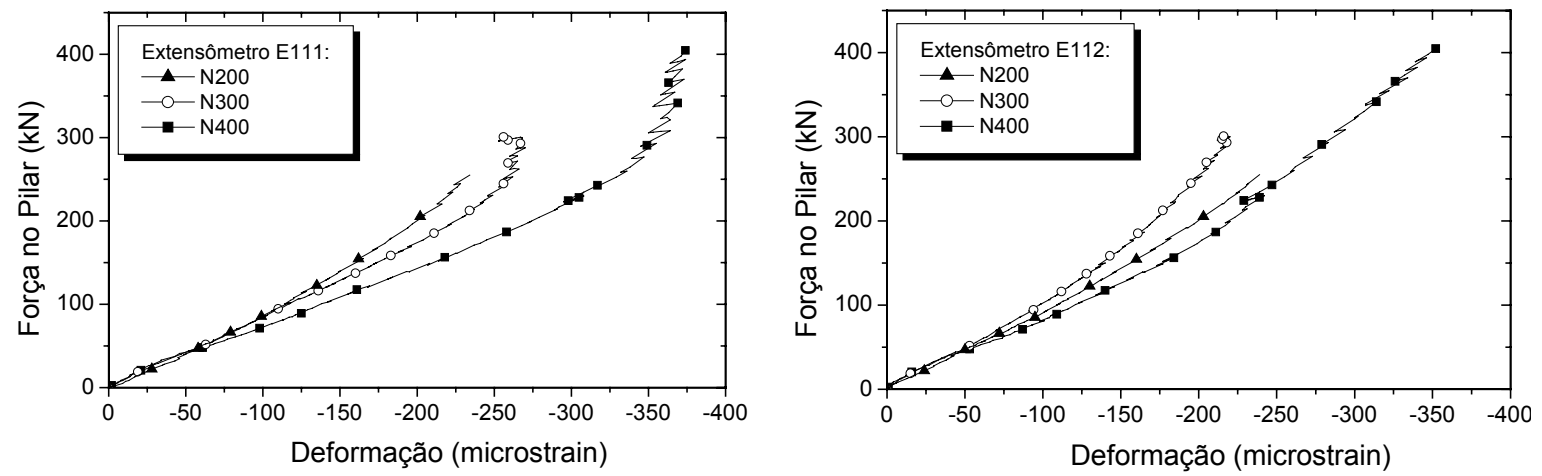

Figura 5.47 - Deformação da dobra das barras da viga vs. Força no pilar.

Esta porção da barra é solicitada pela flexão da viga praticamente só na proximidade da ruína (Figura 5.48), o que confirma a afirmação feita por Ortiz (1993) que a ancoragem só pode ser considerada com confiabilidade no trecho reto das armaduras longitudinais. A solicitação da dobra pela flexão da viga, assim como na porção horizontal da barra dentro da região nodal, varia de acordo com a força normal aplicada e com a resistência à tração do concreto.
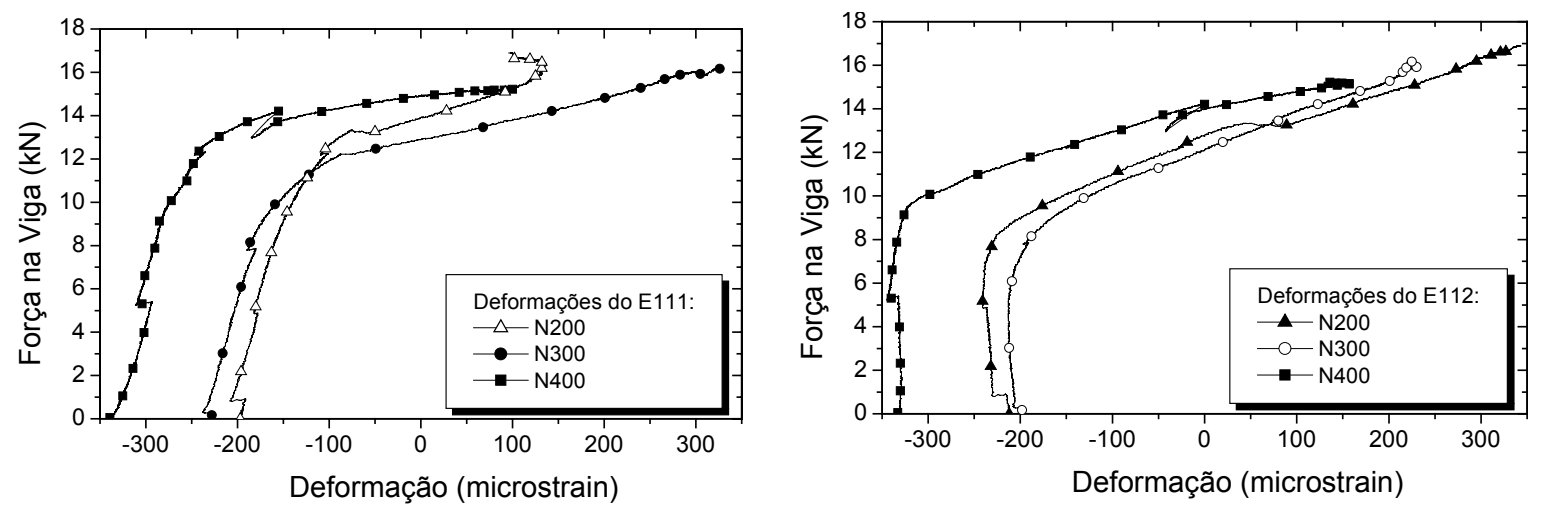

Figura 5.48 - Deformação da dobra das barras da viga vs. Força a viga. 


\subsubsection{Armadura Longitudinal do pilar}

Assim como para a viga, também foram delimitadas seções no pilar para melhor apresentação dos resultados (Figura 5.49).

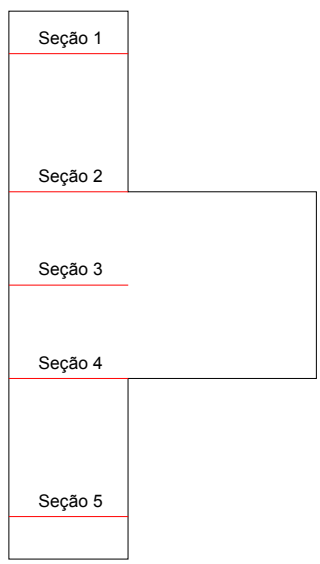

Figura 5.49 - Seções de instrumentação do pilar.

Nas seções 1 e 5, as barras do pilar apresentaram deformações que variaram linearmente com a aplicação da força na viga, com exceção do modelo N400 que apresentou um pequeno "salto" na proximidade da ruptura, causado pela acomodação de um dos tirantes como explicado anteriormente. Como era esperado, ao carregar a viga houve um acréscimo de deformações na armadura do pilar localizada na região externa e um decréscimo na região externa acima do nó, enquanto abaixo da região nodal ocorreu o inverso (Figura 5.50 e Figura 5.51).
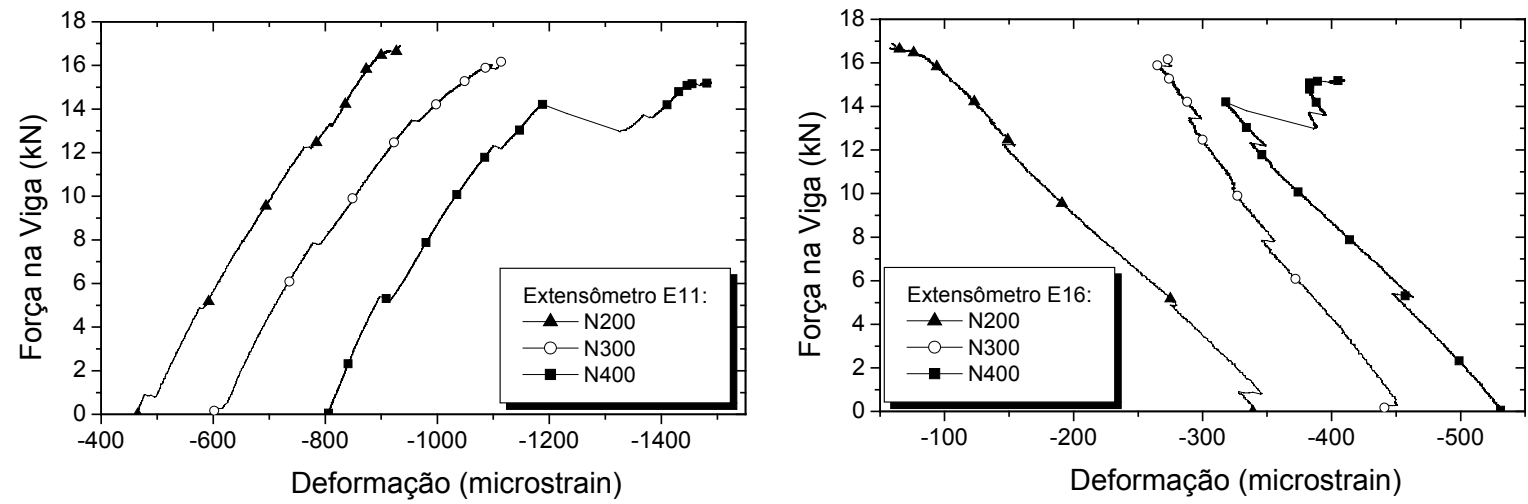

Figura 5.50 - Deformação da armadura longitudinal do pilar vs. Força no pilar (Seção 1). 

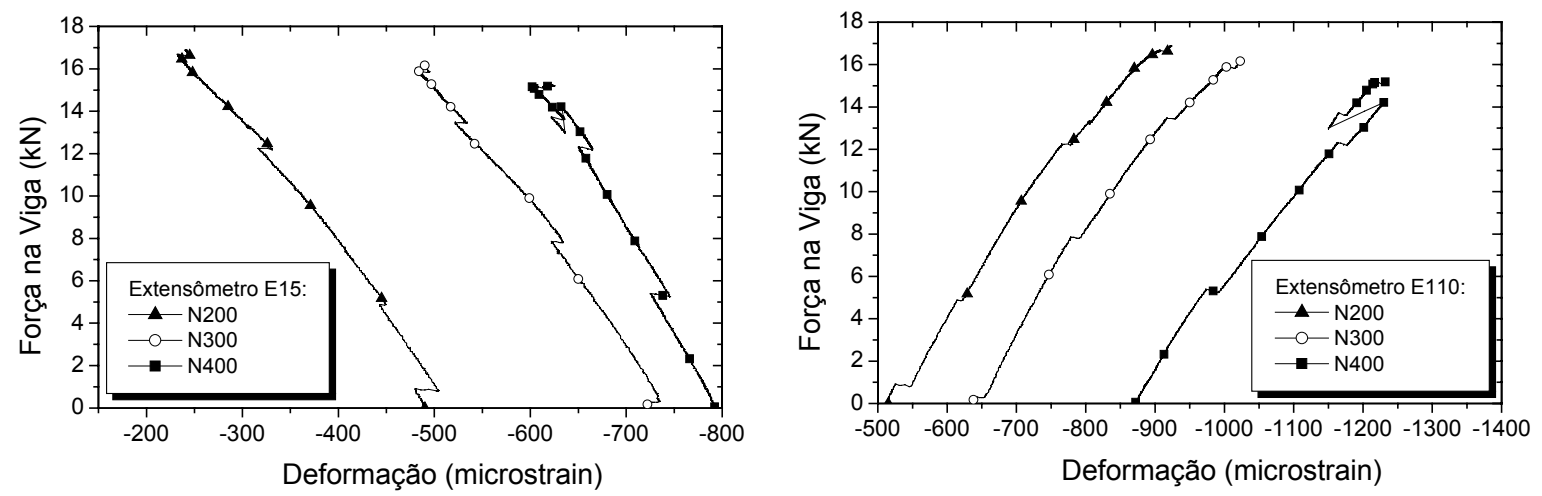

Figura 5.51 - Deformação da armadura longitudinal do pilar vs. Força no pilar (Seção 5).

As barras das seções 2 e 4 apresentaram comportamento similar às das seções 1 e 5 respectivamente, com relação às faces externas e internas (Figura 5.52 e Figura 5.53). Contudo, a partir do momento em que a biela começou a ser danificada, as deformações do estribo do nó aumentaram e todo o comprimento de ancoragem passou a ser solicitado, as barras do pilar sofreram modificação em seu comportamento. Na face externa, nas seções 2 e 3 intensificou-se as deformações de compressão, na seção 4, onde a flexão da viga aliviava as tensões de compressão advindas do pilar, as barras voltaram a ser comprimidas com a mesma intensidade ou até mesmo maior, no caso do modelo N400. Na face interna, os modelos apresentaram um comportamento que não pode ser explicado, não seguindo aparentemente nenhum padrão.
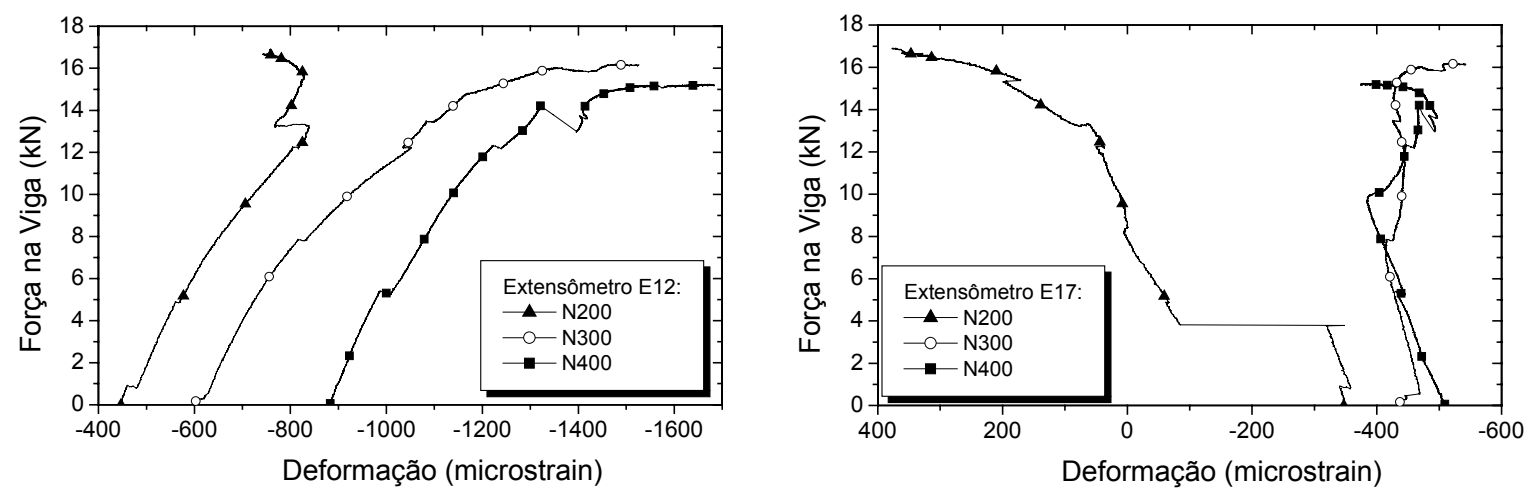

Figura 5.52 - Deformação da armadura longitudinal do pilar vs. Força no pilar (Seção 2). 

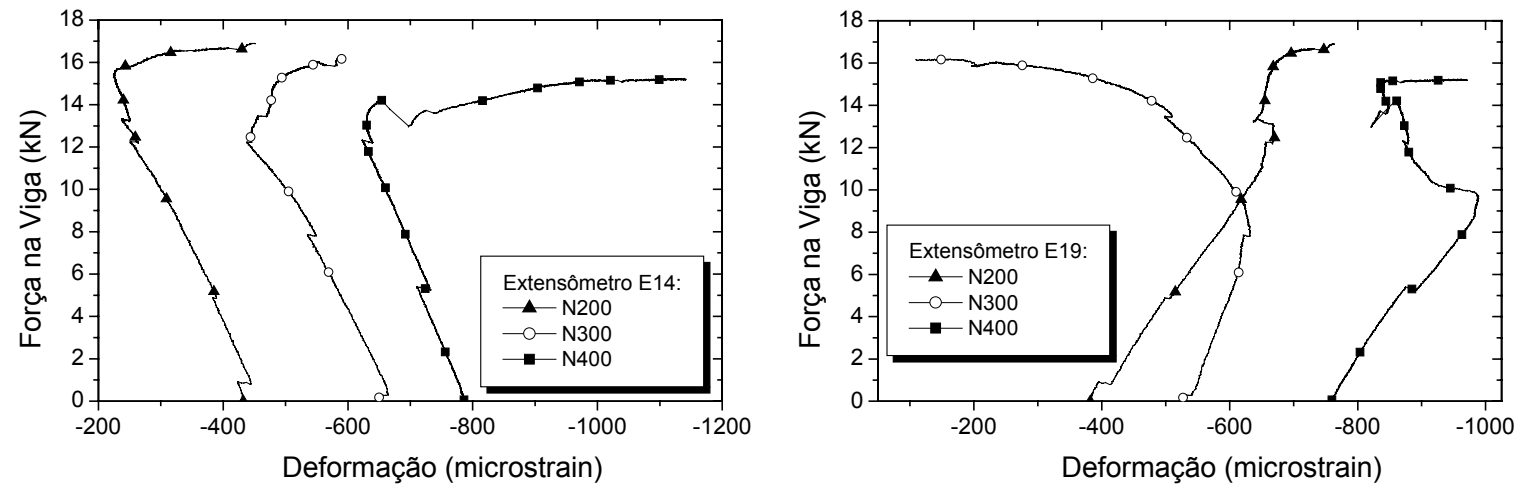

Figura 5.53 - Deformação da armadura longitudinal do pilar vs. Força no pilar (Seção 4).

No interior do nó as barras do pilar na face externa, que recebiam a colaboração da dobra da armadura da viga para resistir às tensões de compressão, apresentaram um acréscimo na taxa de compressão à medida que a dobra da viga começou a ser solicitada (Figura 5.54).
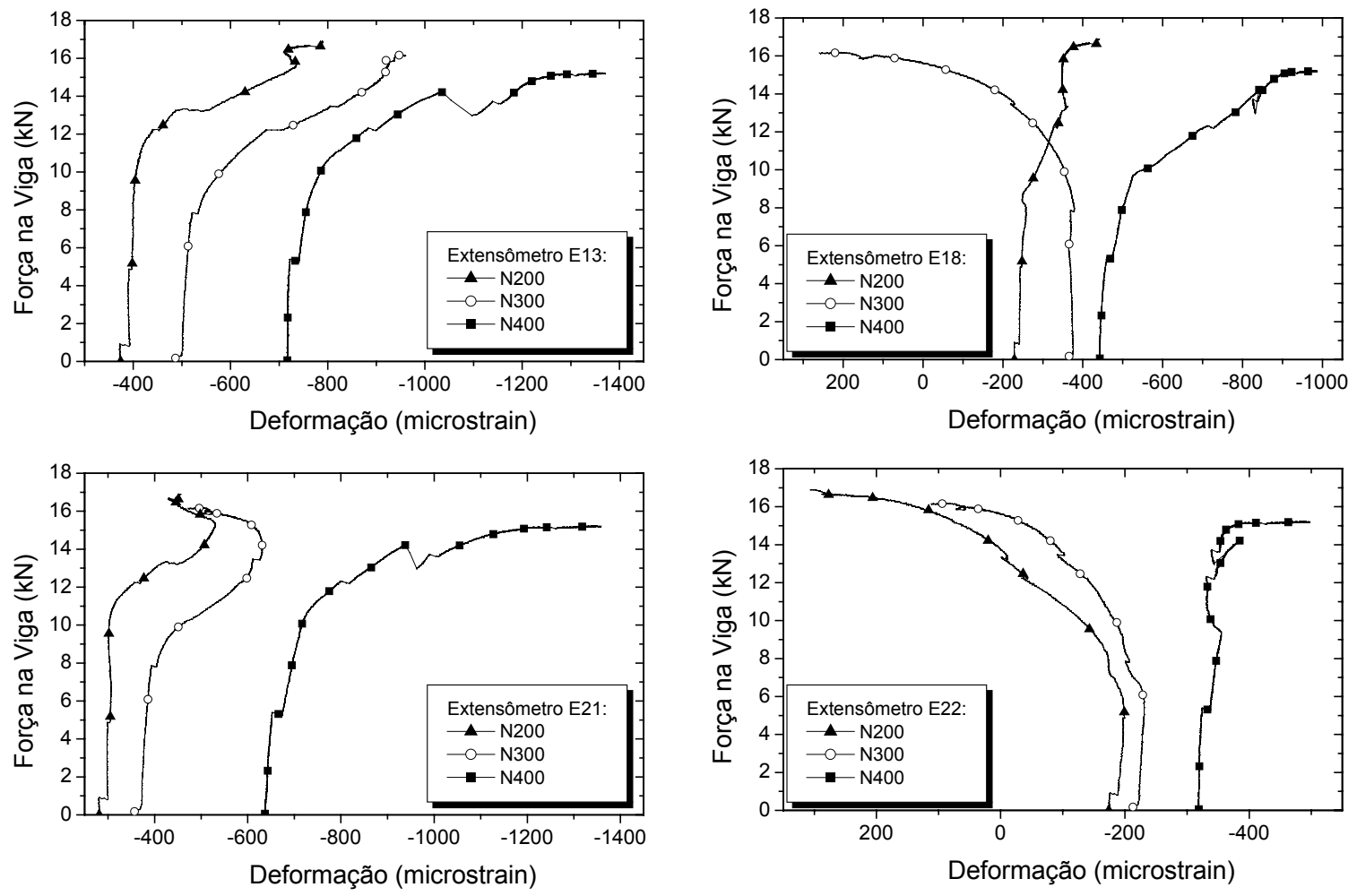

Figura 5.54 - Deformação da armadura longitudinal do pilar vs. Força no pilar (Seção 3). 


\subsubsection{Armadura Transversal do pilar}

A armadura transversal, durante o carregamento do pilar, apresentou uma pequena deformação que variou de maneira linear com a força normal. Na etapa do carregamento da viga, apenas o estribo localizado logo acima da região nodal é que apresentou deformações significativas, e mesmo assim, somente na proximidade da ruína.

A solicitação destes estribos depende basicamente do comportamento das tensões de aderência nas armaduras tracionadas longitudinais da viga, ou seja, eles passam a ser solicitados à medida que aumentam as tensões de aderência ao longo das barras da viga dentro da região nodal. Como explicado anteriormente, a força normal melhora as condições de aderência, sendo necessário uma maior força de tração nas barras para solicitar um mesmo comprimento de ancoragem. Conseqüentemente, o estribo acima do nó, para modelos com maior força normal, demora mais a ser solicitado (Figura 5.55), porém vale ressaltar que a resistência à tração do concreto também apresenta uma grande influência sobre a transferência de tensões das armaduras longitudinais para o concreto.

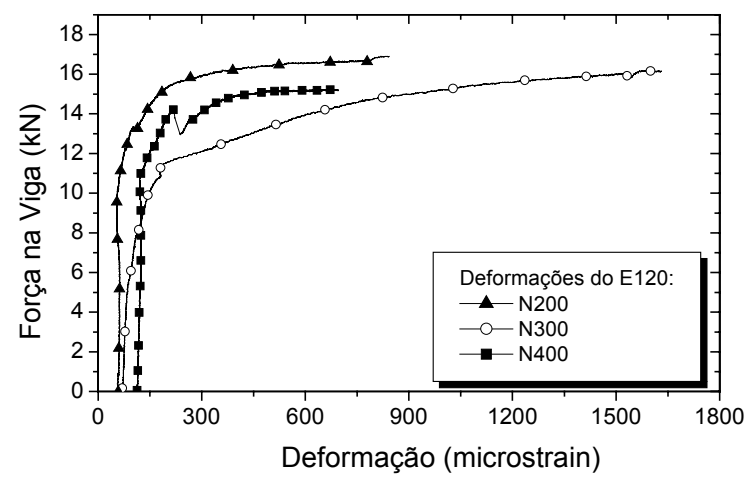

Figura 5.55 - Deformação do estribo do pilar acima do nó vs. Força na viga.

\subsection{Resultados Experimentais vs. Modelos Teóricos}

A maioria dos modelos teóricos é baseada em modelos de bielas e tirantes e considera a resistência do nó por meio de duas parcelas: uma referente ao mecanismo da 
biela diagonal principal e a outra referente ao mecanismo de treliça. Esta concepção induz a pensar que a resistência do nó seja igual à soma das resistências oferecidas por cada mecanismo, no entanto eles podem atingir a ruína separadamente. Neste sentido, alguns modelos apresentam como capacidade da ligação a soma das proporções oferecidas por cada mecanismo, porém adotando um valor máximo para esta resistência. Outros que não fazem esta consideração, ficam limitados a alguns casos específicos.

A Tabela 5.2 apresenta o valor das forças últimas calculadas para cada modelo ensaiado, de acordo com os modelos teóricos descritos no Capítulo 3.

Tabela 5.2 - Forças Últimas: Experimental vs. Modelos Teóricos.

\begin{tabular}{|c|c|c|c|c|c|c|c|c|}
\hline Modelo & $\begin{array}{c}\text { Paulay \& } \\
\text { Priesteley } \\
(\mathrm{kN})\end{array}$ & $\begin{array}{c}\text { Ortiz } \\
(\mathrm{kN})\end{array}$ & $\begin{array}{c}\text { Parker \& } \\
\text { Bullman } \\
(\mathrm{kN})\end{array}$ & $\begin{array}{c}\text { Hwang } \\
\& \text { Lee } \\
(\mathrm{kN})\end{array}$ & $\begin{array}{c}\text { Tsonos } \\
(\mathrm{kN})\end{array}$ & $\begin{array}{c}\text { Bakir \& } \\
\text { Boduroglu } \\
(\mathbf{k N})\end{array}$ & $\begin{array}{c}\text { Hegger } \\
\text { et al. } \\
(\mathrm{kN})\end{array}$ & $\begin{array}{c}\text { Exp. } \\
(\mathrm{kN})\end{array}$ \\
\hline N400 & 20 & 20 & 15 & 24 & 20 & 30 & 11 & 15,2 \\
\hline N300 & 20 & 21 & 15 & 22 & 20 & 30 & 15 & 16,0 \\
\hline N200 & 21 & 22 & 15 & 21 & 21 & 30 & 20 & 16,9 \\
\hline
\end{tabular}

No caso do modelo de Paulay \& Priesteley (1992) o limitante da resistência foi a tensão de cisalhamento máxima, e no modelo de Bakir \& Boduroglu (2002) o limitante foi a capacidade da seção da viga. Desta forma, não se pode tirar conclusões quanto à força normal para estes modelos para os casos ensaiados. Contudo, nota-se pelas formulações que no primeiro modelo a força normal contribui para a resistência do nó, diminuindo o esforço a ser resistido pelas armaduras e no segundo os autores consideram que a força axial aplicada no pilar não apresenta influência na ligação.

Com relação aos outros modelos observa-se que apenas em Hwang \& Lee (1999) o aumento da força normal provoca um ganho de resistência, uma vez que neste modelo isto gera um acréscimo da largura da biela diagonal principal. Porém esta consideração apresenta um aspecto negativo, pois da mesma maneira que a biela sofre um enrijecimento com o aumento da força normal na ligação, representado neste caso pelo aumento da largura da biela, sua danificação se torna mais acentuada reduzindo assim sua rigidez por outro lado. Nota-se que este modelo não representou bem o tipo de ruptura dos experimentos, indicando que esta se daria por escoamento dos estribos, o que não aconteceu. Hwang \& Lee (1999) consideram valores limites na distribuição de 
esforços de acordo com a inclinação da biela, ou seja, adota-se que a força cortante em ligações onde a inclinação da biela apresenta tangente superior a 2 é absorvido totalmente pelos estribos, e caso esta tangente seja inferior a 0,5 a parcela dos estribos é nula, para valores intermediários é feito uma interpolação. No entanto, nos modelos ensaiados experimentalmente, cujas inclinações de biela eram próximas a este limite superior a ruína da ligação se deu pelo esmagamento da biela. Analisando-se os resultados do modelo, observou-se que $90 \%$ da força cortante que agia no nó era absorvida pelos estribos, contudo os resultados experimentais mostraram que esta porcentagem foi de apenas $25 \%$. Utilizando no modelo o valor da força última absorvida pelo estribo obtida do ensaio, obteve-se a capacidade do nó limitada pela biela, como observado nos experimentos. Isto comprova que a deficiência do modelo proposto por Hwang \& Lee (1999) está na consideração das parcelas da força cortante horizontal que são absorvidas pelos estribos e pela biela diagonal comprimida.

No modelo de Parker \& Bullman (1997) são realizadas duas verificações, a influência da força normal é considerada em uma delas, no entanto esta consideração não é percebida para configuração dos nós de pórtico estudados, uma vez que a resistência não é limitada por esta verificação.

O modelo proposto por Ortiz (1993) considera a influência da força normal no cálculo da inclinação da biela, pois esta é função das forças cortantes vertical e horizontal no nó. Pode-se considerar como um ponto positivo no modelo de Ortiz (1993), a limitação da quantidade de estribos no nó, pois acima de um certo valor não há mais ganho de resistência. Desta maneira, indiretamente, considera-se a possibilidade da ruína da biela diagonal prematuramente, porque ao se aumentar o número de estribos na região nodal para se atingir uma maior resistência, "esbarra-se" na capacidade da biela.

Tsonos (1999), não considera a influência da força normal em seu modelo de cálculo, apesar deste ser baseado no equilíbrio de forças considerando tensões normais e tangenciais uniformemente distribuídas na região nodal, pois seu modelo faz a simplificação da relação entre as forças cortantes vertical e horizontal, como sendo igual à relação das alturas da viga e do pilar.

No caso de Hegger et al. (2003), a força normal limita o valor máximo da resistência da parcela do mecanismo da biela diagonal, o que vai de acordo com as observações feitas nos ensaios experimentais.

De um modo geral, os modelos teóricos previram uma resistência maior que a verificada nos modelos ensaiados, apresentando-se contra a segurança. 


\section{SIMULAÇÃO NUMÉRICA}

\subsection{Introdução}

Antes do estudo numérico do nó de pórtico externo propriamente dito, foi realizada uma avaliação detalhada do comportamento de modelos de arrancamento com o intuito de se compreender melhor a interface aço-concreto (Apêndice B). Este estudo procurou simular numericamente as propriedades do contato existente entre as barras da armadura e o concreto, utilizando as ferramentas disponíveis no aplicativo $A B A Q U S^{\circledR}$. Num segundo instante seriam utilizados estes modelos para a calibragem das propriedades da interface a serem aplicadas na simulação do nó externo.

A simulação numérica do nó de pórtico externo, assim como a dos modelos de

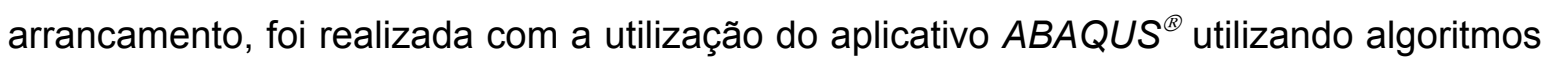
baseados em técnicas do tipo Newton-Raphson, e teve como objetivo inicial representar o comportamento dos modelos ensaiados em laboratório adotando-se as propriedades mecânicas observadas na análise experimental de cada material. Numa segunda etapa, foi então realizada a variação da força normal aplicada ao pilar para a análise da sua influência sobre o comportamento da ligação.

\subsection{Definição do modelo}

Inicialmente, pensou-se na simulação tridimensional da ligação, representando todas as armaduras do modelo por meio de elementos sólidos de oito nós. Porém 
surgiram várias dificuldades no instante da geração da malha na região nodal, principalmente por causa do formato circular das barras, do encontro das armaduras da viga e do pilar e das pequenas dimensões da região (Figura 6.1).

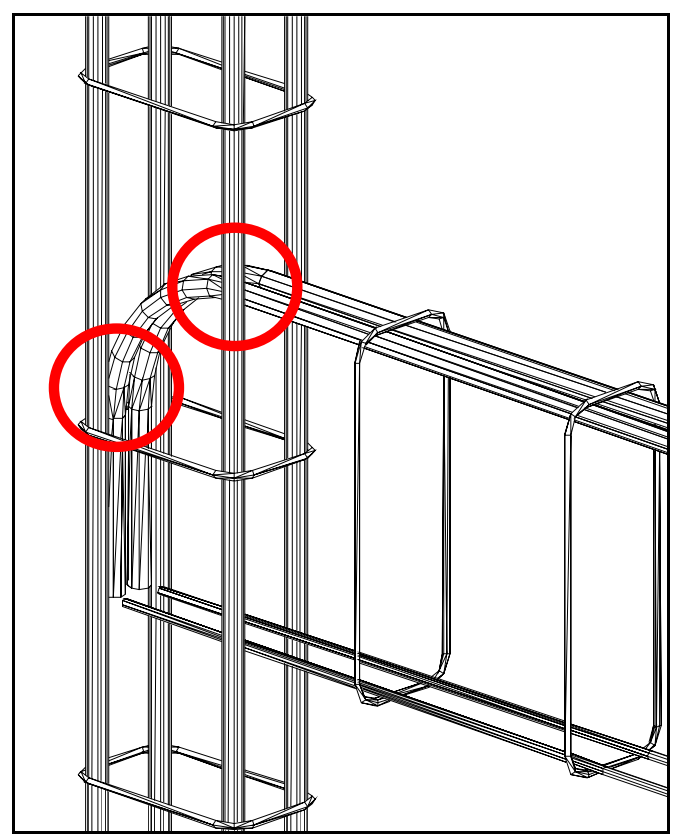

Figura 6.1 - Pontos de dificuldade de geração da malha de elementos finitos.

Desta forma, optou-se pela modelagem bidimensional, utilizando elementos de chapa. No entanto, não era possível a utilização destes elementos para as barras do pilar e da viga simultaneamente, por causa da impossibilidade da continuidade dos elementos no encontro destas armaduras. Sendo assim, adotou-se elementos de chapa apenas para as barras da viga e no caso das armaduras do pilar optou-se pela adoção de elementos de barra perfeitamente aderentes ao concreto. Contudo, surgiram muitos problemas de convergência neste modelo, causados principalmente pela utilização da superfície de contato entre os elementos. Outra dificuldade encontrada foi a de definir a superfície de contato, pois não havia como manter uma mesma taxa de armadura na viga com mesma área da superfície da interface. Em virtude, dos inúmeros problemas encontrados, decidiu-se utilizar elementos de chapa apenas para o concreto, enquanto que as armaduras foram representadas por elementos de barra.

A malha de elementos finitos utilizada está apresentada na Figura 6.2. 


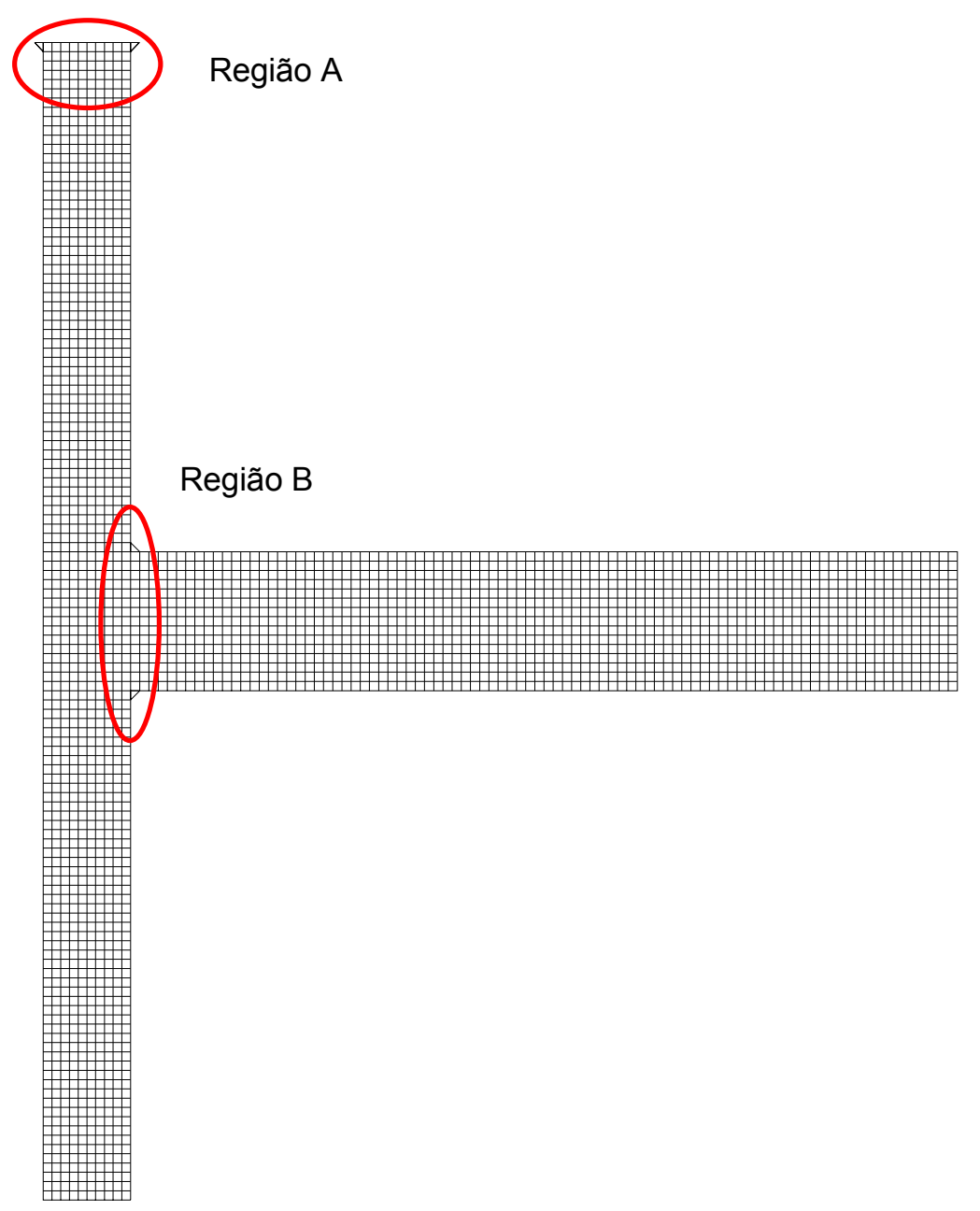

Figura 6.2 - Malha de elementos finitos.

Foram utilizados elementos quadrangulares sólidos com dois graus de liberdade por nó, do tipo CPS4 da biblioteca do aplicativo $A B A Q U S^{\circledR}$ para representar o concreto. As armaduras longitudinais e os estribos, da viga e do pilar, foram representados por elementos de barras com dois graus de liberdade por nó, do tipo T2D2, com seus nós acoplados aos nós dos elementos de chapa por meio do comando EMBEDDED ELEMENT (Figura 6.3).

Na extremidade superior (região A da Figura 6.2), onde era aplicada uma força de compressão axial ao pilar, e na ligação da viga com o pilar (região B da Figura 6.2), foram colocados elementos triangulares adicionais com dois graus de liberdade por nó, do tipo CPS3, para se evitar a ruptura prematura do modelo causada pela concentração de tensões nos cantos.

A Tabela 4.3 apresenta a quantidade de elementos utilizados no modelo. 


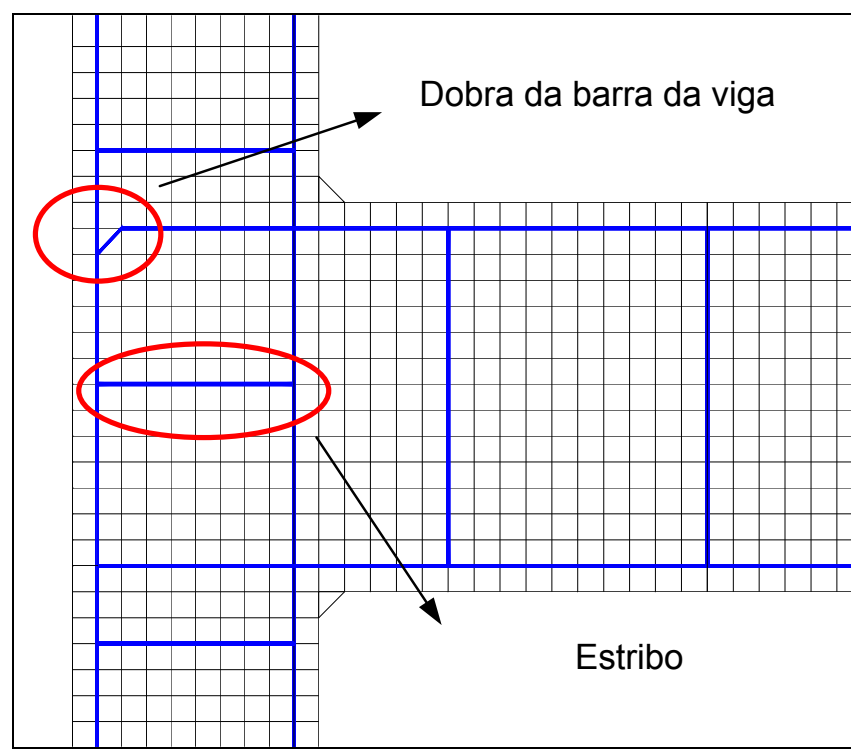

\section{NÓS DO ESTRIBO DA REGIÃO NODAL}

Figura 6.3 - Consideração das armaduras do modelo.

Tabela 6.1 - Quantidade de elementos utilizados no modelo numérico.

\begin{tabular}{|c|c|c|}
\hline Elemento & Tipo & Quantidade \\
\hline \multirow{2}{*}{ Concreto } & CPS4 & 2600 \\
\cline { 2 - 3 } & CPS3 & 4 \\
\hline Estribos do pilar & T2D2 & 8 por estribo = 88 \\
\hline Estribos da viga & T2D2 & 13 por estribo $=182$ \\
\hline Barras Longitudinais do pilar & T2D2 & 125 por barra $=250$ \\
\hline Barras tracionadas da viga & T2D2 & 110 \\
\hline Barras comprimidas da viga & T2D2 & 88 \\
\hline
\end{tabular}

Para que o modelo 2D tivesse representatividade, manteve-se constante: a taxa de armadura longitudinal e transversal do pilar e da viga, a tensão normal aplicada ao pilar e o momento adimensional $\mu$ no nó, gerado pela força aplicada no balanço.

$$
\mu=\frac{M_{\text {balanço }}}{A_{c v}{ }^{*} f_{c}{ }^{*} h_{v}}
$$

Onde, $A_{c v}$ é a área da seção transversal da viga, $h_{v}$ é a altura da viga e $M_{\text {balanço é o }}$ momento gerado pela força aplicada na extremidade do balanço. 


\subsection{Comportamento dos materiais}

Inicialmente foram consideradas, para aço e concreto as propriedades: módulo de elasticidade e resistências à tração e compressão obtidas pelos experimentos realizados em laboratório, tentando com isso representar da melhor maneira possível o comportamento destes materiais durante o ensaio. A análise da influência da força normal no comportamento do nó de pórtico foi realizada considerando o comportamento do concreto de acordo com o CEB-FIP (1990), já que este código apresenta um diagrama Tensão-deformação mais completo do que a norma brasileira, incluindo o amolecimento do material. No caso do aço, considerou-se sua resistência característica e módulo de elasticidade como sugerido pelo mesmo código.

\subsubsection{Aço}

O modelo reológico adotado para o aço foi o elasto-plástico perfeito, já que não interessa-nos o comportamento deste material após o escoamento.

As propriedades das armaduras do modelo numérico estão apresentadas na Tabela 6.2 .

Tabela 6.2 - Propriedades das armaduras.

\begin{tabular}{|c|c|c|c|}
\hline Diâmetro $(\mathrm{mm})$ & $v$ & $E_{\text {exp }}-E_{N B R}\left(k N / c^{2}\right)$ & fyexp - fyk $\left(\mathrm{kN} / \mathrm{cm}^{2}\right)$ \\
\hline 16,0 & 0,3 & $20576-21000$ & $51,5-50,0$ \\
\hline 6,3 & 0,3 & $20576-21000$ & $56,0-50,0$ \\
\hline$\overline{5,0}$ & 0,3 & $20576-21000$ & $68,4-60,0$ \\
\hline $\begin{array}{l}E_{\text {exp }}-\text { Módulo de elasti } \\
E_{N B R}-\text { Módulo de elast } \\
f_{\text {exp }}-\text { Resistência de e } \\
\text { fyk - Resistência de es }\end{array}$ & $\begin{array}{l}\text { obs } \\
\text { le su } \\
\text { nent } \\
\text { ento }\end{array}$ & $\begin{array}{l}\text { ervado em laboratóri } \\
\text { yerido pela NBR } 611 \\
\text { observada em labo } \\
\text { característica }\end{array}$ & $\begin{array}{l}2003 \\
\text { atório }\end{array}$ \\
\hline
\end{tabular}




\subsubsection{Concreto}

Foi considerado para o concreto o comportamento biaxial de acordo com a superfície teórica proposta por Kupfer \& Gerstle (1973) (Figura 6.4), que segue as equações ( 6.2 ), ( 6.3 ) e ( 6.4 ).

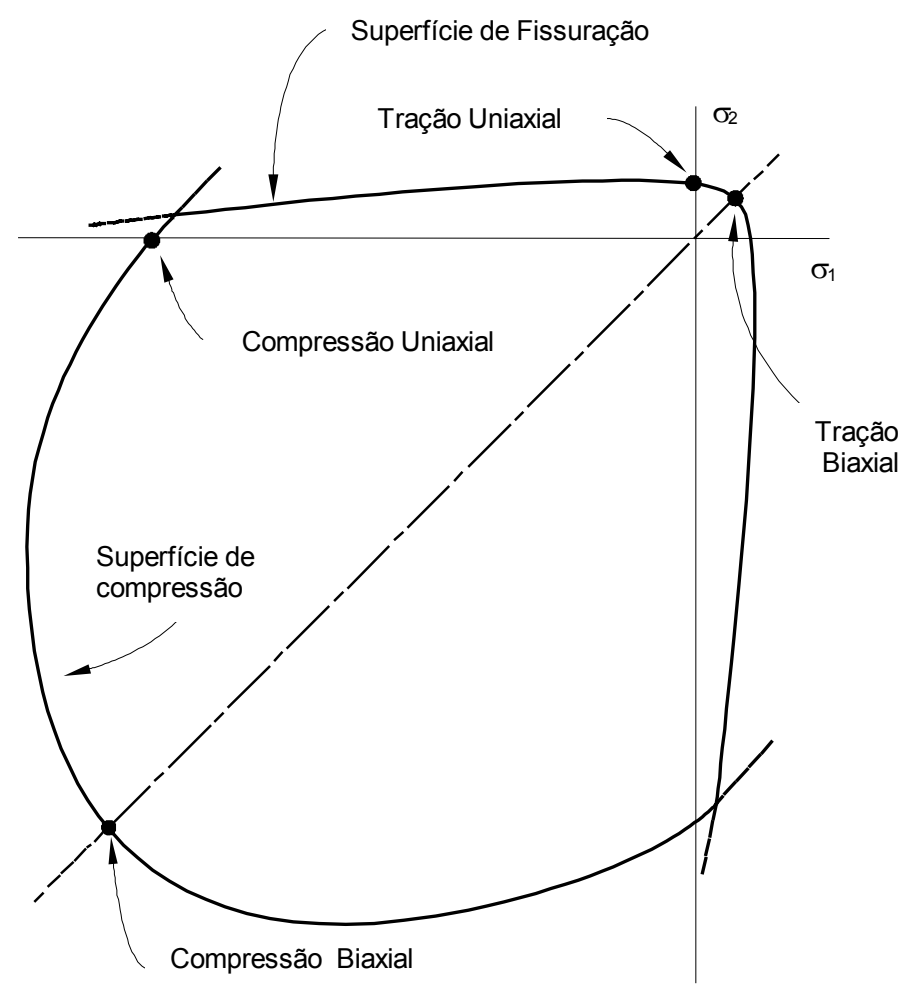

Figura 6.4 - Superfície Teórica proposta por Kupfer \& Gerstle (1973).

Fonte: Adaptado do manual do programa $A B A Q U S^{\circledR}$

$$
\begin{array}{lr}
f\left(\sigma_{1}, \sigma_{2}\right)=\left(\frac{\sigma_{1}}{f_{c}}+\frac{\sigma_{2}}{f_{c}}\right)^{2}+\frac{\sigma_{1}}{f_{c}}+3,65 * \frac{\sigma_{2}}{f_{c}}=0 & \text { (compressão biaxial) } \\
f\left(\sigma_{1}, \sigma_{2}\right)=\frac{\sigma_{2}}{f_{t}}-1-0,8 * \frac{\sigma_{1}}{f_{c}}=0 & \text { (tração-compressão) } \\
\sigma_{2}=f_{t}=0,64 * \sqrt[3]{f_{c}^{2}} & \text { (tração-tração) }
\end{array}
$$


Para o comportamento uniaxial à compressão adotou-se o diagrama tensãodeformação apresentado pelo Código Modelo CEB-FIP (1990) (Figura 6.5) definido pelas equações de ( 6.5 ) à ( 6.8 ).

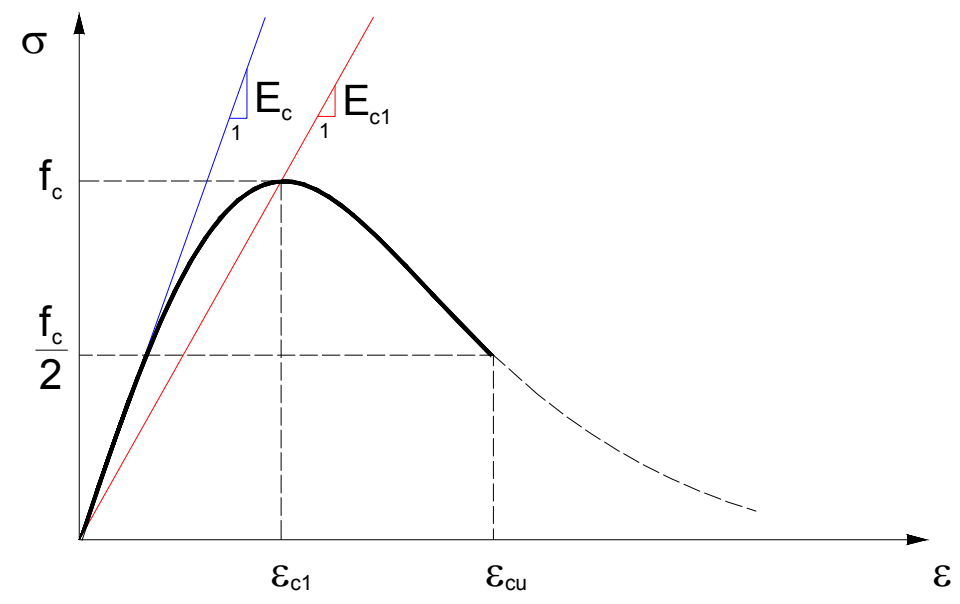

Figura 6.5 - Diagrama Tensão-Deformação para o concreto (CEB-FIP, 1990).

$\sigma_{c}=-\frac{\frac{E_{c}}{E_{c 1}} * \frac{\varepsilon_{c}}{\varepsilon_{c 1}}-\left(\frac{\varepsilon_{c}}{\varepsilon_{c 1}}\right)^{2}}{1+\left(\frac{E_{c}}{E_{c 1}}-2\right) * \frac{\varepsilon_{c}}{\varepsilon_{c 1}}}{ }^{*} f_{c} \rightarrow$ para $\left|\varepsilon_{c}\right|<\left|\varepsilon_{c u}\right|$

$\sigma_{c}=-\frac{f_{c}}{\left[\left(\frac{1}{\frac{\varepsilon_{c u}}{\varepsilon_{c 1}}} * \xi-\frac{2}{\left(\frac{\varepsilon_{c u}}{\varepsilon_{c 1}}\right)^{2}}\right) *\left(\frac{\varepsilon_{c}}{\varepsilon_{c 1}}\right)^{2}+\left(\frac{4}{\frac{\varepsilon_{c u}}{\varepsilon_{c 1}}}-\xi\right) * \frac{\varepsilon_{c}}{\varepsilon_{c 1}}\right]} \rightarrow$ para $\left|\varepsilon_{c}\right|>\left|\varepsilon_{c u}\right|$

$\varepsilon_{c u}=\varepsilon_{c 1} *\left\{\frac{1}{2} *\left(\frac{E_{c}}{2 * E_{c 1}}+1\right)+\sqrt{\left[\frac{1}{4} *\left(\frac{E_{c}}{2 * E_{c 1}}+1\right)^{2}-\frac{1}{2}\right]}\right\}$

$\xi=\frac{4 *\left(\left(\frac{\varepsilon_{c u}}{\varepsilon_{c 1}}\right)^{2} *\left(\frac{E_{c}}{E_{c 1}}-2\right)+2 * \frac{\varepsilon_{c u}}{\varepsilon_{c 1}}-\frac{E_{c}}{E_{c 1}}\right)}{\left(\frac{\varepsilon_{c u}}{\varepsilon_{c 1}} *\left(\frac{E_{c}}{E_{c 1}}-2\right)+1\right)^{2}}$ 
Para o comportamento à tração, como o modelo de material utilizado do aplicativo $A B A Q U S^{\circledR}$ não permitia a consideração de um diagrama bilinear no trecho entre zero e a resistência à tração, adotou-se então o comportamento elástico com módulo de elasticidade igual ao da compressão. Para representar a deformação das armaduras através das fissuras, foi considerado o comportamento pós-ruptura, de maneira linear (Figura 6.6). Este comportamento simula de maneira simplificada a interação entre concreto e armadura. A deformação última de tração $\left(\varepsilon_{m}\right)$ para o concreto fica limitada pelo escoamento das armaduras, ou seja, $\varepsilon_{\mathrm{m}}$ igual a $\varepsilon_{\mathrm{y}}$.

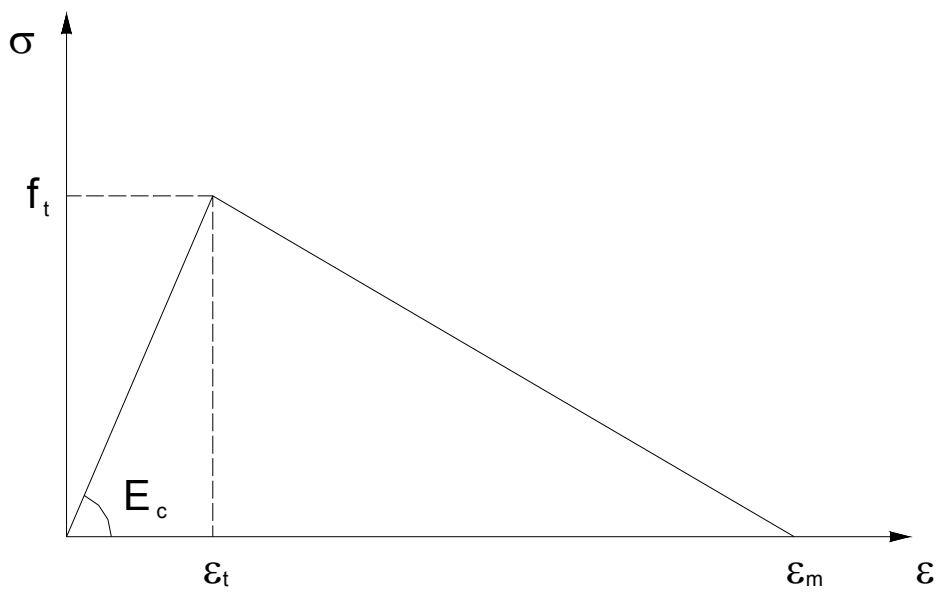

Figura 6.6 - Modelo para enrijecimento à tração.

Na análise da influência da força normal no comportamento do nó de pórtico foram admitidos o módulo de elasticidade e a resistência à tração a partir da resistência à compressão, como sugeridos pelo CEB-FIP (1990).

Tanto para análise dos modelos ensaiados quanto para a análise da influência da força normal no comportamento do nó de pórtico, adotou-se um coeficiente de Poisson para o concreto igual a 0,2 .

\subsection{Condições de contorno e carregamento}

Como a região de interesse era o nó, desprezou-se as porções do pilar que ultrapassavam os apoios laterais do modelo. Sendo assim, adotou-se que os nós da extremidade superior do pilar não apresentavam deslocamentos horizontais, enquanto 
que aqueles localizados na porção inferior do pilar não apresentavam deslocamentos horizontais e verticais (Figura 6.7).
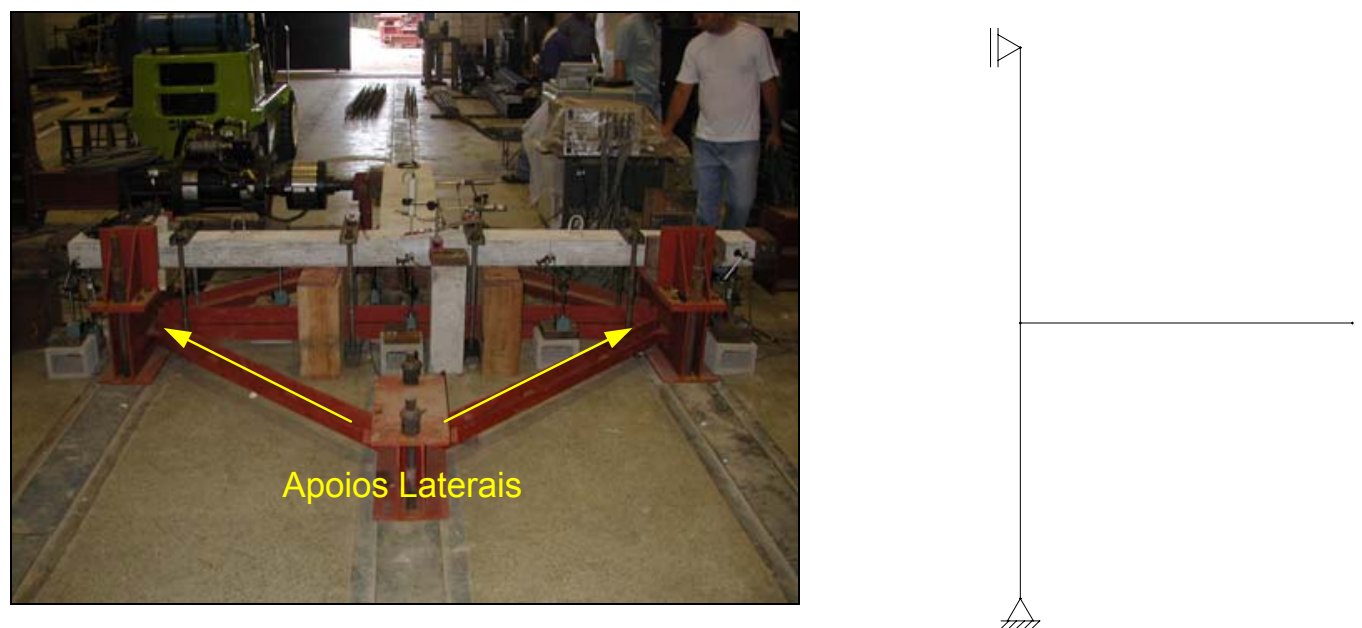

Figura 6.7 - Condições de contorno do modelo numérico.

O carregamento aplicado ao modelo numérico procurou ao máximo representar o mesmo utilizado no programa experimental. Desta forma, definiu-se dois passos de carga, onde no primeiro foi aplicada toda força normal pretendida e no segundo foram prescritos deslocamentos na extremidade da viga. O processamento deste segundo passo foi bastante trabalhoso, pois à medida que o modelo se aproximava da ruína, os problemas de convergência aumentavam muito sendo necessário diminuir o tamanho do incremento de deslocamento assim como fazer modificações nas variáveis de controle de convergência, por causa do comportamento não-linear. Em conseqüência destes agravantes, infelizmente o modelo numérico não conseguiu avaliar a força última dos modelos analisados, com exceção daqueles em que houve o escoamento de alguma armadura, por causa do surgimento de instabilidades locais. No entanto, o comportamento dos modelos ao longo do carregamento apresentou-se satisfatório na região nodal, principalmente, comparando-os com os experimentos realizados em laboratório. 


\subsection{Resultados}

O modelo numérico, de maneira geral, apresentou-se mais rígido que o modelo experimental (Figura 6.8 à Figura 6.10). Vale lembrar, que não foram consideradas as excentricidades da força normal em relação às duas direções localizadas no plano da seção do pilar, como foi observado no modelo experimental. Desta forma, algumas das diferenças encontradas entre os dois modelos podem ter ocorrido por causa deste efeito.

As deformações das armaduras representaram o comportamento experimental de maneira satisfatória para alguns pontos do modelo, em especial no estribo localizado na região nodal (Figura 6.11 à Figura 6.13) e nas barras tracionadas da viga na vizinhança do nó (Figura 6.14 à Figura 6.16).
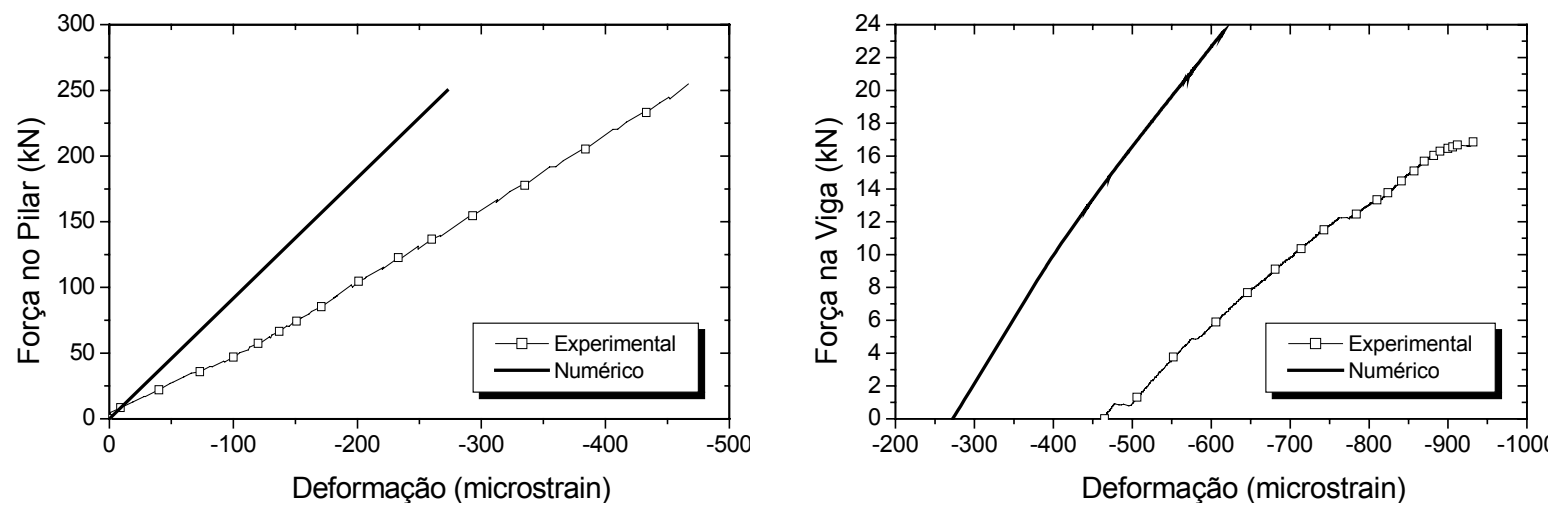

Figura 6.8 - Deformações da armadura na posição do extensômetro E11 (N200).
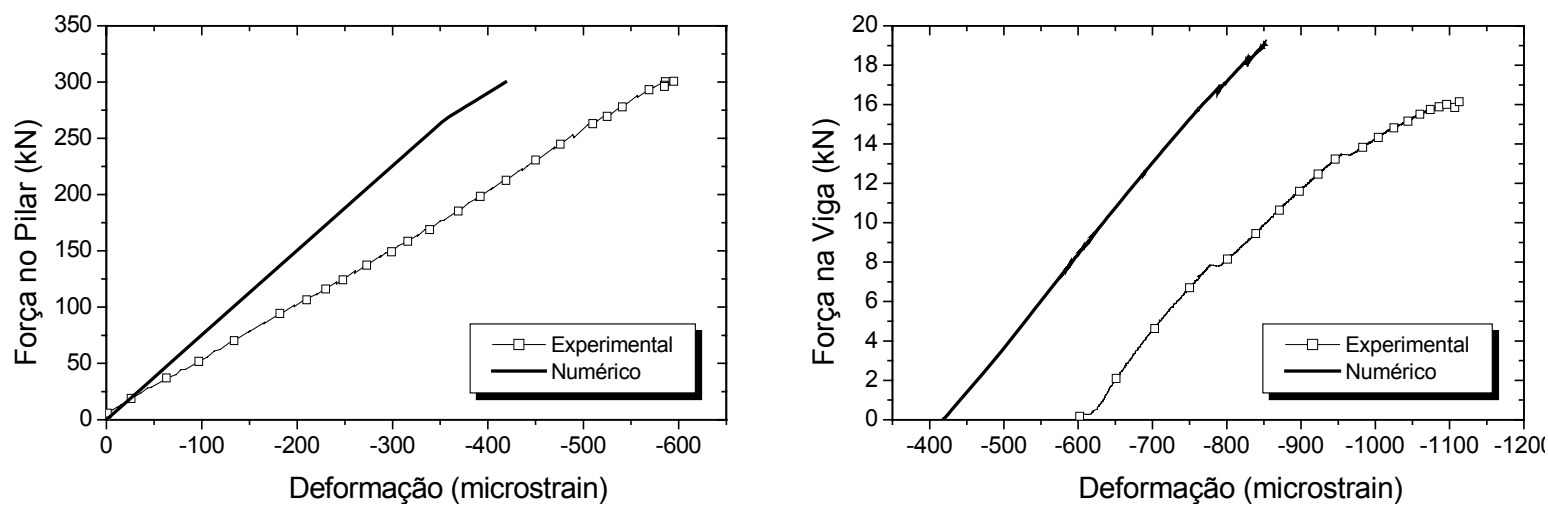

Figura 6.9 - Deformações da armadura na posição do extensômetro E11 (N300). 

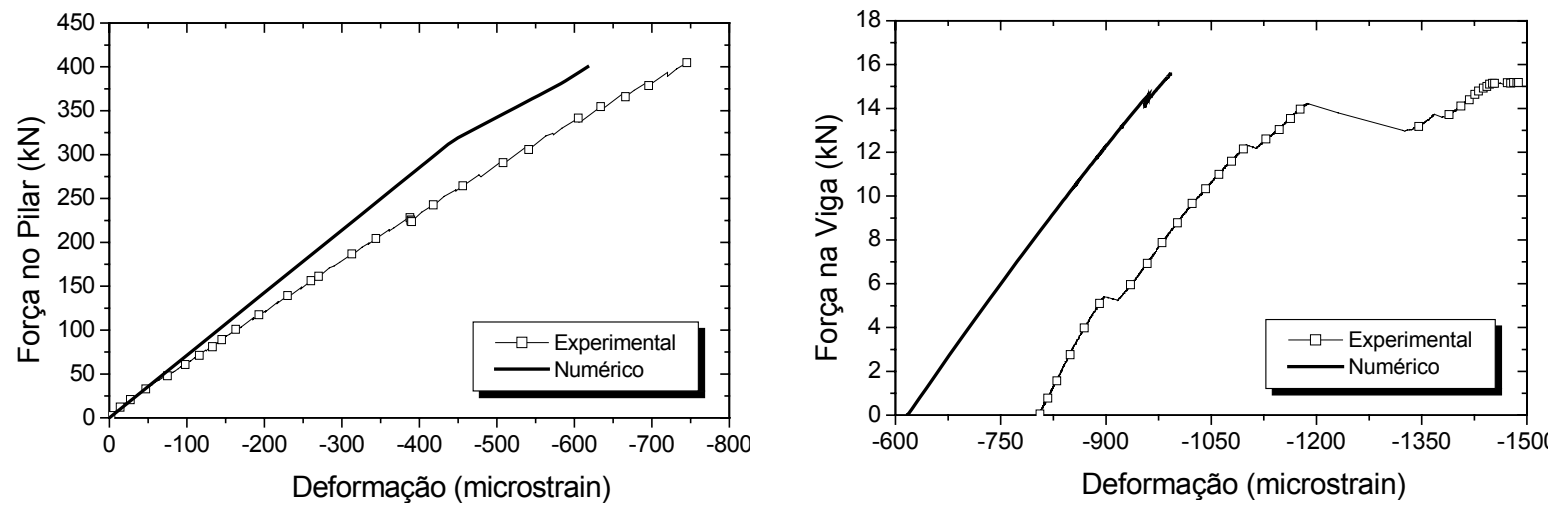

Figura 6.10 - Deformações da armadura na posição do extensômetro E11 (N400).
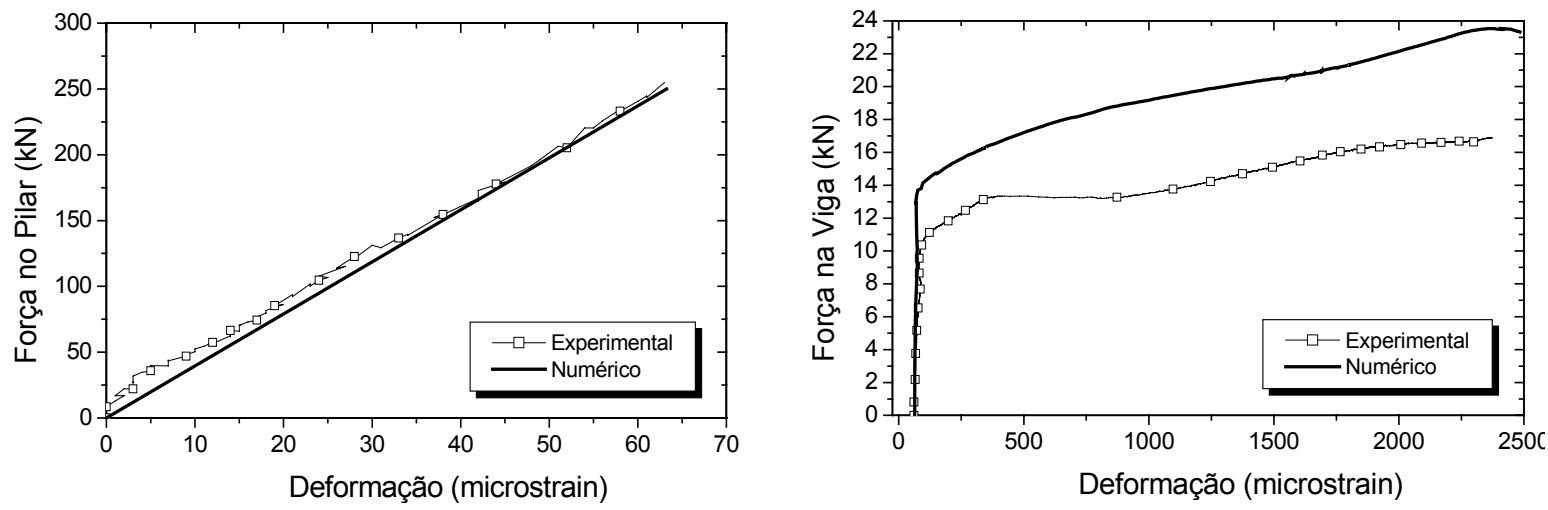

Figura 6.11 - Deformações do estribo localizado na região nodal (N200).
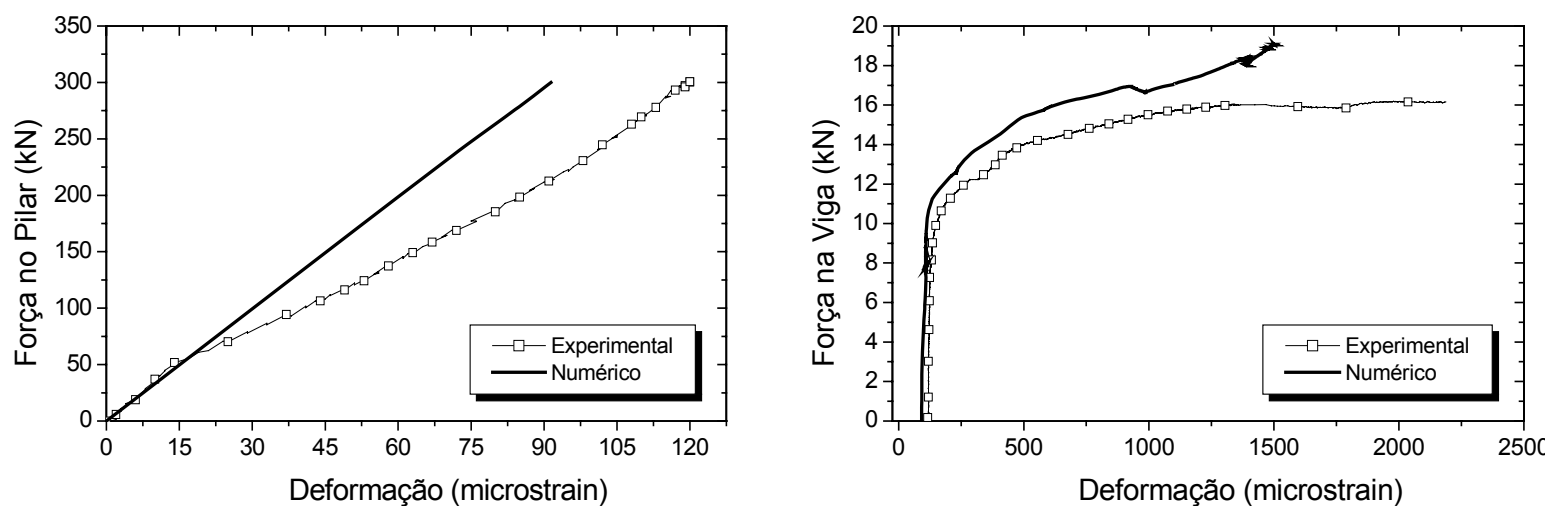

Figura 6.12 - Deformações do estribo localizado na região nodal (N300). 

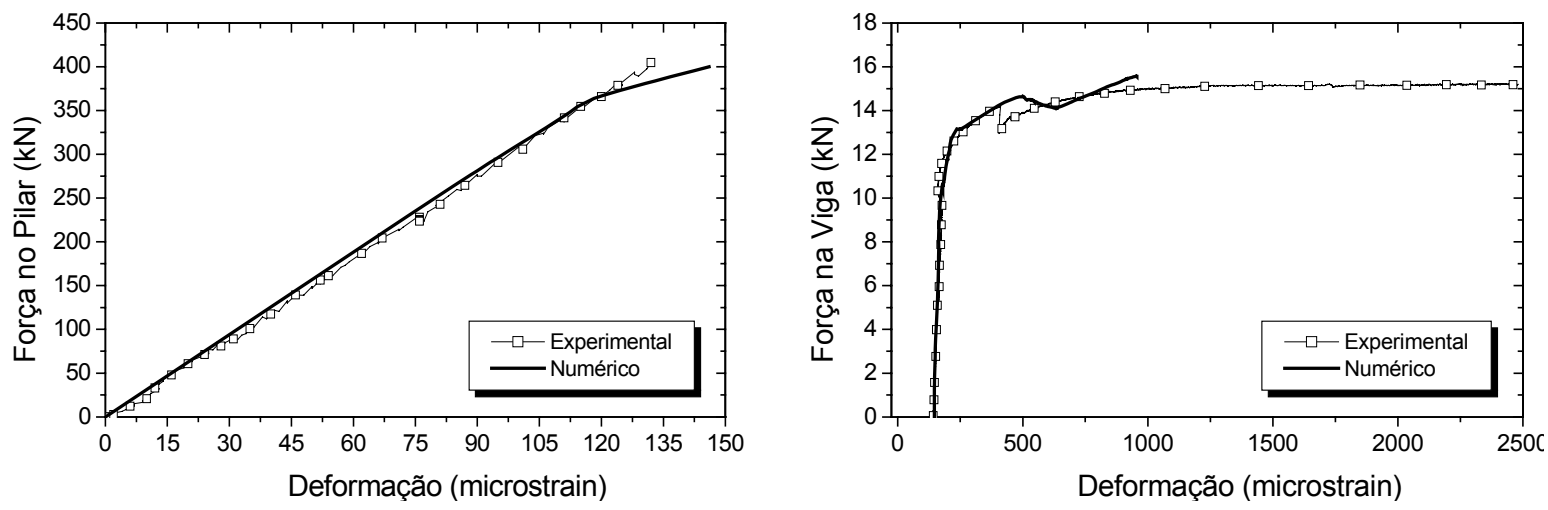

Figura 6.13 - Deformações do estribo localizado na região nodal (N400).
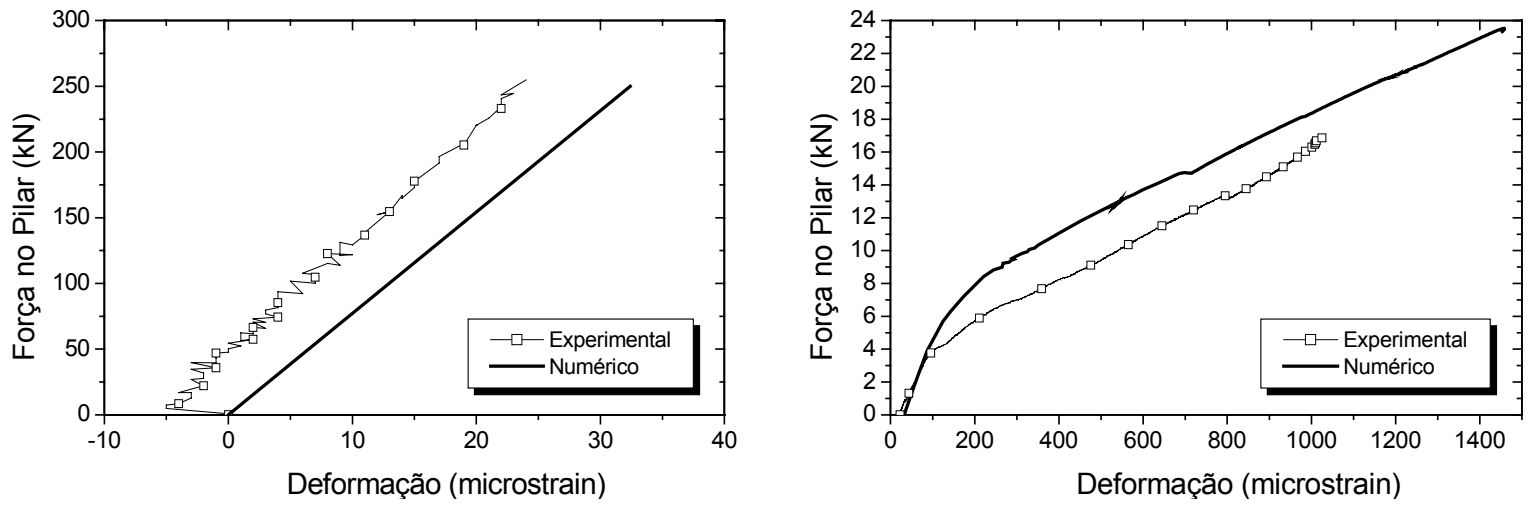

Figura 6.14 - Deformações da armadura na posição do extensômetro E114 (N200).
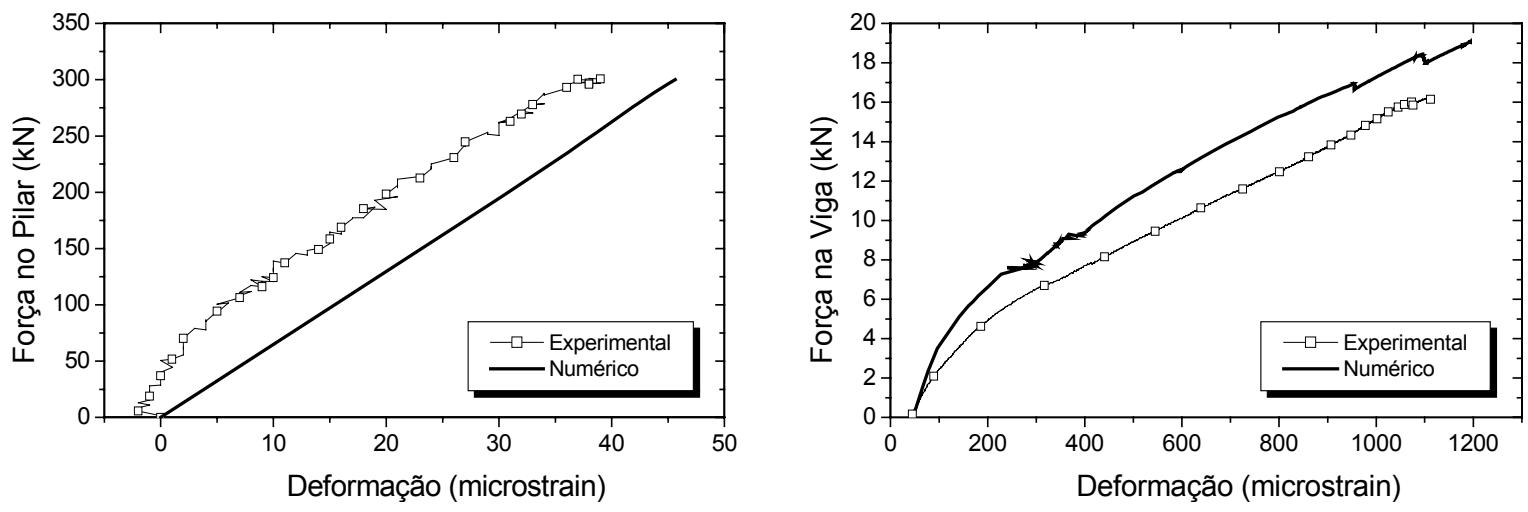

Figura 6.15 - Deformações da armadura na posição do extensômetro E114 (N300). 

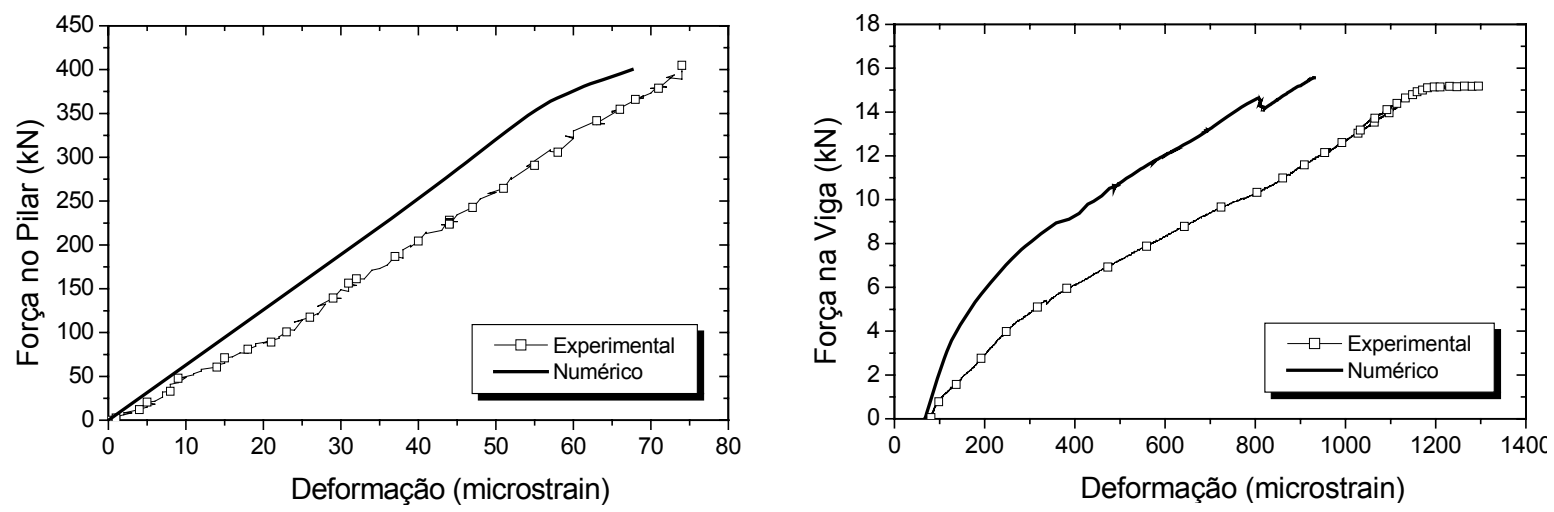

Figura 6.16 - Deformações da armadura na posição do extensômetro E114 (N400).

No entanto, alguns pontos das armaduras apresentaram comportamentos distintos entre os modelos numérico e experimental (Figura 6.17 à Figura 6.19). Estas diferenças ocorrem nas armaduras do pilar na vizinhança do nó, sendo assim pode-se pensar na possível danificação destes extensômetros já que esta é uma região com alta fissuração.
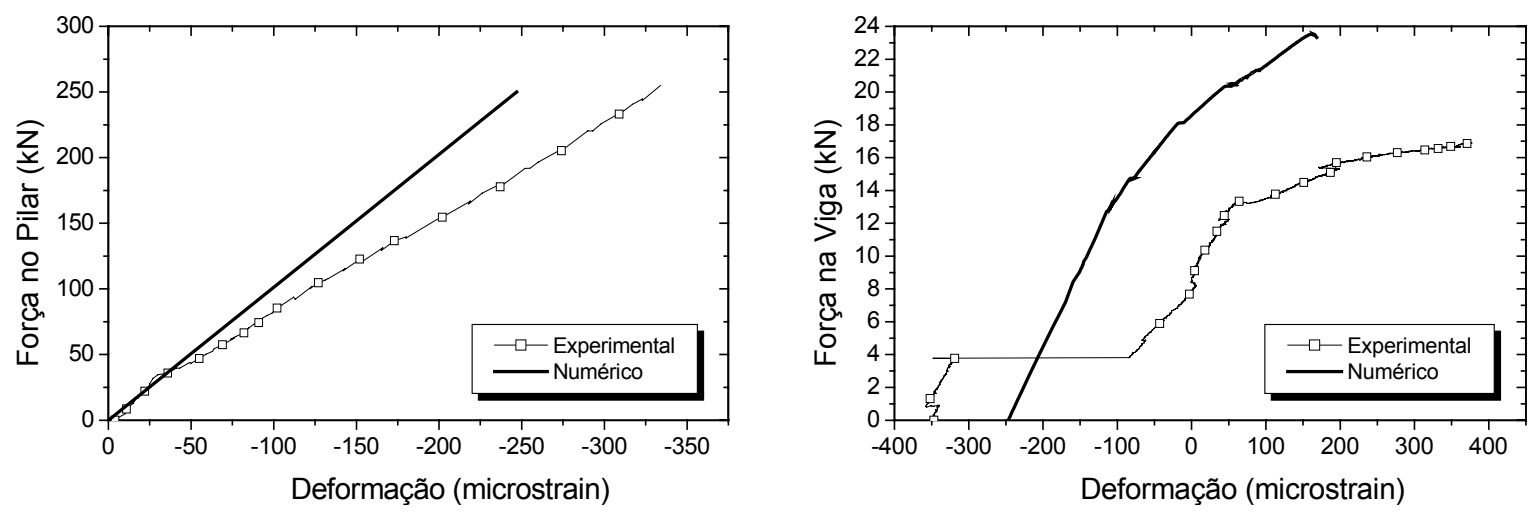

Figura 6.17 - Deformações da armadura na posição do extensômetro E17 (N200).
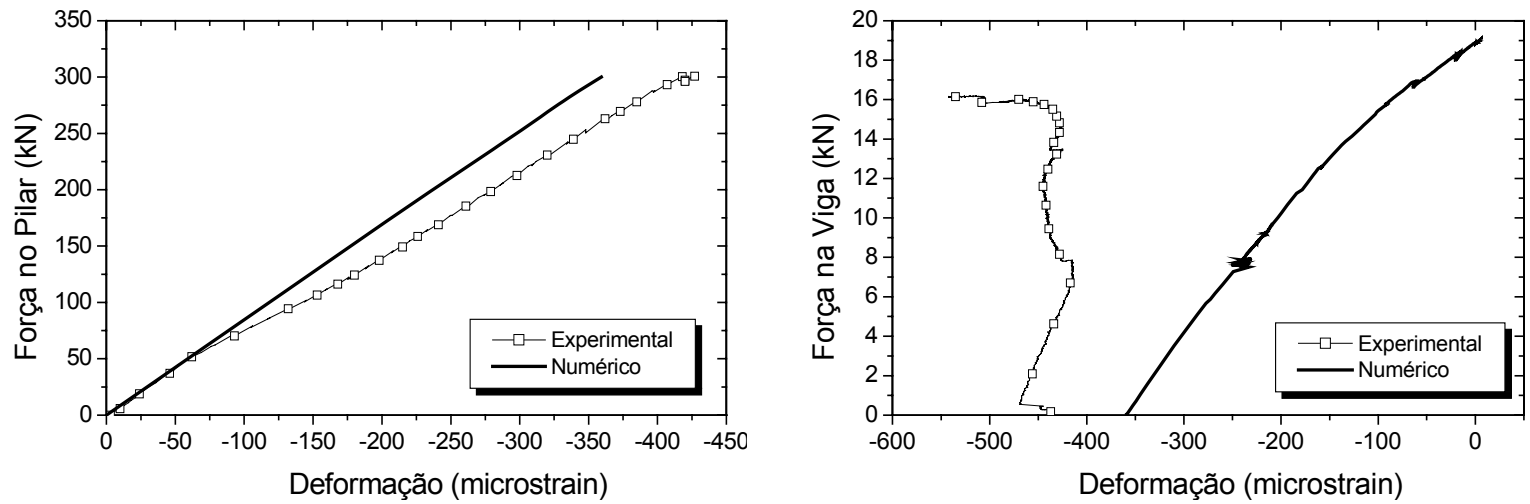

Figura 6.18 - Deformações da armadura na posição do extensômetro E17 (N300). 

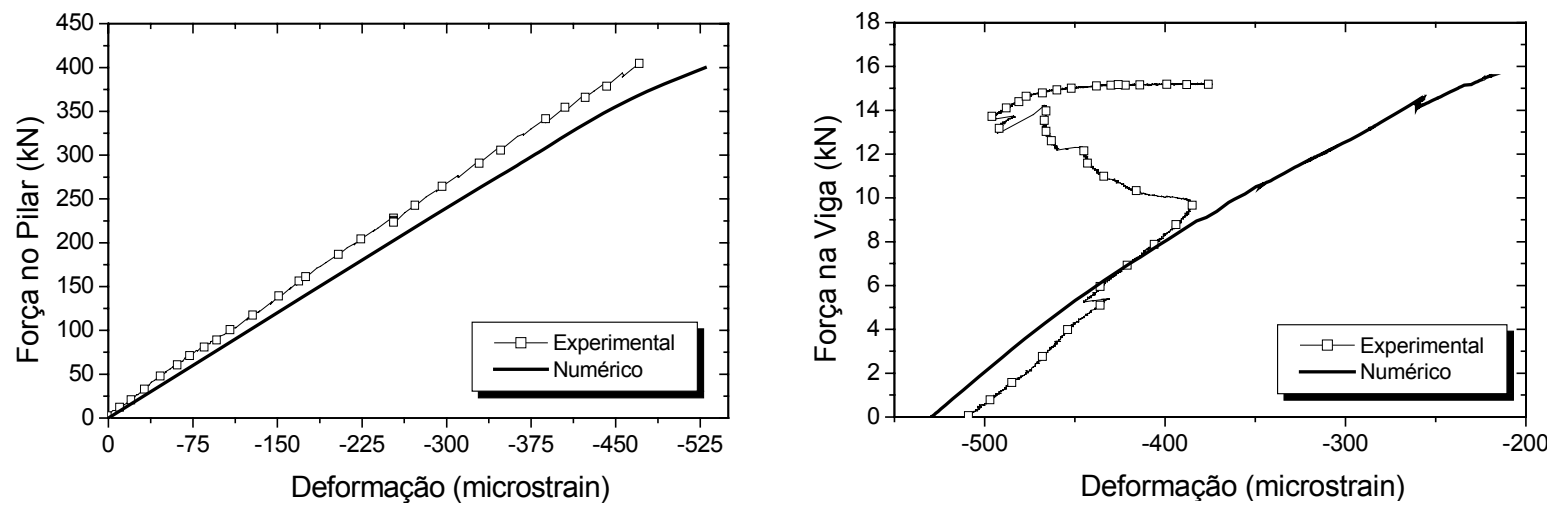

Figura 6.19 - Deformações da armadura na posição do extensômetro E17 (N400).

Os estribos do pilar apresentaram comportamento satisfatório no modelo numérico, representando: a transferência de tensões que ocorre entre a barra tracionada da viga e o estribo acima do nó (Figura 6.20 à Figura 6.22) e a perda de deformação do estribo localizado abaixo do nó (Figura 6.23 à Figura 6.25), na proximidade da ruína.
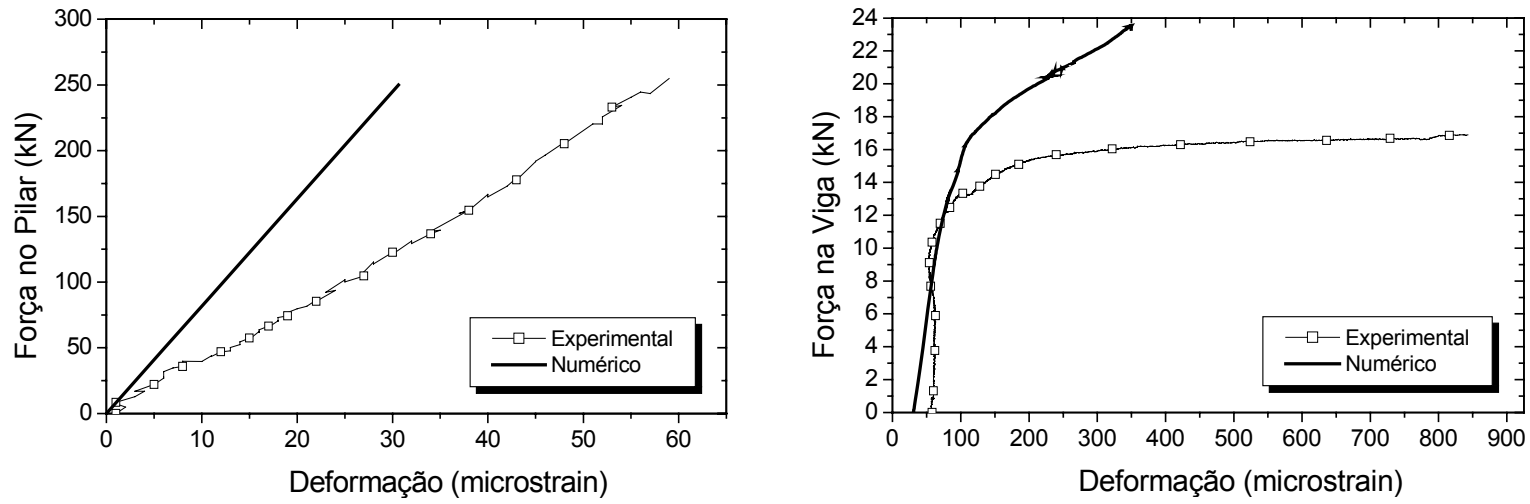

Figura 6.20 - Deformações do estribo localizado acima da região nodal (N200).
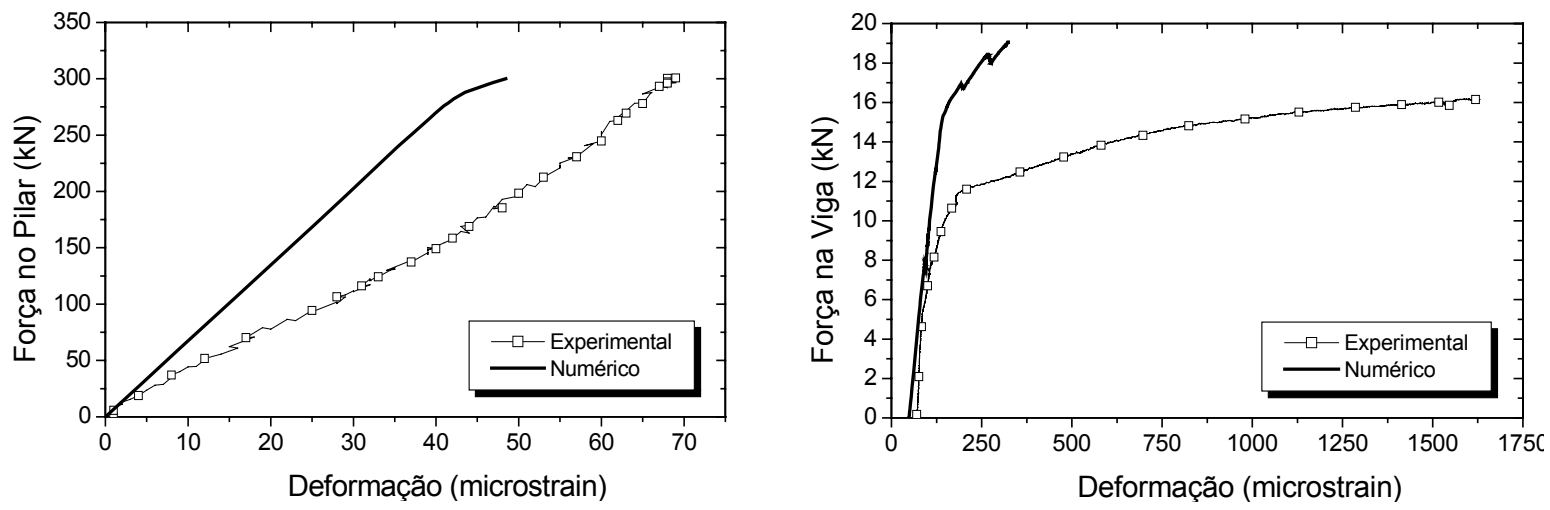

Figura 6.21 - Deformações do estribo localizado acima da região nodal (N300). 

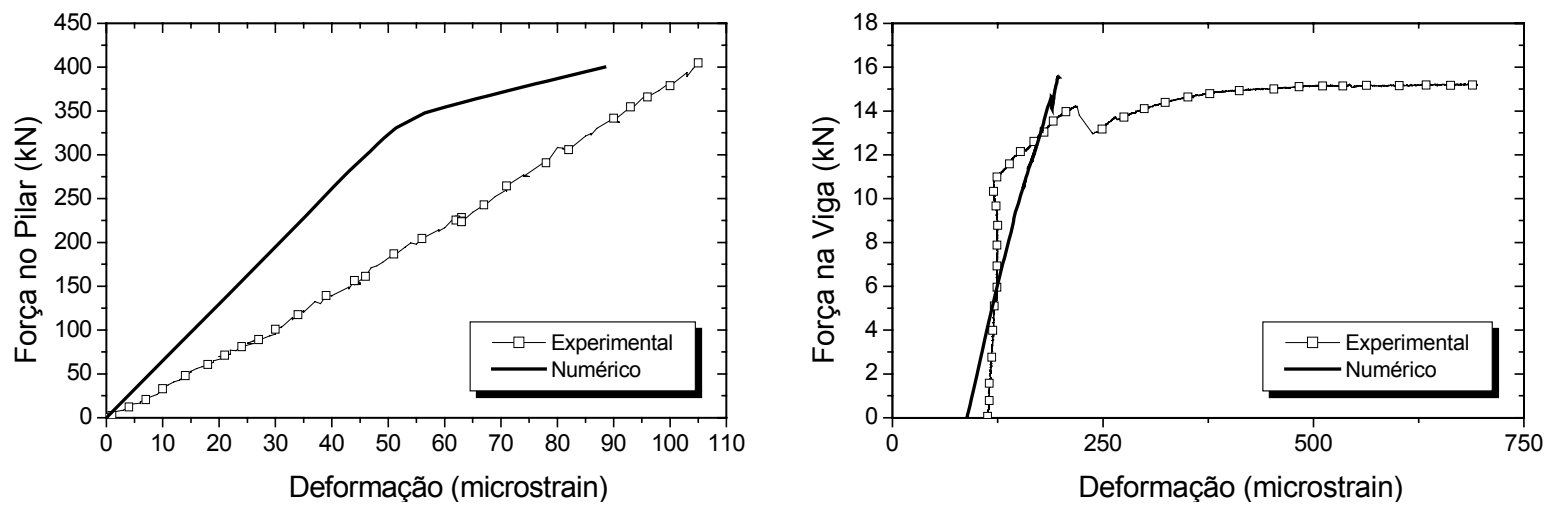

Figura 6.22 - Deformações do estribo localizado acima da região nodal (N400).
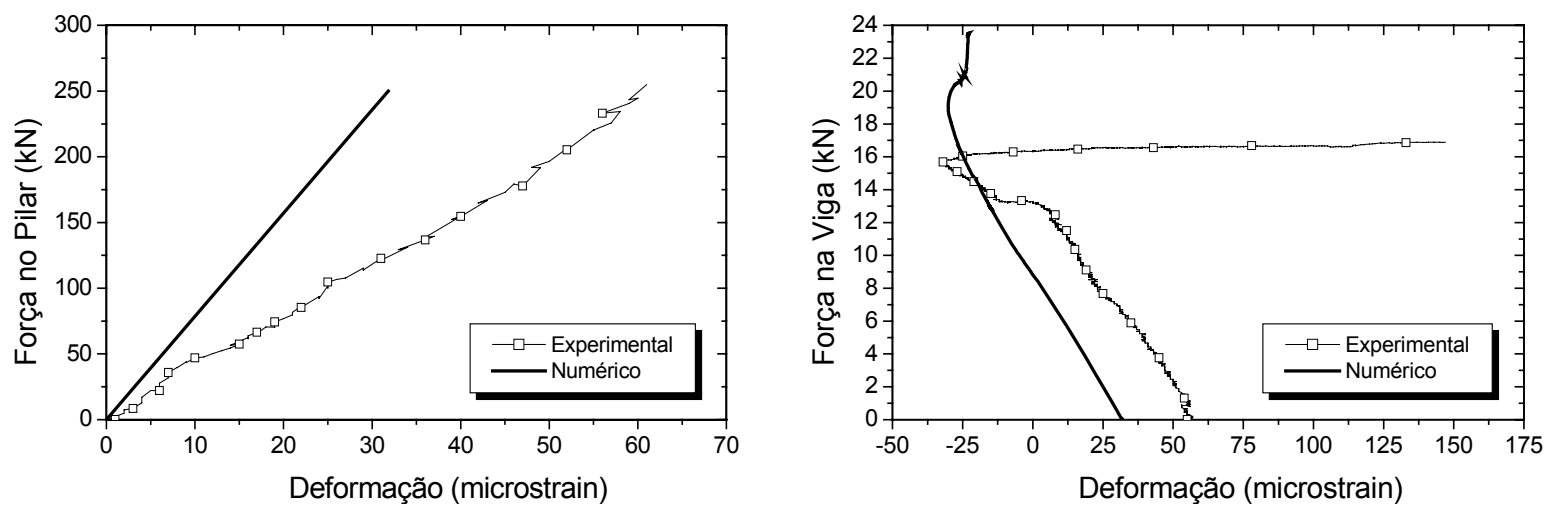

Figura 6.23 - Deformações do estribo localizado abaixo da região nodal (N200).
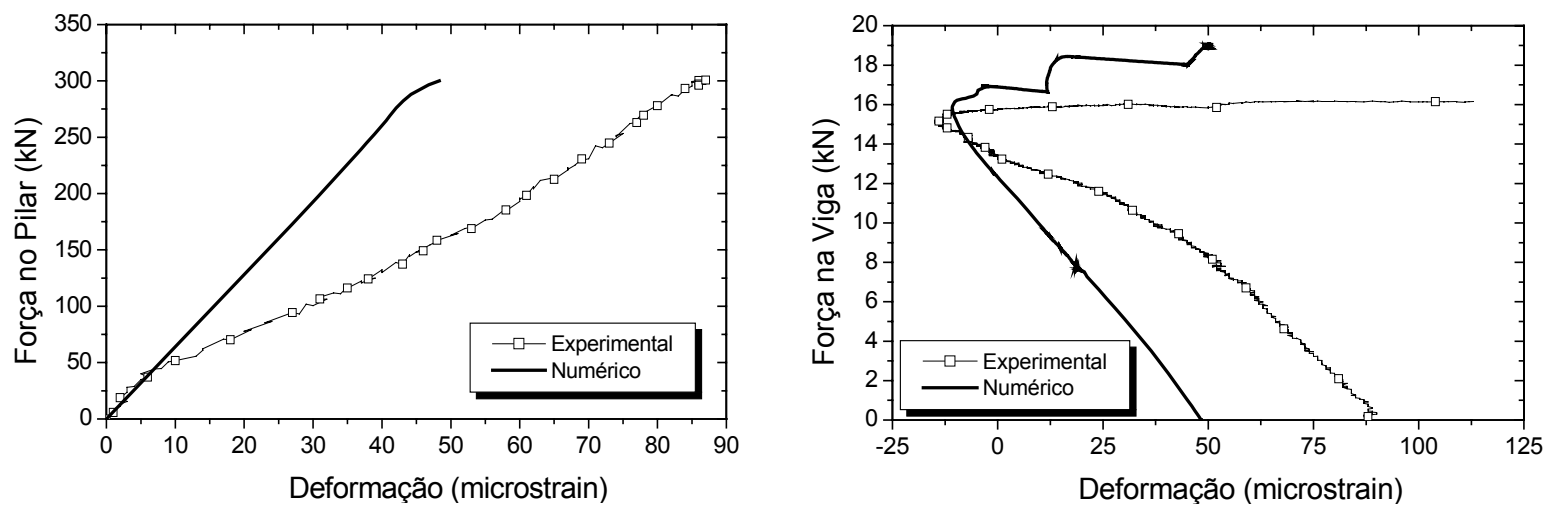

Figura 6.24 - Deformações do estribo localizado abaixo da região nodal (N300). 

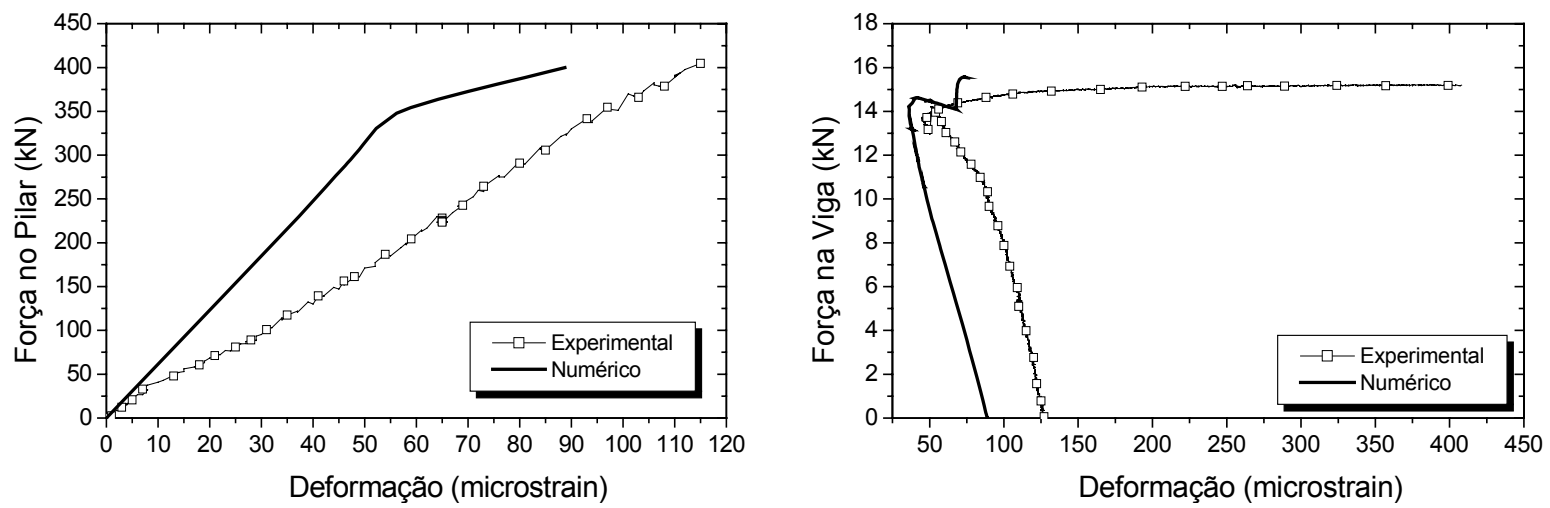

Figura 6.25 - Deformações do estribo localizado abaixo da região nodal (N400).

Com relação à dobra da barra tracionada da viga, observa-se que esta absorve parte das tensões de compressão advindas da força normal aplicada ao pilar, como mostram os experimentos, porém o modelo numérico não consegue representar de maneira adequada o instante em que a dobra começa a deixar de contribuir para este efeito de resistência (Figura 6.26 à Figura 6.28) por causa da tração advinda da viga. Isto se dá, provavelmente, pela pobre discretização adotada para a dobra (um elemento de barra, Figura 6.3), sendo esta dependente da malha adotada.

De um modo geral, o modelo numérico conseguiu representar os experimentos realizados na região de interesse de maneira satisfatória e com isso torna-se possível uma análise paramétrica para se avaliar a influência de cada variável no comportamento do nó de pórtico externo.
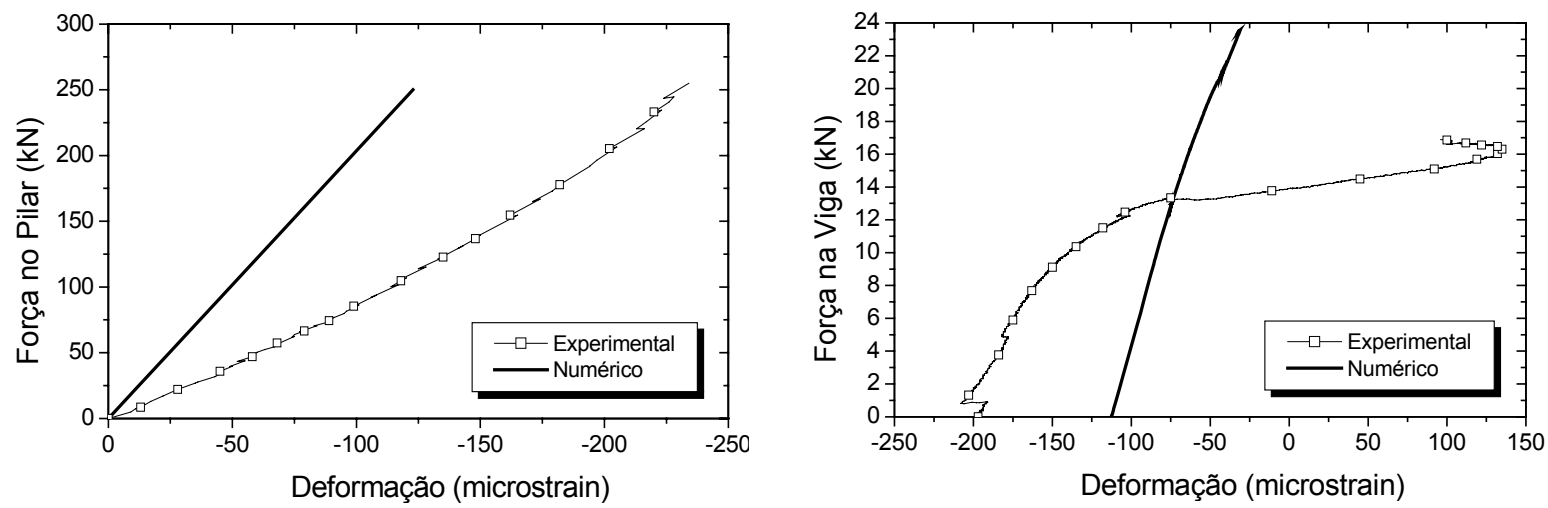

Figura 6.26 - Deformações da armadura na posição do extensômetro E111 (N200). 

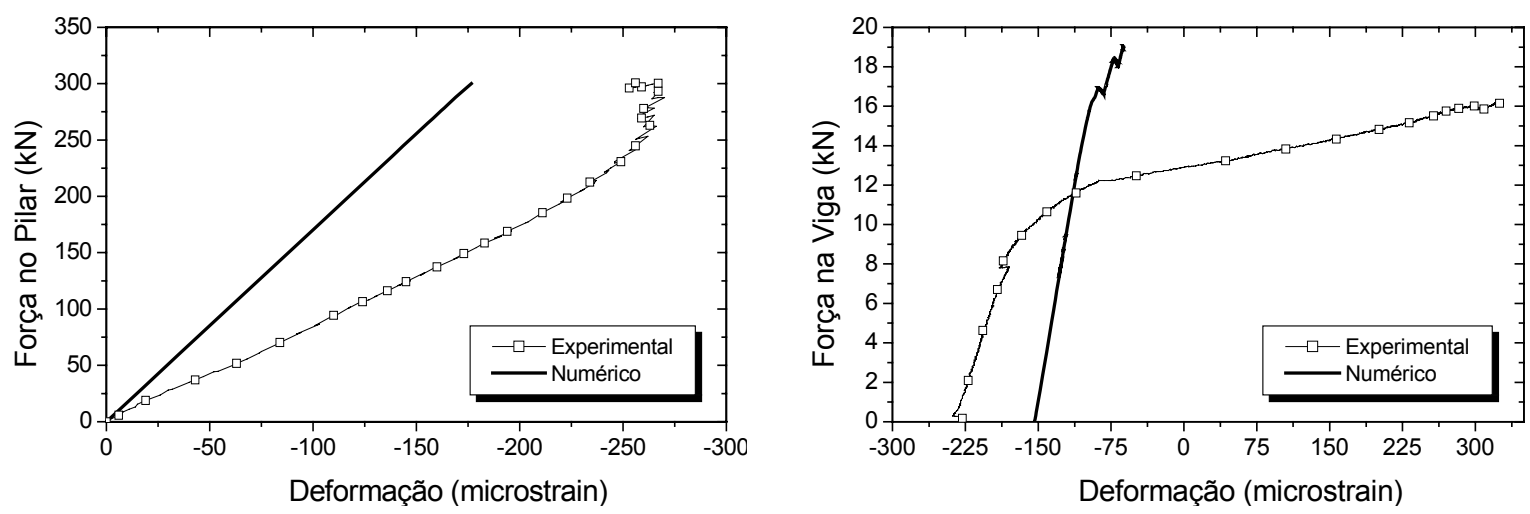

Figura 6.27 - Deformações da armadura na posição do extensômetro E111 (N300).
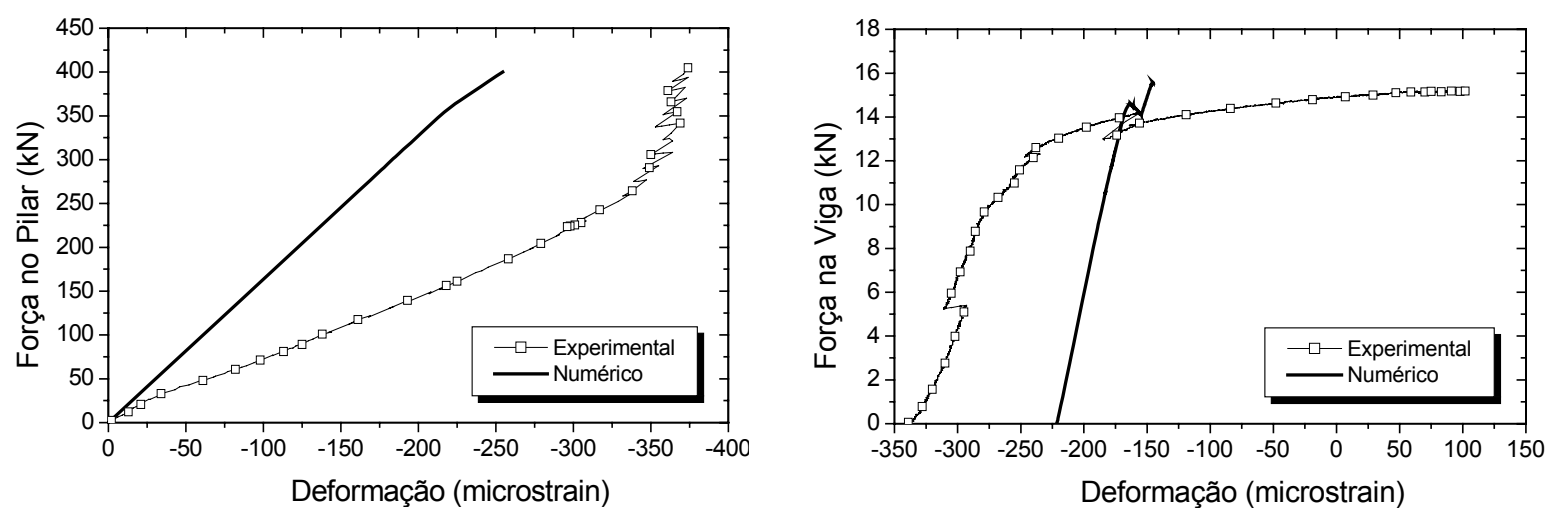

Figura 6.28 - Deformações da armadura na posição do extensômetro E111 (N400).

\subsection{Análise da influência da força normal}

Para analisar a influência da força normal aplicada ao pilar no comportamento dos nós de pórtico externos, foi simulado o modelo numérico apresentado anteriormente variando-se a força normal adimensional $(v)$ entre 0,0 e 0,8. Manteve-se constante a geometria do modelo e as armaduras. As propriedades do concreto foram consideradas de acordo com o código modelo CEB-FIP (1990), para uma resistência característica de de $20 \mathrm{MPa}$, para a armadura adotou-se as resistências características à tração das barras utilizadas nos modelos experimentais.

Como nem todos os pontos de armadura analisados nos modelos anteriores, representaram o comportamento do modelo experimental, considerou-se apenas aqueles que obtiveram resultados satisfatórios para a realização da análise da influência da força 
normal. Além da avaliação das deformações das armaduras, supôs-se válida a observação do caminhamento das tensões dentro da região nodal, uma vez que este se apresentava de acordo a bibliografia estudada. Sendo assim, não se pôde tirar conclusões sobre a influência da força normal sobre o comportamento último da ligação, porém se conseguiu compreender melhor o comportamento da ligação durante o histórico de carregamento.

De um modo geral, a variação da força normal não influenciou o comportamento das armaduras. Analisando o estribo localizado na região nodal, observa-se que há um pequeno aumento da força em que se inicia a solicitação efetiva deste elemento à tração (Figura 6.29). Este retardamento de solicitação causado pelo aumento da força normal, pode ser observado em outros pontos da armadura como: nos estribos superior e inferior ao nó (Figura 6.30 e Figura 6.31).
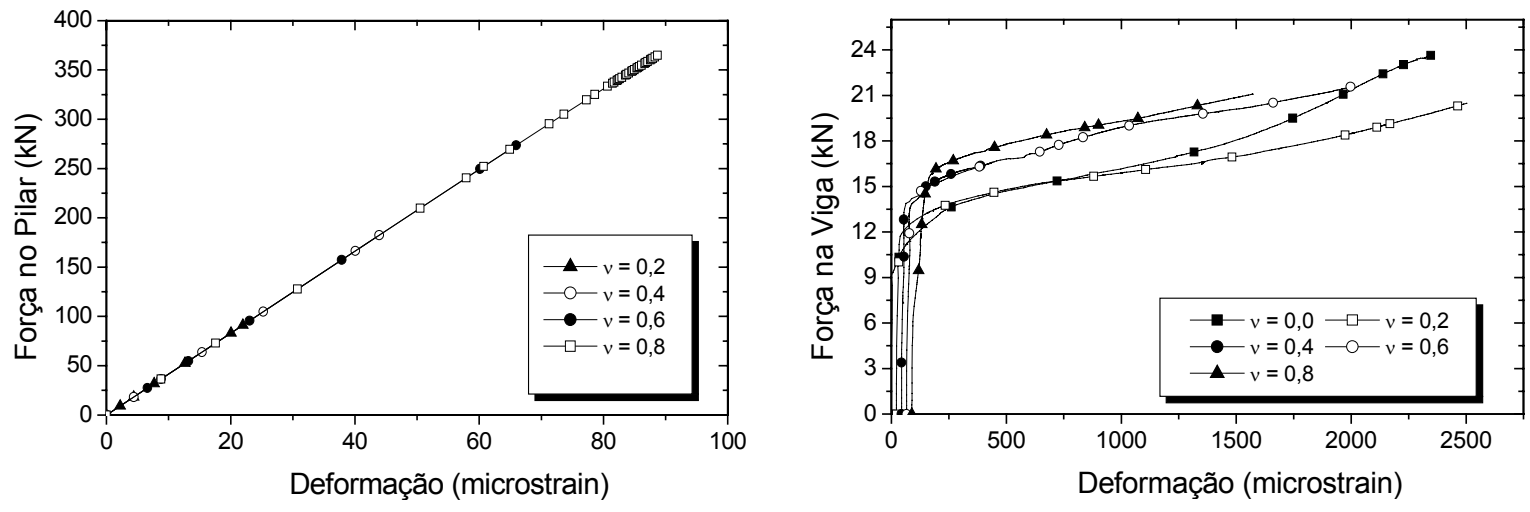

Figura 6.29 - Variação da força normal - Estribo localizado na região nodal.
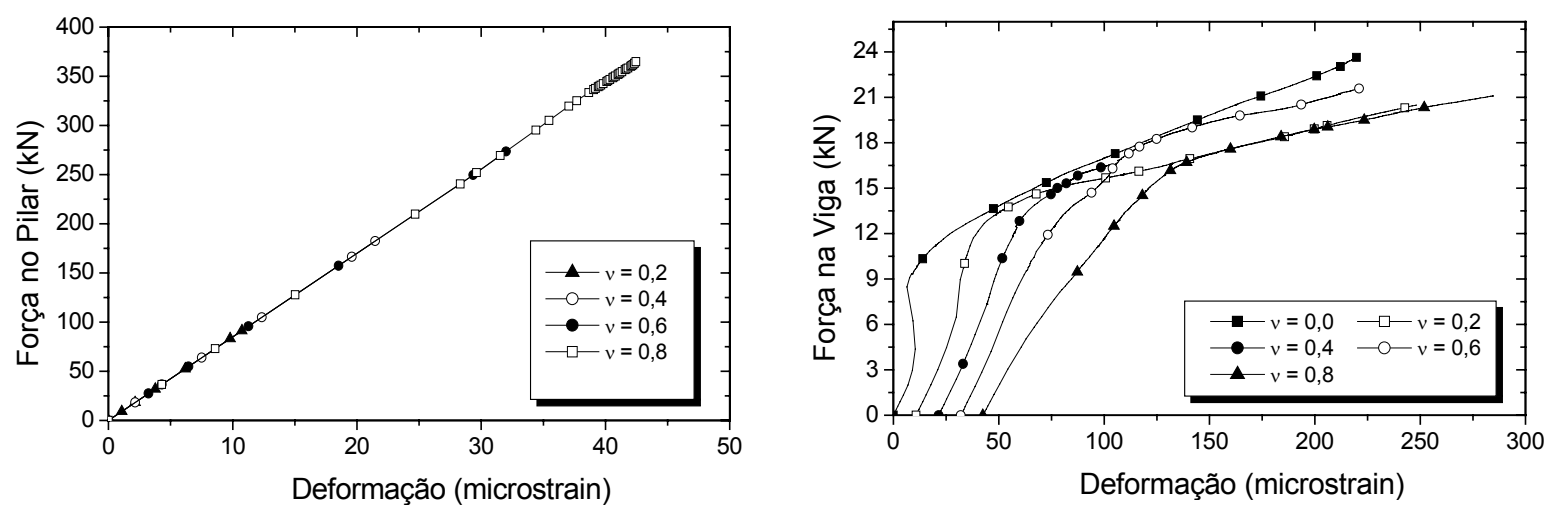

Figura 6.30 - Variação da força normal - Estribo localizado acima do nó. 

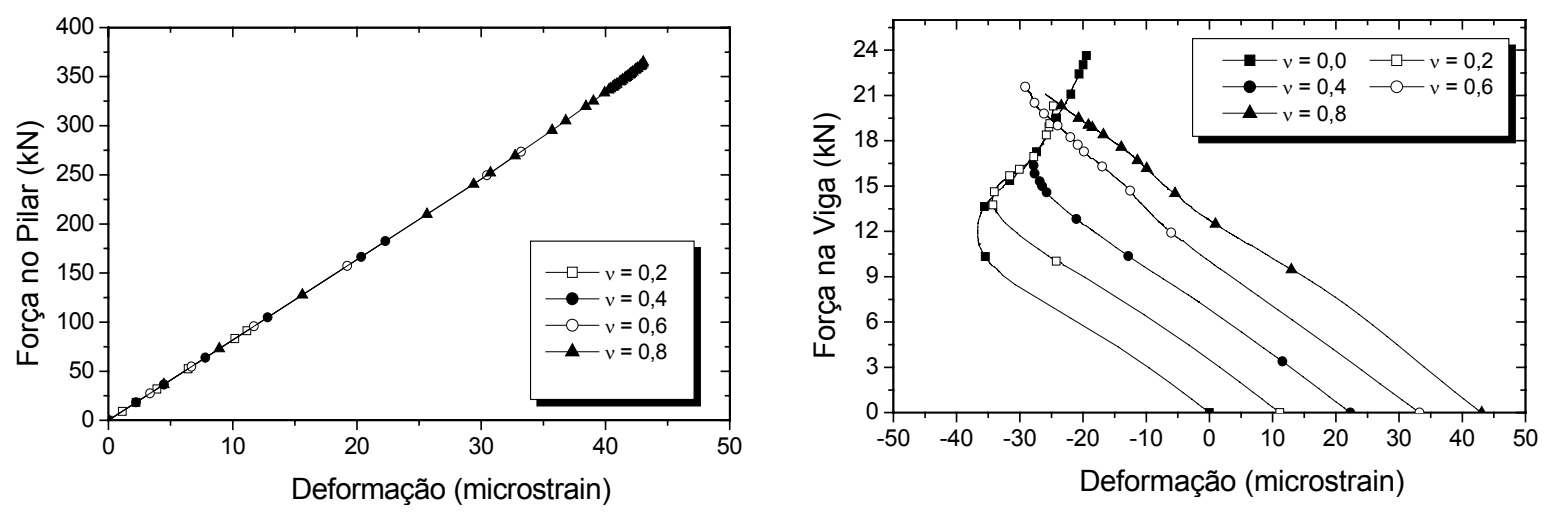

Figura 6.31 - Variação da força normal - Estribo localizado abaixo do nó.

A armadura tracionada da viga praticamente não sofreu influência com a variação da força normal, como era de se esperar. A pequena variação ocorrida é pelo fato da região ao redor do nó ser descontínua, ou seja, não são válidas as hipóteses de Bernoulli, sendo assim ocorre uma pequena tração nas armaduras da viga por causa da força normal do pilar (Figura 6.32).
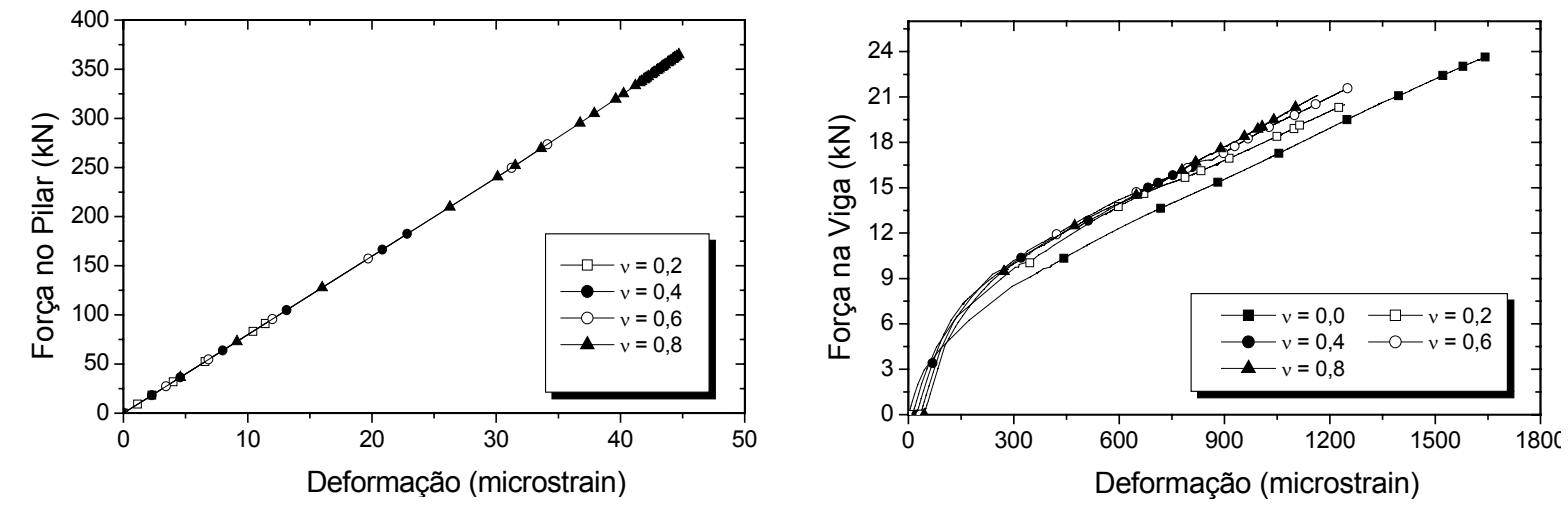

Figura 6.32 - Variação da força normal - Armadura Tracionada da viga (E114).

Observando o comportamento das tensões no concreto, nota-se que à medida que a força normal reduz, ocorre o surgimento de uma biela secundária ligando o canto superior externo do nó e a extremidade do estribo (Figura 6.33 e Figura 6.34). Esta biela secundária é considerada nos modelos de Ortiz (1993), Parker \& Bullman (1997) e Hwang \& Lee (1999) de acordo com as figuras Figura 3.3, Figura 3.4 e Figura 3.6 respectivamente. 

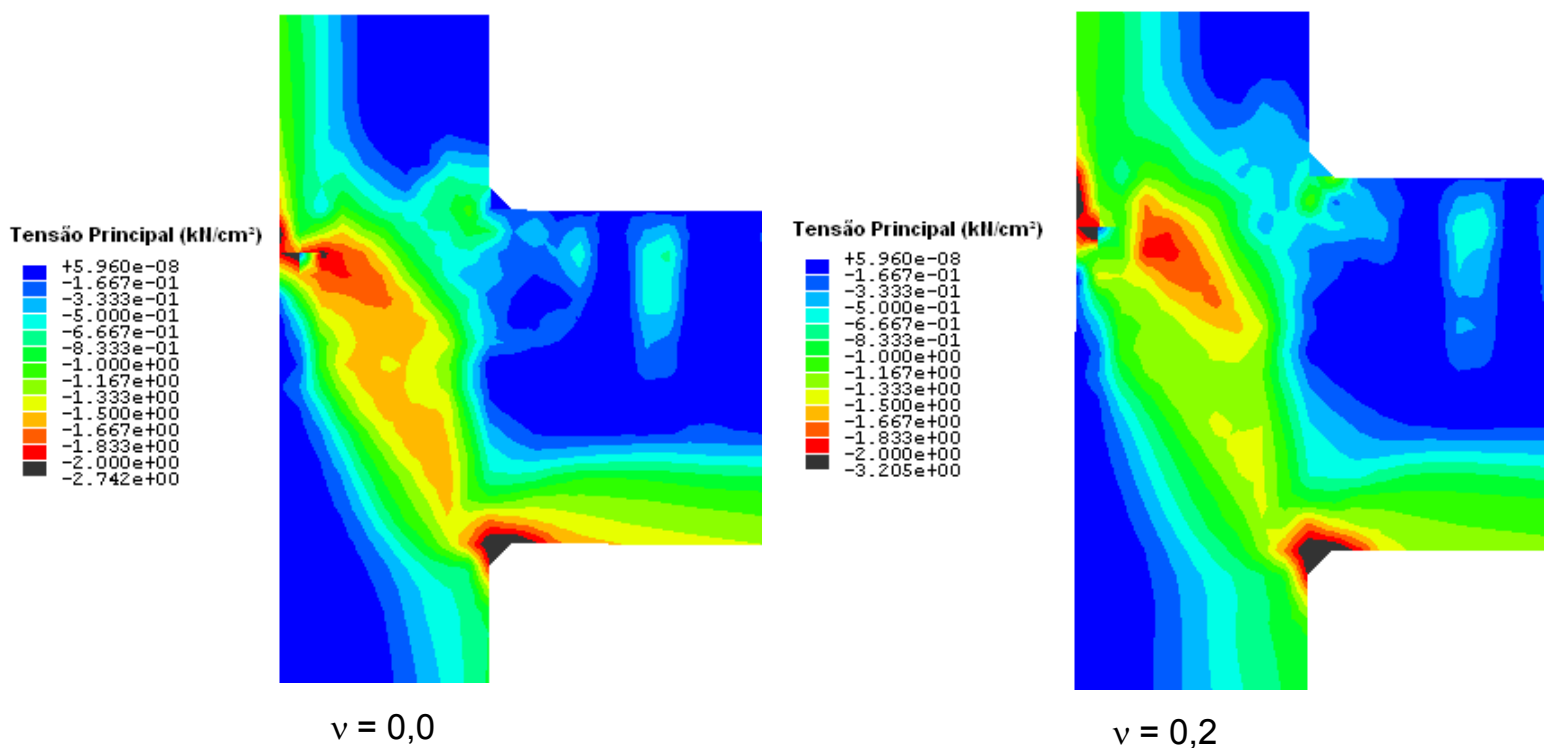

$$
v=0,2
$$

Figura 6.33 - Variação da força normal - Tensões Principais no concreto $(v=0,0$ e $v=0,2)$.

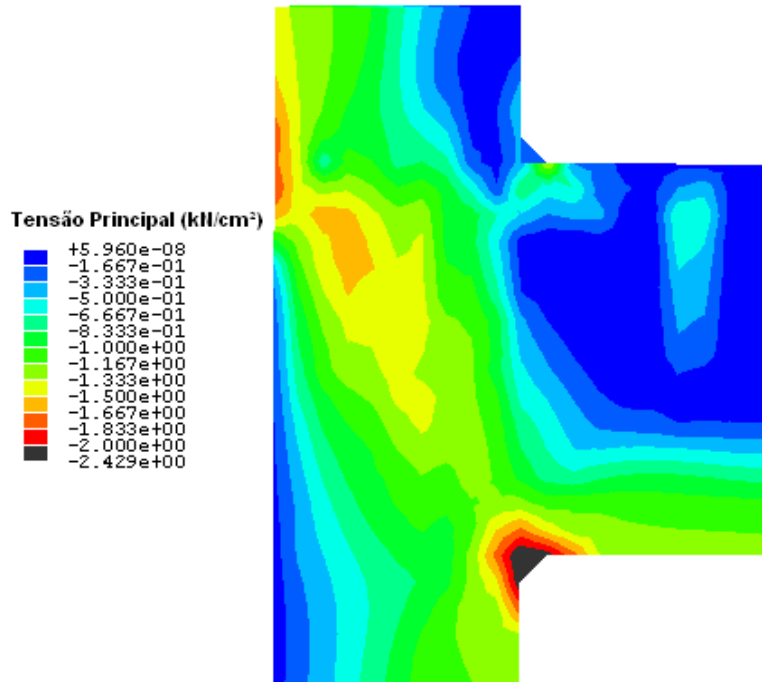

$v=0,6$
Tensäo Principal $\left(\mathbf{k H} / \mathrm{cm}^{2}\right)$

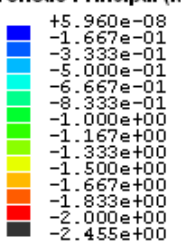

Figura 6.34 - Variação da força normal - Tensões Principais no concreto $(v=0,6$ e $v=0,8)$.

Analisando as tensões principais pode-se concluir que para forças normais pequenas os mecanismos secundários são solicitados tão logo inicie o carregamento. À medida que a força normal aumenta, a biela principal vai se enrijecendo, absorvendo inicialmente uma maior porcentagem das tensões, fazendo com que seja retardada a solicitação dos mecanismos secundários. Este enrijecimento da biela diagonal principal nada mais é que o efeito do confinamento do concreto. 
Os modelos numéricos com a força normal adimensional de 0,1 e 0,2 , atingiram a ruína por escoamento dos estribos, sendo que o primeiro modelo atingiu uma força de ruína maior que o segundo. Desta forma, analisando os resultados obtidos, tanto numéricos quanto experimentais, pode-se afirmar que a força normal influencia no comportamento da ligação, tornando-a mais frágil e diminuindo sua capacidade resistente à medida que seu valor aumenta. Da mesma forma, pode-se concluir que o modo de ruína do modelo é diretamente influenciado pela intensidade de força normal aplicada no pilar, uma vez que para valores baixos, onde os mecanismos secundários são solicitados antecipadamente, os estribos atingem o escoamento antes da ruína da biela. No entanto, quando a biela diagonal apresenta uma rigidez bastante alta, ela absorve uma maior parcela de tensões, o que provoca sua ruína antes da dos estribos. 


\section{CONSIDERAÇÕES FINAIS}

\subsection{Conclusão}

Observou-se com os estudos realizados que diversas são as dificuldades encontradas ao se tentar representar um nó de pórtico o mais próximo possível da realidade. Como exemplo de dificuldades pode-se citar: a construção da ligação na vertical, como é feito nas obras reais, é extremamente penoso no laboratório por causa das dificuldades de escoramento e posterior desforma dos modelos, a execução da ligação considerando a viga transversal no nó e a contribuição da laje faz com que os modelos se tornem muito grandes e de difícil manipulação, a realização do ensaio com a ligação na vertical apresenta dificuldades quanto ao escoramento desta e necessita de cuidados para que no instante da ruína não ocorra o tombamento do modelo. No caso da avaliação da força normal, que foi o foco desta pesquisa, se fossem utilizadas seções usuais para os pilares, as forças a serem aplicadas seriam altíssimas, por conseguinte seriam necessárias estruturas de reação um tanto robustas para suportar os esforços gerados durante o ensaio. Desta forma, foi necessário que as seções dos pilares fossem reduzidas para possibilitar um intervalo maior de valores de força normal que pudessem ser aplicadas à ligação. No entanto, pode-se obter algumas conclusões sobre o comportamento da ligação nas condições propostas de carregamento.

De maneira geral, para as intensidades de força normal aplicadas nos modelos experimentais, seu aumento fez com que a força última da ligação reduzisse. O panorama de fissuração mostrou que a força normal torna a ligação mais frágil, fazendo com que não surjam muitas fissuras, no caso de altas forças normais, e o nó apresente ruína brusca. Além disso, quanto maior a força normal aplicada no pilar, maior é a força 
necessária, aplicada na viga, para que haja uma solicitação efetiva do estribo localizado no nó, ou seja, maior é a força de fissuração.

Com relação à ancoragem da barra tracionada da viga dentro da região nodal, o aumento da força normal faz com que as condições de aderência melhorem bastante nesta região, proporcionando uma melhor ancoragem das barras aí alocadas. Os resultados experimentais mostraram que a porção da barra localizada dentro do nó demora mais a ser solicitada quanto maior for a força normal e a resistência à tração do concreto, indicando uma melhor transferência das tensões do aço para o concreto. Foi observado, assim como por Ortiz (1993), que a dobra da armadura da viga absorve tensões de compressão advindas do pilar e é solicitada à tração somente na proximidade da ruína, portanto como nesta etapa do carregamento é extremamente alta a fissuração do modelo, é recomendável que esta parte da armadura não seja computada no comprimento de ancoragem efetivo. O estribo localizado acima da região nodal mostrou uma certa contribuição nos mecanismos de transferência de tensões, colaborando com a armadura tracionada da viga, principalmente para intensidades mais baixas de força normal.

No sentido do dimensionamento da ligação, pôde-se observar que os modelos teóricos encontrados na bibliografia apresentam uma estimativa para a capacidade da ligação que pode ir contra a segurança da estrutura. Em alguns modelos a capacidade resistente do nó é estimada simplesmente somando-se as resistências da componente horizontal da biela diagonal principal e dos estribos, no entanto foi observado com os modelos experimentais ensaiados que pode ocorrer a ruptura da biela antes que os estribos atinjam toda a sua capacidade resistente. Por conseguinte, no dimensionamento da ligação devem ser consideradas no mínimo duas verificações, referentes à capacidade da biela diagonal e à contribuição dos estribos caso aquela não atinja a ruína.

O modelo numérico construído representou o modelo experimental de maneira satisfatória, apesar de mais rígido; com isso pôde-se fazer a variação da força normal para a análise de sua influência no comportamento do modelo. A simulação numérica não permitiu a avaliação da força última, por causa de problemas de instabilidade numérica provocados pela não-linearidade dos materiais. Contudo, foi possível a análise do comportamento da ligação ao longo do histórico de carregamento.

O modelo numérico conseguiu representar principalmente o comportamento da região nodal, com as deformações dos estribos apresentando-se muito similares àquelas observadas nos experimentos. Desta forma, pôde-se avaliar as tensões principais no 
concreto na região nodal, observando a formação da biela diagonal e, para valores baixos da força normal, o aparecimento de bielas secundárias.

Nos modelos simulados com a força normal adimensional igual a 0,1 e 0,2 , se atingiu o escoamento dos estribos. Este fato faz acreditar que a intensidade da força normal influencia diretamente o tipo de ruína da ligação. Em casos onde a força normal é pequena, as bielas secundárias são solicitadas desde o início do carregamento, fazendo com que a solicitação do estribo seja feita de maneira mais uniforme durante todo o carregamento do elemento estrutural, portanto atingindo o escoamento antes da ruína da biela diagonal. Quando a força normal é alta, a biela diagonal fica mais enrijecida o que proporciona que absorva maiores tensões e atinja a ruína antes do escoamento dos estribos.

Resumidamente a força normal influencia o comportamento dos nós de pórtico externos principalmente tornando-os mais frágeis para grandes compressões, modificando o padrão de fissuração, o tipo de ruptura da ligação e melhorando a ancoragem da barras tracionadas da viga. Altos valores de força normal enrijecem a ligação, pois aumentam o confinamento na região nodal, no entanto este enrijecimento faz com que a biela diagonal principal absorva maiores tensões de compressão atingindo a ruína "antecipadamente".

\subsection{Propostas para trabalhos futuros}

Considerando as conclusões obtidas neste trabalho e analisando a dimensão do assunto em questão nota-se que há ainda um grande número de informações a respeito dos nós de pórtico externos a serem examinadas. Desta forma, esta seção apresenta algumas direções iniciais para a continuidade do estudo destas ligações.

\subsubsection{Trabalhos Experimentais}

- Estudar a influência da força normal em modelos reduzidos de nós de pórtico externos, com isso evitando limitações de equipamento para ensaio e de estruturas de reação. 
- Estudar a influência da força normal para nós de pórtico externos com diferentes taxas de armadura transversal, para se entender melhor a formação das bielas secundárias e o modo de ruptura da ligação.

- Estudar a influência da força normal excêntrica em nós de pórtico externos, uma vez que na prática não existem forças axiais centradas.

\subsubsection{Trabalhos Numéricos}

- Estudar a influência da variação da malha de elementos finitos, em modelos 2D, nos resultados do comportamento de nós de pórtico externos.

- Estudar o comportamento de nós de pórtico externos, em modelos 2D, com a consideração das propriedades de contato na interface aço-concreto baseando-se em modelos da literatura.

- Estudar o comportamento de nós de pórtico externos, em modelos 3D, considerando as armaduras como elementos de barra perfeitamente aderentes ao concreto.

- Estudar a distribuição das tensões no concreto localizado na região nodal, para se tentar propor uma melhor consideração das dimensões da biela diagonal principal.

Atualmente não é dada atenção para o dimensionamento dos nós de pórtico nos projetos usuais, no entanto as análises teóricas e numéricas, juntamente com os experimentos realizados nesta pesquisa, mostraram que a resistência dos nós de pórtico não é limitada pela menor capacidade resistente entre os elementos que ali concorrem (viga e pilar), podendo ser inferior. Isto comprova que mais estudos devem ser realizados sobre o assunto, buscando uma maior compreensão do comportamento desta parte da estrutura e modelos de cálculo mais representativos. 


\section{REFERÊNCIAS BIBLIOGRÁFICAS}

ABAQUS, (2003). Standard User's Manual, versão 6.3. Hibbitt, Karlsson \& Sorensen, Inc.

ABAQUS, (2003). Theory Manual, versão 6.3. Hibbitt, Karlsson \& Sorensen, Inc.

ACI-ASCE Committee 352 (1991). Recommendations for design of beam-column joints in monolithic reinforced concrete structures. American Concrete Institute, Detroit.

AMERICAN CONCRETE INSTITUTE (1995). ACI 318R-95 - Building Code Requirements for Structural Concrete. Detroit.

ASSOCIAÇÃO BRASILEIRA DE NORMAS TÉCNICAS (2003). NBR 6118. Projeto de estruturas de concreto - Procedimento. Rio de Janeiro, ABNT.

ASSOCIAÇÃO BRASILEIRA DE NORMAS TÉCNICAS (1992). NBR 6152. Materiais Metálicos - Determinação das Propriedades Mecânicas à Tração. Rio de Janeiro, ABNT.

ALVA, G. M. S. (2002). Análise numérica do comportamento de ligações viga-pilar de concreto armado submetidas a ações cíclicas. In: XXX JORNADAS SUL-AMERICANAS DE ENGENHARIA ESTRUTURAL,2002, Brasília. Anais. Brasília, 14p.

ALVA, G. M. S. (2004). Estudo Teórico-Experimental do comportamento de nós de pórtico de concreto armado submetidos a ações cíclicas. São Carlos. 218p. Tese (Doutorado) Escola de Engenharia de São Carlos. Universidade de São Paulo. 
BARBOSA, L. A. G.; ALMEIDA, P. A. O. (2001). Nós de pórtico em estruturas de concreto armado. In: CONGRESSO BRASILEIRO DO CONCRETO, 43, 2001, Foz do Iguaçu. Anais. Foz do Iguaçu, IBRACON, 16p.

BAKIR, P. G.; BODUROGLU, H. M. (2002). A new design equation for predicting the joint shear strength of monotonically loaded exterior beam-column joints. Engineering Structures, V. 24, September-October, p. 1105-1117.

BRITISH STANDARD (1985). BS 8110: Structural use of concrete. Part 1. Code of practice for design and concstruction.

CEB-FIP Model code 1990 - final draft. Bulletin D'Information, n. 203-205; 1991.

CHEUNG, P. C.; PAULAY, T.; PARK, R. (1991). New Zealand tests on full-scale reinforced concrete beam-column-slab subassemblages designed for earthquake resistance. American Concrete Institute, SP 123-1, 1-3B.

COMITEE EURO-INTERNATIONAL DU BETON - CEB (1985). Model Code for seismic design of concrete structures. Bulletin d'Information, n.165.

COMITEE EURO-INTERNATIONAL DU BETON - CEB (1994). Behavior and analysis of reinforced concrete structures under alternate actions inducing inelastic response. Bulletin d'Information, n.220.

DURRANI, A. J.; ASCE, A. M.; ZERBE, H. E. (1987). Seismic Resistance of reinforced concrete exterior connections with floor slab. Journal of Structural Engineering, V. 13, August, p. 1850-1865.

EHSANI, M.R.; WIGHT, J.K. (1985). Exterior reinforced concrete beam-to-column connections subjected to earthquake-type loading. ACl Journal, v.82, p.492-9, JulyAugust.

EHSANI, M.R.; WIGHT, J.K. (1990). Confinement steel requirements for connections in ductile frames. Journal of Structural Engineering, v.116, p.761-767, February. 
FERNANDES, R.M. (2000). A influência das ações repetidas na aderência aço-concreto. São Carlos. 155p. Dissertação (Mestrado) - Escola de Engenharia de São Carlos. Universidade de São Paulo.

GEFKEN, P. R.; RAMEY, M. R. (1989). Increased joint hoop spacing in type 2 seismic joints using fiber reinforced concrete. ACI Structural Journal, V. 86, No. 2, March-April, p. 168-172.

HA, G. J.; KIM, J. K.; CHUNG, L. (1992). Response of reinforced high-strength concrete beam column joints under load reversals. Magazine of Concrete Research, V. 44, No. 160, September, p. 175-184.

HANSON, N.W.; CONNOR, H.W. (1967). Seismic resistance of reinforced concrete beamcolumn joints. Journal of the Structural Division, v.93, n.5, p.533-60, October.

HEGGER, S. J.; SHERIF, A.; ROESER, W. (2003). Nonseismic design of beam-column joints. ACI Structural Journal, V. 100, No. 5, September-October, p. 654-664.

HELENE, P.; TERZIAN, P. (2001). Manual de Dosagem e Controle do Concreto. São Paulo, Pini.

HWANG, S. J.; LEE, H. J. (1999). Analytical model for predicting shear strengths of exterior reinforced concrete beam-column joints for seismic resitance. ACI Structural Journal, V. 96, No. 5, September-October, p. 846-857.

KITAYAMA, K.; OTANI, S.; AOYAMA, H. (1991). Development of design criteria for RC interior beam-column joints. In: Design of beam-column joints for seismic resistance, $\mathrm{ACl}$ Special Publication SP-123, American Concrete Institute, Detroit, p.97-123.

KORDINA, K. (1984). Bewehrungsfuhrung in Ecken und Rahmenendknoten. Deutscher Auschuss fur Stahlbeton, part 354. 
LAFAVE, J. M.; WIGHT, J. K. (1999). Reinforced concrete exterior wide beam-column-slab connections subjected to lateral earthquake loading. ACI Structural Journal, V. 96, No. 4, July-August, p. 577-585.

LEONHARDT, F.; MÖNNIG, E. (1977). Construções de concreto: Princípios básicos sobre a armação de estruturas de concreto armado. 1.ed. Rio de Janeiro, Interciência. v.3.

MACGREGOR, J.G. (1988). Reinforced concrete-Mechanics and design. New Jersey, Prentice Hall.

MARQUES, J. L. G.; JIRSA, J. O. (1975). A study of hooked bar anchorages in beamcolumn joints. ACl Journal, Proceedings, V. 72, No. 5, May, p. 198-209.

MEINHEIT, D. F.; JIRSA, J. O. (1981). Shear strength of reinforced concrete beam-column connections. Proceedings ASCE, 107 (ST11), 2227-2244.

MEHTA, P.K.; MONTEIRO, P.J.M. (1994). Concreto: estrutura, propriedade e materiais. São Paulo, Pini.

MURTY, D. S. R.; SASTRY, S. G.; LAKSHMI, P. N. V. A. P. P.; RAO, D. L. N. (1998). Adequacy of development lengths of beam bars in end column - Beam junctions. In: INTERNATIONAL SYMPOSIUM ON INNOVATIVE WORLD OF CONCRETE, Calcutta, 199B. Proceedings. Indian Concrete Institute, V.1, p.4.99-4.111.

MURTY, D. S. R; DURGESH, C. R.; BAJPAI, K. K. e JAIN, S. K. (2003). Effectiveness of reinforcement details in exterior reinforcement concrete beam column joints for earthquake resistance. ACI Structural Journal, V. 100, No. 2, March-April, p. 149-156.

NEVILLE, A.M. (1997). Propriedades do concreto. São Paulo, Pini.

OLIVEIRA, R. S. (2001). Análise de pavimentos de edifícios de Concreto armado com a consideração da Não-linearidade física - modelagem e Metodologia de aplicação a projetos. São Carlos. 197p. Tese (Doutorado) - Escola de Engenharia de São Carlos. Universidade de São Paulo. 
ORTIZ, I. R. (1993). Strut-and-Tie modelling of reinforced concrete. Short beams and beam-column joints. 208p. A thesis submited for the Doctor of Philosophy - University of Westminster, London, United Kingdom. 1993.

PANTELIDES, C. P.; HANSEN, J.; NADAULD, J.;REAVELEY, L. D. (2002). Assessment of reinforced concrete building exterior joints with sustandard details. Berkeley, Pacific Earthquake Engineering Research Center, College of Engineering University of California, PEER Report 2002/1B.

PARK, R. ; PAULAY, T. (1975). Beam-Column joints. In: Reinforced Concrete Structures, p. 716-736.

PARKER, D. E.; BULLMAN, P. J. M. (1997). Shear strength within reinforced concrete beam-column joints. The Structural Engineer, V. 75, No. 4, February, p. 53-57.

PAULAY, T.; PRIESTLEY, M. (1992). Seismic design of reinforced concrete and mansory buildings. 2ed. New York, John Wiley \& Sons, p.1-303.

PATTON, R. N. (1972). Behaviour under seismic loading of reinforced concrete beamcolumns joints with anchorage blocks. Master of engineering report, University of Canterbury, Christchurch, New Zealand, 103 pp.

PAULTRE, P.; CASTELE, D.; RATTRAY, S.; MITCHELL, D. (1989). Seismic response of reinforced concrete frame subassemblages - a Canadian code perspective. Canadian Journal of Civil Engineering, v.16, p.627-49.

PICON, R.A.; FLÓREZ-LÓPEZ, J. (2000). Evolucion de la degradacion de rigidez en porticos de concreto armado (CD-ROM). In: XXIX JORNADAS SUDAMERICANAS DE INGENIERIA ESTRUCTURAL. Punta del Leste, Uruguay.

POPOV, E.P. (1984). Bond and anchorage of reinforced bars under cyclic loading. Journal of American Concrete Institute, v.81, n.4, p.340-9, Jul-Aug. 
SCOTT, R. H.; FELTHMAN I.; WHITTLE, R. T. (1994). Reinforced concrete beam-column connections and BS 8110. The Structural Engineering, V. 72, No. 4, February, p. 55-60.

SCOTT, R. H. (1996). Intrinsic Mechanisms in reinforced concrete beam-colun connection behavior. ACI Structural Journal, V. 93, No. 3, May-June, p. 336-346.

SCOTT, R. H.; HAMIL, S. J.; BAGLIN, P. S. (1999). Behaviour of high strength concrete beam-column connections. In: SECOND INTERNATIONAL CONFERENCE ON HIGHPERFORMANCE CONCRETE, PERFORMANCE AND QUALITY OF CONCRETE STRUCTURES. Gramado, 1999, pp. 699-713.

SILVA, R. C.; GIONGO J. S. (2000). Modelos de bielas e tirantes aplicados a estrutura de concreto armado. São Carlos: EESC-USP.

SOROUSHIAN, P.; OBASEKI, K.; NAGI, M.; ROJAS, M. C. (1988). Pullout behavior of hooked bars is exterior beam-column connections. ACl Structural Journal, V. 85, No. 3, May-June, p. 269-276.

TAYLOR, H.P.J. (1974). The behaviour of in-situ concrete beam-column joints. Cement and Concrete Association, Wexham Springs, technical Report 42.492.

TSONOS, A. G.; TEGOS, I. A.; PENELIS, G. G. (1994). Influence of Axial force variations on the seismic behavior of exterior beam-column joints. European Earthquake Engineering, Ano IX, No. 3, p. 51-63.

TSONOS, A. G. (1999). Lateral load response of strengthened reinforced concrete beam to column joints. ACI Structural Journal, V. 96, No. 1, January-February, p. 46-56.

TSONOS, A. G. (2001). Seismic retrofit of reinforced concrete beam-to-column joints using local three-sided jackets. European Earthquake Engineering, Ano XVI, No. 1, p. 48-64.

TSONOS, A. G. (2002). Seismic repair of reinforced concrete beam-column subassembleges of modern structures by epoxy injection technique. Structural Eingineering and Mechanics, V. 14, No. 5, p. 543-563. 
TSONOS, A. G. (2004). Improvement of the Earthquake resistance of reinforced concrete beam-column joints under the influence of P- $\Delta$ effect and axial force variations using inclined bars. Structural Eingineering and Mechanics, V. 18, No 4. 


\section{APÊNDICE A - ESTUDO DE DOSAGEM}

\section{A.1 Generalidades}

Apesar de muitos engenheiros não se preocuparem muito com a dosagem dos concretos, adotando valores de tabelas "mágicas" que apresentam traços para qualquer resistência como se todos os materiais constituintes (areia, pedra britada, cimento, etc.) apresentassem sempre as mesmas propriedades independentemente do lugar em que fossem extraídos; o estudo de dosagem é uma ferramenta que pode ser bastante interessante não apenas na definição do traço para se atingir uma determinada resistência, mas também para se conseguir uma economia no consumo de cimento.

\section{A.2 Materiais utilizados}

\section{A.2.1 Agregados}

A maior parte do concreto é constituída pelos agregados, sendo assim suas propriedades como: composição granulométrica, massa específica, módulo de finura, diâmetro máximo entre outras, são essenciais para a dosagem, pois elas determinam as propriedades no estado fresco e endurecido do concreto. Outro fator que deve ser levado em consideração, é que os agregados possuem um custo mais baixo que o cimento, desta forma, é mais econômico a utilização de maior quantidade de agregado e menor de cimento. 
Neste trabalho foram utilizados dois tipos de agregados, com as seguintes propriedades:

Tabela A.1 - Propriedades do agregado miúdo.

\begin{tabular}{|c|c|}
\hline Massa Específica $\left(\mathrm{kg} / \mathrm{m}^{3}\right)$ & 2630 \\
\hline Massa Unitária $\left(\mathrm{kg} / \mathrm{m}^{3}\right)$ & 1513 \\
\hline Módulo de Finura & 1,9 \\
\hline Diâmetro máximo $(\mathrm{mm})$ & 1,2 \\
\hline
\end{tabular}

Tabela A.2 - Granulometria do agregado miúdo.

\begin{tabular}{|c|c|c|c|}
\hline Peneiras (mm) & Material Retido (g) & $\%$ retida & \% acumulada retida \\
\hline 9,5 & 0,00 & 0,0 & 0,0 \\
\hline 6,3 & 0,00 & 0,0 & 0,0 \\
\hline 4,8 & 0,00 & 0,0 & 0,0 \\
\hline 2,4 & 0,00 & 0,0 & 0,0 \\
\hline 1,2 & 7,90 & 1,6 & 1,6 \\
\hline 0,6 & 28,50 & 5,7 & 7,3 \\
\hline 0,3 & 390,90 & 78,2 & 85,5 \\
\hline 0,15 & 62,10 & 12,4 & 97,9 \\
\hline Fundo & 9,90 & 2,0 & 100,0 \\
\hline
\end{tabular}

Tabela A.3 - Propriedades do agregado graúdo.

\begin{tabular}{|c|c|}
\hline Massa Específica $\left(\mathrm{kg} / \mathrm{m}^{3}\right)$ & 2890 \\
\hline Massa Unitária da pedra britada solta $\left(\mathrm{kg} / \mathrm{m}^{3}\right)$ & 1435 \\
\hline Massa Unitária da pedra britada compactada $\left(\mathrm{kg} / \mathrm{m}^{3}\right)$ & 1575 \\
\hline Diâmetro máximo (mm) & 19 \\
\hline
\end{tabular}


Tabela A.4 - Granulometria do agregado graúdo.

\begin{tabular}{|c|c|c|c|}
\hline Peneiras (mm) & Material Retido (g) & \% retida & \% acumulada retida \\
\hline 25 & 0,00 & 0,0 & 0,0 \\
\hline 19 & 0,00 & 0,0 & 0,0 \\
\hline 12,5 & 140,90 & 28,2 & 28,2 \\
\hline 9,5 & 181,70 & 36,3 & 64,5 \\
\hline 6,3 & 153,20 & 30,6 & 95,2 \\
\hline 4,8 & 11,20 & 2,2 & 97,4 \\
\hline 2,4 & 7,40 & 1,5 & 98,9 \\
\hline 1,2 & 1,50 & 0,3 & 99,2 \\
\hline 0,6 & 0,50 & 0,1 & 99,3 \\
\hline 0,3 & 0,50 & 0,1 & 99,4 \\
\hline 0,15 & 0,90 & 0,2 & 99,6 \\
\hline Fundo & 1,30 & 0,3 & 100,0 \\
\hline
\end{tabular}

\section{A.2.2 Cimento}

O cimento utilizado foi o CPV-ARI Plus Ciminas, por apresentar alta resistência nas primeiras idades, apresentando um comportamento estável após os 28 dias, já que inicialmente pretendia-se ensaiar os modelos com esta idade, podendo haver atrasos devido ao volume de serviços no laboratório. Como a resistência à compressão do concreto era uma variável fundamental na definição da intensidade de força normal a ser aplicada no pilar, utilizando o CPV-ARI se tinha uma certa folga na data de realização do ensaio, ou seja, caso ocorresse algum atraso, o ganho de resistência do concreto seria pequeno.

\section{A.3 Estudo de dosagem}

Para o estudo de dosagem, foram adotados os procedimentos descritos por Helene \& Terzian (2001). Basicamente, são necessários três pontos para poder montar o 
diagrama de dosagem, que correlaciona a resistência à compressão, relação água cimento $(\mathrm{a} / \mathrm{c})$, traço e consumo de cimento. Este estudo é baseado em tentativas e observações práticas.

Definido o abatimento do tronco de cone que será utilizado nesta pesquisa, no valor de $80 \pm 10$, a primeira etapa do estudo teve por objetivo encontrar o teor ideal de argamassa. Segundo Helene \& Terzian, a falta de argamassa na mistura acarreta porosidade no concreto ou falhas na concretagem, já o excesso proporciona um concreto de melhor aparência, mas aumenta o custo por metro cúbico como, também, o risco de fissuração por origem térmica e por retração de secagem.

Inicialmente, lançou-se na betoneira já imprimada, um traço estabelecido de 1:5,0 e após a mistura, verificou-se se era possível efetuar a abatimento do tronco de cone, ou seja, se havia coesão e plasticidade adequada. Após este procedimento, foram realizados acréscimos sucessivos de argamassa na mistura, através do lançamento de cimento e areia (Tabela A.5). A quantidade de agregados graúdos não foi alterada.

Tabela A.5- Tabela de acréscimos no teor de argamassa.

\begin{tabular}{|c|c|c|c|c|c|c|c|c|}
\hline \multirow{2}{*}{$\begin{array}{l}\text { Teor } \\
\text { de } \\
\text { Arga- } \\
\text { masseg } \\
\text { (\%) }\end{array}$} & \multirow[b]{2}{*}{$\begin{array}{c}\text { Traço Unitárlo } \\
\text { (1:A : p ) }\end{array}$} & \multicolumn{2}{|c|}{ 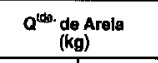 } & \multicolumn{2}{|c|}{$\begin{array}{c}0^{160.0} \text { de Cimento } \\
(\mathrm{kgg})\end{array}$} & \multicolumn{2}{|c|}{ 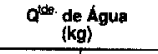 } & \multirow{2}{*}{$\begin{array}{c}\text { Relaçato } \\
\text { a/c } \\
\text { Final }\end{array}$} \\
\hline & & $\begin{array}{l}\text { Massa } \\
\text { Total }\end{array}$ & $\begin{array}{c}\text { Acroseclmo } \\
\text { nat } \\
\text { Mistura }\end{array}$ & $\begin{array}{l}\text { Massa } \\
\text { Total }\end{array}$ & $\begin{array}{c}\text { Acresscimo } \\
\text { net } \\
\text { Mlstura }\end{array}$ & $\begin{array}{c}\text { Massa } \\
\text { Total }\end{array}$ & $\begin{array}{c}\text { Acresclmo } \\
\text { na } \\
\text { Mistura }\end{array}$ & \\
\hline 35 & $1: 1,10: 3,90$ & 8,46 & 122 & 7,69 & 0.25 & & & \\
\hline 37 & $1: 1,22: 3,78$ & $9,68^{\prime \prime}$ & $1,<2$ & $7,94^{4}$ & 0.26 & & & \\
\hline 39 & $1: 1,34: 3,66$ & $10,99^{\prime}$ & 137 & $8,20^{\prime}$ & 0.27 & & & \\
\hline 41 & $1: 1,46: 3,54$ & 12,36 & 150 & 8,47 & 0.30 & & & \\
\hline 43 & $1: 1,58: 3,42$ & 13,86 & 1.59 & 8,77 & 0.32 & & & \\
\hline 45 & $1: 1,70: 3,30$ & 15,45 & 172 & 9,09 & 0.34 & & & \\
\hline 47 & $1: 1,82: 3,18$ & 17,17 & & 9,43 & 037 & & & \\
\hline 49 & $1: 1,94: 3,06$ & 19,02 & 200 & 9,80 & 0,0 & & & \\
\hline 51 & $1: 2,06: 2,94$ & 21,02 & 17 & 10,20 & , 44 & & & \\
\hline 53 & $1: 2,18: 2,82$ & 23,19 & 3.16 & 10,64 & 0,47 & & & \\
\hline 55 & $1: 2,30: 2,70$ & 25,55 & 2,59 & 11,11 & 0,52 & & & \\
\hline 57 & $1: 2,42: 2,58$ & 28,14 & 2,84 & 11,63 & 0,57 & & & \\
\hline 59 & $1: 2,54: 2,46$ & 30,98 & 3,12 & 12,20 & 0,62 & & & \\
\hline 61 & $1: 2,66: 2,34$ & 34,10 & 3,47 & 12,82 & 0,69 & & & \\
\hline 63 & $1: 2,78: 2,22$ & 37,57 & 386 & 13,51 & 078 & & & \\
\hline 65 & $1: 2,90: 2,10$ & 41,43 & & 14,29 & & & & \\
\hline
\end{tabular}

Fonte: Helene \& Terzian (2001) 
Após cada acréscimo foram feitas observações práticas, descritas por Helene \& Terzian (2001):

1. Passar a colher de pedreiro sobre a superfície do concreto fresco, introduzir dentro da massa e levantar no sentido vertical. Verificar se a superfície exposta está com vazios, indicando falta de argamassa (Figura A.1).

2. Introduzir novamente a colher de pedreiro no concreto e retirar uma parte do mesmo, levantando-o até a região superior da cuba da betoneira. Com o material nesta posição, verificar se há desprendimento de agregado graúdo da massa, o que indica falta de argamassa. Após esta observação, soltar a porção de concreto que está sobre a colher e verificar se a mesma cai de modo compacto e homogêneo, o que indica teor de argamassa adequado (Figura A.2).
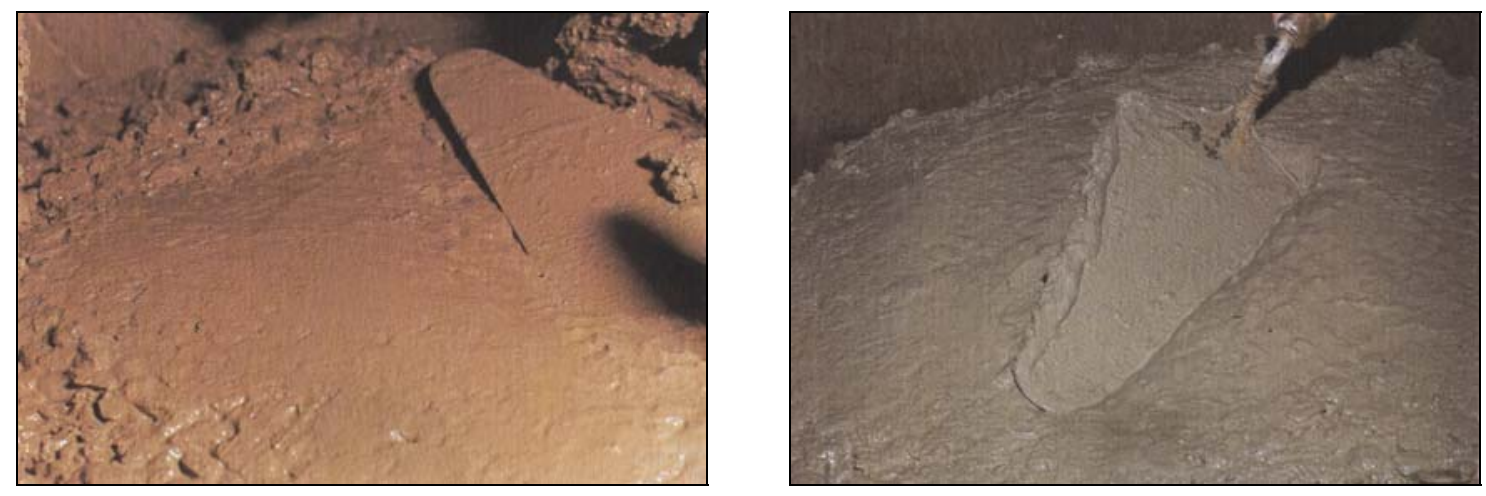

Figura A.1 - Propriedades da superfície do concreto com teor de argamassa ideal.

Fonte: Helene \& Terzian (2001)
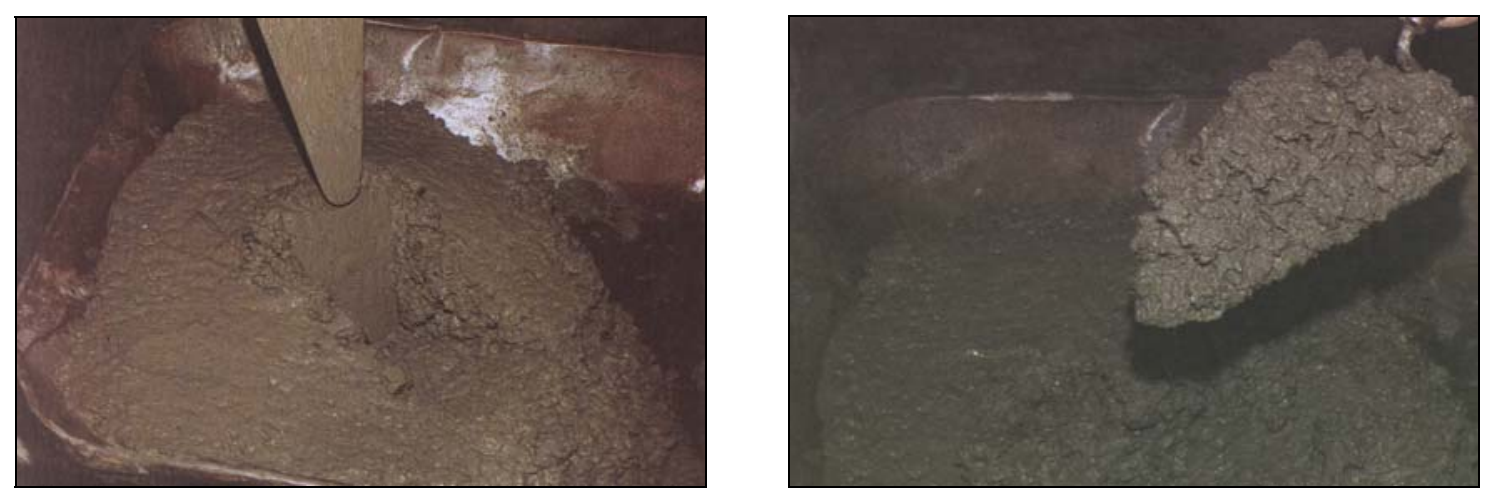

Figura A.2 - Aspecto homogêneo do concreto com teor de argamassa ideal.

Fonte: Helene \& Terzian (2001) 

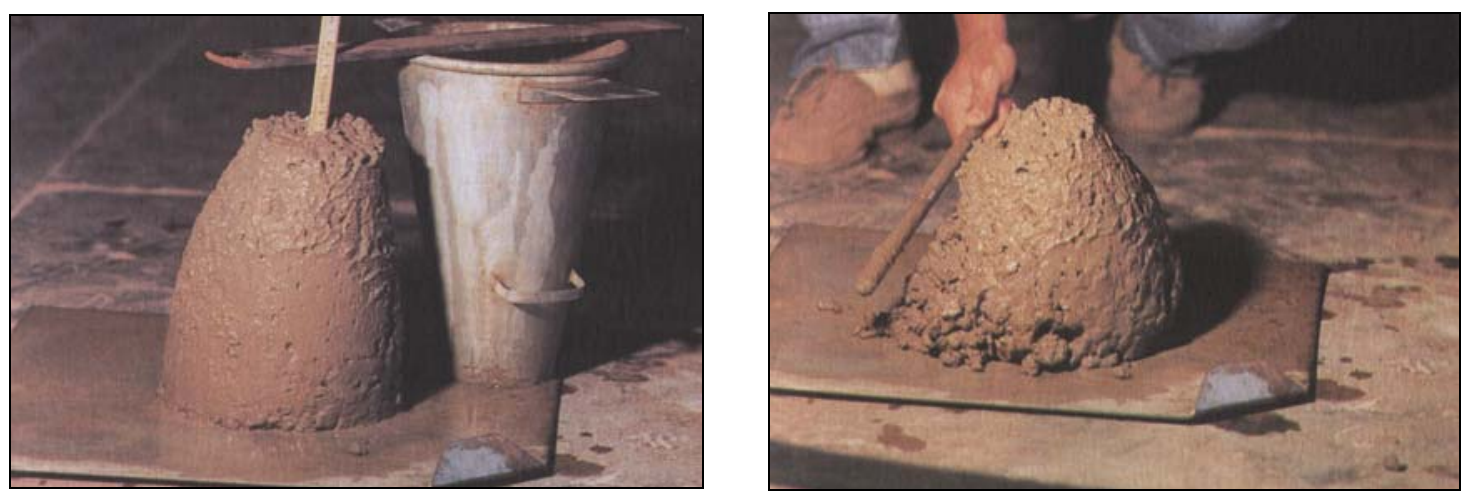

Figura A.3 - Aspecto compacto e coeso do concreto com teor de argamassa ideal.

Fonte: Helene \& Terzian (2001)

Quando os itens, acima descritos, foram observados, pode então ser realizada a verificação do abatimento do tronco de cone. Enquanto este não atingiu a faixa estabelecida, foram feitos acréscimos na quantidade de água. Após o ensaio do abatimento, foram realizadas verificações batendo suavemente na lateral do tronco de cone, para se verificar durante a queda se a mistura apresentava um aspecto homogêneo e foi observado também, se a superfície lateral se encontrava compacta, indicando bom teor de argamassa (Figura A.3).

Por meio destes procedimentos encontrou-se o teor de argamassa de $53 \%$. A este valor foram acrescentados $4 \%$ para se levar em consideração a perda de argamassa durante o transporte e o lançamento do concreto. Com este teor de argamassa, foi feito uma nova mistura com traço de 1:5,0 e determinou-se todas as propriedades do concreto fresco: relação a/c, massa específica do concreto, consumo de cimento (equação ( A.1 )) e abatimento do tronco de cone. Então foram moldados doze corpos-de-prova para se avaliar a resistência à compressão do concreto aos 3 dias, 9 dias, 28 dias e 60 dias.

$C=\frac{\gamma_{\text {concreto }}}{1+a+p+(a / c)}$

Onde a e $p$ são as quantidades de areia e pedra britada, respectivamente, C é o consumo de cimento e $\gamma_{\text {concreto }}$ é a massa específica do concreto.

Após esta etapa, foram produzidos mais dois traços auxiliares, para possibilitar a montagem do diagrama: um traço rico em cimento $(1: 3,5)$ e um traço pobre em cimento $(1: 6,5)$. Estes traços foram obtidos pelas equações seguintes: 
$a+p=m$

$\frac{1+a}{1+a+p}=\alpha$

Onde $\alpha$ é o valor do teor de argamassa e m é a quantidade de agregados secos totais em massa.

O estudo de dosagem realizado nesta pesquisa resultou no seguinte diagrama de dosagem:
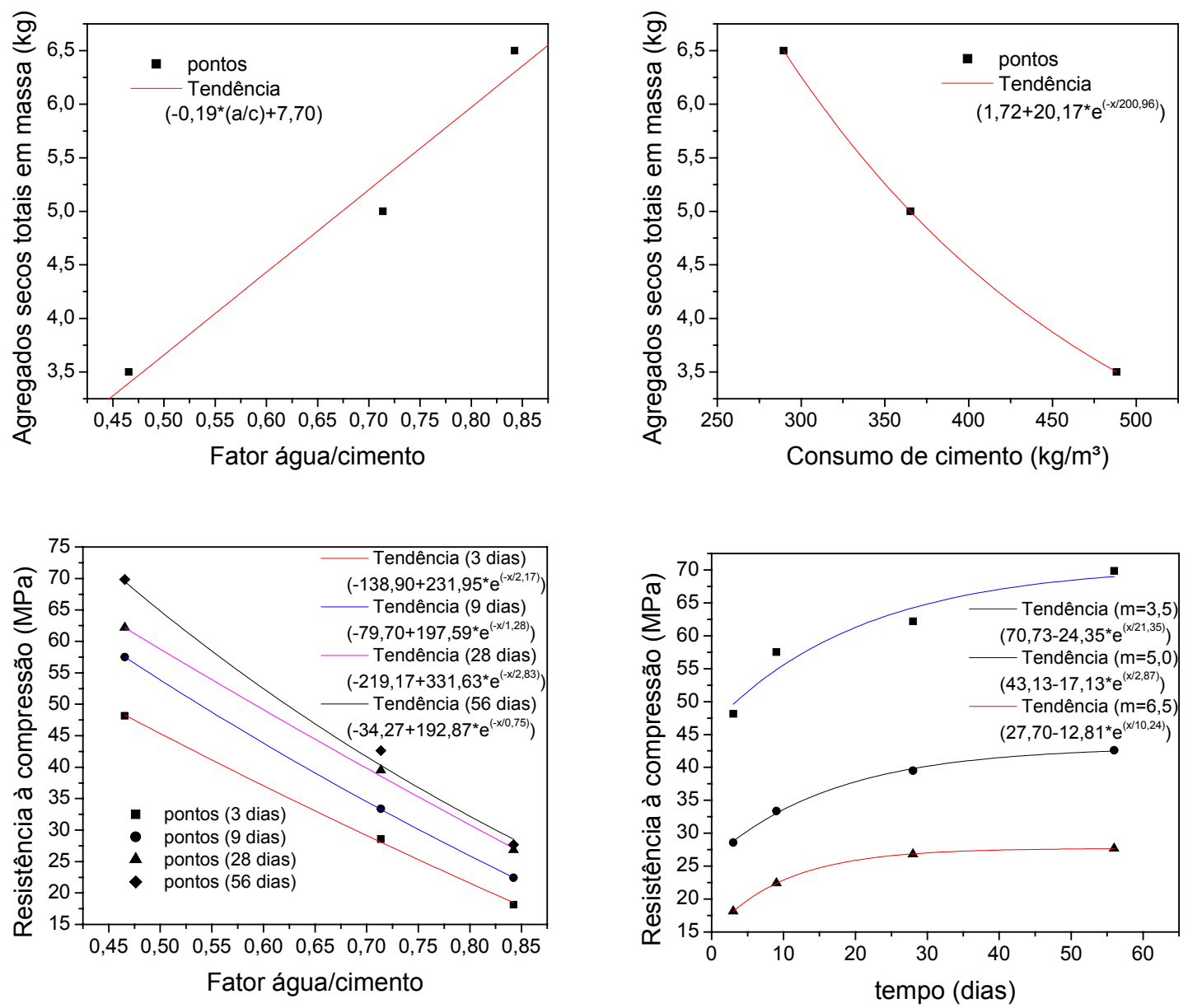

Figura A.4 - Diagramas de dosagem. 


\section{APÊNDICE B - SIMULAÇÃO NUMÉRICA DO ENSAIO DE ARRANCAMENTO}

\section{B.1 Generalidades}

A simulação numérica teve como objetivo principal, o estudo detalhado do comportamento do contato da barra de aço com o concreto envolvente, por meio da distribuição das tensões de aderência ao longo da barra, cujo comportamento teórico é apresentado na Figura B.1, e dos diagramas Tensão de Aderência vs. Deslizamento e Força vs. Deslizamento. Para a análise inicial foram utilizados resultados do ensaio de arrancamento padronizado pelo Código do Rilem-Ceb-Fib (1973), realizado por Fernandes (2000) para se fazer a calibração dos parâmetros envolvidos na teoria.

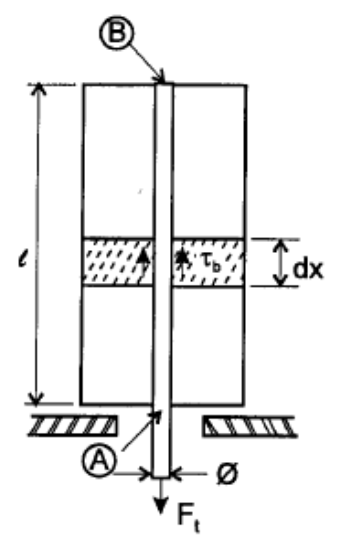

(a)
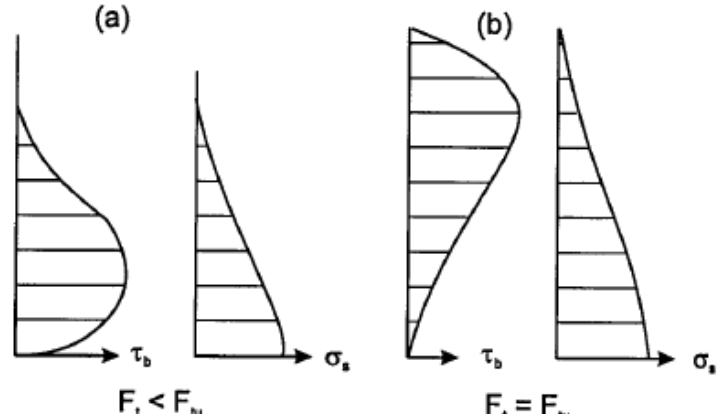

$F_{t}=F_{t u}$

Figura B.1 - Distribuição das tensões de aderência no ensaio de arrancamento.

Fonte: Fusco (1995) 
A questão, quanto à modelagem do comportamento do sistema aço-concreto, freqüentemente é levantada quando da utilização de métodos numéricos para a avaliação de estruturas de concreto armado. Isto se dá principalmente pelo fato deste fenômeno ser de natureza não-linear. Para que a simulação numérica seja representativa é importante que seja bem definido o comportamento constitutivo da interface entre os dois materiais. A simulação do contato entre as superfícies da barra de aço e do concreto que a envolve foi feita por meio de um algoritmo contido no aplicativo Abaqus ${ }^{\circledR}$, construído com base em técnicas do tipo Newton-Raphson. A modelagem de barras nervuradas dispende um trabalho muito grande na geração da malha e no processamento do modelo, desta forma procurou-se representar o contato entre uma barra de aço nervurada e o concreto por meio da utilização de barra lisa na simulação.

Os modelos foram construídos com elementos tridimensionais e axissimétricos, para fins de comparação. Resultados de ensaios de modelos de arrancamento, submetidos a carregamento monotônico, foram usados com o intuito de validar a simulação numérica.

\section{B.2 Modelo experimental ensaiado por Fernandes (2000)}

A geometria do modelo experimental é mostrada na Figura B.2a.

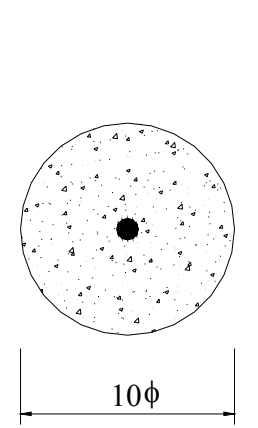

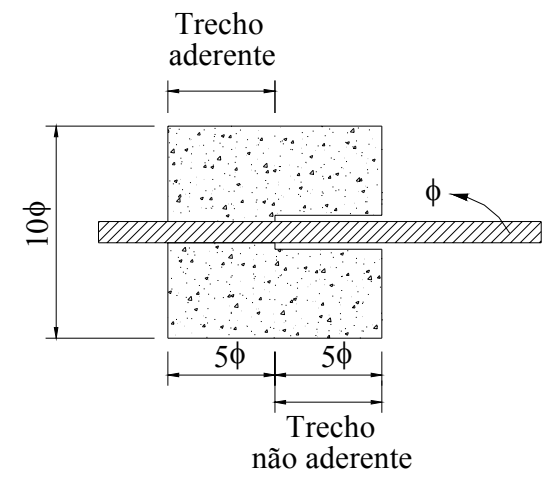

(a)

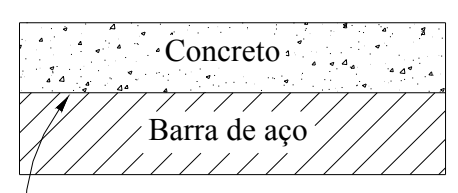

Superfície de contato

(b)

Figura B.2 - Geometria do modelo (a) e consideração da interface aço-concreto (b).

De acordo com a pesquisa de Fernandes (2000), foi utilizado o modelo de arrancamento padronizado pelo Código do Rilem-Ceb-Fib (1973) com barras de diâmetro 
igual a $10 \mathrm{~mm}$. Assim, o comprimento de ancoragem utilizado foi de $5 \mathrm{~cm}$. Ainda, a Figura B.2b ilustra o modelo de interação aço-concreto adotado. Esse modelo não leva em consideração as nervuras da barra de aço, pois, a priori, esse é um modelo simplificado e, seu objetivo é o de avaliar a influência dos parâmetros numéricos do contato.

\section{B.3 Modelo utilizado na Simulação Numérica}

Para a simulação numérica foram utilizados elementos C3D8R (modelos tridimensionais) e CAX4R (modelos axissimétricos), da biblioteca do ABAQUS ${ }^{\circledR}$, para o concreto e para o aço respectivamente. Para a representação do contato, o programa possibilita dois métodos para simulação: elementos de contato ou superfícies, dentre os quais o segundo foi o utilizado.

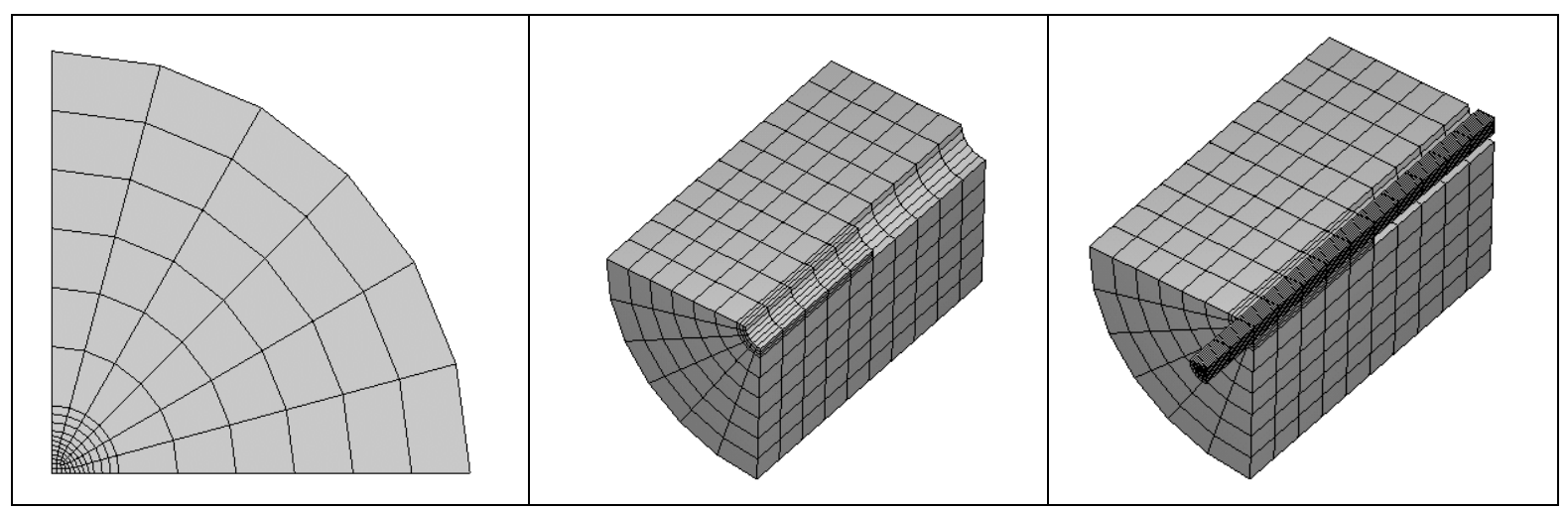

(a)

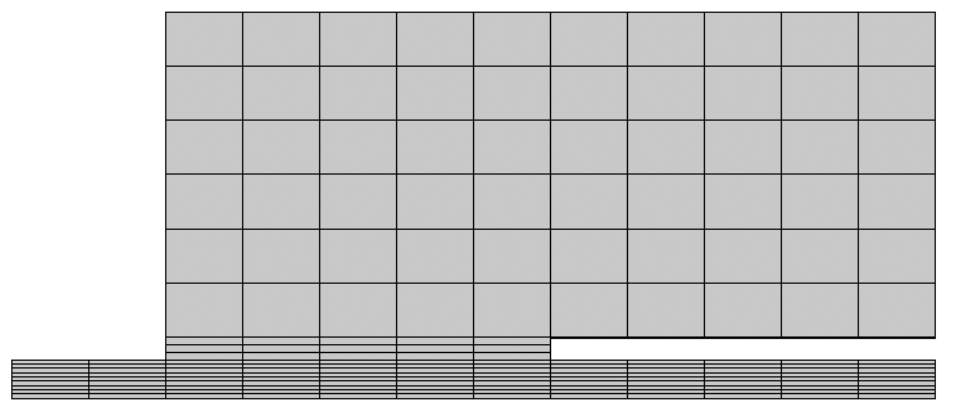

(b)

Figura B.3 - Discretizações adotadas para os modelos numéricos: tridimensional (a) axissimétrico(b). 
A Tabela B.1 ilustra a quantidade de elementos utilizados para cada exemplo.

Tabela B.1 - Quantidade de elementos utilizados para cada modelo numérico.

\begin{tabular}{|c|c|c|}
\hline Elemento & Tridimensional & Axissimétrico \\
\hline Concreto & 450 & 75 \\
\hline Aço & 540 & 108 \\
\hline
\end{tabular}

Optou-se por simular apenas $1 / 4$ do modelo tridimensional, devido à simetria, para diminuir o esforço computacional. A discretização das malhas do modelo tridimensional e axissimétricos é mostrada na Figura B.3.

\section{B.4 Comportamento constitutivo dos materiais}

O comportamento de uma estrutura sob carregamento depende essencialmente da relação constitutiva dos seus materiais; de maneira resumida é necessário conhecer os diagramas tensão vs. deformação.

A simulação numérica foi realizada levando em consideração o comportamento linear dos materiais e não-linear do contato.

A Tabela B.2 ilustra o comportamento dos materiais obtidos na pesquisa de Fernandes (2000).

Tabela B.2 - Valores adotados para os materiais com comportamento linear.

\begin{tabular}{|c|c|c|}
\hline Parâmetro & Concreto & Aço \\
\hline Módulo de elasticidade longitudinal $\left(\mathrm{kN} / \mathrm{cm}^{2}\right)$ & 2568 & 20717 \\
\hline Coeficiente de Poisson & 0,2 & 0,3 \\
\hline
\end{tabular}

\section{B.4.1 Concreto}

Consideraram-se, para o comportamento constitutivo do concreto, as propriedades observadas por Fernandes (2000) em sua investigação experimental. 


\section{B.4.2 Aço}

A armadura, entretanto, pode ser considerada com comportamento linear, pois: consiste de uma conveniência para reduzir o custo computacional e o comportamento de elementos estruturais de concreto armado é fortemente influenciado pelo escoamento da armadura (Kwak \& Kim, 2001). Desse modo, a Tabela B.2 ilustra o valor adotado para o módulo de elasticidade e coeficiente de Poisson da armadura.

\section{B.4.3 Interface aço-concreto}

$\mathrm{Na}$ interface aço-concreto foram definidas propriedades quanto ao comportamento normal e tangencial.

Para o comportamento normal adotou-se o modelo "HARD CONTACT" permitindo a separação das superfícies após o contato. Este modelo faz as seguintes considerações:

$$
\begin{aligned}
& p=0 \rightarrow h<0 \\
& h=0 \rightarrow p>0
\end{aligned}
$$

Onde $p$ é o valor da pressão de contato e $h$ é a interpenetração das superfícies em contato.

Para o comportamento tangencial foi utilizado o modelo de atrito de Coulomb. Este considera que não ocorrerá nenhum escorregamento entre as superfícies enquanto a tensão de cisalhamento equivalente $\left(\tau_{\text {eq }}\right)$ for menor que um valor crítico $\left(\tau_{\text {critico }}\right)$ definido pelo coeficiente de atrito $(\mu)$ entre as superfícies e a pressão de contato $(p)$.

$$
\begin{gathered}
\tau_{\text {eq }}=\sqrt{\tau_{1}^{2}+\tau_{2}^{2}} \\
\tau_{\text {critico }}=\mu^{*} p
\end{gathered}
$$

Onde $\tau_{1}$ e $\tau_{2}$ representam as tensões nas duas direções da superfície em questão. 


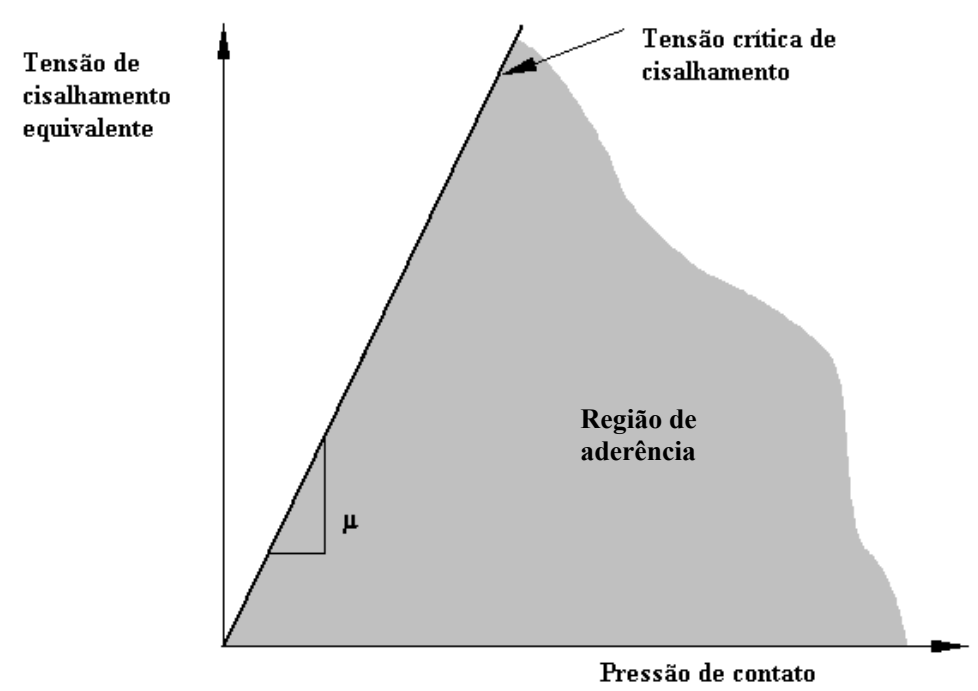

Figura B.4 - Modelo de atrito de Coulomb.

Leonhardt \& Mönnig (1973) sugerem que o coeficiente de atrito por causa da rugosidade da superfície do aço seja um valor compreendido entre 0,3 e 0,6.

Observou-se que sem a aplicação de tensões de confinamento não ocorre convergência, pois o contato não fica definido. Conforme o modelo "HARD CONTACT", se a pressão de contato é nula a interpenetração entre as superfícies é negativa o que significa que estas não estão em contato. Na realidade estas tensões transversais existem, e são causadas por tensões de compressão transversais provocadas pelas ações, pela retração ou pela expansão do concreto. Com o intuito de representar estes efeitos foram aplicadas tensões de confinamento apenas na região aderente do modelo. Variaram-se estas tensões até o valor correspondente a resistência à compressão do concreto, para procurar entender a sua influência no comportamento da aderência.

\section{B.5 Carregamento}

O carregamento aplicado no modelo numérico procurou ao máximo representar o mesmo utilizado no programa experimental, onde, a barra de aço era presa à máquina de ensaios universal e um dispositivo acoplado a mesma puxava o prisma de concreto (Figura B.5a). Desta forma, o carregamento foi aplicado ao prisma de concreto e se engastou a barra de aço. 


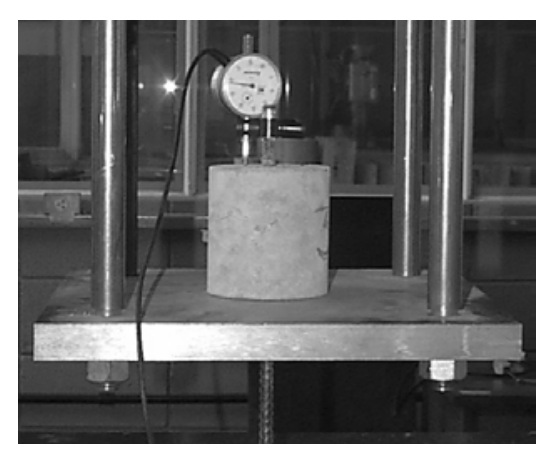

(a)

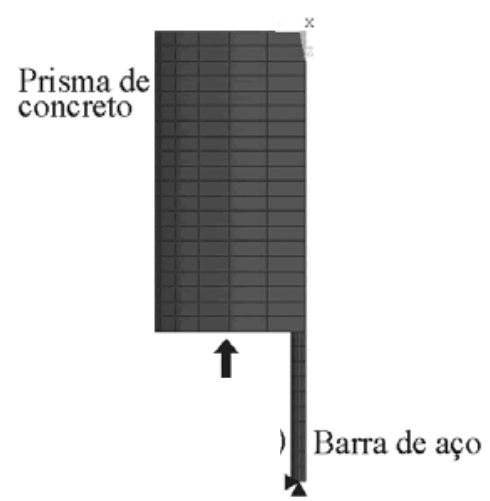

(b)

Figura B.5- Esquema de ensaios do modelo experimental (a) e considerações para o modelo numérico (b).

A aplicação do carregamento foi feita inicialmente por meio de aplicação de deslocamento, com passos de carga da ordem de $10 \%$ do carregamento último. Porém, não se observou o comportamento inicial das tensões de aderência mostrado na Figura B.1a, apenas o comportamento como mostrado na Figura B.1b. Por conseguinte, resolveu-se aplicar o carregamento por meio de força. Todavia, o modelo passou a não convergir até o último passo de carga, ou seja, o processamento era abortado quando todo o comprimento aderente passava a opor resistência ao carregamento. Contudo, as tensões de aderência ao longo da barra de aço apresentavam o comportamento mostrado na Figura B.1a. Conseqüentemente, concluiu-se que as etapas (a) e (b) do comportamento das tensões de aderência mostradas na Figura B.1 não conseguem ser representadas quando utiliza-se a aplicação de força como carregamento, pois quando todo o contato passa a opor resistência ao carregamento, toda a sua extensão começa a escorregar, logo surge movimento de corpo rígido e, por causa disso o processamento é abortado.

Assim sendo, optou-se pela aplicação do carregamento por meio de deslocamento no prisma de concreto em passos de carga da ordem de $1 \%$ do deslizamento último até atingir-se $10 \%$ deste, a partir daí os passos são aumentados para $10 \%$ do valor último.

O deslocamento aplicado foi de $1,25 \mathrm{~mm}$, valor máximo de deslizamento encontrado no modelo experimental de arrancamento e que corresponde à tensão máxima de aderência (Figura B.5b). 


\section{B.6 Resultados}

O modelo axissimétrico (Figura B.6) e o modelo tridimensional (Figura B.7) apresentaram praticamente o mesmo comportamento, a menos do primeiro absorver maiores tensões de aderência durante o início do carregamento. Desta forma, para a análise realizada, mostrou-se ser mais vantajoso a modelagem utilizando-se da axissimetria, pois, o tempo de processamento ficou bastante reduzido, uma vez que o número de elementos decresceu aproximadamente $1 / 5$ do valor do modelo tridimensional.

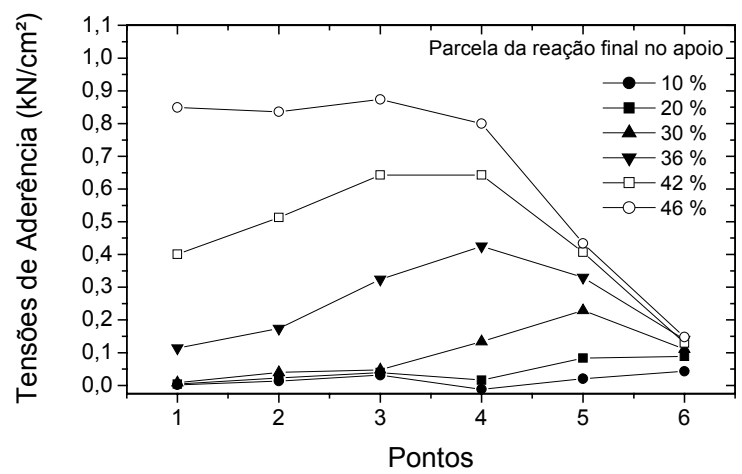

(a)

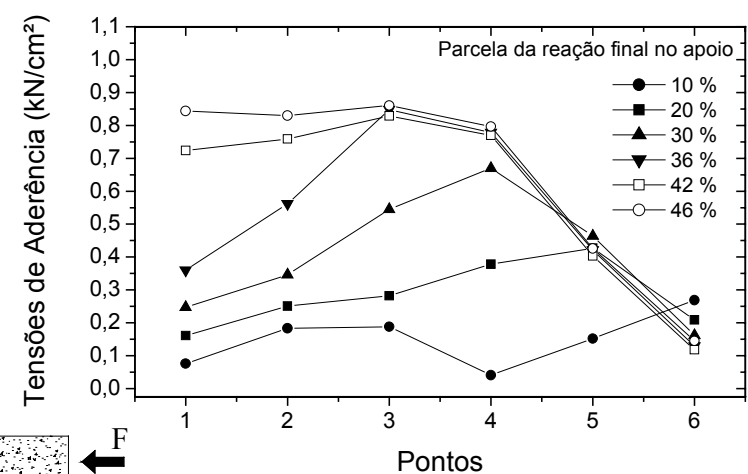

(b)

Figura B.6- Tensões iniciais ao longo da barra no modelo tridimensional (a) e no modelo axissimétrico (b) com $\mu=0,4$ e $p=3 \mathrm{kN} / \mathrm{cm}^{2}$.

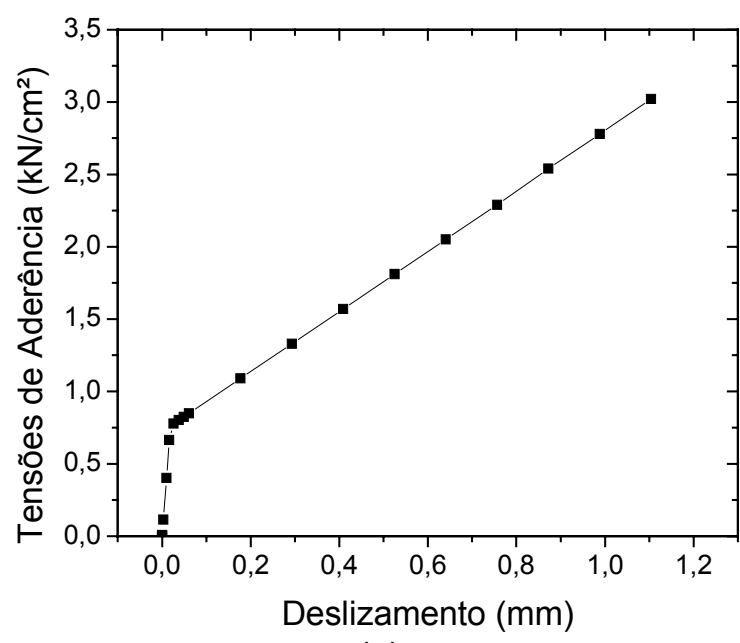

(a)

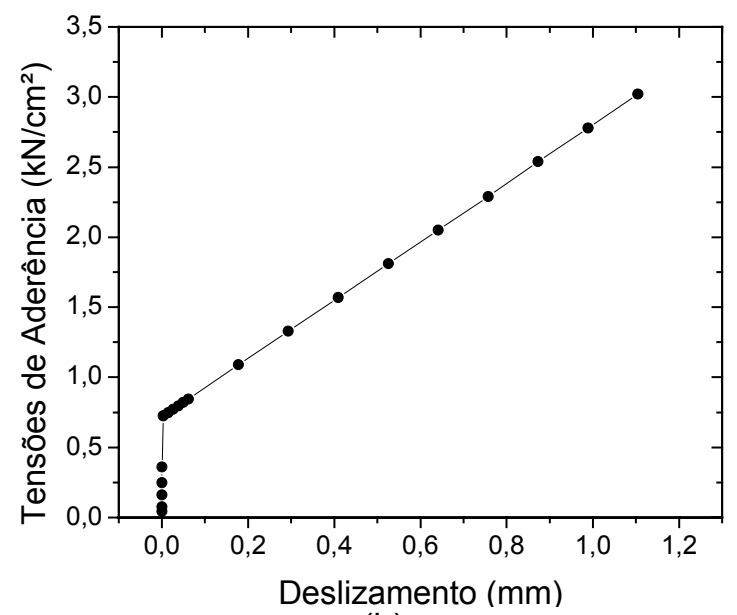

(b)

Figura B.7- Diagrama Tensão de aderência vs. Deslizamento para o modelo tridimensional (a) e para o modelo axissimétrico (b) $\operatorname{com} \mu=0,4$ e $p=3 \mathrm{kN} / \mathrm{cm}^{2}$. 
Como já comentado anteriormente, foi necessária a aplicação de tensões de confinamento para que houvesse a convergência do modelo. Contudo, estas tensões são desprezíveis quando comparadas às tensões de aderência finais.
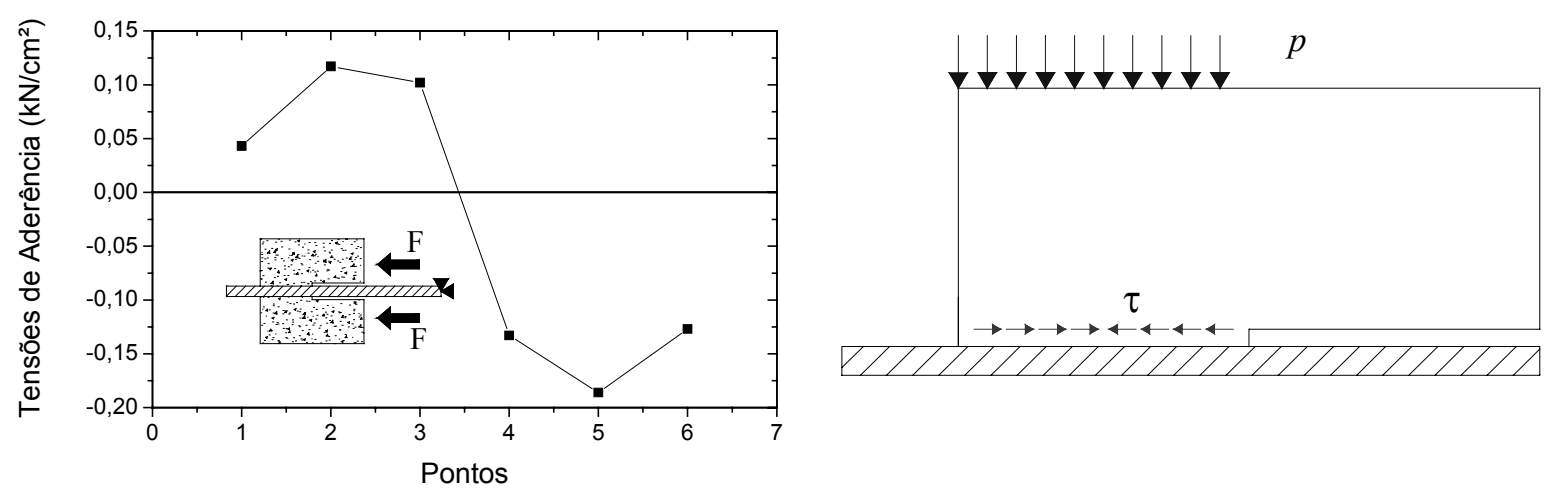

Figura B.8- Variação da tensão de aderência na região de contato devido ao confinamento $(\mu=$ 0,4 e $\left.p=3 \mathrm{kN} / \mathrm{cm}^{2}\right)$.

Como se pode ver, o confinamento gera tensões de cisalhamento no bloco de concreto em sentidos opostos em relação ao centro da área aderente (Figura B.8). Observa-se que na região mais próxima da carga existem tensões de aderência no sentido contrário às geradas pelo carregamento.
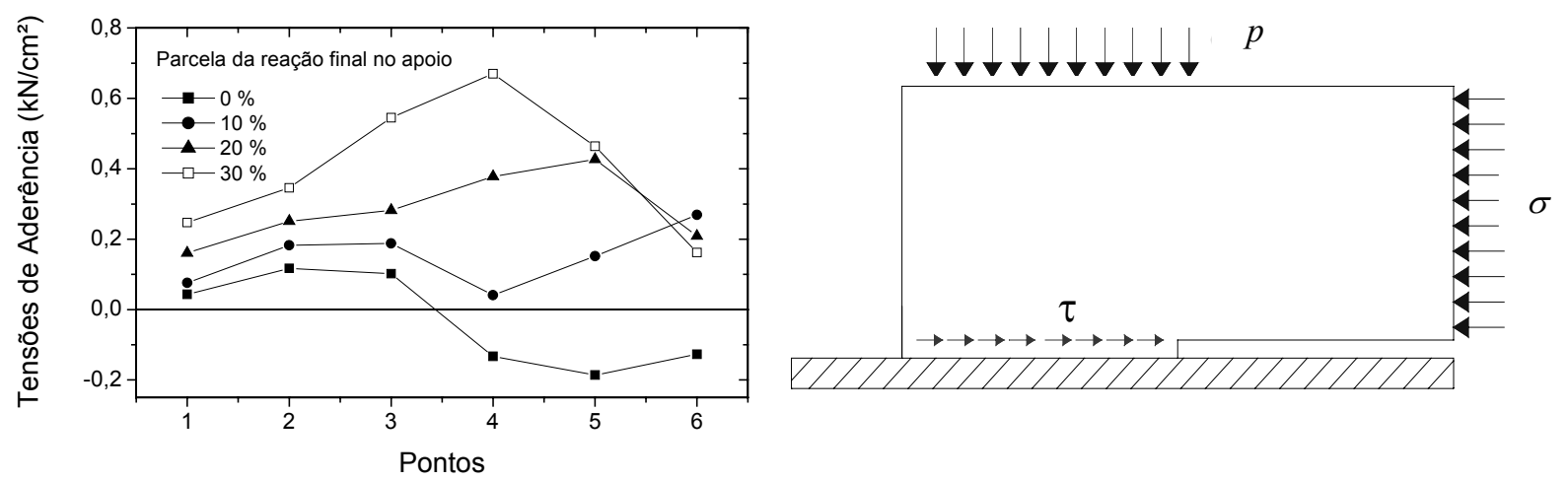

Figura B.9- Mudança de direção das tensões de aderência na região do contato próximo ao carregamento. $\left(\mu=0,4\right.$ e $\left.p=3 \mathrm{kN} / \mathrm{cm}^{2}\right)$.

Desta forma, à medida que o carregamento aumenta, as tensões nesta região trocam de sinal (Figura B.9). 
Analisando o comportamento das tensões de aderência ao longo do comprimento aderente com a variação do carregamento, pode-se dizer que o modelo numérico consegue representar o fenômeno apresentado na Figura B.1, ou seja, as tensões de aderência assumem seu valor máximo no ponto mais próximo do carregamento e, conforme o carregamento vai aumentando, um trecho maior da barra é solicitado e desta forma, o ponto de máxima ordenada se desloca para a extremidade contrária (Figura B.10).
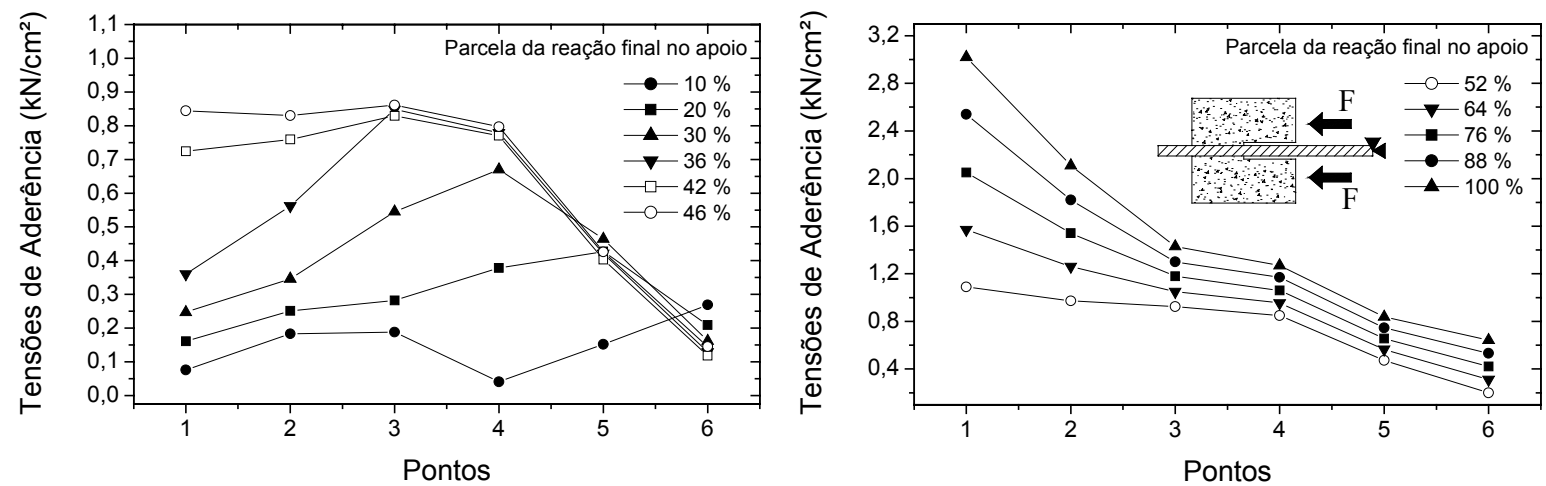

Figura B.10- Variação das tensões de aderência ao longo do comprimento da barra com $\mu=0,4$ e $p=3 \mathrm{kN} / \mathrm{cm}^{2}$.

As figuras abaixo mostram que para cada tensão de confinamento há um coeficiente de atrito que melhor representa o modelo experimental. Isto se dá, pois o confinamento gera pressões de contato no contorno da barra, e como já visto na equação ( B.3 ) a pressão de contato é diretamente proporcional a tensão de cisalhamento crítica. $\mathrm{Na}$ Figura B.12 os diagramas experimentais foram desenhados parcialmente para se poder ter maior percepção dos resultados.

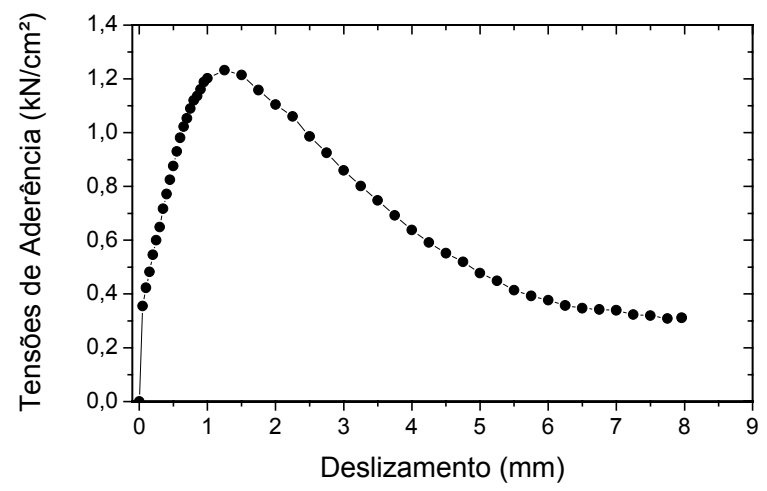

Figura B.11- Diagrama Tensão de aderência vs. Deslizamento extraído dos resultados experimentais de Fernandes (2000). 


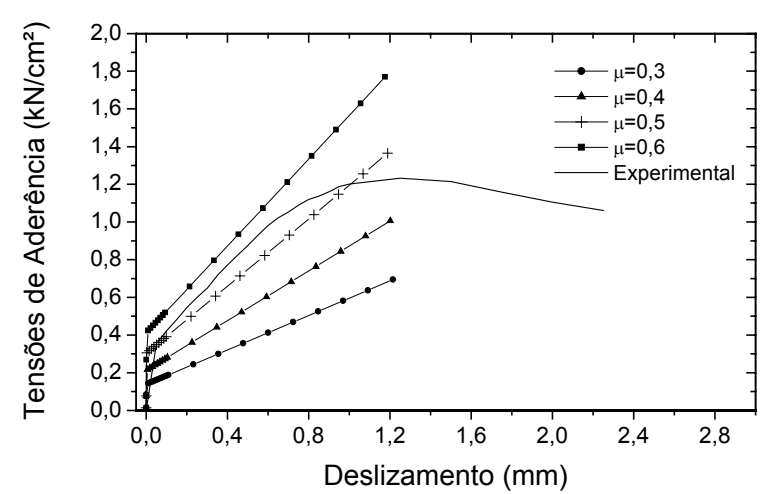

(a)

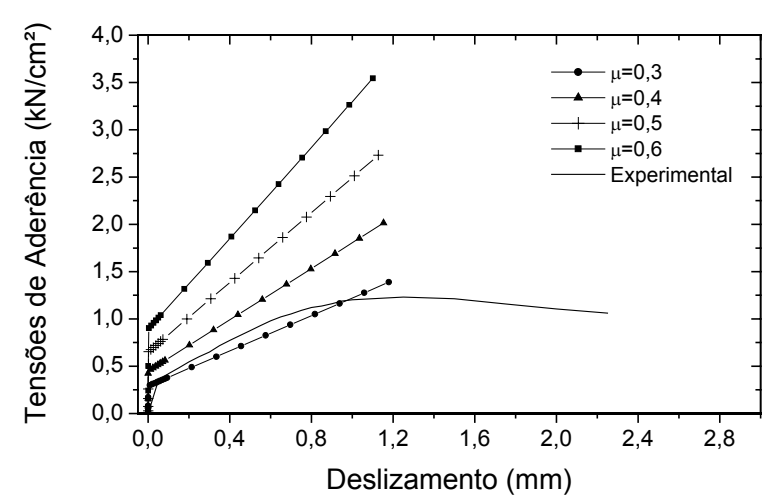

(b)

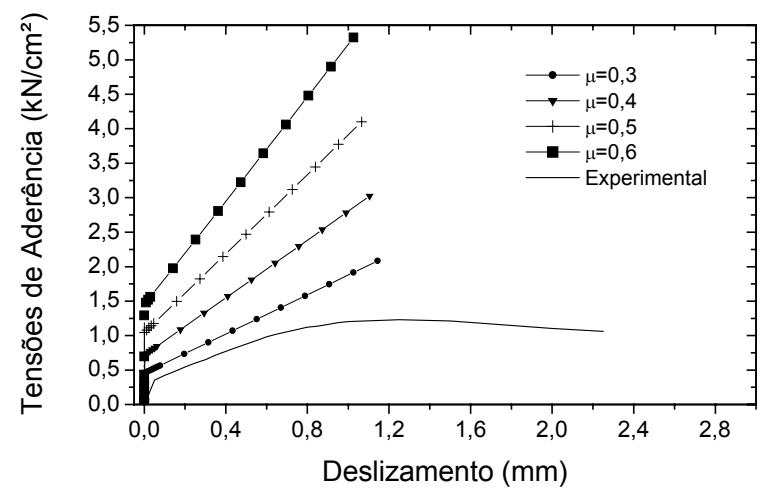

(c)

Figura B.12- Diagrama Tensão de aderência vs. Deslizamento com confinamento de $1 \mathrm{kN} / \mathrm{cm}^{2}(\mathrm{a})$, com $2 \mathrm{kN} / \mathrm{cm}^{2}$ (b) e com $3 \mathrm{kN} / \mathrm{cm}^{2}$ (c). 